\title{
Der Narbenzug am und im Gehirn bei traumatischer Epilepsie in seiner Bedeutung für das Znstandekommen der Anfälle und für die therapeutische Bekämpfung derselben.
}

\author{
Von \\ o. Foerster-Breslau und W. Penfield-Montreal. \\ Mit 65 Textabbildungen.
}

(Eingegangen am 4. Februar 1930.)

\section{Einleitung.}

Den Ausgangspunkt der hier mitzuteilenden Untersuchungen bilden zwei bei traumatischen Epilepsien häufig gemachte Beobachtungen. Die eine Tatsache, auf welche wir bereits 1925 (vgl. Lit. 1) und dann später des öfteren zusammen mit unseren Mitarbeitern $O$. Schwab ${ }^{3}$, A. Rosenstein ${ }^{2}$ und $P$. Bielschowsky ${ }^{4}$ aufmerksam gemacht haben, ist die, daß bei Traumen, die den Schädel einseitig treffen, im encephalographischen Bilde häufig der Seitenventrikel dieser Seite mehr oder weniger dilatiert erscheint; dieser Befund ist sowohl bei Traumen, welche mit Verletzung des Knochens einhergehen, als auch bei solchen ohne ossale Läsion erhoben worden; bei ersteren ist er in der Regel viel stärker ausgesprochen als bei letzteren, besonders stark dann, wenn ein Knochendefekt besteht und die Haut mit der Dura mater und diese mit der Hirnoberfläche verwachsen ist. Die Wand des der Seite der Verletzung entsprechenden Seitenventrikels erscheint in solchen Fällen vielfach förmlich nach der Verletzungsstelle zu ausgezogen. Ähnliche Befunde sind auch von anderer Seite erhoben worden (z. B. Wartenberg ${ }^{5}$, Heidrich $^{6}$ u. a.). Vielfach haben wir beobachtet, daß die Ventrikelverziehung nach der Stelle des Knochendefektes sich nicht nur auf den korrespondierenden Seitenventrikel beschrankt, sondern das gesamte Ventrikelsystem umfaßt; auch der der Verletzung gegenüberliegende Seitenventrikel erscheint mehr oder weniger über die Medianlinie hinaus nach der Seite der Verletzung hinüber gezogen und der dritte Ventrikel weist auf den Aufnahmen in antero-posteriorer Richtung eine mehr oder weniger ausgesprochene Schrägstellung auf, wobei der obere Pol nach der Seite der Verletzung zu inkliniert. Wenn das Trauma nicht auf einer Seite des Schädels, sondern mehr oder weniger in der Mitte, auf der Höhe des 
Scheitels, angreift, so sind nicht selten beide Seitenventrikel nach oben ausgezogen, ihr Dach kann dann geradezu nach oben verzerrt erscheinen.

Die Tatsache, daß der Ventrikel auf der Seite der Verletzung oft beträchtlich erweitert ist, war uns schon vor langer Zeit, noch ehe die Ventrikulographie bekannt war, während des Weltkrieges aufgefallen. Es konnte in zahlreichen Fällen von Kopfschuß mit Knochendefekt mittels Punktion des Ventrikels durch die Stelle des Defektes hindurch ein oft hochgradiger Hydrocephalus internus festgestellt werden, erkennbar an den riesigen Liquormengen, welche extrahiert werden konnten und ferner erkennbar dadurch, daß der Liquor bei Einführung der Nadel ins Gehirn schon bei relativ geringer Tiefe in die aspirierende Spritze stürzte. Darüber hinaus konnte aber auch schon damals während der Kriegsjahre festgestellt werden, daß diese Dilatation des Ventrikels allmählich zunimmt; es wurde in einzelnen Fällen, die in längeren Abständen wiederholt punktiert wurden, der Ventrikel bei der Punktion, die im einzelnen Falle stets an der gleichen Stelle erfolgte, bei den späteren Punktionen in viel geringerer Tiefe erreicht als bei früheren Punktionen. In einzelnen Fällen, in denen anfangs der Ventrikel bei der Punktion von der Stelle des Knochendefektes aus erst in beträchtlicher Tiefe erreicht worden war, konnte später bei der Operation, die wegen epileptischer Anfälle an der Stelle der Verletzung vorgenommen wurde, festgestellt werden, daß der Ventrikel jetzt bis dicht an die Hirnoberfläche reichte, da $B$ die Wandung desselben nur aus einer papierdünnen Membran bestand, welche mit der Dura verwachsen war und welche bei der Circumcision der Dura um die Stelle der Läsion herum und beim Anheben des circumzidierten Durastückes sofort einriß, so daß nach dem Herausheben des umschnittenen Durastückes das Innere des Ventrikels breit zutage lag. In der oben zitierten Arbeit aus dem Jahre 1925 haben wir diese progressive bis zur Porencephalie gehende $\mathrm{Zu}$ nahme der Dilatation des Seitenventrikels der verletzten Hirnhemisphäre als Ventrikelwanderung bezeichnet. Der Ausdruck ist, wie die in dieser Arbeit vorzubringenden Befunde zeigen werden, nicht besonders zweckmäßig. Es hat sich nämlich herausgestellt, daß die Ventrikelwandung durch die von der Verletzungsstelle ins Gehirn reichende Narbe, welche allmählich mehr und mehr schrumpft, direkt nach der Stelle, an welcher Haut, Dura und Gehirnoberfläche verwachsen sind, hin ausgezogen wird, bis zuletzt, in vielen Fällen wenigstens, die Ventrikelwand bis hart an die Oberfläche heranreicht. Die in dieser Arbeit mitgeteilten Fälle 1, 2, 5, 8, 910 und 11 stellen charakteristische Belege für diese extreme Ventrikeldilatation dar.

Die zweite Tatsache, welche für unsere Untersuchungen bestimmend war, ist die von uns häufig, in Fällen von traumatischer Epilepsie bei der operativen Intervention gemachte Beobachtung, daß ein Zug mit der Pinzette an der Dura im Bereiche der Verwachsung zwischen letzterer 
und der Hirnoberfläche, einen epileptischen Anfall auslöst. Wir haben das bescnders dann beobachtet, wenn die Dura um die Stelle der Verwachsung herum circumzidiert war und nun an den freien Rändern derselben mit der Pinzette gezogen wurde, wobei der Zug sich naturgemäß, da ja der Duralappen in seiner Mitte an der Hirnoberfläche fest adhärent ist und wie wir sehen werden, Bindegewebszüge von hier mehr oder weniger tief ins Gehirn eindringen, auf das Gehirn selbst überträgt und einen krampfauslösenden Reiz bildet. Wir haben solche Krampfanfälle auch schon bei der Ablösung der Haut, welche an der Stelle des Knochendefektes oft äußerst fest mit der darunter befindlichen Dura verwachsen ist, auftreten sehen, was verständlich ist, wenn man bedenkt, daß beim Abpräparieren der Hautlappen stark angezogen werden muß, damit das Messer in der richtigen Schicht zwischen Dura und Haut bleibt. Ganz besonders eindrucksvoll war ein Fall, in welchem gleich bei der ersten Untersuchung ein schwerer Anfall auftrat, als wir prüften, ob die Haut in der Umgebung des Schädeldefektes verschieblich sei, und wir dieselbe auf der knöchernen Unterlage hin- und herschoben; der hierbei an der Haut vorgenommene Zug übertrug sich auf die Dura an der Stelle der Verwachsung und damit auf das Gehirn und wurde zum krampfauslösenden Reiz. In den hier mitgeteilten 12 Fällen wurde in nicht weniger als 5 Fällen (Fall 6, 7, 8, 10 und 11) bei der Operation durch Zug an der Dura ein epileptischer Anfall ausgelöst. Es ergab sich für uns auf Grund dieser Beobachtungen die Frage, ob nicht in Fällen von traumatischer Epilepsie, in denen eine Verwachsung zwischen Haut, Dura und Hirnoberfläche besteht, der durch die Verwachsung auf das Gehirn permanent ausgeübte Zug schon an und für sich einen der Faktoren bildet, welche bei dem Zustandekommen der Anfälle zusammenwirken. Ehe wir das Material unterbreiten, das zur Lösung dieser Fragen beitragen soll, müssen wir einen kurzen Blick auf die Vorgänge werfen; welche bei experimentellen Gehirnwunden festgestellt werden konnten.

\section{Experimentelle Gehirnwunden.}

Der Heilungsmechanismus bei experimentell erzeugten Gehirnwunden ist von uns bereits in früheren Arbeiten dargelegt worden (Penfield ${ }^{7} \mathrm{u}^{8}{ }^{8}$, del Rio Hortega and Penfield ${ }^{9}$, Penfield und Buckley ${ }^{10}$ ). In diesen Arbeiten ist auch die frühere einschlägige Literatur berücksichtigt worden. Die Ergebnisse dieser Arbeiten sollen hier kurz zusammengefaßt werden.

Im Tierexperiment führt eine Verletzung, welche nur die Dura, aber nicht die Arachnoidea betrifft, zu keiner Verklebung. Nur wenn die Pia mater verletzt wird und Gehirngewebe exponiert wird, kommt es zu einer bindgewebigen Reaktion und narbigen Adhäsion zwischen Dura, Arachnoidea und Pia mater, also zwischen Dura und Hirnoberfläche.

Wenn die Wunde tiefer ins Gehirn eindringt, so kommt es in ihrem Bereich zu Hämorrhagien und Hirngewebszerstörung. Sehr schnell 
treten in dieser Zone große Abräumzellen auf, innerhalb der Wunde und um sie herum schwellen und vermehren sich die Astrocyten und senden lange und vielfach verzweigte Fortsätze aus, es erfolgt eine erhebliche Neubildung von Gefäßen in der Zerstörungszone und ihrer Umgebung. Diese neugebildeten Capillaren, die bald durch größere Arterien verstärkt werden, stammen sowohl aus den umgebenden Gehirnpartien als auch von den extracerebralen Gefäßen ab, welche von außen her in die Narbe eindringen. Es kommt sehr bald zu einer Fibroblastenwucherung innerhalb der Zerstörungszone und auf der Oberfläche der Wunde. Das resultierende Bindegewebe enthält viel Kollagen und besonders erscheinen viele junge kollagene Fasern auf den neugebildeten Gefäßen.

Zunächst ist die Gewebsreaktion lokal, abgesehen von der initialen vorübergehenden Hirnschwellung. Jetzt beginnt aber der Prozeß der Narbenschrumpfung, welcher die primär nicht affizierten Hirnpartien in einem gewissen Umkreis um die zerstörte Zone herum mit ergreift. Bei einfacher meningealer Adhäsion entwickeln die oberflächlichen subpialen Astrocyten dicke Fortsätze, welche einerseits nach der Stelle der Adhäsion zu und andererseits diametral entgegengerichtet sind; sie zeigen auf diese Weise die Richtung des Zuges an. An der Stelle der Adhäsion können hypertrophierte Astrocytenfortsätze festgestellt werden, welche aufwärts durch die Linie der subpialen gliösen Gefäßfußplatten hindurch in die darüberliegende Narbe eindringen, woselbst diese Fortsätze mit perivasculären Fußplatten auf den dort liegenden Gefäßen endigen. Das kann besonders mit der Cajalschen Goldchloridmethode festgestellt werden, dank ihrer unbedingten Spezifität für die Neuroglia. Wir verweisen besonders auf Abb. 1 und 2, S. 502 der Arbeit von Penfield ${ }^{7}$. Dieser Befund kann dadurch erklärt werden, daß das Narbengewebe bei seiner Zusammenziehung Gefäße und mit den Gefäßen die perivasculären Gliainsertionen nach oben gezogen hat.

Die fibrösen Astrocyten mit ihren perivasculären Insertionen bilden zusammen mit dem Gefäßbaum das Stützgerüst des Gehirns. Im Gegensatz zu anderen Organen besitzt das Gehirn trotz seiner Größe keine bindegewebigen Septen. Man kann des öfteren Neurogliafasern durch einen Astrocytenzelleib hindurch von einem Gefäß zu einem andern ziehen sehen. Solche Fasern verbinden die Gefäße untereinander. Dieses Gerüst (,,vasoastral-frame work") ist an dem Prozeß der Narbenzusammenziehung primär beteiligt. Das geht daraus hervor, daß die großen Astrocytenfortsätze, welche gleichzeitig perivasculäre Ausbreitungen besitzen, auf die Narbe zu und von ihr weg gerichtet sind; es hat förmlich den Anschein, als ob diese Astrocytenfortsätze hypertrophiert wären unter dem Einfluß des mechanischen Zuges. Diese linienförmige Anordnung der Astrocytenfasern ist allerdings nur in der unmittelbaren Umgebung der Narbe vorhanden, aber das ganze Gehirngewebe wird dadurch aufwärts gezogen, und bei kleinen experimentell erzeugten Gehirnwunden 
kann man sehen, daß die Pia mater an der Narbenstelle eingezogen ist oder, daß die Grenzlinie zwischen grauer und weißer Substanz an der Narbenstelle ausbiegt $\left({ }^{10}\right)$. Außerdem wird die Wand des benachbarten Ventrikels nach der Läsionsstelle zu hingezogen ?

Ein derartiger Narbenzug kommt nicht zustande, wenn Hirngewebe ausgeschnitten und kein beschädigtes Gewebe zurückgelassen wird. Selbst wenn sich die Excisionshöhle mit Blutgerinnseln füllt, so werden diese nicht durch Bindegewebe ersetzt; im Gegenteil, es kommt zur Bildung einer mit Flüssigkeit erfüllten Cyste und diese enthält kein Bindegewebe oder höchstens in ganz spärlichen Mengen. Die Höhle ist von keiner Gliose der weißen Substanz und einer sehr geringen in der grauen Substanz umgeben. Die Astrocyten sind nicht auf die Wände zu orientiert und die Blutgefäße sind nicht vermehrt. Mit anderen Worten, es besteht keine Narbe.

Dieses Fehlen von Narbenbildung, welche unter analogen Umständen in jedem anderen Gewebe Platz greift, ist vielleicht die Folge der Anwesenheit der Cerebrospinalflüssigkeit, welche sehr schnell jeden leeren Raum erfüllt und zum Teil wohl auch der Starre der Schädeldecke zu danken, welche das Gehirn gegen jeden Druck von außen schützt $\left({ }^{10} \mathrm{u} .{ }^{7}\right)$. Die Bedingung, von welcher die Anwesenheit oder das Fehlen von Narbenbildung bei Gehirnwunden abhängt, ist die Anwesenheit oder Abwesenheit geschädigten Hirngewebes innerhalb der Wände.

\section{Casuistik.}

Wir schreiten jetzt zur Mitteilung der Ergebnisse unserer Untersuchungen beim Menschen. Es wurden die durch Operation gewonnenen Excisa von 12 Fällen von traumatischer Epilepsie, in welchen die Encephalographie die Ventrikelverziehung meist sehr deutlich erkennen ließ, untersucht. In 9 Fällen handelte es sich um Schußverletzungen, die aus dem Weltkriege stammten (Fall 1, 2, 3, 4, 6, 7, 9, 11 und 12), in 2 Fällen um Geburtstraumen (Zangengeburt, Fall 5 u. 9), in einem Fall (Fall 10) um Schädelverletzung durch stumpfe Gewalt (Sturz von der Treppe). In allen diesen Fällen bestand mit zwei Ausnahmen (Fall 3 und 5) ein mehr oder weniger großer Knochendefekt. Die Haut war mit der Dura und diese ihrerseits mit der Hirnoberfläche fest verwachsen; letzteres war auch der Fall in dem einen nicht mit Knochendefekt einhergehenden Fall (Fall 3), in dem nur eine flache Knochenimpression bestand. Im Falle 5, der eine Zangengeburt darstellt, war weder ein Knochendefekt vorhanden noch bestand eine Adhassion zwischen Dura und Gehirnoberfläche. Bei der Operatien wurde stets so vorgegangen, daß ein Hautlappen gebildet wurde, und daß dieser sorgfältig von der unterliegenden Dura abpräpariert wurde; diese Prozedur erwies sich in vielen Fällen besonders wegen der derb narbigen Beschaffenheit der 
Haut als recht schwierig, da naturgemäß einerseits der stellenweise recht dünne Hautlappen nicht verletzt, andererseits aber während des Abpräparierens auch die darunterliegende Dura und das mit ihr verwachsene Gehirn nicht beschädigt werden durften. Sehr schwierig gestaltete sich meist auch die Lösung der Haut an den Rändern des Knochendefektes, da sie hier mit letzteren stets besonders fest verwachsen ist. Nach der Ablösung des Hautlappens wurde die Knochenbresche beträchtlich erweitert. Danach wurde die Dura, parallel und nahe dem Rande der jetzt vorhandenen Schädellücke um die Läsionsstelle herum völlig circumzidiert, die Dura war in der Mitte dieses circumzidierten Abschnittes mit der Hirnoberfläche verwachsen. Es wurde nicht versucht, sie von der Gehirnoberfläche abzulösen, vielmehr wurde der freie Rand des Duracircumcisums nach dem Zentrum zu umgeklappt. Es konnte fast regelmäßig beobachtet werden, $d a ß$ es auch nach völliger Circumcision des adhärierenden Duraabschnittes aus der Außenfläche der Dura heraus blutete, ein Beweis, daß Gefäße aus dem Gehirn in die Dura eingedrungen waren. Die Dura selbst erwies sich an der Stelie der Verwachsung und darüber hinaus vielfach verdickt, manchmal an der Verwachsungsstelle selbst durchlöchert. Das Gehirn zeigte an der Stelle der Verwachsung, aber auch fast stets in der Umgebung derselben beträchtlicheVeränderungen; teils handelt es sich um bräunlichgelbe Kontusionsherde, teils mehr um grau erscheinende harte narbige Herde. In 7 Fällen (Fall 1, 2, 5, 8, 9, 10 u. 11) erwies sich der Hirnmantel äußerst verdünnt, indem der Ventrikel, wie es schon die encephalographischen Bilder vor der Operation gelehrt hatten, bis dicht an die Hirnoberfläche heranreichte. Zur genaueren Orientierung über die Lage des Herdes wurde stets die elektrische Reizung herangezogen. Die Ergebnisse sind in den einzelnen Krankengeschichten niedergelegt. Darauf wurde diese veränderte Hirnpartie zirkulär umstochen und exzidiert. Das Excisium enthielt dann die an der veränderten Hirnpartie adhärierende Dura. In das narbige Hirngewebe eingebettet fanden sich wiederholt Knochensplitter und Projektilteile. Nach sorgfältiger Blutstillung wurde der entstandene Duradefekt durch Plastik aus der Fascia lata gedeckt; darauf wurden Galea und Haut getrennt sorgfältig vernäht. Der Knochendefekt wurde stets in vollem Umfange offen gelassen.

Die gewonnenen Excisa wurden histologisch untersucht. Angewandt wurde die Nißlmethode zu Färbung der Ganglienzellen und die Silbercarbonatneurofibrillenmethode zur Färbung der Nervenfasern. Das Bindegewebe wurde mit van Gieson dargestellt, die kollagenen Fasern mittels der Silbercarbonatfärbung. Zur Darstellung der Astrocyten wurde in den Fällen, in welchen frisch gewonnenes Material vorlag, Cajals Goldchlorid-Sublimatmethode angewandt, das übrige Material, das zum Teil bereits jahrelang in Scheringschem Formalin konserviert worden war, wurde mit del Rio Hortegas Silbercarbonat-Astrocytenfärbung behandelt; die letztere Methode bringt die abnormen Astrocyten, besonders deren Beziehung zu den kollagenen Fasern sehr gut zur Darstellung. Die Mikroglia und Oligodenđroglia wurden, da das Material zum größten Teil sehr alt war, mit 
einer besonderen Modifikation der Hortegaschen Silbercarbonatmethode gefärbt; diese weicht etwas von der, welche wir früher beschrieben haben (12), ab. Die Excisa wurden eine Nacht lang in fließendem Wasser ausgewaschen, darauf geschnitten und die Schnitte in zugedeckten Schalen mit Ammoniakwasser über Nacht konserviert; dann wurden sie durch destilliertes Wasser gezogen und für 2 Stunden in $3 \%$ ige Ammoniumbromidlösung verbracht, rasch ausgewaschen und in 5\% Sodalösung für 1 Stunde oder länger gegeben; von hier aus kamen sie direkt in Hortegas schwache Silbercarbonatlösung, um dann in der üblichen Weise weiter behandelt zu werden. In der Regel konnte auf diese Weise durch verschieden langes Verweilen in der Silberlösung sowohl Mikroglia wie Oligodendroglia gefärbt werden.

\section{Fall 1.}

E. B., 35 Jahre. August 1914 Kopfschußverletzung (Infanterieprojektil) am linken Os parietale, 12 Stunden bewußtlos, rechtsseitige Hemiplegie und Aphasie. 2 Tage nach der Verletzung ausgiebiges Debridement, Wunde hat lange geeitert, erst März 1915 definitiv geschlossen. Allmähliche Wiederkehr der Sprache, Besserung der Hemiplegie, Pat. mußte aber lernen mit der linken Hand zu schreiben.

1920: Erster epileptischer Anfall, danach Hemiparese wieder stärker.

10. 12. 1925: Zweiter epileptischer Anfall, am nächsten Morgen wiederholte sich derselbe. Seitdem starke Häufung der Anfälle.

11. 12. 1925: Aufnahme ins Wenzel-Hancke-Krankenhaus. Am linken Scheitelbein über dreimarkstückgroße Hautnarbe, in deren Bereich ein gleich großer Knochendefekt.

Beträchtliche spastische Parese des rechten Armes und Beines; Facialis, Zunge, GaumensegeI nicht beteiligt; auch Daumen und Zeigefinger zu isolierten Bewegungen fähig.

Hochgradige Ataxie des rechten Armes und Beines.

Hemianästhesie der rechten Körperhälfte, die Berührungsempfindung, Druckempfindung, Warm- und Kaltempfindung, Bewegungsempfindung betreffend; Störung stärker an den distalen Abschnitten als an den proximalen Abschnitten der Extremitäten, mediale Rumpfpartien frei von Sensibilitätsstörungen, ebenso Gesicht. Keine Störung des Schmerzgefühls. Schwerste Störung des Raumsinnes der Haut und völlige Aufhebung des Tastvermögens recht seitig. Keine Gesichtsfelddefekte, Augenhintergrund normal, keine Zeichen von Aphasie oder Alexie, schreibt gut mit der linken Hand; keine Zeichen von Apraxie.

Charakter des Anfalls: Es bestehen fortgesetzt während der Beobachtung vom 11-20. XII. epileptische Anjälle, die in Abständen von etwa 5 Minuten auftreten, sie beginnen in der Regel im rechten Mundfacialis, greifen dann auf den rechten oberen Facialis über, wobei auch der linke obere Facialis etwas mitbeteiligt ist, dann auf das rechte Platysma und den linken Sternocleidomastoideus (Kopf dreht sich nach rechts), wobei aber auch der rechte Kopfnicker etwas mitzuckt, dann auf den Daumen und zuletzt auf den Zeigefinger über; manchmal beteiligt sich auch die Zunge und das Gaumensegel. Bisweilen beginnen die Anfälle im Daumen oder im Zeigefinger und greifen von hier aus auf den Hals, den oberen Facialis, den unteren Facialis und die Zunge über. Die übrigen Finger und die anderen Armmuskeln beteiligen sich nicht an diesen echten Jacksonschen Krämpfen, welche vollkommen den Typus der Irritation des Feldes 4 tragen. Bei einem Teil der Anfälle besteht vor dem Beginn der Krampfentladung eine sensible Aura Kribbeln am rechten Mundwinkel, gleich danach auch am Auge und dann auf der Zunge, an diese sensible Aura schließt sich die Krampfentladung an, in derselben Reihenfolge wie bei den vorerwähnten Anfällen. Beide Arten von Anfällen gehen in der Regel ohne Bewußtseinsverlust einher, Pupillenreaktion voll erhalten. 
Außerdem aber kommt es auch noch zu großen, sehr schweren Anfällen (am 13. XII. 7 derartige Anfälle), welche in derselben Weise beginnen wie die kleinen Anfälle; aber kurz nachdem der Daumen und Zeigefinger zu krampfen begonnen haben, werden mit einem Schlage der gesamte rechte Arm und das gesamte rechte

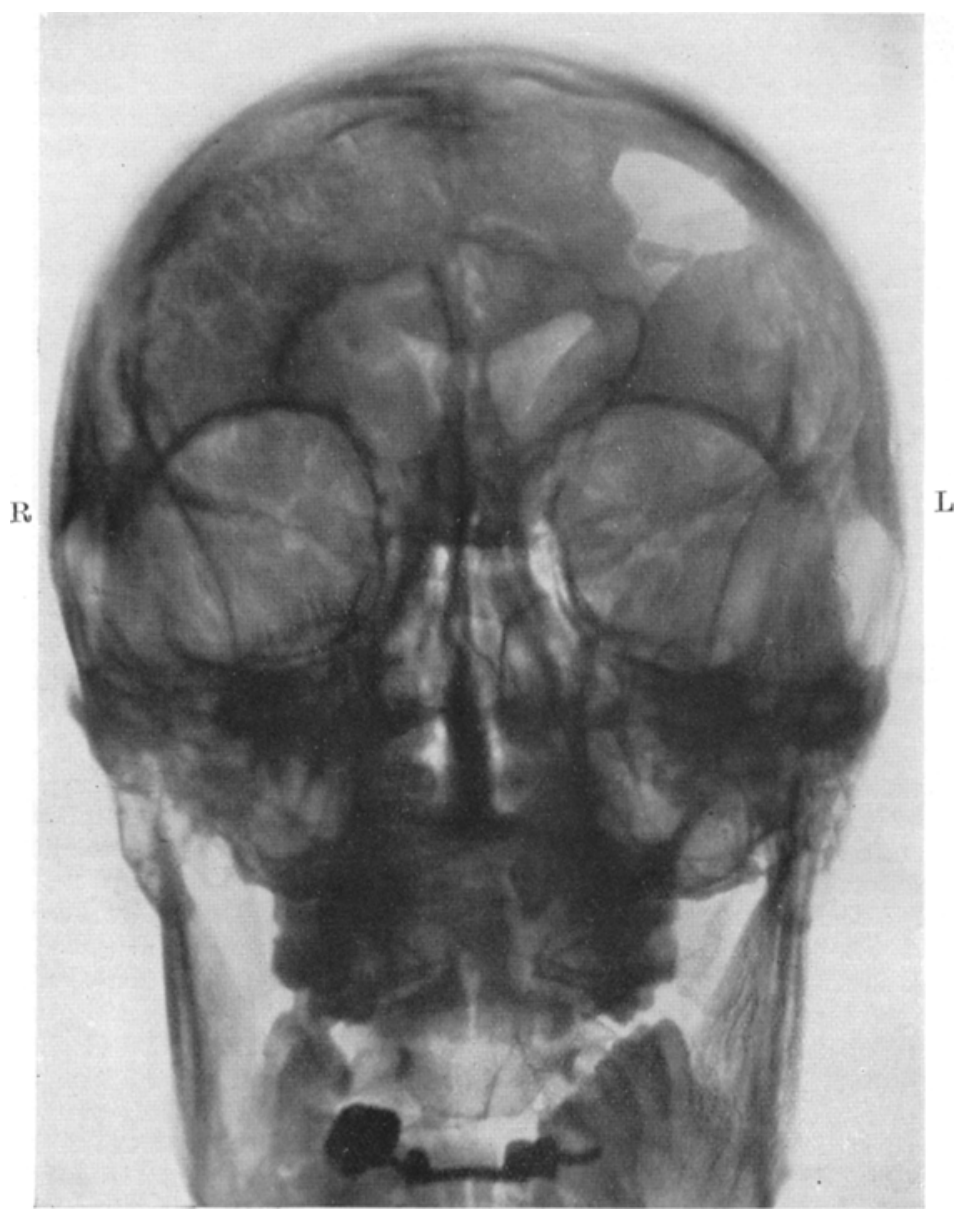

Abb. 1a. Encephalogramm von Fall 1. Aufnahme in antero-posteriorer Richtung, Hinterhaupt auf der Platte. Verziehung der Seitenventrikel und des 3. Ventrikels nach links, auf den Knochendefekt zu. Der linke Seitenventrikel ist dilatiert, seine spitze ist stark abgerundet. Im Bereich des Knochendefoktes ein Knochensplitter.

Bein simultan vom schwersten tonisch-klonischen Krampf ergriffen; Kopf, Augen und Rumpf werden nach rechts verdreht, dann nimmt auch das linke Bein am Krampf teil, zuletzt schwerste allgemeine Krämpfe, schwerster Stertor der Atmung, hochgradige Cyanose.

Die epileptischen Anfälle haben also zum Teil den Charakter echter Jacksonscher Anfälle, teils vom reinen C-a-Typus (Feld 4), teils vom C-p-Typus (Feld 3, 1, 2), wobei die der somatotopischen fokalen Gliederung der Zentralwindungen 
entsprechende Krampfsukzession sich ausschließlich auf das Gebiet der Zunge, des Facialis, des Halses, des Daumens und Zeigefingers beschränkt, letzteren jedenfalls nicht überschreitet, was bei der beträchtlichen spastischen Parese der rechten oberen und unteren Extremität, die auf eine tiefgehende Destruktion des Feldes 4

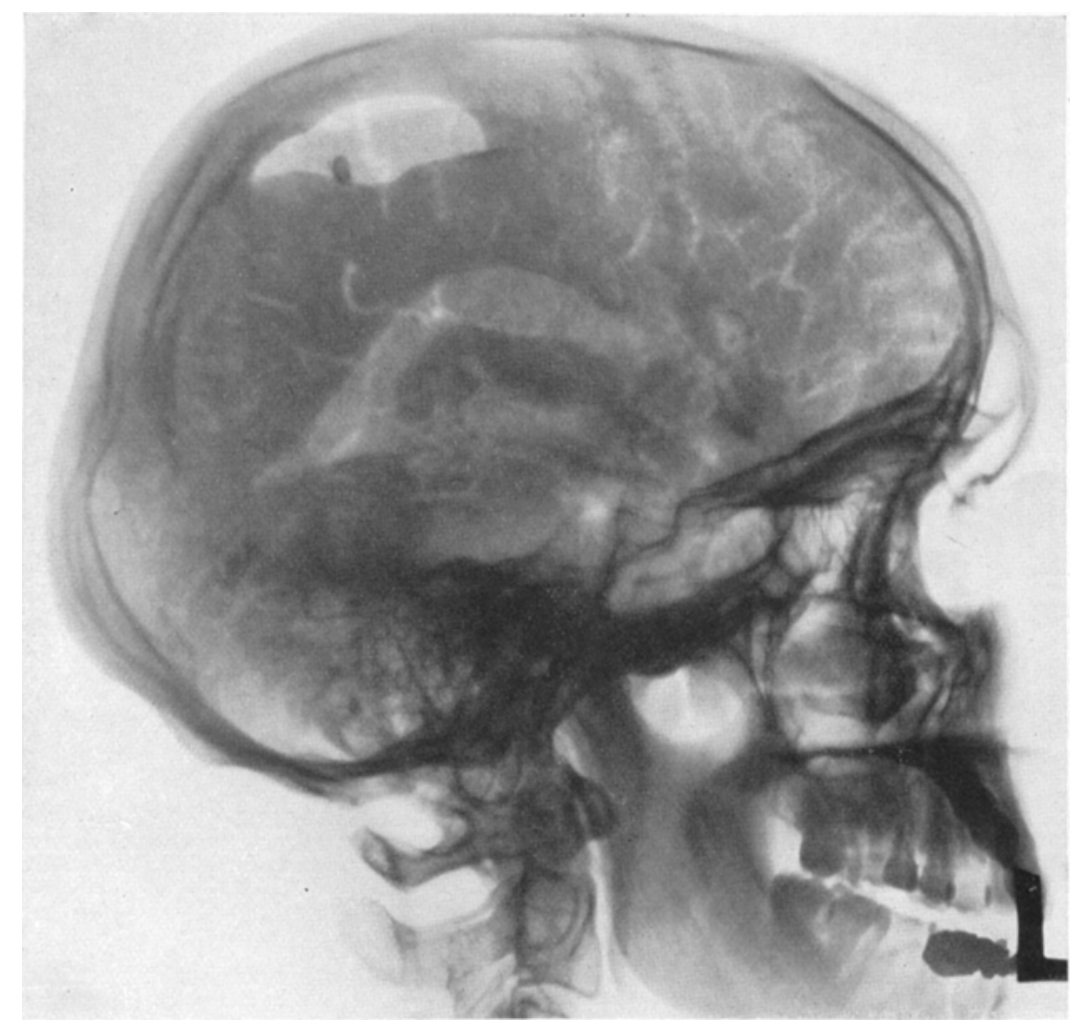

Abb. 1b. Encephalogramm von Fall 1. Seitenaufnahme. Ventrikelzeichnung mäßig ausgeprägt. Doch ist die Ausziehung des Daches des Cella media nach dem Knochendefekt zu erkennbar. Im Bereiche des Knochendefektes ein Knochensplitter.

(Area gigantopyramidalis) bzw. der von ihm ausgehenden Pyramidenbahn hinweist, vollkommen einleuchtet. Die Foki des Zeigefingers, Daumens, des Halses, des Facialis und der Zunge müssen als intakt angesehen werden. Die hintere Zentralwindung bzw. deren Stabkranz muß mit Ausnahme der Foki des Faciolingualgebietes als zerstört betrachtet werden. Außer den umschriebenen Caund $\mathrm{Cp}$-Anfällen treten aber auch schwere typische Adversivfeldanfälle auf, welche in Drehung der Augen, des Kopfes und Rumpfes nach rechts und tonisch-klonischem Simultankrampf aller Muskeln des rechten Armes und Beines bestehen. Es muß angenommen werden, daß der traumatische Hirnherd irritativ auch auf eines der in der Nachbarschaft der Zentralregion gelegenen, aber nicht mitzerstörten Adversivfelder wirkt; hierbei ist in erster Linie an das Parietalfeld (5a und 5b, oberer Scheitellappen) zu denken, obwohl an sich auch eine Einwirkung des Herdes auf das frontale Adversivfeld $(6 \alpha \beta)$ in Betracht kommen könnte. 
Das encephalographische Bild (vgl. Abb. la u. b) zeigt eine markante Verziehung beider Seitenventrikel nach links; der linke Seitenventrikel ist weiter als der rechte und deutlich nach oben gegen den Knochendefekt zu ausgezogen; der dritte Ventrikel ist schräg gestellt. Mehrere Knochensplitter im Bereiche des Knochendefektes, ein Splitter besonders deutlich auf der Seitenaufnahme Abb. 1 b.

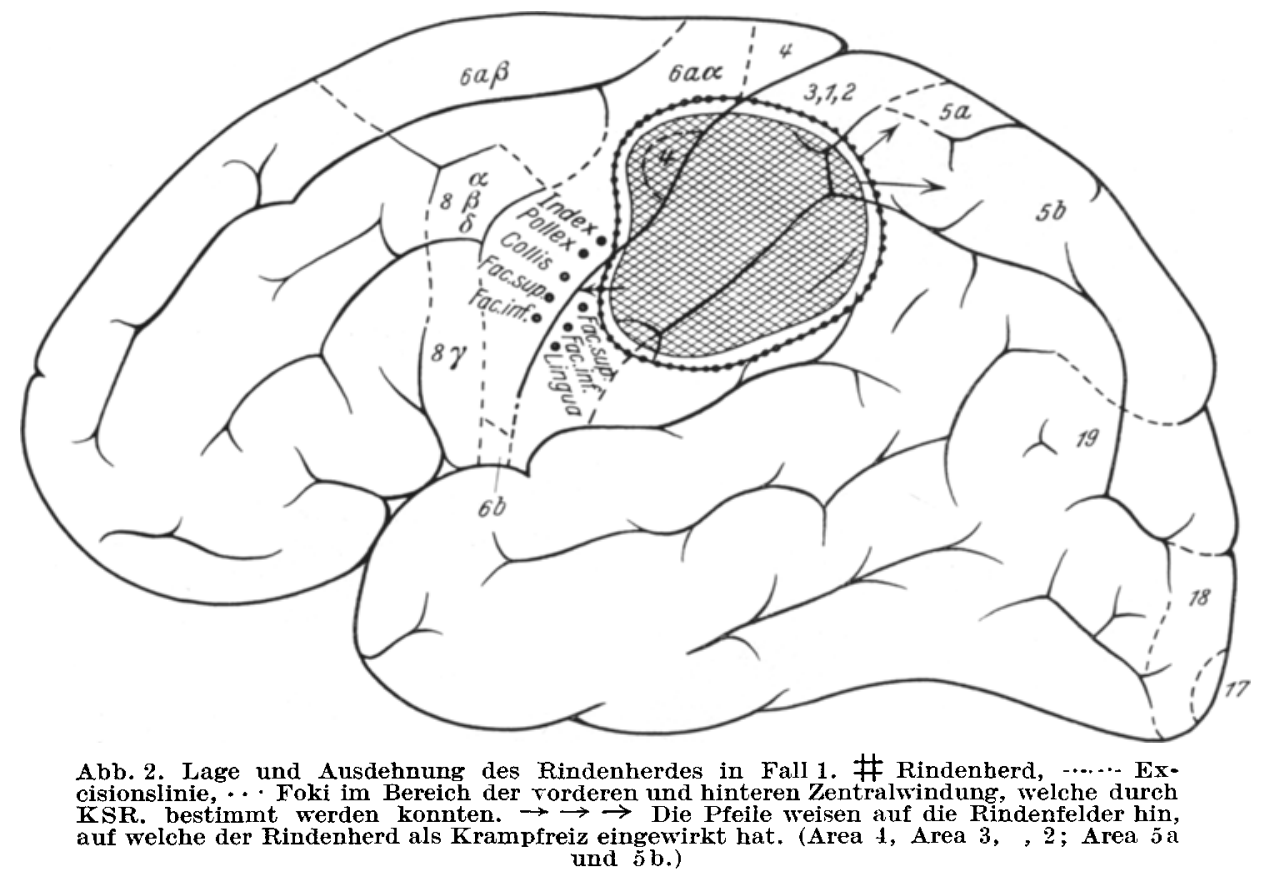

Operation (21. 12. 1925 und 14. 1. 1926). Entfernung des Knochens in breitem Umfang um den bestehenden Defekt herum. Im Bereiche des Defektes ist die Dura fest mit der Hautnarbe verwachsen, ebenso haftet die Dura sehr fest an den Rändern des Knochendefektes; starke Blutung aus der Duraoberfläche im Bereiche des Defektes. In der Mitte des Defektes ist die Dura zerstort, hier wölbt sich das Gehirn cystisch in einer Ausdehnung von der Größe eines Zweimarkstückes hervor. Zirkuläre Durchschneidung der Dura in weitem Umkreis um die Verwachsungsstelle herum; Zurückklappen der freien Duraränder nach der Verwachsungsstelle zu. In deren Bereich Knochensplitter fühlbar, nachdem sich die erwähnte oberflächliche Cyste entleert hat. Hirnsubstanz hier und in breitem Umkreis schwer destruiert. Ausdehnung und Lage des Herdes in Abb. 2 dargestellt. Durch galvanische KSR. können die Foki des Index, Pollex, Platysma, Sternocleidomastoideus, des oberen und unteren Facialis in der vorderen Zentralwindung bei 2,5 M A gut isoliert erregt werden, weiter oberhalb keine fokale Erregbarkeit in Ca. Im Gebiete von Cp. kann der Fokus des oberen und unteren Facialis sowie der der Zunge mit 4,0 M A erregt werden; andere Foki sprechen von $\mathrm{Cp}$. aus ebensowenig an wie von $\mathrm{Ca}$.

Zirkuläre Umstechung des Herdes mit Ligaturen. Die Dura bleibt an der Stelle der Adhäsion mit der Hirnsubstanz in Verbindung. Excision der destruierten Hirnstelle in dem in Abb. 2 angegebenem Umfang; die Hirnnarbe reicht bis in 
den stark dilatierten Ventrikel, dieser wird bei der Excision breit eröffnet, das exzidierte Hirnstück hat etwa die Dicke von $2 \mathrm{~cm}$ und einen Durchmesser von $5 \mathrm{~cm}$. Deckung des Duradefektes durch Plastik aus der Fascia lata. Heilung per primam.

Nach der Operation Temperaturen zwischen 38 und $39^{\circ}$ (Ventrikel eröffnet) bis 25. 1., von da ab unter $38^{\circ}$, vom 12. 2. ab fieberfrei. Während des Fiebers absolutes Wohlbefinden. Leukocytenzahl im Blut nicht wesentlich erhöht. Nach der Operation rechter Arm und rechtes Bein stärker paretisch als vorher, aber nach wenigen Tagen wieder Status quo ante operationem.

Keine epileptischen Anfälle mehr seit

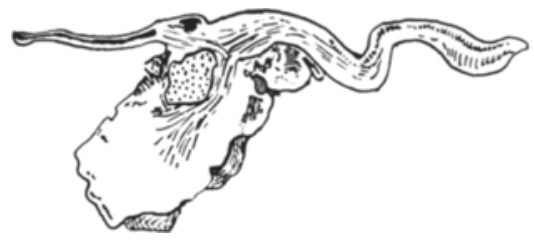

Abb. 3. Dura-Gehirn-Excisum von Fall 1. $3 \mathrm{~cm}$ breit, $4 \mathrm{~cm}$ tief, Durchsehnitt. Dura verdickt, mit dem Gehirn verwachsen. An der Adhäsionsstelle strahlen reichlich Bindegewebsziige in die Hirnsubstanz ein. In der Operation. Laufend beobachtet bis letzterer ein Knochensplitter eingebettet. Ende des Jahres 1929, also 4 Jahre lang. Patient ist voll berufsfähig (Bürobeamter).

Anatomischer Befund: Abb. 3 stellt eine Skizze des exzidierten Hirnstückes auf dem Durchschnitt dar. Man sieht die verdickte Dura innig mit der Gehirnmasse verwachsen; von der Dura ziehen dichte Bindegewebszüge in das Gehirn herein; in diesem letzteren ist ein Knochenfragment eingebettet.

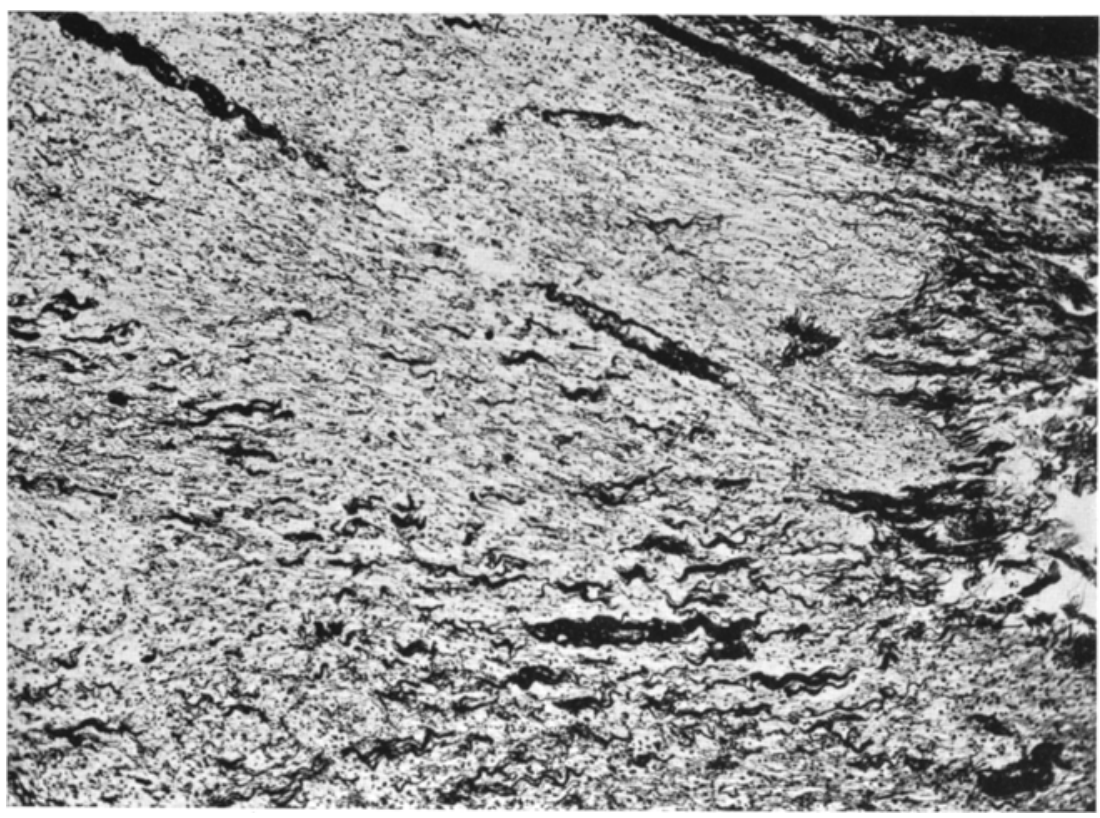

Abb. 4. Mikroskopisches Präparat des Dura-Gehirn-Excisums von Fall 1. Vergrößerung $70 \mathrm{fach}$. Zahlreiche neugebildete Gefäße und kollagene Bindegewebsfasern dringen in das Hirngewebe ein. Die kleinen Kerne sind Gliakerne.

Die mikroskopische Untersuchung zeigt, daß die von der Dura ausgehenden bindegewebigen Formationen tief in das Hirngewebe eindringen. Die kollagenen Fasern und zahlreichen Gefäße verlieren sich in das gliöse Gewebe der Hirnnarbe 


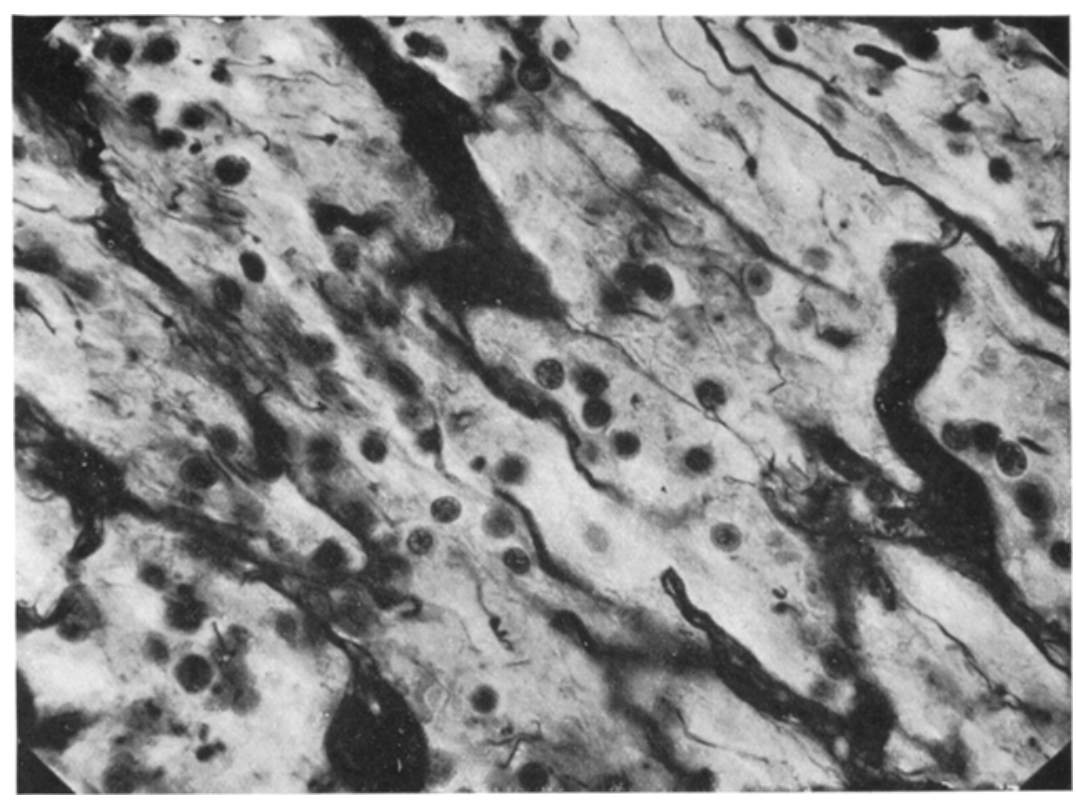

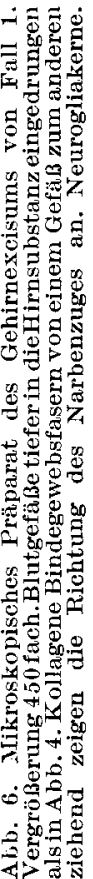

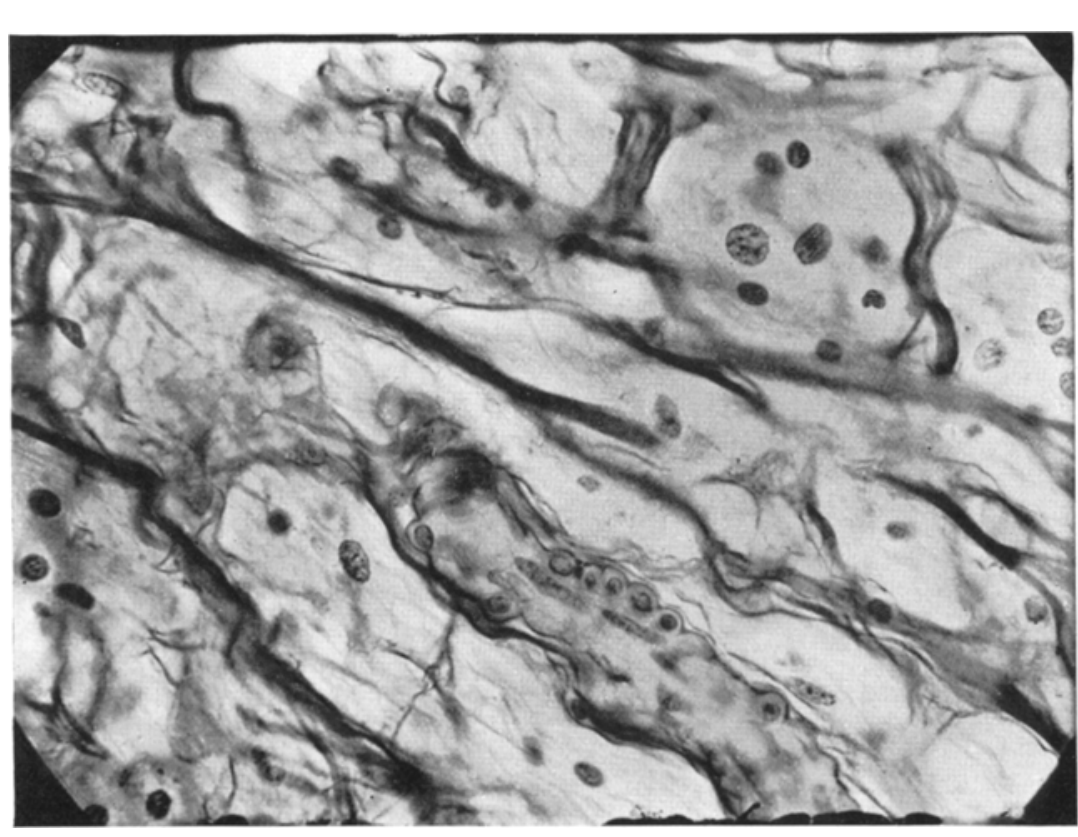

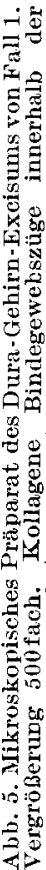




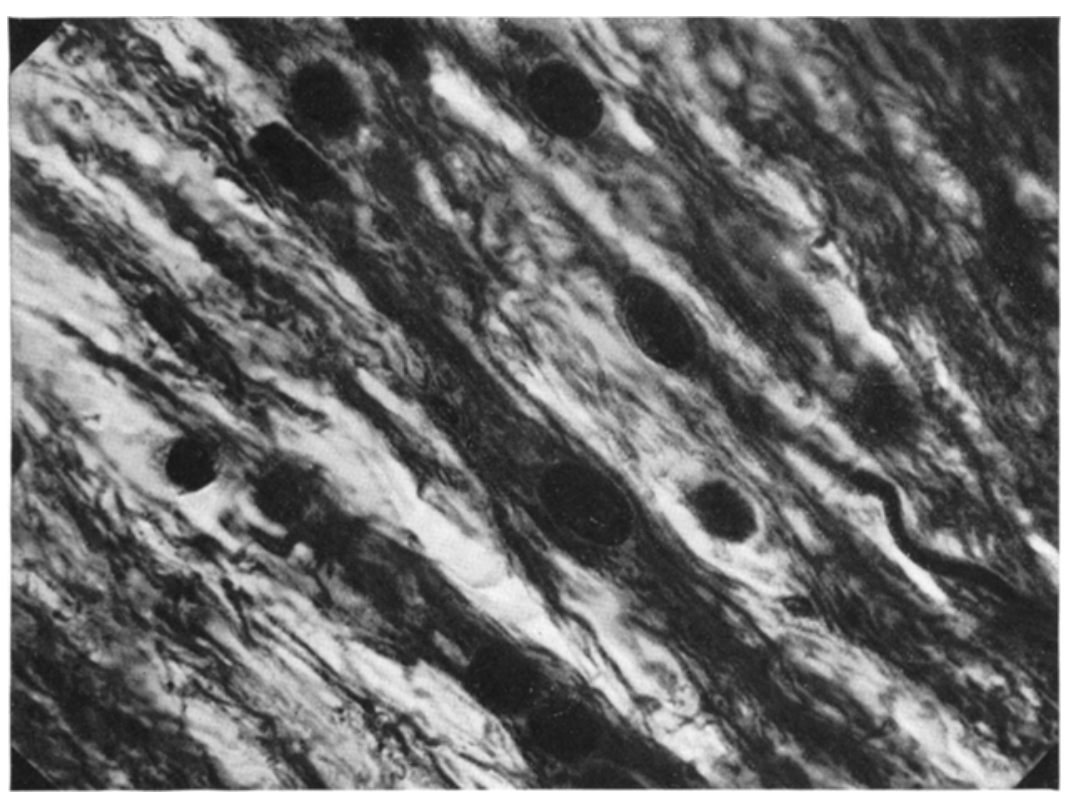

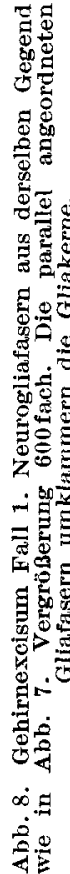

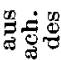

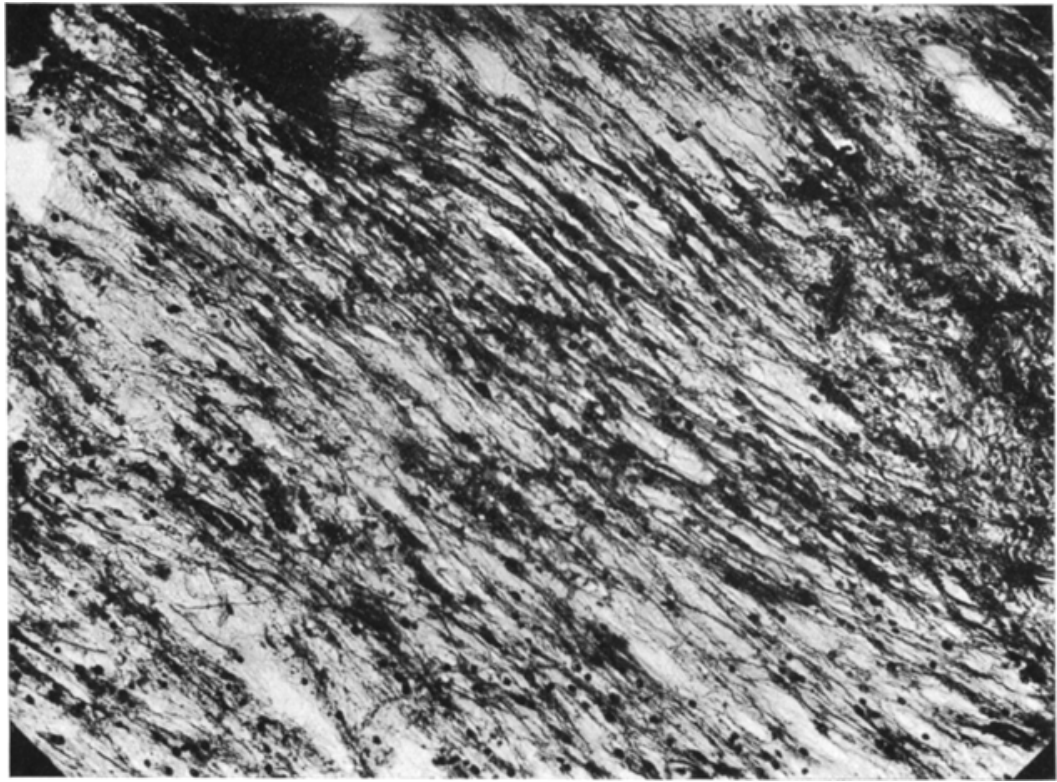

동

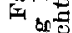

뭉후

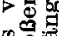

象:

要

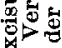

계․․

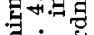

80

我

क्ष

证

究

क力

象里

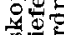

$8+\infty$

记

然

急 
(Abb. 4). Da wo die kollagenen Fasern in das Hirngewebe eindringen, bilden sie ein Netzwerk und anastomosieren miteinander und mit dem Bindegewebe um die zahlreichen neugebildeten Capillaren herum (Abb. 5). Tiefer im Hirngewebe finden sich ebenfalls zahlreiche Gefäße und reichliche Bindegewebszüge gehen von einem Gefäß zu dem anderen. Es fällt auf, daß diese intervasculären Bindegewebsfasern eine parallele Anordnung aufweisen, sie sind alle nach der darüberliegenden Duranarbe zu gerichtet (Abb. 6).

Diese Bindegewebszüge dringen, wie schon oben erwähnt, in das gliöse Gewebe der Hirnnarbe ein. Dieses letztere, setzt sich aus feinen Fasern zusammen, die zu parallelen Bündeln angeordnet sind (Abb. 7). Diese Gliafasern sind in Zellcytoplasmen eingeschlossen und liegen den Kernen benachbart, welche über das Gewebe

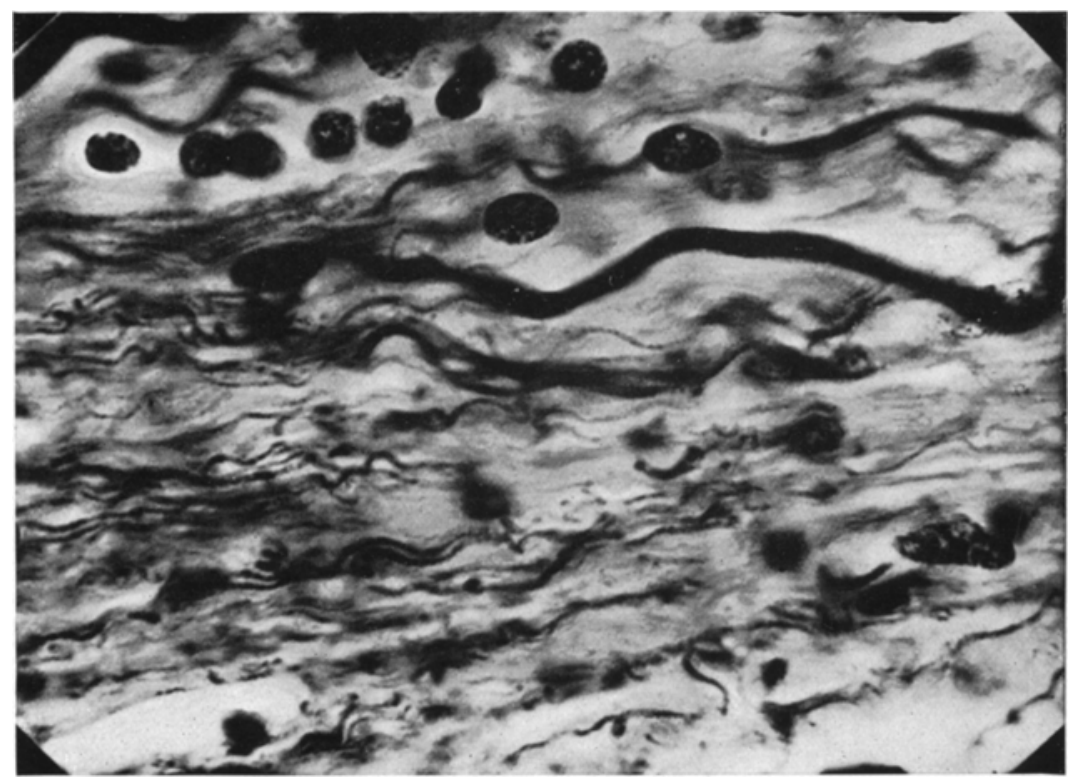

Abb. 9. Gehirnexcisum von Fall 1. Vergrößerung $600 \mathrm{fach}$. Neurogliafasern und Bindegewebsfasern nobeneinander; letztere erheblich stäker als erstere.

verstreut liegen (Abb. 8). Die Kerne haben zum größten Teil ovale Gestalt und gleichen Astrocytenkernen, wie man sie auch sonst sieht, aber das Cytoplasma besitzt nicht die Sternform der Astrocyten im normalen Hirngewebe; vielmehr sind die Zellfortsätze und Fasern dicht zusammengeballt und senden stellenweise lange, schwanzartige Gebilde aus. Da wo die Bindegewebsfasern in die gliöse Hirnnarbe eindringen, liegen sie mit den erwähnten Gliafasern innig untermischt (Abb.9). Die Richtung der Gliafasern ist genau die gleiche wie die der Bindegewebsfasern, sie verlaufen direkt auf die Adhäsionsstelle zwischen Dura und Hirnoberfläche zu.

Das gliöse Hirnnarbengewebe enthält keine Nervenzellen, wohl aber vereinzelte Nervenfasern. Spezifische Neurofibrillenfärbungen zeigen, daß diese Nervenfasern äußerst dünn sind und gebrochen erscheinen. (Abb. 10.) Selbst wenn diese Fasern alle markhaltig wären, was nicht der Fall ist, so ist ihre Zahl doch so gering und ihr Kaliber so fein, daß das Hirnnarbengewebe praktisch als markfaserlos angesehen werden kann. 
Die parallelfaserigen Glianarbenzonen haben kaum noch die Eigenschaften von Hirngewebe. An den wenigen Stellen, an denen eine halbwegs normale Gehirnstruktur noch besteht, gehen die sternförmigen Astrocyten fast plötzlich in den „sprowling type“ über und inserieren mit ihren Füßen überall an den Gefäßen (vgl. diesen Befund in Abb. 65 B. u. C. -). Diese Astrocyten sieht man besonders in der Nachbarschaft des Ventrikelependyms, sie haben lange zierliche Fortsätze und gleichen den Zellen, welche man in dem äußerst verdünnten Pallium bei starker Hydrocephalie findet.

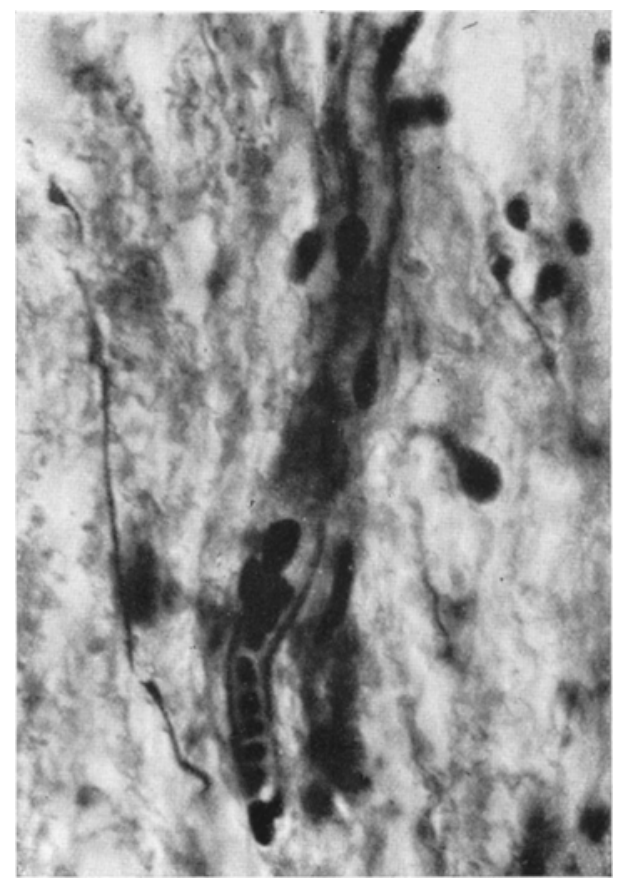

Abb. 10 : Gehirnexcisum von Fall 1. Der gliöse Narbenzug enthält eine Nervenfaser. In zahlreichen anderen Gesichtsfeldern fehlen Nervenfasern vollkommen. Vergrößerung $500 \mathrm{fach}$.

Die Oligodendroglia hat, soweit sie sich in der exzidierten Hirnnarbe findet, normales Aussehen. Die Zellen sind nicht geschwollen und die Cytoplasmakörnchen sind nicht abnorm. In den Zonen der dichten parallelfaserigen Gliazüge scheint überhaupt keine Oligodendroglia vorhanden zu sein. Das gänzliche Fehlen von Ganglienzellen und die sehr spärliche Anwesenheit von Nervenfasern in diesen Bezirken läßt ja auch kaum die Existenz dieser Trabantzellen erwarten.

Die Mikroglia hat sich schlecht färben lassen, wohl infolge des Umstandes, daß das exzidierte Hirnstück 3 Jahre in Formalin gelegen hat, ehe es verarbeitet wurde. Da wo in der Rinde Mirkogliazellen gefärbt wurden, erscheinen sie normal.

$\mathrm{Zu}$ unterscheiden von der direkten Bindegewebsinvasion im Gehirn an der Stelle der Adhäsion der Dura mit der Hirnoberfläche, ist die subpiale Sklerose oder sog. flächenhafte Erweichung Jakobs (13), ein dichter vasculärer Plexus mit starker Bindegewebsbildung in den oberflächlichen Rindenschichten, ungefähr gerade unterhalb der Lamina zonalis (Abb. 11). An vereinzelten Stellen erreicht 
der Plexus die Pia, aber fast überall liegt er tiefer. Die Pia selbst ist, da wo es zu dieser Plexusbildung kommt, nicht durchbrochen, die Rinde unterhalb derselben ist im großen ganzen normal. $\mathrm{Zu}$ beiden Seiten dieses vasculären Plexus finden sich zahlreiche fibröse Astrocyten. Dieselbe mesodermale vasculäre Proliferation findet sich auch in mehreren anderen der hier mitgeteilten Falle.

Zusammenfassung. Es handeit sich um einen Fall von Granatsplitterverletzung der linken Scheitelregion mit Versprengung von Knochenfragmenten ins Gehirn (1914). 6 Jahre später (1920) traten die ersten epileptischen Anfälle auf (Typus 4; 3, 1, 2; 5 u. 5b). Die Encephalographie zeigt

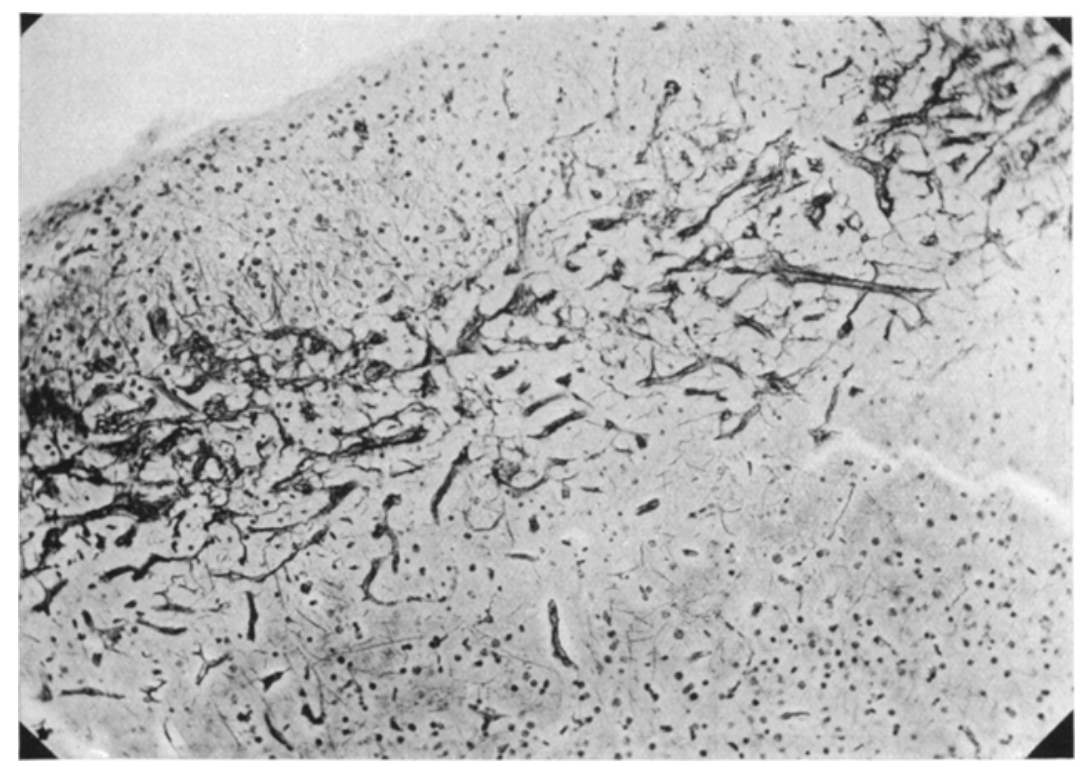

Abb. I1. Gehirnexcisum von Fall 1. Sklcrotische Rindenpartie. Ausgeprägter Plexus von neugebildeten Gefäßen und kollagenen Bindegewebsfascrn. Vergrößerung 70 fach.

die starke Verziehung des ganzen Ventrikelsystems nach der Stelle der Knochenverletzung zu. Die Kopfhaut ist an der Stelle des Knochendefektes mit der Dura und diese mit der Hirnoberfläche fest verwachsen. Das ausgeschnittene Hirnstück zeigt deutlich den Narbenzug, ähnlich wie er im Tierexperiment nachgewiesen werden konnte. Stark parallel gerichtete Bindegewebszüge ziehen von der ihrerseits verdickten Dura ins Gehirn herein und verankern sich überall an die Gefäße; die unmittelbare Fortsetzung dieser Bindegewebszüge bilden dicht gedrängte fibröse Gliafaserzüge, deren Richtung genau die gleiche ist wie die der Bindegewebszüge. Die Gliafaserzüge reichen bis an das Ventrikelependym heran. E's wird also durch diese mesodermal-fibröse-gliöse Fasermasse, welche an der Haut einerseits fest angewachsen ist, andererseits bis zum Ventrikelependym reicht, ein starker Narbenzug auf die Ventrikelwandung 
ausgeübt und diese letztere wird in dem Maße als die Narbe sich zusammenzieht, nach dem Knochendefekt hingezogen.

\section{Fall 2.}

K. W., 28 Jahre alt. Mutter litt an Epilepsie. 20. 10. 1918. Granatsplitterverletzung am rechten Scheitelbein; nicht bewußtlos, aber sofort linksseitig gelähmt, sofortiges Debridement, bis März 1919 bettlägerig. 1920 begann er zu studieren, mußte aber wegen starker Kopfschmerzen abbrechen, übernahm eine Stelle beim Finanzamt, die er seither ausfüllte.

Juli 1919. Erster epileptischer Anfall; die Anfälle wiederholten sich anfangs in Abständen von 3 Wochen, später teils häufiger, teils seltener, seit Februar 1928 sehr gehäufte Anfälle, täglich mehrmals.

1. 4. 1929. Aufgenommen im Status epilepticus. Auf dem rechten Scheitelbein ein sagittal verlaufender, $7 \mathrm{~cm}$ langer, $3 \mathrm{~cm}$ breiter Knochendefekt, Haut in dessen Bereich stark eingezogen, in der Mitte eine reaktionslose Hautnarbe. An der Zunge linkerseits eine frische Bißwunde. Spastische Hemiplegia sinistra. Facialis und Zunge mäßig beteiligt, linker Vorderarm in starker Beugecontractur, Oberarm etwas abduziert und stark innenrotiert, Hand proniert und flektiert, Finger flektiert, hochgradiger Dehnungswiderstand der Muskeln des linken Armes, zum Teil ausgesprochen clonisch, lebhafte Sehnen- und Periostreflexe an der linken oberen Extremität. Die willkürliche Beweglichkeit des linken Armes ist fast aufgehoben, Einzelbewegungen der einzelnen Abschnitte der oberen Extremität ganz aufgehoben. Es kommt bei jeder Bewegungsintention nur zu einer Beugesynergie oder Strecksynergie des gesamten Armes und nur im geringen Ausmaß. Bauchreflex links sehr abgeschwächt, Cremasterreflex fehlt links, willkürliche Neigung und Drehung der Wirbelsäule nach links eingeschränkt. Linker $F u B$ in starker Spitzfußstellung, starker Fuß- und Patellarklonus, Beuge- und Streckreflexsynergie am linken Bein sehr ausgesprochen; Babinski und Oppenheim positiv; stark erhöhter Dehnungsreflex der Adductoren des Oberschenkels, der langen Knieflexoren, des Quadriceps, des Gastrocnemius und Soleus, Rossolimo stark ausgeprägt. Patellar- und Achillesreflex sehr stark erhöht. Mendel-Bechterew positiv. Am linken Bein willkürliche Einzelbewegungen der einzelnen Abschnitte (Zehen, FuB, Unterschenkel, Oberschenkel) unmöglich, es kommt stets zur gesamten Beugeoder Strecksynergie. Beim Gang wird das linke Bein beim Vorsetzen im Knie nur minimal gebeugt, der Fuß wird nicht dorsalflektiert, sondern er verharrt in Spitzfußstellung, wird aber stark supiniert; das Bein wird beim Vorsetzen in der Hüfte stark circumduziert, aber nur wenig nach vorne gebracht. Beim Aufsetzen des Fußes auf dem Boden krallen sich die Zehen stark in den Boden ein.

Die Sensibilität ist an der ganzen linken Körperhälfte für alle Qualitäten (Berührung, Druck, Stich, Temperatur, Vibration, passive Bewegungen der einzelnen Extremitätenabschnitte) schwer gestört. Am wenigsten ausgesprochen ist die Analgesie. An den Extremitäten ist die Sensibilitatsstörung distal stärker als proximal, am Rumpf an den lateralen Partien stärker als an den medialen Abschnitten; doch sind selbst im Gesicht, in der Umgebung des Mundes und in der des Anus deutliche Sensibilitatssstörungen nachweisbar. Der Raumsinn der Haut (Lokalisation punktförmiger Reize, Diskrimination zweier gleichzeitig applizierter, aber räumlich getrennter Reize, Erkennen von Zahlen die auf die Haut geschrieben werden) ist auf der ganzen linken Körperhälfte schwerstens gestört. Gegenstände, welche dem Kranken in die geschlossene Hand gelegt und in dieser hin- und herbewegt werden, werden nicht erkannt; eigene Tastbewegungen kann der Kranke überhaupt nicht ausführen.

Z. f. d. g. Neur. u. Psych. 125. 
Keine Hemianopsie. Augenhintergrund normal. Gehör, Geruch, Geschmack zeigen keine Störung. Lumbalpunktion: Druck $190 \mathrm{~mm}$ in horizontaler Lage, Liquor qualitativ normal.

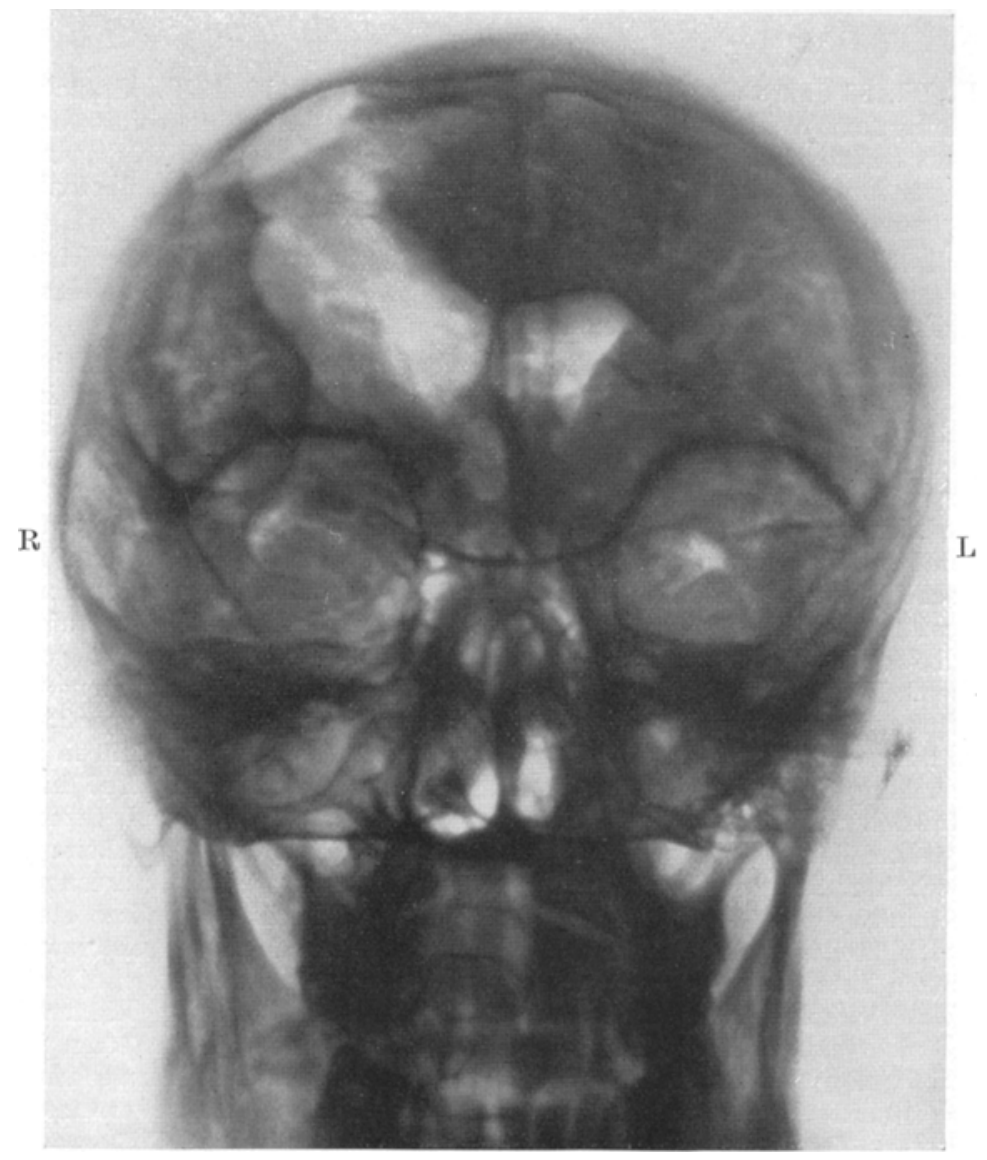

Abb. 12 a. Encephalogramm des Falles 2. Aufnahme in antero-posteriorer Richtung, Hinterkopf auf Platte. Beide Seitenventrikel und 3. Ventrikel stark dilatiert und nach rechts, nach dem Knochendefekt zu verzogon; der 3 . Ventrikel dentlich schrïg gestellt, findet sich ganz innerhalb der rechten Schädelhälfte. An den an sich schon enorm dilatierten rechten Seitenventrikel ist eine cystische Kanmer angeschlossen, welche bis hart an den Knochendefekt heranreicht.

Das Encephalogramm (vgl. Abb. 12 a-c) zeigt eine riesige Dilatation des rechten Seitenventrikels, der linke ist auch etwas erweitert; der rechte Seitenventrikel reicht bis zum Knochendefekt hin. Das ganze Ventrikelsystem ist stark nach rechts verzogen, der dritte Ventrikel schräg von unten links nach oben rechts gerichtet. In der Sagittalaufnahme erscheint der rechte Ventrikel weniger luftgefüllt als der linke, aber seine Ausdehnung bis zum Knochendefekt hin ist auch deutlich erkennbar.

Der Charakter der in Abständen von 5-10 Minuten sich ständig wiederholenden epileptischen Anfälle ist folgender : Sensible Aura im gesamten linken Bein, manchmal zunächst allein im Fuß, dann aber rasch auf das gesamte Bein sich ausbreitend, 
häufig im gesamten linken Arm und Bein zugleich und rasch die gesamte Körperhälfte einnehmend; die motorische Entladung, welche stets sehr rasch folgt, besteht in Drehung der Augen und des Kopfes nach links, Rumpfdrehung nach links, starkem Beugekrampf des linken Beines und linken Armes, sehr bald partizipiert auch das rechte Bein in Form starken Beugekrampfes; der rechte Arm folgt erst

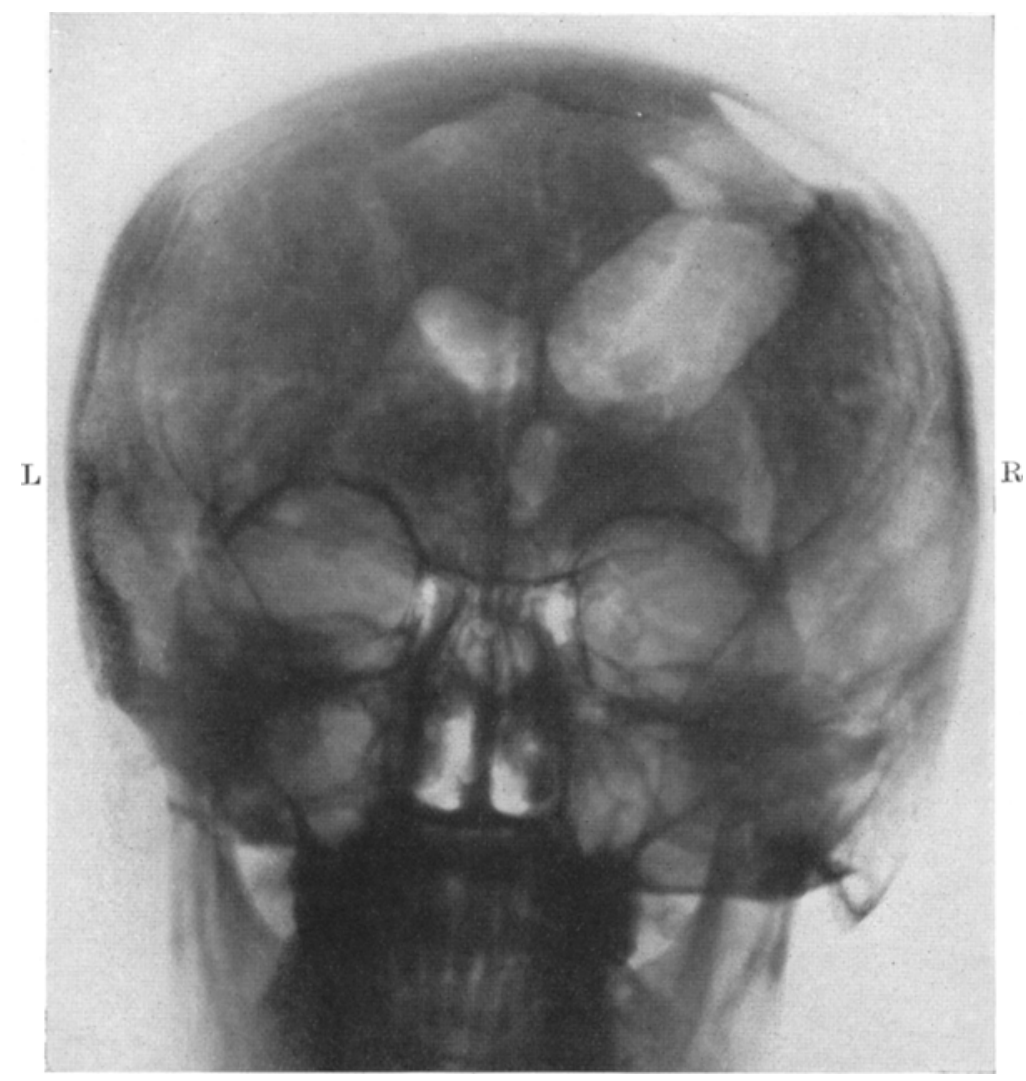

Abb. 12 b. Encephalogramm des Falles 2. Aufnahme in postero-anteriorer Richtung, Stirn auf Platte. Beide Seitenventrikel und 3 . Ventrikel sehr dilatiert und nach rechts zum Defekt herübergezogen. Jer rechte Seitenventrikel reicht mit der an ihn angeschlossenen cystischen Kammer im Bereiche des Knochendefektes bis hart an die Hirnoberfläche heran.

später nach, vielfach nimmt er gar nicht am Krampfe teil. Nachdem der Beugekrampf des linken Armes und Beines einige Minuten angehalten hat, kommt es zu abwechselnden Streck- und Beugestößen des linken Armes und Beines. Während des ganzen Anfalles sind der Kopf und die Augen permanent nach rechts gedreht. Die Art der Anfälle ist durch die Abbildungen 13 und 14 dargestellt.

Der Charakter der Anfälle weist auf das Parietalfeld 5b und 5a hin (sensible Aura, Drehung der Augen und des Kopfes nach der Gegenseite, simultaner tonischklonischer Krampf des kontralateralen Armes und Beines, rasche Beteiligung des homolateralen Beines). Die bei einzelnen Anfällen auf den linken Fuß beschränkte initiale Aura dürfte auf eine Irritation des Fußfokus in der hinteren Zentralwindung 
zurückzuführen sein. Zu bemerken ist, da B in früherer Zeit die Anfälle nach Angabe des Kranken ohne Drehung der Augen und des Kopfes und Rumpfes einhergingen und nur in einem Beugekrampf des linken Beines und Armes bestanden; es hat sich also früher offenbar um reine 5a-Anfälle gehandelt. Die Mehrzahl der Anfälle geht ohne Bewußtseinsverlust einher; doch kommt es auch besonders dann, wenn auch der rechte Arm am Anfall partizipiert, zu schwersten generalisierten Krämpfen

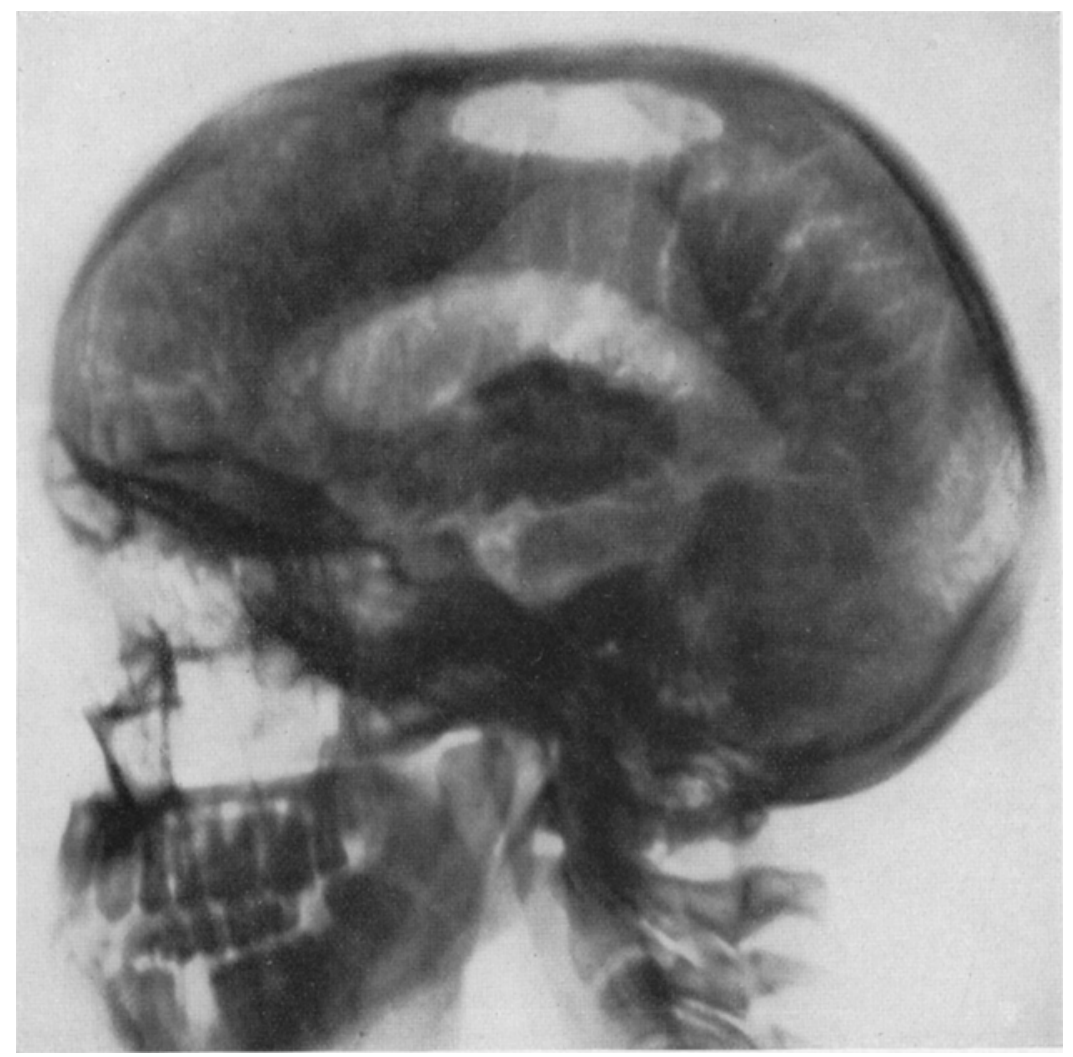

Abb. 12c. Encephalogramm des Falles 2. Seitenaufnahne. Das Dach des schwächer sichtbaren reehten Seitenventrikels erscheint im Bereiche des Knochendefektes fast bis an diesen herangezogen.

mit völligem Bewußtseinsverlust, tiefem Stertor, schwerer Cyanose, Zungenbiß, Stuhl- und Urinabgang; nach jedem derartigen Anfall besteht totale schlaffe linksseitige Hemiplegie. Nach einem solchen schweren Anfall setzen die Anfälle für etwa 1 Stunde aus.

16. 4. 1928 Operation. Lokalanästhesie, großer Lappenschnitt mit nach unten gelegener Basis um den vorhandenen Knochendefekt herum. Abpräparieren der Haut von der Dura im Bereiche des Knochendefektes äußerst schwierig. Erweiterung des Knochendefektes in breitem Umkreis, nach medial zu wird der Sinus longitudinalis freigelegt. Zirkuläre Durchtrennung der Dura um den Herd herum; in der Mitte ist die Dura mit dem Gehirn fest verwachsen; es blutet auch nach der 
Umschneidung aus der Dura an der Stelle ihrer Verwachsung mit dem Gehirn stark aus der Dura nach außen. Lage und Ausdehnung des Kontusionsherdes an der Hirnoberfläche in Abb. 15 dargestellt. Bei schwacher faradischer Reizung der markierten Stelle Beugesynergie des linken Armes und Beines, bei stärkerer Reizung epileptischer Anfall (simultaner Beugekrampf des linken Armes und Beines, dem sich rasch ein Beugekrampf des rechten Beines anschließt). Der Anfall kann mehrmals nacheinander durch erneute Reizung ausgelöst werden. Kopf, Augen und Rumpf nehmen nicht am Anfall teil. Der Anfall hat also das reine Gepräge des 5a-Anfalles, welches die früher bei dem Kranken beobachteten Anfälle

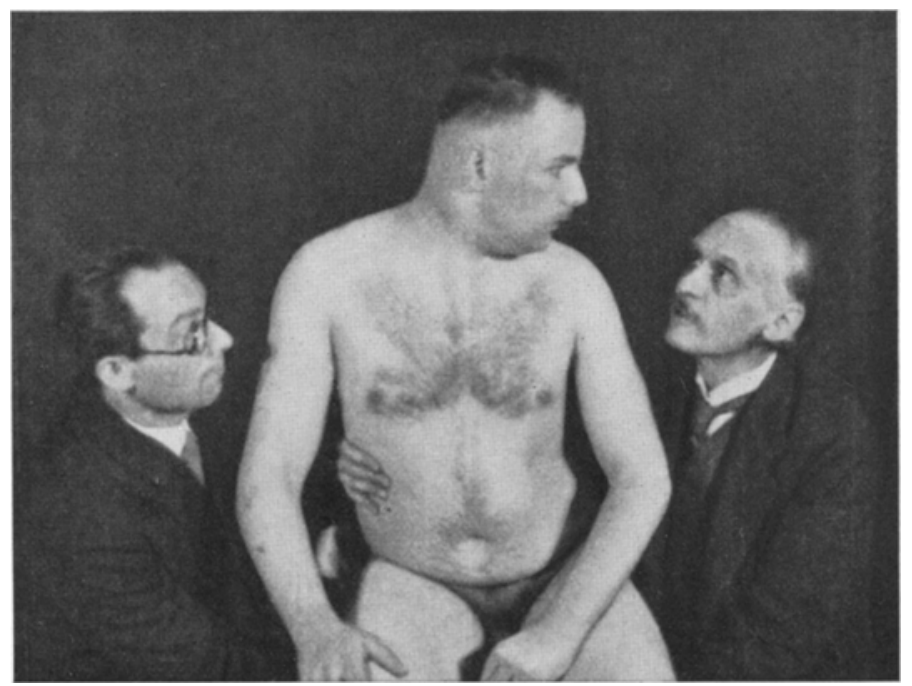

Abb. 13. Frste Phase des epileptischen Anfalles in Fall 2. Kopf und Augen stark nach links gedreht (Feld $5 \mathrm{~b}$ ).

hatten. Auch bei faradischer Reizung weiter hinten gelegener, dem Felde $5 \mathrm{~b}$ angehöriger Rindenabschnitte kommt keine Augen-Kopfdrehung zustande. Umstechung des Herdes, Excision, dabei wird der Ventrikel breit eröffnet; der Plexus chorioideus liegt am Grunde breit zutage. Deckung des Duradefektes durch Transplantat aus der Fascia lata. Galeanaht. Hautnaht. Heilung per primam.

Am 18. 4. Temperaturanstieg auf $40,5^{\circ} \mathrm{C}$ (Ventrikel eröffnet), auch in den folgenden Tagen bis 25. 4. Temperatur zwischen $39^{\circ}$ und $40^{\circ} \mathrm{C}$; dann allmählicher Abfall; vom 14. 5. ab normale Temperaturen. Während der ganzen Zeit der Temperatursteigerung, auch während der Tage mit sehr erhöhter Temperatur, vollkommenes Wohlbefinden. Im objektiven Status durch die Excision keine Veränderung hervorgerufen. Patient hat keine Anfälle mehr gehabt. Keine Kopfschmerzen mehr.

12. 7. 1928. Auf eigenen Wusch entlassen. Hat während der seit der Operation bisher verstrichenen 24 Monate nie wieder Anfälle gehabt. Ist voll berufsfähig als Steuerpraktikant.

Anatomischer Befund: Abb. 16 gibt in geringer Vergrößerung eine skizzenhafte Darstellung der anatomischen Verhältnisse in situ wieder. Abb. 17 stellt einen Durchschnitt durch das exzidierte Dura-Hirnstïck dar. Das Hirngewebe haftet der Dura fest an. Das exzidierte Hirnstück hat $6 \mathrm{~cm}$ im Durchmesser 
und etwa $2 \mathrm{~cm}$ Dicke. Inmitten des Hirngewebes findet sich eine Cyste von $3 \mathrm{~cm}$ Durchmesser. Der hintere Teil des exzidierten Hirnstückes ist sehr derb und grau verfärbt.

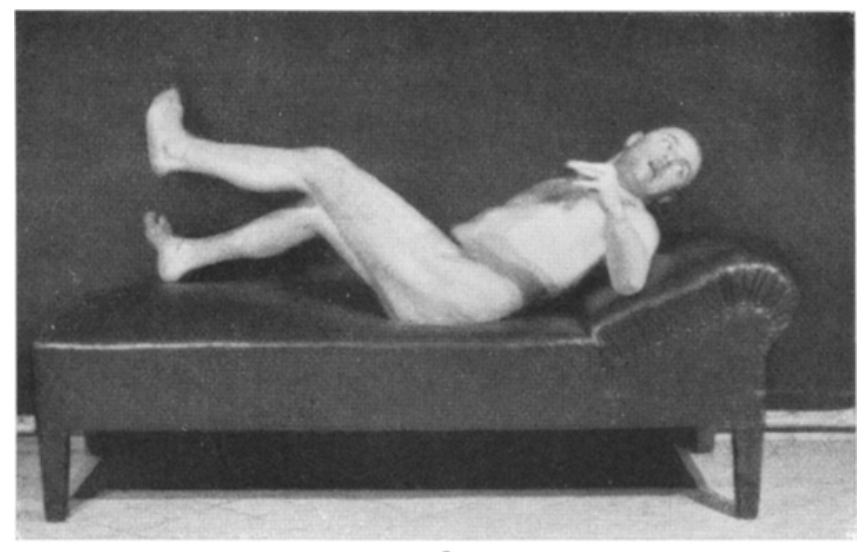

$\mathbf{a}$

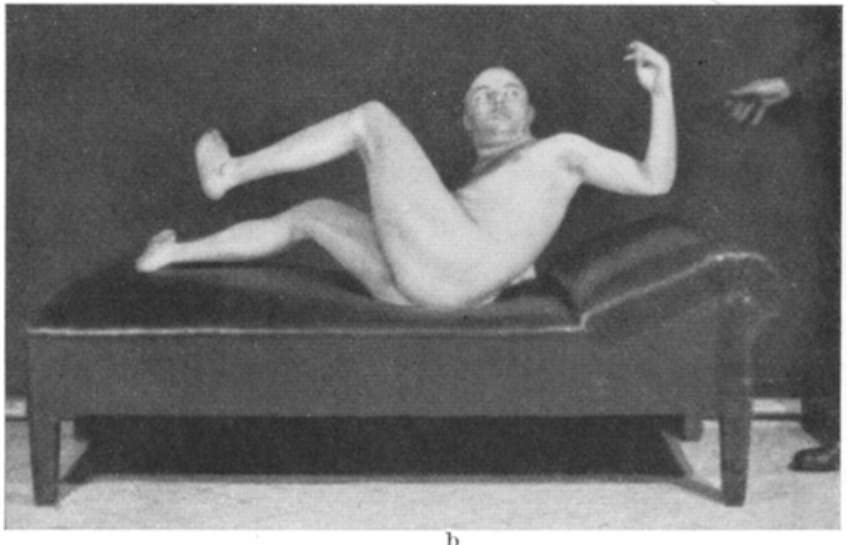

Abb. 14 a und b. Zweite Phase des epileptischen Anfalles in Fall 2. Zu der Drehung des Kopfes und der Augen ist tonisch-kfonischer Beugekramif des linkem Ammes und beider Beine hinzugetreten (Feld 5a).

Die mikroskopische Untersuchung deckt die Anwesenheit zahlreicher Gefäße zwischen der adhärenten Dura und dem Gehirngewebe auf (Abb. 18); an vielen Stellen dringen mit den Gefäßen starke Bindegewebszüge ins Gehirn ein. Dichtgedrängte parallelfaserige Gliafaserzüge sind in diesem Falle spärlicher vorhanden als im Falle 1. Die weiße Gehirnsubstanz unterhalb der Dura zeigt ausgesprochene Erweichung. Die Mitschädigung der Glia geht so weit, daß die Astrocyten mit der Cajalschen Methode nicht färbbar sind, aber sie können mit der Hortegas schen Astrocytenmethode dargestellt werden. Sie erscheinen deformiert und entbehren meistens der Fortsätze. Um die erweichte Zone herum findet sich starke Gliaproliferation. An manchen Stellen ist die perivasculäre Gliose so stark, daß jedes einzelne Gefäß durch die Gliafärbung scharf hervortritt (Abb. 19). 


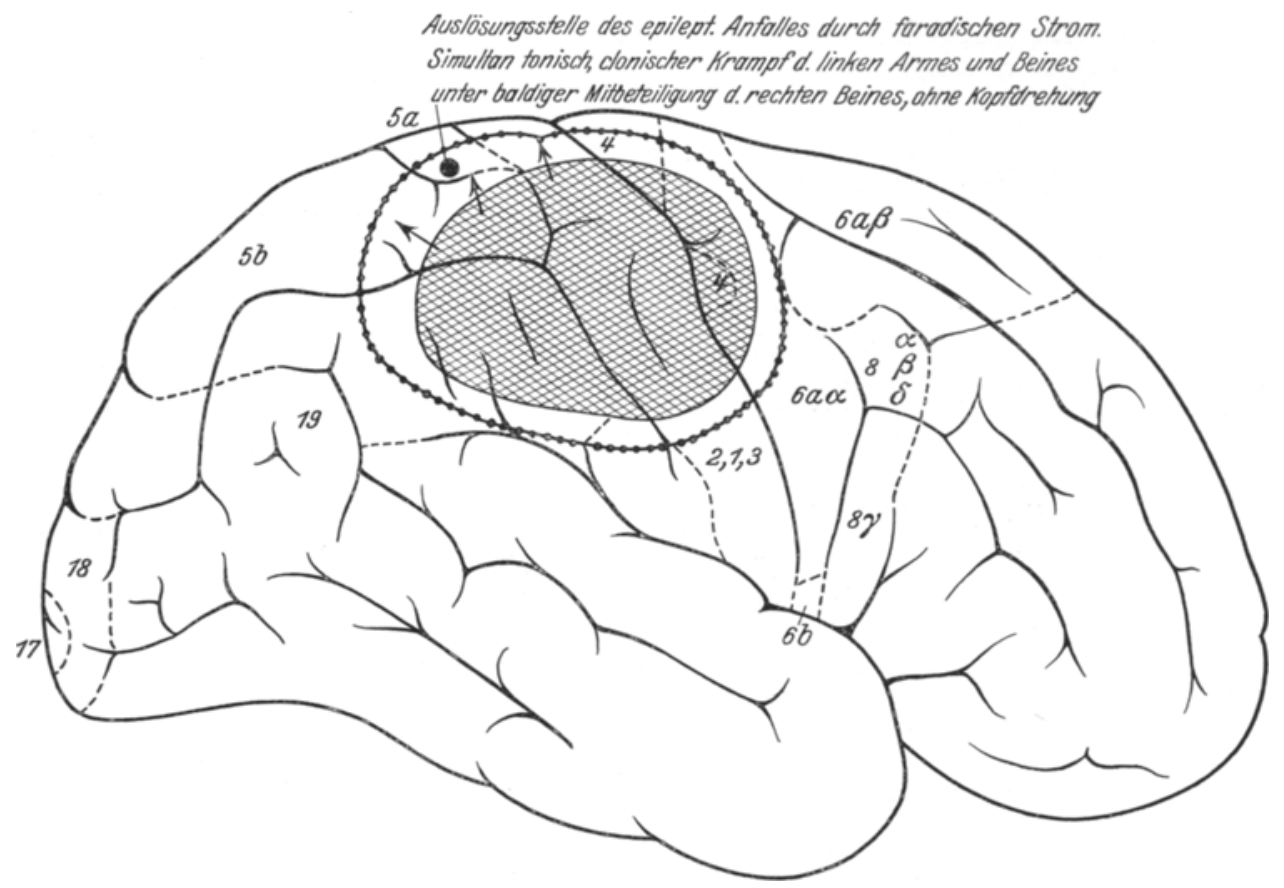

Abb. 15. Lage und Ausdehnung des Rindenherdes in Fall 2. \# Rindenherd. ........ Excisionslinie, Auslösungsort des epileptischen Anfalles durch den faradischen Strom. Simultaner tonisch-klonischer Bengekrampf des linken Armes und Beines unter baldiger Mitboteiligung des rechten Beines; keine Kopf-Augen-Rumpfdrehung.

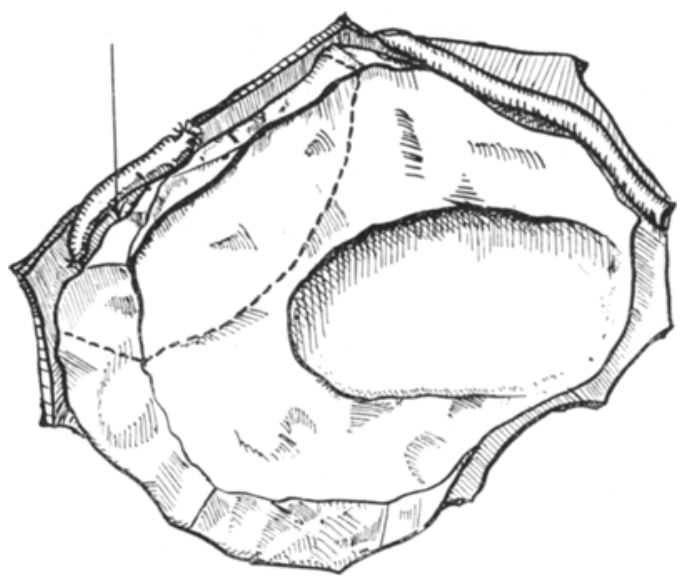

Abb. 16. Dura-Gehimexcisum von Fall 2 in natürlicher Größe von der Unterseite gesehen. In dem Gehirngewebe befindet sich eine Vertiefung von $3: 2 \mathrm{~cm}$ Durchmesser, welche das Dach der cystischen, bis hart an die Hirnoberfläche reichenden Aussackung des rechten Seitenventrikels (vgl. Abb. 12a-c) bildete. Der Pfeil weist auf die Stelle, von welcher der epileutische Anfall während der Operation ausgelöst wurde, hin. Die Linie - _ - markiert das besonders derb sklerosierte Hirngewebe. 
In den oben erwähnten erweichten Bezirken zeigen die Neurofibrillen ausgesprochene Alterationen auf. Statt des gleichmäßigen, höchstens durch vereinzelte Nodositäten ausgezeichneten Kalibers der normalen Fasern weisen sie hier starke

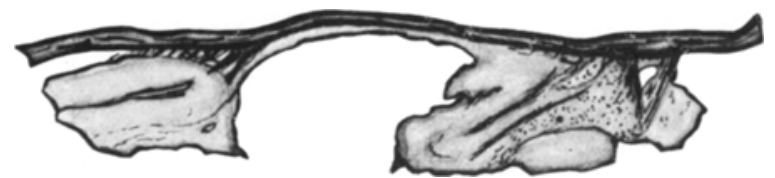

Abb. 17. Dura-Gehirnexcisum von Fall 2 im Durchschnitt zeigt deutlich das an der Unterfläche der Dura adhärierende Hirngewebe, in das Bindegewebszürge eindringen. In der Mitte die cystische Vertiefung, ein Teil der durch die Exeision eröfneten großen cystischen Aussackung des rechten Seitenventrikels.

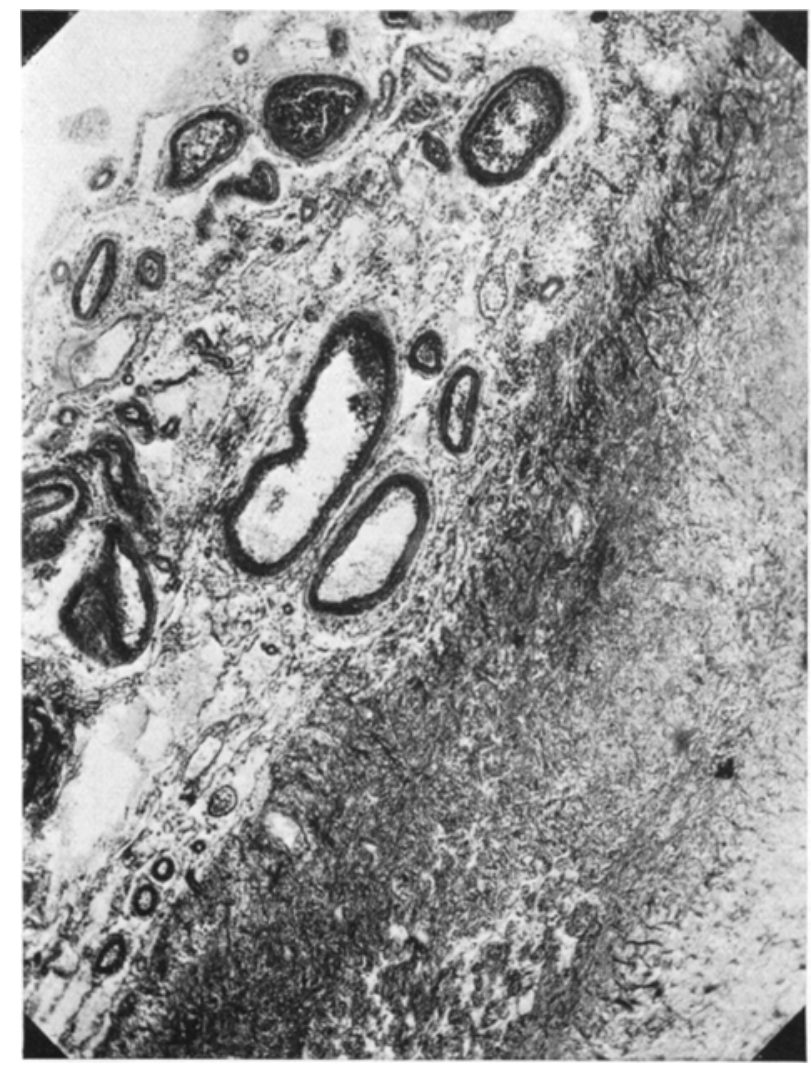

Abb. 18. Mikroskopisches Präparat des Dura-Hirnexcisums von Fall 2 bei 70 facher Vergrößerung. Zahlreiche Gefäße zwischen Dura und sklerosierter Gehirnsubstanz.

kolbige Verdickungen auf (Abb. 20 u. 21), sie enden frei, teilweise mit Anschwellungen. Stellenweise erscheinen die Verdickungen vakuolisiert und durchsichtig. Diese pathologischen Neurofibrillenveränderungen fanden sich nur ganz vereinzelt an den Nervenfasern in den nicht erweichten Partien (Abb. 22). 
Die Narbenzug am und im Gehirn bei traumatischer Epilepsie usw.
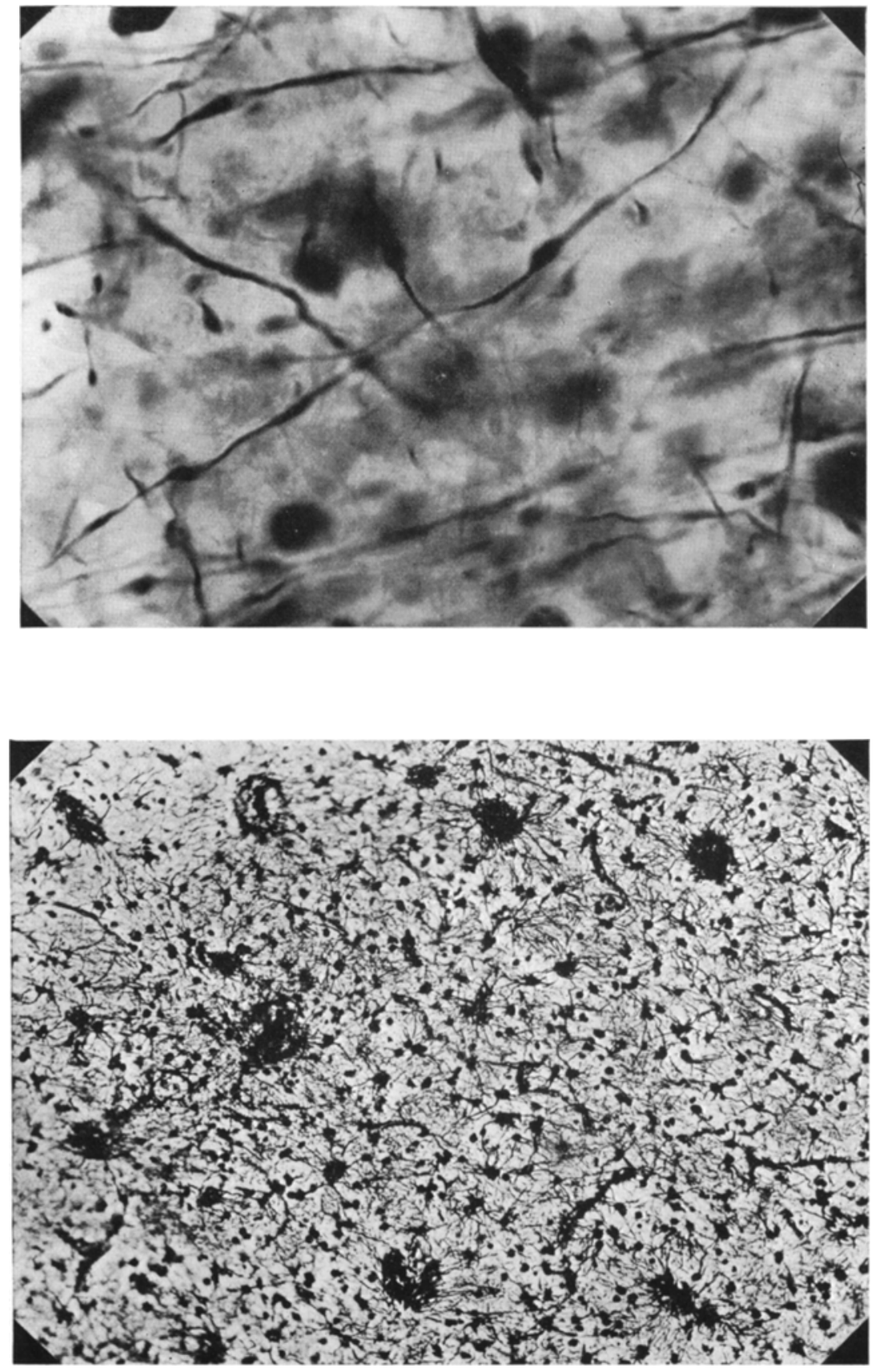

Si 
Unterhalb der Dura findet sich ein ganz eigenartiges Gebilde, eine becherartige Einstülpung, in derem Innern zahlreiche Gefäße Abb. 23). Die Wandung der Einstülpung besteht aus dichten primitiven Astrocyten, welche Fußplatten auf dem Piä̈berzug bilden. Abgeschlossen wird die Einstülpung durch eine Lage von Bindegewebe und außerhalb dieses besteht starke Malacie und erhebliche Gliaalteration; die oberflächliche Glia ist nach der Einstülpung zu orientiert.

Die Nervenzellen zeigen, soweit solche vorhanden sind, nichts Besonderes. In der Nachbarschaft der Gefäße sehr viel pigmentierte Phagocyten. Oligodendroglia und Mikroglia erscheinen normal mit Ausnahme einer Zone nahe der Hirnoberfläche, woselbst die Mikrogliazellen sehr verdickte Cytoplasmen aufweisen.

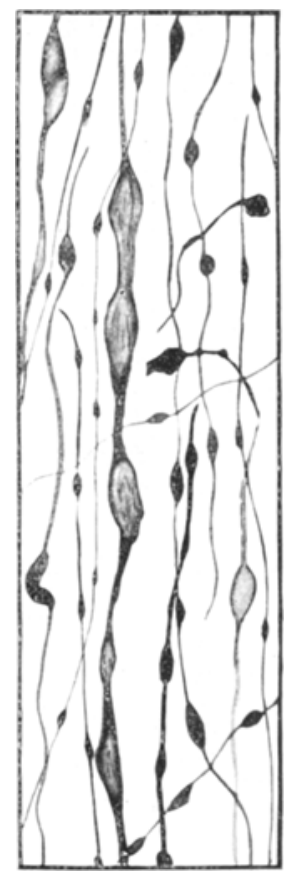

Abb. 21.

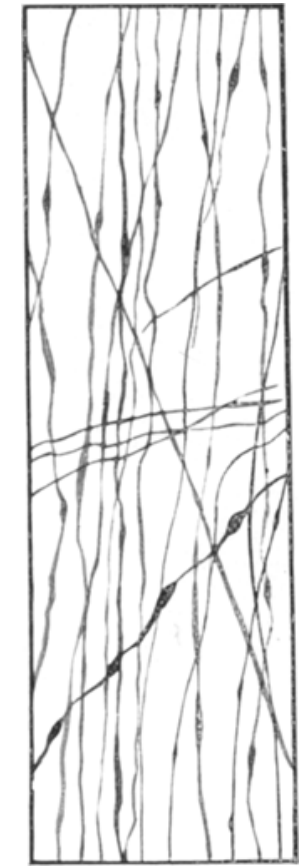

Abb. 22.

$A b b .21$. Dasselbe wie in Abb, 20. Zeichnung.

Abb. 22. Mikroskopisches Präparat des Gehirnexcisums von Fall 2. Darstellung der Neurofibrillen wie in $\mathrm{Abb}, 20$ und 21 , aber an anderer Stelle; die meisten Nervenfitsern erseheinen im wesentlichen normal, eine Faser zeigt starke Nodulation.

Zusammenfassung. Es handelt sich um eine Granatsplitterverletzung in der rechten Parietalregion (1918). Ein Jahr später epileptische Anfälle (Feld 5a, 5b). Die Encephalographie zeigt die starke Ausziehung des rechten Seitenventrikels zum Defekte hin, sowie die Verziehung des ganzen Ventrikelsystems nach diesem zu. Die Haut ist an der Stelle des Knochendefektes fest mit der Dura verwachsen und diese adhäriert ihrerseits fest an der Hirnoberfläche. Von der Dura aus sind zahlreiche Gefäße und Bindegewebsfaserzüge ins Gehirn eingedrungen. Die Eintrittsstelle einiger Gefäße ist von einem Ring 
Der Narbenzug am und im Gehirn bei traumatischer Epilepsie usw. 501

fibröser Gliafasern umgeben. Es besteht eine progressive Gewebsdestruktion noch 10 Jahre nach der Verwundung, wie aus den

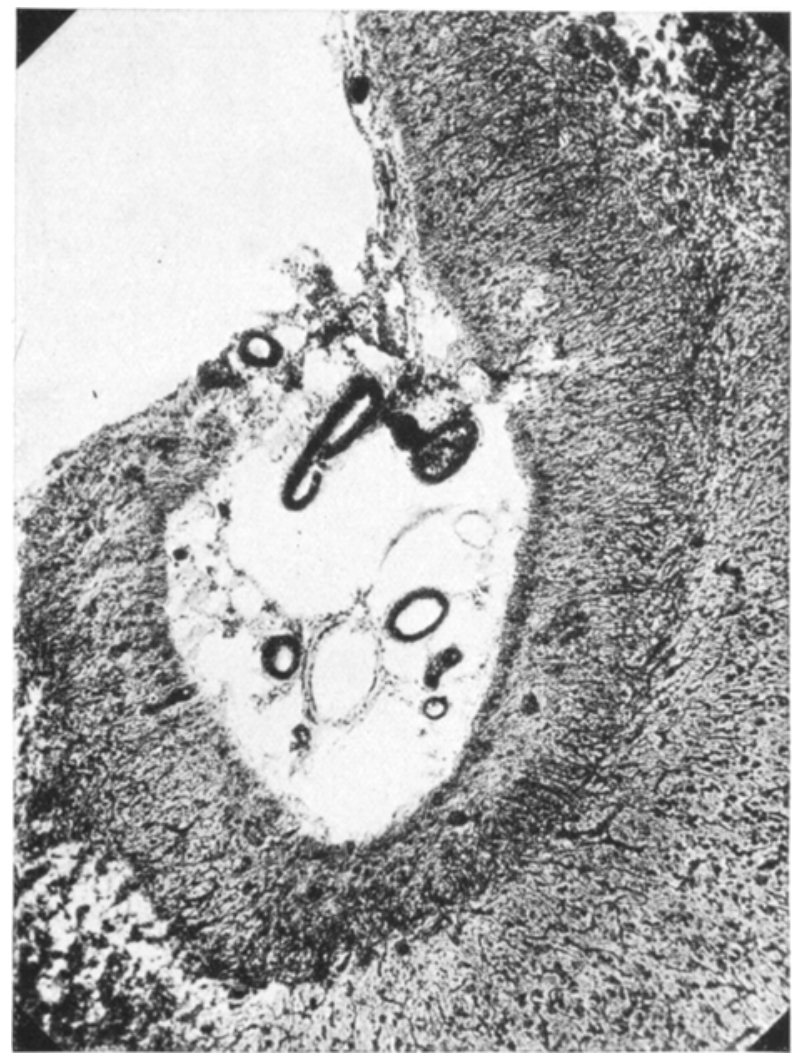

Abb. 23. Mikroskopisches Präparat von Fall 2. Gefäße, welche in das Gehirn cindringen von einem breiten Wall von Glia umgeben. Vergrößerung 70 fach.

pigmentbeladenen Zellen in der Umgebung mancher Gefäße und der stellenweise vorhandenen Mikrogliaveränderung hervorgeht.

\section{Fall 3.}

J. S., 33 Jahre alt. Juli 1916. Granatsplitterverletzung am linken Os parietale. 3 Tage bewußtlos, keine Lähmung oder andere cerebrale Ausfallsymptome. In der Folge häufig Kopfschmerzen, welche seit 1922 in verstärktem Grade auftreten. Schwindelgefühl, Abnahme der geistigen Leistungsfähigkeit, zunehmende Vergeßlichkeit, große Reizbarkeit, Neigung zu hypochondrischer Verstimmung.

Januar 1927. Erster epileptischer Anfall, nach 7 Monaten wiederholte sich derselbe, allmählich immer häufiger, 2-3 Anfälle in der Woche. Im März 192818 Anfälle an einem Tage, 2 Tage lang bewußtlos. Seit dem Auftreten der Anfälle stark zunehmende Vergeßlichkeit, starke Reizbarkeit, hypochondrische Verstimmung, Angstzustände, unruhiger Schlaf, wilde Träume. Seit Januar 1927 außer Dienst. 
April 1928. Aufnahme ins Wenzel-Hancke-Krankenhaus. Am linken Os parietale eine $4 \mathrm{~cm}$ lange Hautnarbe, nicht mit dem Knochen verwachsen. Im Bereich der Narbe eine flache Impression im Knochen fühlbar, es besteht aber kein durchgehender Knochendefekt. Objektiv keinerlei Ausfallssymptome von seiten des Gehirns, insbesondere keine Lähmung, keine Ataxie, keine Apraxie,

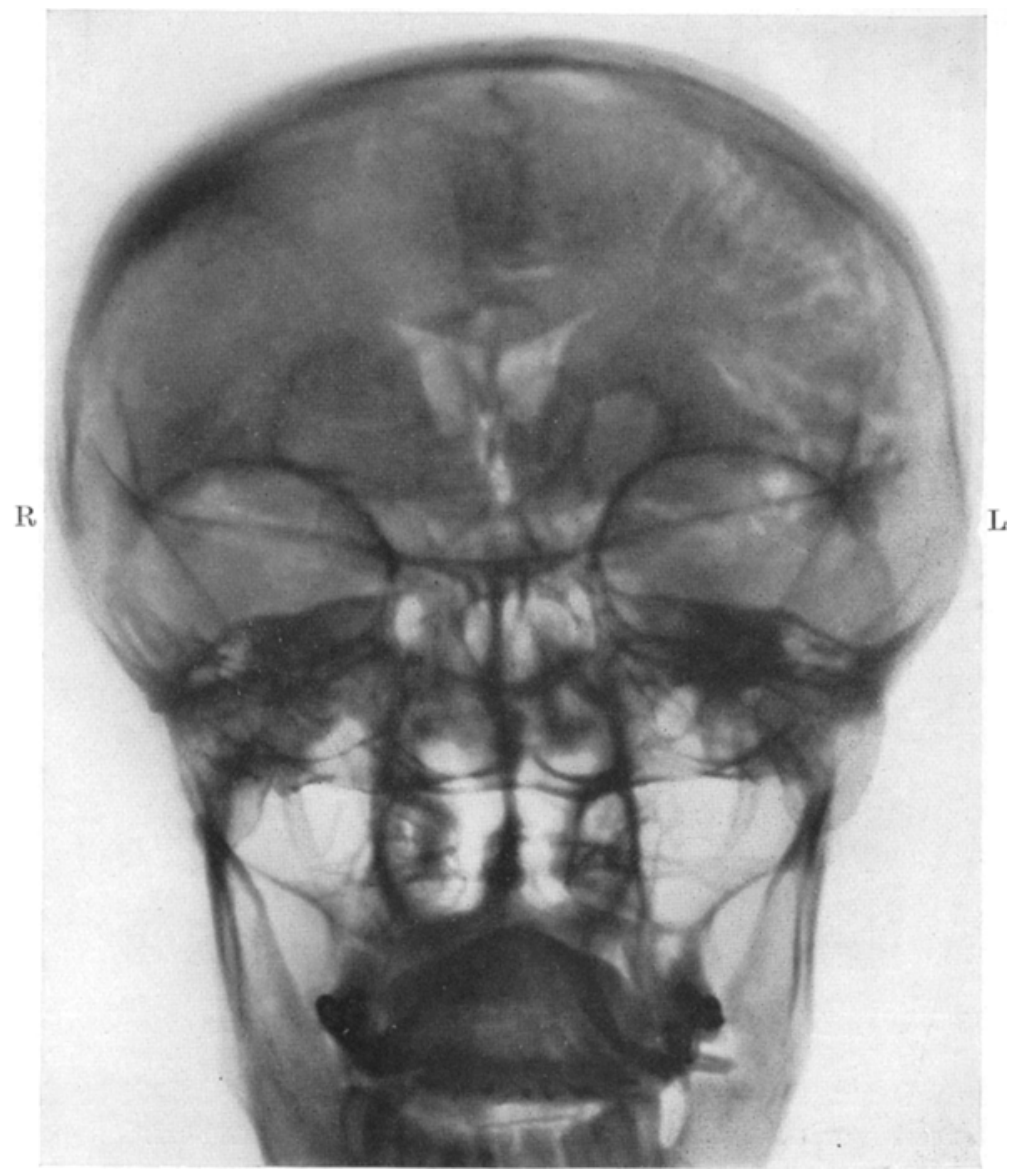

Abb. 24. Encephalogramm von Fall 3. Aufnahme in antero-posteriorer Richtung, Hinterhaupt auf Platte. Spitze des linken Seitenventrikels noch links ausgezogen.

keine Reflexstörungen, keine Sensibilitätsstörungen, auch keine Tastlähmung, keine Gesichtsfeldstörungen, keine Andeutung von Seelenblindheit und Alexie, keine Agraphie.

Charakter der Anfälle: Anfälle beginnen stets mit Drehung der Augen, des Kopfes und Rumpfes nach rechts, tonisch-klonischer Simultankrampf des rechten Armes und Beines. Manchmal sensible Aura in Form von rieselndem Schmerz im rechten Arm und Bein verbunden mit Leibschmerz. Niemals optische Aura, niemals sensible Aura vom Charakter der Cp.-Anfälle. Für die meisten Anfälle 
Aura nicht feststellbar, da das BewuBtsein sehr zeitig erlischt und nach dem Anfall absolute, zum Teil retrograde Amnesie besteht. Wiederholt wird der Kranke im Beginn des Anfalls, wenn er in aufrechter Stellung sich befindet, um die Längsachse des Körpers 2-3mal herumgedreht, worauf er dann hinstürzt. Die Anfälle sind als typische Parietalfeldanfälle aufzufassen (5b u. 5a). Nach jedem Anfall lange Bewußtlosigkeit, bis 3 Stunden lang, im März 1928 sogar 2 Tage bewußtlos. Nach jedem Anfall Sprache erschwert, findet die Worte nicht, ebenso Lesesinnverständnis hochgradig erschwert.

Lumbalpunktion zeigt erhöhten Liquordruck $(220 \mathrm{~mm}$ in horizontaler Lage), sonst Liquor o. B.

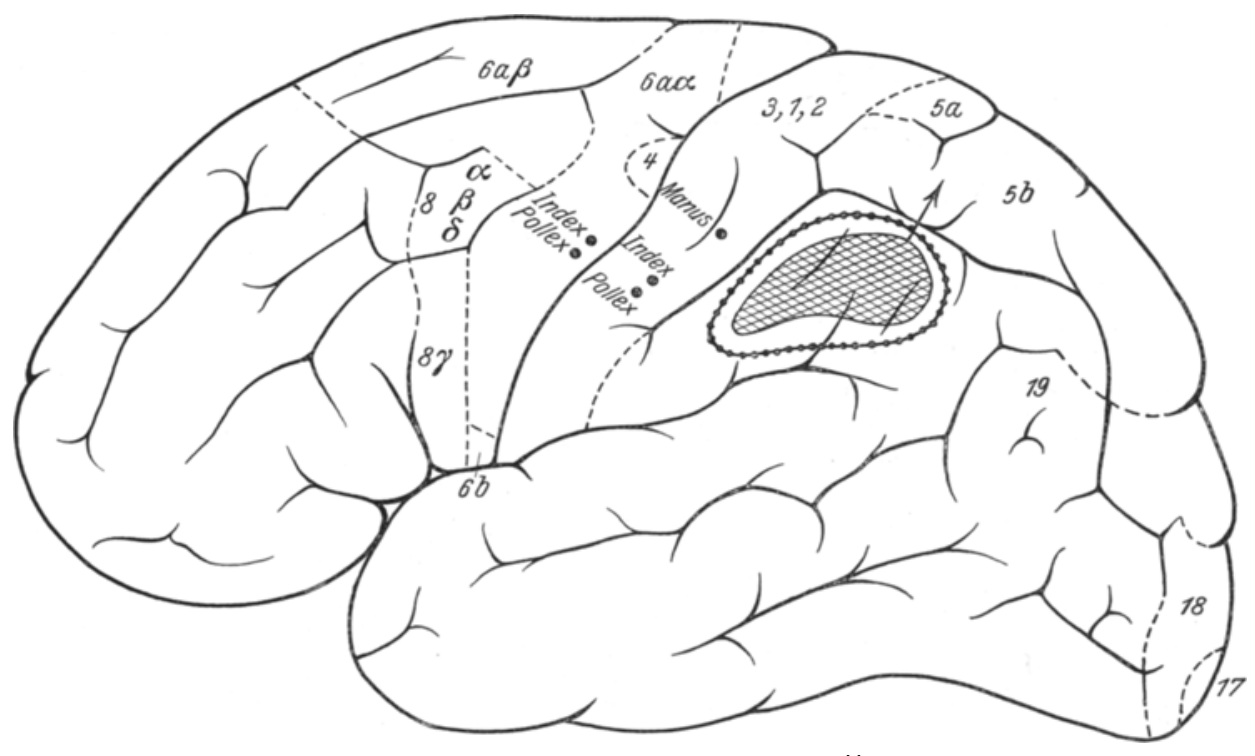

Abb. 25. Lage und Ausdehnung des Rindenherdes in Fall 3. \# Rindenherd, ........ Excisionslinie, .. Foki innerhalb der vorderen und hinteren Zentralwindung, welche durch KSR, erregt wurden. Der Pfeil $\rightarrow$ bedeutet die Richtung, in welcher der Rindenherd auf das benachbarte Feld $5 \mathrm{~b}$ krampfauslösend gewirkt hat.

Encephalographie (Abb. 24) zeigt eine geringe Ausdehnung beider Seitenventrikel, die Spitze des linken ist nach links links ausgezogen; der dritte Ventrikel erscheint schräg von links nach rechts gerichtet.

24. u. 25. 4. 1928. Operation. Entfernung des Os parietale im breiten Umkreis um die Knochendelle. Knochen nirgends mit der Dura verwachsen. Tabula interna an der Stelle der Impression nur sehr wenig nach innen vorgewölbt. An der Stelle der Impression ist die Dura verdickt und gelblich verfärbt; diese Stelle fühlt sich hart an, es blutet aus dieser Stelle nach außen. Zirkuläre Durchschneidung der Dura im Umkreis um diese Stelle (Durchmesser 7,5 cm). Im Bereiche der verhärteten Stelle feste Verwachsung der Dura mit der Gehirnoberfläche, auch nach der völligen Umschneidung der Dura blutet die Stelle auf der Außenseite weiter, ein Beweis dafür, daß Gefäße aus der Gehirnoberfläche in die Dura eingedrungen sind, sie durchdrungen haben und bei der Entfernung des Knochens an der Außenseite verletzt worden sind. An der Stelle der Verwachsung findet sich ein Kontusionsherd an der Gehirnoberfläche; diese Stelle fühlt sich hart an, in der unmittelbaren Umgebung Rinde bräunlich verfärbt. Unmittelbar nach der völligen 
Circumcision der Dura sinkt die verwachsene Stelle beträchtlich ein und bildet eine Vertiefung von mindestens $1 \mathrm{~cm}$ Tiefe, ein Beweis, daß das Gehirn an der Stelle der Verwachsung durch die allseitig rings gespannte Dura festgehalten und nach außen gezogen worden war.

Über die genaue Lage des Kontusionsherdes bzw. der Gehirnnarbe gibt Abb. 25 Auskunft. Durch fokale elektrische Reizung wurden in der vorderen und hinteren Zentralwindung die Foki des Daumens, Index und der Hand identifiziert (an der ersteren bei 2 MA KSR., in der letzteren bei 3 MA KSR. erregbar). Der Kontusionsherd liegt im Bereich des unteren Scheitellappens, nach oben reicht er fast bis zur Fissura interparietalis, nach vorne nicht ganz an die hintere Zentralwindung heran. Die den schwarz gehaltenen Herd umkreisende Linie gibt den Umfang an, in welchem die Narbe exzidiert wurde. Die mit der Narbe verwachsene Dura wurde in Verbindung mit dem exzidierten Hirnstück belassen. Deckung des Dura-

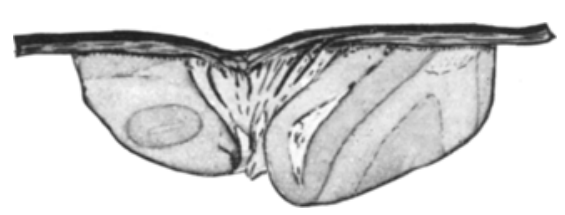

Abb. 26. Dura-Hirnexcisum von Fall 3, $5,5 \mathrm{~cm}$ breit, $2,5 \mathrm{~cm}$ tief im Durchschnitt. Von der verdickten Dura dringt in der Mitte ein Bindegewebskeil in das Gehiru ein. Dura an dieser stelle dentlich eingezogen. Gehirnrinde nach dem Bindegewebskeil zu ausgebuebtet. defektes durch freie Plastik aus der Fascia lata.

Der Exzision, welche bis an das Marklager heranreichte, sind nicht die geringsten Ausfallserscheinungen gefolgt; weder Lähmung noch Ataxie der rechten Hand, nicht die geringsten Sensibilitätsstörungen sind aufgetreten; Raumsinn der Haut, Bewegungsempfindungen, Tastvermögen völlig normal; keine Spur von Apraxie oder Agraphie, keine Gesichtsfeldstörungen, keine optische Asymbolie, keine Lesestörung.

Anfälle sind bei dem Kranken bisher nicht wieder aufgetreten (beobachtet bis Ende 1929, also 20 Monate). Was den Typus der Anfälle und den Ort der Auslösung anlangt, so hat der Herd auf den benachbarten oberen Scheitellappen irritativ eingewirkt, und zwar auf das parietale Adversivfeld (Drehung der Augen, des Kopfes und Rumpfes nach rechts (5b) mit anschließendem tonisch-klonischem Krampf der rechten Extremitäten (5a). Charakteristisch für den Parietalfeldanfall ist die gelegentlich beobachtete sensible Aura (vgl. oben).

Hervorzuheben ist das lange Intervall zwischen Trauma (1916) und erstem epileptischen Anfall (1927). Hervorzuheben ist ferner die Größe des Hirnkontusionsherdes bei nicht perforiertem Schädel, es bestand nur eine flache Impression ohne Kontinuitätstrennung der Tabula interna. Keinerlei Herderseheinungen wiesen auf das Vorhandensein des Kontusionsherdes hin, bis die epileptischen Anfälle und das encephalographische Bild einen solchen wahrscheinlich machten.

Anatomischer Befund: Abb. 26 ist eine Skizze des exzidierten Dura-Hirnstückes. Sehr deutlich tritt die Stelle hervor, an welcher nach der zirkulären Durchtrennung der Dura das Zentrum der Stelle, an welcher die Dura mit der Hirnoberfläche verwachsen ist, eingesunken ist. Vor der Excision war diese Stelle noch viel stärker eingezogen, offenbar der Ausdruck für die Tatsache, daß vom Innern des Gehirns her ein Zug auf sie ausgeübt wurde. Von dieser eingezogenen Stelle aus dringt ein schwammig fibröses Bindegewebe in das Hirngewebe ein (Abb. 26). Durch diese bindegewebigen Züge ist die benachbarte, ebenfalls an der Dura adhärente Hirnrinde deutlich nach der Stelle des Einbruchs des Durabindegewebes ins Gehirn verzogen.

Die mikroskopische Untersuchung zeigt, daß von der Dura zahlreiche Gefäße und Bindegewebszïge ins Gehirn eingedrungen sind. Unterhalb der bindegewebigen Zone enthält das Hirngewebe zahlreiche große fibröse Neurogliazellen. Diese Gliose ist sehr dicht, aber sie zeigt nicht dieselbe Üppigkeit parallel geordneter 
Gliafasern wie Fall 1. Gleichwohl ist die überwiegende Richtung der langen Gliazellfortsätze auf die Stelle der Adhäsion zu nicht zu verkennen. An einer Stelle sind die Gefäße, welche aus der Dura ins Gehirn eindringen, durch einen dichten Gliafilz umgeben, ähnlich wie es im Fall 2 gefunden wurde; die Astrocyten zu beiden Seiten dieser Stelle richten ihre Fortsätze auf diese zu. An manchen Gefäßen liegen Gruppen pigmentbeladener Zellen (Abb. 27). Die Mikrogliazellen erscheinen normal, nur an zwei umschriebenen Stellen sind ihre Fortsätze deultich verdickt.

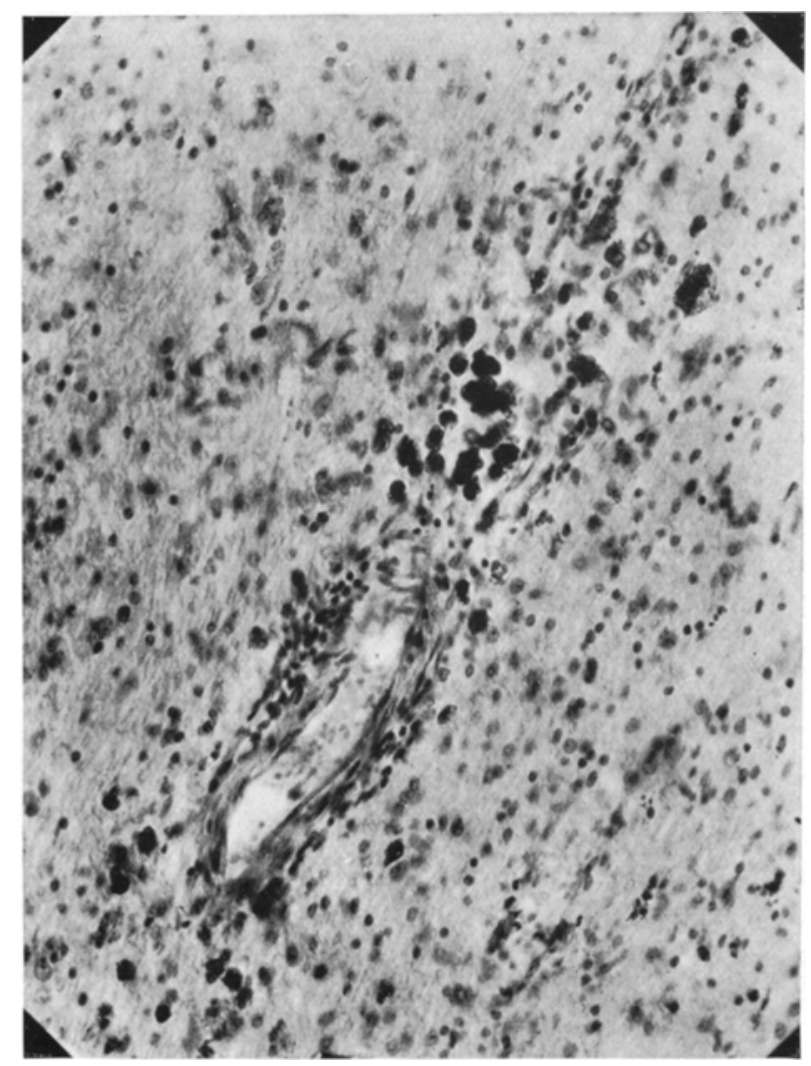

Abb. 27. Mikroskopisches Präparat ron Fall 3. Zahlreiche phagocytäre Elemente beladen mit Pigment in der Umgebung eines Gefäßes.

Die mit Eisenpigment beladenen Zellen und die Alteration der Mikroglia beweisen, daß selbst nach so langer Zeit nach dem Trauma (12 Jahre) noch progressiv-destruktive Prozesse im Spiele sind. Nißlbilder zeigen im großen ganzen normale Zellen, an manchen Stellen ist die Zahl der Trabantzellen beträchtlich vermehrt. Im übrigen erweist sich auch die Oligodendroglia als normal.

Zusammenfassung. Es handelt sich um eine oberflächliche Schußverletzung der linken Parietalregion mit geringer Impression des Knochens. Kein Knochendefekt. 11 Jahre nach dem Trauma traten die ersten epileptischen Anfälle auf (Typus 5b und 5a). Dieselben bildeten 
das einzige objektive klinische Krankheitszeichen. Das Encephalogramm zeigt leichte Verziehung des Ventrikelsystems nach der Stelle der Verletzung zu. Bei der Operation erweist sich die Dura adhärent an einem im unteren Scheitellappen gelegenen Kontusionsherd. Nach Circumcision der Dura um diese Stelle herum sinkt letztere mindestens um $1 \mathrm{~cm}$ ein, ein Beweis, daß sie vorher durch die allseitig gespannte Dura nach außen gezogen worden war. Auch nach der Circumcision Blutung aus der Dura nach außen, ein Beweis, daß Gefäße aus dem Gehirn in die Dura eingewachsen sind. Im ausgeschnittenen Duragehirnstück deutliche Zeichen von Narbenzug. Ferner Zeichen rezenter destruktiver Prozesse.

\section{Fall 4.}

P. J., 35 Jahre alt. Nov. 1914 Tangentialschuß am rechten Os occipitale. Sofort bewußtlos. Debridement. Nach Wiederkehr des Bewußtseins zunächst einige Tage total blind, dann längere Zeit desorientiert, verkannte Personen und Gegenstände; allmähliches Verschwinden dieser Störungen. Winter 1915 rückte
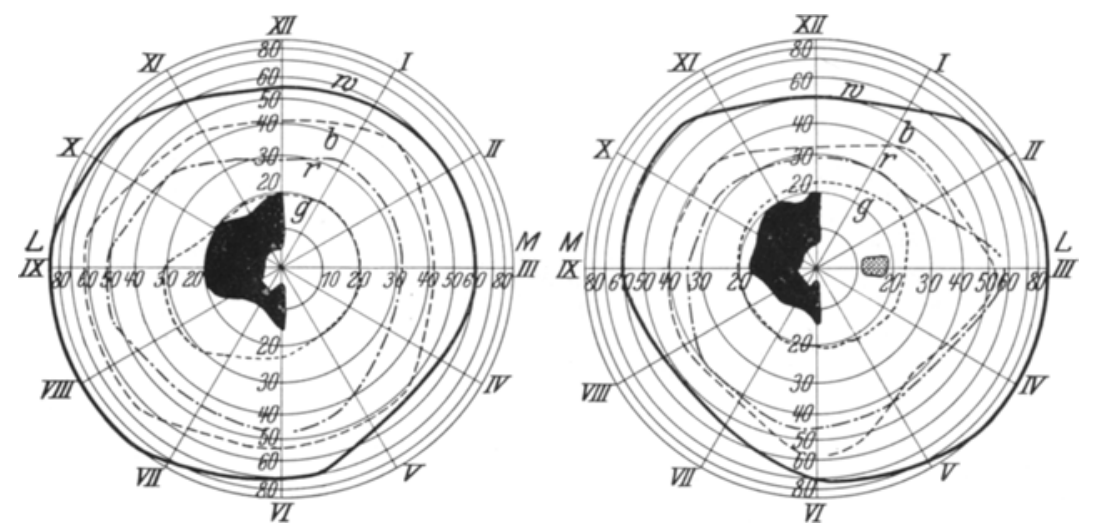

Abb. 28. Gesichtsfelddefekt in Fall 4. Paramakuläres skotom mit junktförmigem objekt geprüf. Peripherie mit $1 \mathrm{ccm}$ aufgenommen.

er wieder ins Feld; hier traten zum erstenmal epileptische Antälle auf, deswegen aus der Front zurückgeschickt, Herbst 1916 vom Militär entlassen. Häufig Kopfschmerzen, starke Blendungserscheinungen vor den Augen, allmähliche Zunahme der Anfälle, die jetzt fast täglich, manchmal mehrere Male an einem Tage auftreten.

26. 1. 1925 aufgenommen; klagt über starke Kopfschmerzen, Schwindel, Ohrensausen, Blendungserscheinungen, große Vergeßlichkeit. Stimmung sehr gedrückt, sehr reizbar. Fällt bei den Anfällen häufig um.

Über das rechte Os occipitale verläuft eine $15 \mathrm{~cm}$ lange Narbe von der Scheitelhöhe herab, Knochen fehlt in einer Breite von $2 \mathrm{~cm}$ und einer Höhe von $6 \mathrm{~cm}$. Haut in den Knochendefekt stark eingezogen, Gehirnpulsation in der Rinne fühlbar. Keine Lähmungen. Am linken Arm ausgesprochene Adiadochokinese, zeigt beim Zeigefingernasenversuch stets mit dem linken Arm nach links, also nach außen vorbei. Beim Stehen mit geschlossenen Augen Neigung nach links hinten zu fallen. Keinerlei Sensibilitätsdefekte. Beiderseits nervöse Schwerhörigkeit, rechts mehr 
wie links. Vestibularis übererregbar. Pupillen gleichweit, prompte Reaktion auf Licht und bei Konvergenz. Augenbewegungen nicht eingeschränkt, aber in seitlichen Endstellungen ausgesprochener Nystagmus, keine Doppelbilder. Augenhintergrund zeigt auffallende venöse Stase, rechts mehr wie links. Gesichtsfeld: Hemianopisches, paramakuläres Skotom in beiden linken Gesichtsfeldhälften (vgl. Abb. 28).

Die Röntgenaufnahme (Abb. 29a u. b) des Schädels nach erfolgter Luftfüllung zeigt in der Frontalaufnahme (Stirn auf Platte), daß der rechte Seitenventrikel deutlich nach dem Knochendefekt zu ausgebuchtet ist; die Falx cerebri zeichnet sich scharf ab, ebenso das rechte Tentorium cerebeili. Auf der Sagittalaufnahme erscheint das blasser gefärbte rechte Hinterhorn dilatiert und die Spitze reicht bis an den Knochendefekt heran; in dem Bereich des letzteren ausgesprochene Luftansammlung.

Charakter der Anfälle: Die Anfälle beginnen stets mit einer ausgesprochenen optischen Aura; der Kranke sieht Funken und Sterne, alle möglichen schwarzen Gestalten und Figuren, zum Teil sogar bekannte Personen von links außen her auf sich zukommen; die Aura dauert verschieden lange, fast stets so lange, daß Patient Zeit hat, sich hinzulegen; die Krampfentladung beginnt stets mit isoliertem tonischem Blickkrampf beider Augen nach links, häufig auch gleichzeitig nach oben; dann erfolgt Rumpf- und Kopfdrehung nach links; wenn der Anfall den Kranken im Stehen befällt, so fällt er in diesem Stadium nach links hinten um, darauf tonisch-klonischer Massenkrampf des linken Armes und Beines, darauf folgt das rechte Bein, danach generalisierte Krämpfe mit Bewußtseinsverlust.

Die Anfälle gehen also aus vom Felde 19 (komplexe optische Aura, tonischer Blickkrampf nach links); die Erregungswelle greift vom Felde 19 auf das Feld 5b über (Kopf-Augen-Rumpfdrehung nach links), dann wird Feld 5a miteinbezogen (simultaner tonisch-klonischer Krampf des linken Armes und Beines mit rascher Beteiligung des rechten Beines), zuletzt generalisierte corticale Erregung. Nach jedem Anfall besteht postparoxysmale linksseitige Hemianopsie, welche 10-20 Min. anhält. Die Anfälle können bei dem Patienten gesetzmäßig durch Hyperventilation ausgelöst werden.

5. 3. und 10. 3. 1925 Operation. Bogenförmiger Hautschnitt um die Narbe und den Knochendefekt am rechten Os occipitale herum, Basis abwärts. Die Hautnarbe ist in der Gegend des Knochendefektes fest mit der Dura verwachsen; das Abpräparieren äußerst schwierig. Erweiterung des Knochendefektes; er blutet stark aus der Dura in der Gegend der Verwachsung nach außen. Tamponade durch einige Muskelstückchen. Galeanaht, Hautnaht.

Am 10. 3, 1925 Fortsetzung der Operation. Zirkuläre Durchschneidung der Dura um die Stelle der Verwachsung herum. Dura fest am Gehirn in der Ausdehnung eines Fünfmarkstückes adhärent. Die Adhärenz nimmt die Außenfläche des Occipitallappens ein; der Hinterhauptspol sowie die Medianfläche und Unterfläche des Occipitallappens sind frei. Es blutet auch nach völliger Umschneidung der Dura aus derselben an der Stelle, an welcher sie mit dem Gehirn verwachsen ist, noch stark nach außen. Lage und Ausdehnung des Herdes s. Abb. 30. Besonders im oberen Bereich der Verwachsungsstelle fühlt sich das Gehirn sehr derb an. Faradische Reizung der Außenfläche dẹs Occipitallappens ergibt von der in der Abb. 30 markierten Stelle lebhafte Flammenskotome, ziehende Wolken, leuchtende Nebelschwaden und schwarze Tiere, die von links außen auf den Patienten zu kommen; bei Reizung des mit + markierten Punktes dieselben optischen Halluzinationen, gleich darauf extreme Wendung der Augen nach links, dann scharf nach links oben, bei Fortsetzung der Reizung Kopf- und Rumpfdrehung nach links, tonisch-klonischer Krampf des linken Armes und beider Beine, zuletzt schwere allgemeine Krämpfe, Anfall dauert fast $10 \mathrm{Min}$. Nach Abklingen des Anfalls Umstechung des Herdes und Exeision desselben, wobei die Dura mit 
dem exzidierten Gehirnstück in Verbindung bleibt; die Excision reicht bis ins Marklager, der Ventrikel wird aber nicht eröffnet. Deckung des Duradefektes aus der Fascia lata. Galeanaht, Hautnaht. Heilung per primam. Keinerlei Temperaturerhöhung nach der Operation, da Ventrikel nicht eröffnet. Nach der Operation besteht vollkommene homonyme linksseitige Hemianopsie mit Maculaaussparung; diese Hemianopsie ist geblieben, letzte Untersuchung Dez. 1929. Ferner besteht

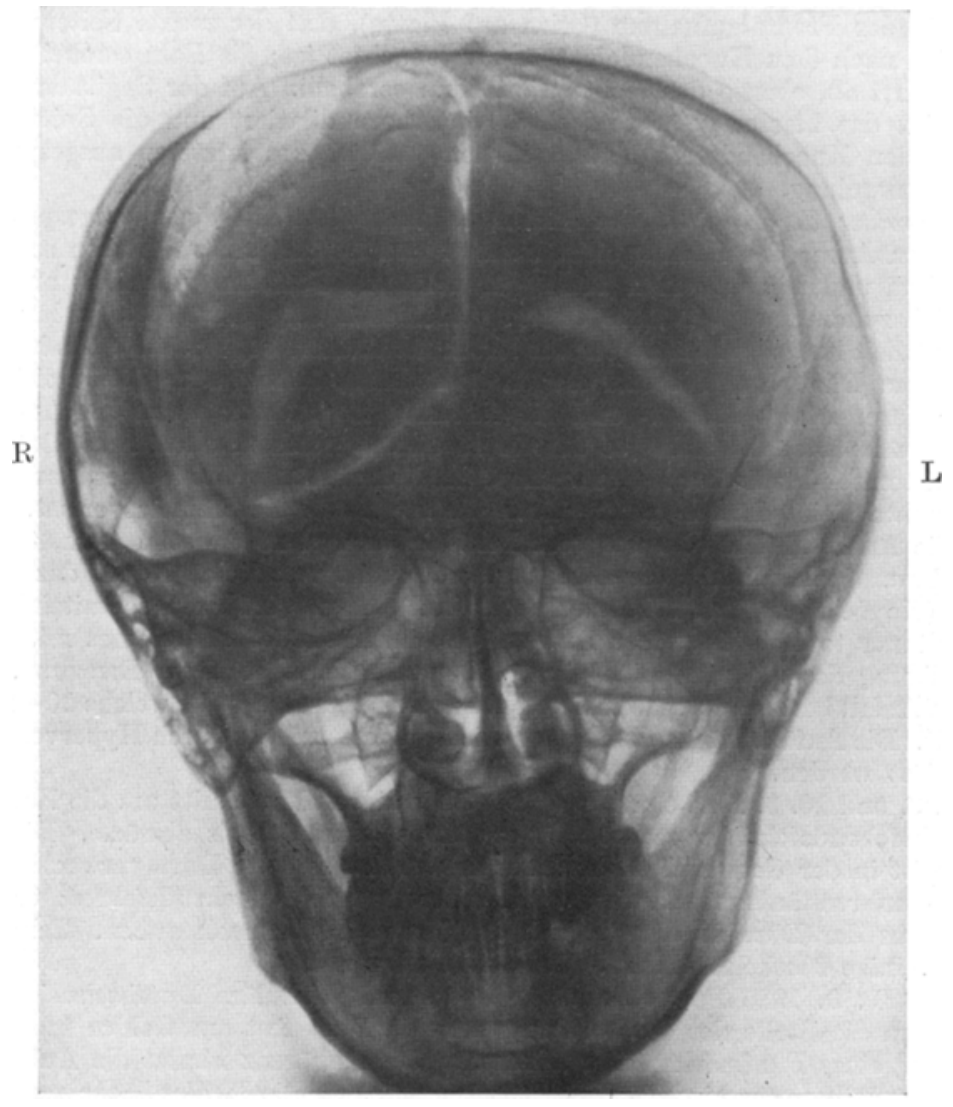

Abb. 29a. Encephalogramm von Fall 4. Aufnahme in postero-anteriorer Richtung. Stirn auf Platte. Die laterale Wand des rechten Hinterhorns ist nach dem Knochendefekt zu ausgebuchtet. Ausgesprochene Luftansammlung rechts neben der Falx cerebri und entlang der rechten Hälfte des Tentorium cerebelli.

nach der Excision eine vorübergehende Ataxie des linken Armes, aber keinerlei Sensibilitätsstörungen. Die Ataxie hat sich nach etwa 14 Tagen vollkommen zurückgebildet. Geblieben ist das vor der Operation bereits vorhandene Vorbeizeigen des linken Armes nach links beim Zeigefingernasenversuch. Anfälle sind seit der Operation nicht mehr aufgetreten (letzte Untersuchung Ende Dezember 1929). Anatomischer Befund: Das ausgeschnittene Dura-Hirnstück hat eine Größe von $7: 6 \mathrm{~cm}$; die Dicke beträgt 4,0-2,5 cm. Die verdickte Dura ist mit der Gehirnmasse fest verlötet (Abb. 31). 
Die mikroskopische Untersuchung lehrt, daß in breiter Ausdehnung breite Bindegewebsfaserzüge von der Dura aus ins Gehirn eindringen, sie reichen aber nicht tief. An diese Zone der mesodermalen Invasion schließt sich eine gliöse Zone an, in welcher die Fasern sehr dünn sind und ganz parallel angeordnet sind; sie mischen sich nach außen zu innig mit den von der Dura her eingedrungenen Bindegewebsfasern. Die Gliazellen haben denselben Typ wie der im Fall 1 beschriebene.

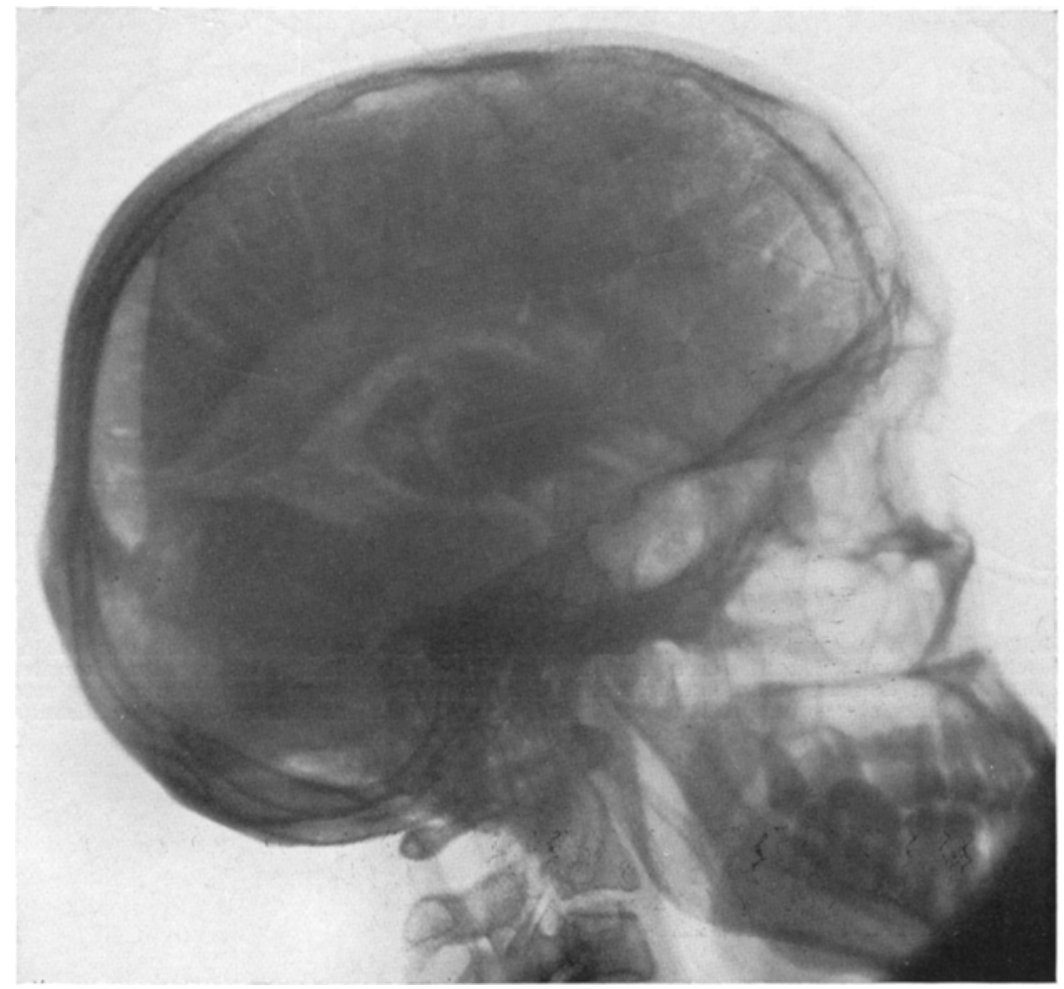

Abb. 29b. Encephalogramm von Fall 4. Seitenbild Das rechte schwach sich abhebende Hinterhorn ist mit seiner Spitze weit nach hinten auf den Knochendefekt zu ausgezogen.

Übergänge in sternförmige Astrocyten kommen vor. Die spärlich vorhandenen Nervenfasern weisen dieselben kolbigen Verdickungen auf wie die im Fall 2 (vgl. Abb. 21). An manchen Stellen ist die parallelfaserige Glia durch Riesengliazellen mit großem Protoplasmaleib ersetzt.

Zusammenfassung. Es handelt sich um eine Schußverletzung der rechten Occipitalregion mit Knochendefekt. Erste epileptische Anfälle 1 Jahr später. Typus der Anfälle Feld 19. Haut im Bereich des Knochendefekts fest mit der Dura und diese fest mit dem Gehirn verwachsen. Hinterhorn nach dieser Stelle zu ausgezogen. Excision der Dura-Hirnnarbe 1925. Histologisch besteht diese aus derbem Bindegewebe, das ins Gehirn eingedrungen ist und an welches sich ein derbes gliöses Gewebe 
nach innen zu anschließt. Sowohl in der bindegewebigen wie in der gliösen Narbe sind die Fasern mehr oder weniger parallel angeordnet

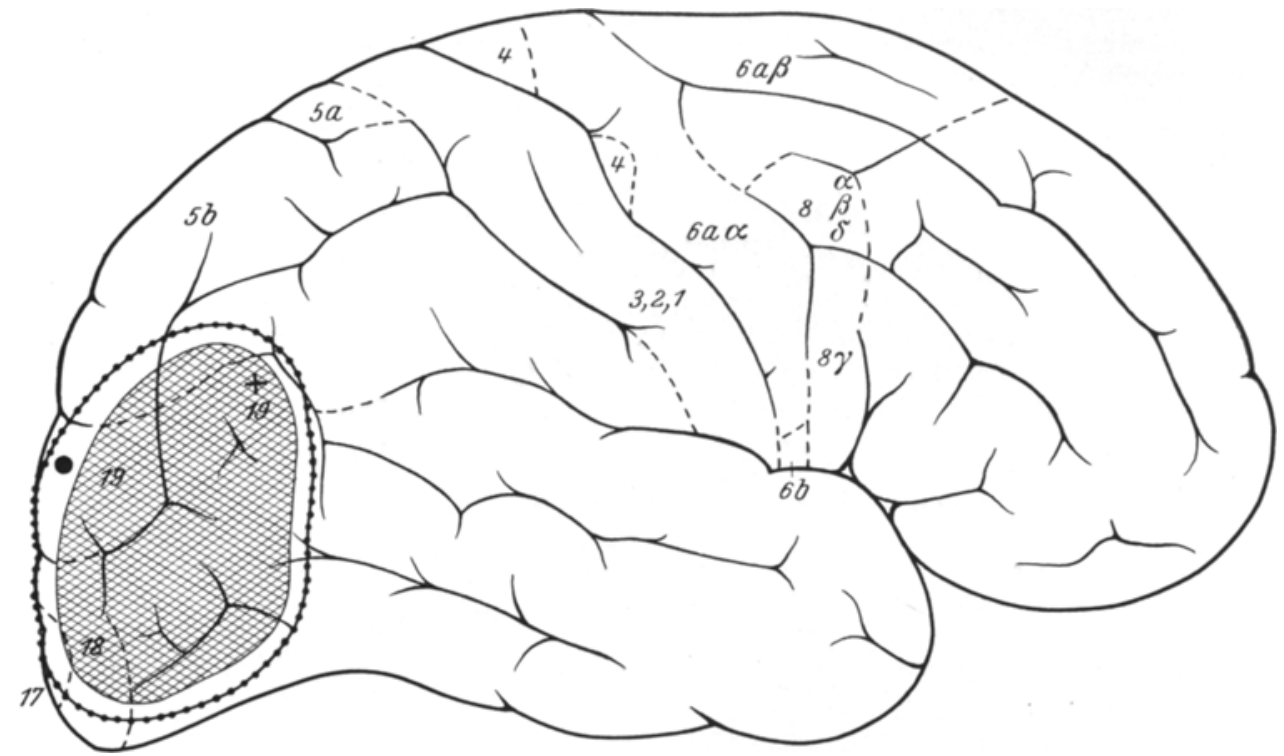

Abb. 30. Lage und Ausdehnung des Rindenherdes in Fall 4. Stelle, von der aus die optischen Halluzinationen durch faradischen Rindenreiz ausgelöst werden konnten. + Stelle, von der aus dieselben optischen Halluzinationen sowie Augenbewegung nach links bzw. links oben und bei längerer Einwirkung des Reizes ein epileptischer Krampfanfall ausgelöst wurde.

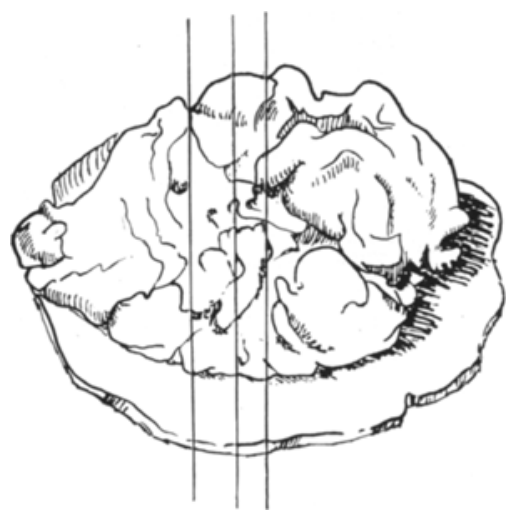

Abb. 31. Dura-Hirnexcisum von Fall 4 von unten gesehen, 7,0:6,0 cm im Durchmesser, $4-2,5 \mathrm{~cm}$ tief; Gehirnsubstanz an der Dura fest anhaftend. Die durchgehenden Linien zeigen die Ebenen an, in welchen das Excisum zum Zwecke der mikroskopschen Untersuchung durchschnitten wurde.

und auf die Verwachsungsstelle zwischen Haut-, Dura- und Hirnoberfläche $\mathrm{zu}$ gerichtet. 


\section{Fall 5.}

W. Z., 18 Jahre alt. Onkel väterlicherseits litt an Epilepsie. Zangengeburt, nach der Geburt lange asphyktisch, Kopf stark deformiert. Es besteht seit Geburt rechtsseitige spastische Hemiparese; der Kranke ist Linkshänder, Sprache nicht im geringsten 'gestört. Lernte bis zum 14. Jahre recht gut. Im Alter von 14 Jahren erster epileptischer Anfall, seitdem geistige Entwicklung stillgestanden. Anfälle, die anfangs nur alle 2-3 Monate auftraten, häuften sich allmählich immer mehr, jede Woche mindestens ein Anfall, manchmal mehrere an einem Tage.

29. 3. 1925 aufgenommen. Graziler Körperbau. Linke Schädelhälfte kleiner als rechte. Keine Narben an der Kopfhaut, keine Impression am Knochen.

Rechtsseitige spastische Hemiparese. Zunge, Gaumensegel, Facialis wenig beteiligt. Rechte Schulter steht etwas tiefer als linke, rechter Oberarm leicht abduziert, rechter Vorderarm etwas gebeugt, rechte Hand proniert und flektiert, Finger gestreckt, im Grundgelenk überstreckt, Daumen adduciert, in den Phalangen gestreckt. Dehnungsreflexe am rechten Arm gesteigert, ebenso Sehnen und Knochenhautreflexe. Willkürliche Beweglichkeit auffallend gut; Oberarm kann fast bis zur Vertikalen erhoben werden, dabei erfolgt geringe Mitbeugung im Ellbogengelenk, starke Pronation und Flexion der Hand, ausgiebige Streckung und Spreizung der Finger. Bei der Beugung des Vorderarms deutliche Abduction des Oberarms und starke Pronation der Hand, bei der Streckung des Vorderarms Adduction des Oberarms und Pronation der Hand. Supination der Hand nicht in vollem Unfang möglich (Contractur der Pronatoren), Handstreckung bei gestreckten Fingern kaum bis zur Verlängerung des Vorderarms, bei gebeugten Fingern etwas besser. Faustschluß kräftig, aber Hand klappt leicht in Flexion um. Faustöffnung unter starker Flexion der Hand. Opposition des Daumens gegen die anderen Finger nicht möglich, es tritt Flexion an die Stelle. Fingerspreizung behindert. Isolierte Bewegungen eines einzelnen Fingers nicht möglich. Am Rumpf keine Behinderung der Beweglichkeit nach rechts (Neigung oder Drehung der Wirbelsäule). Cutaner Bauchreflex und Cremasterreflex rechts gleich links.

Am rechten Bein leichte Spitzfußstellung, große Zehe in Dorsalflexionsstellung; Oberschenkel leicht innenrotiert; gesteigerter Dehnungswiderstand besonders der Adduktoren und Innenrotatoren des Oberschenkels, des Quadriceps, der Plantarflexoren des Fußes und der Zehen; Patellarklonus, Fußklonus, Rossolimo; gesteigerter Patellar- und Achillessehnenreflex; Mendel-Bechterew; lebhafte ausgeprägte Beugereflexsynergie und Streckreflexsynergie, Babinski + . Willkürliche Beweglichkeit auffallend gut, doch sind streng isolierte Bewegungen einzelner Extremitätenabschnitte nicht ausführbar, es kommt stets zur Andeutung der Beuge- oder Strecksynergie des ganzen Beines. Beim Gange wird das rechte Bein beim Vorsetzen etwas circumduziert, im Knie weniger ausgiebig gebeugt als das linke, der Fuß gerät in Supination; beim Aufsetzen des Fußes auf den Boden krallen sich die Zehen in den Boden. Die Prüfung der Sensibilität ergibt keinerlei faßbaren Defekt, höchstens ist die Temperaturempfindung am rechten Bein und der rechten Bauchseite etwas herabgesetzt. Auch der Raumsinn der Haut (Lokalisation punktförmiger Reize, Diskrimination zweier gleichzeitig applizierter, räumlich getrennter Reize, Erkennung von Zahlen und Figuren, die auf die Haut geschrieben werden) ist nicht nachweislich geschädigt. Erkennung von Gegenständen durch Betasten intakt.

Keine Störungen des Gesichtsfeldes. Augenhintergrund normal. Keine GeruchsGeschmacks-Gehörstörung. Sprache, Lesen, Schreiben intakt, keine Andeutung von Apraxie.

Das Encephalogramm (Abb. 32) zeigt auf der Aufnahme in anterior-posteriorer Richtung eine beträchtliche Luftansammlung linkerseits, die linke Hemisphärensubstanz ist auf die Hälfte ihres Volumens reduziert. Der linke Seitenventrikel 
ist dilatiert und scheint in den vorerwähnten lufterfüllten cystischen Raum direkt überzugehen. Der linke Ventrikel ist deutlich nach links verbogen. Auch der rechte Seitenventrikel ist erweitert, ebenso der dritte Ventrikel etwas; letzterer erscheint aber nicht schräg gestellt. Die Falx cerebri und das Tentorium cerebelli

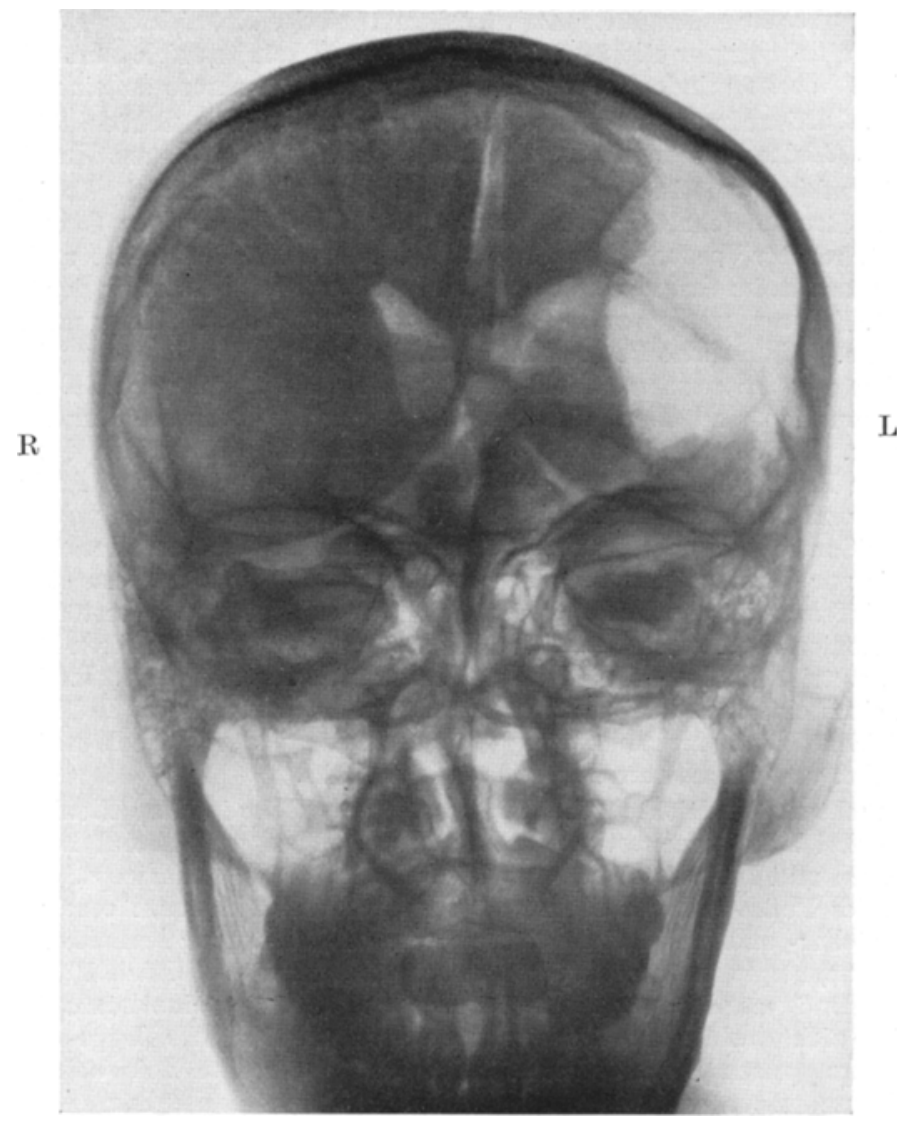

Abb. 32a. Encephalogramm von Fall 5. Aufnahme in antero-posteriorer Richtung, Hinterhaupt auf Platte. Der linke Seitenrentrikel ist nach links ansgezogen und mündet in eine riesige Lufthöhle, welche die Hälfte des linken Schädelinnern umfaßt. Falx und Tentorium deutlich gezeichnet.

sind deutlich gezeichnet. Auf dèr Sagittalaufnahme sieht man gleichfalls außer dem Seitenventrikel zwei große lufterfüllte Räume, welche durch ein von oben nach unten verlaufendes Band getrennt zu werden scheinen.

Charakter der Anfälle: Die Anfälle besitzen keine faßbare Aura. Sie bestehen in forcierter Kopf-Augen-Rumpfdrehung nach rechts, tonisch-klonischem Massenkrampf des rechten Armes und Beines, Kiefer wird weit aufgerissen, rascher Bewußtseinsverlust, Atmung tief stertorös. Häufig Zungenbiß. Dauer eines Anfalles $1 / 2$ Stunde und mehr. Wiederholt ist es vorgekommen, daß Patient durch die gewaltsame plötzliche Rumpfdrehung nach rechts, mit der der Anfall einsetzt, 
Der Narbenzug am und im Gehirn bei traumatischer Epilepsie usw. 513

nach rechts aus dem Bett herausgeschleudert worden ist. Nach dem Anfall noch lange Zeit benommen.

Die Anfälle tragen also den Charakter der Adversioanfälle; ob sie vom frontalen retrozentralen oder temporalen Adversiofeld $(6 \alpha \beta, 3,1,2$ oder 22$)$ ausgehen, läßt sich nicht sicher entscheiden.

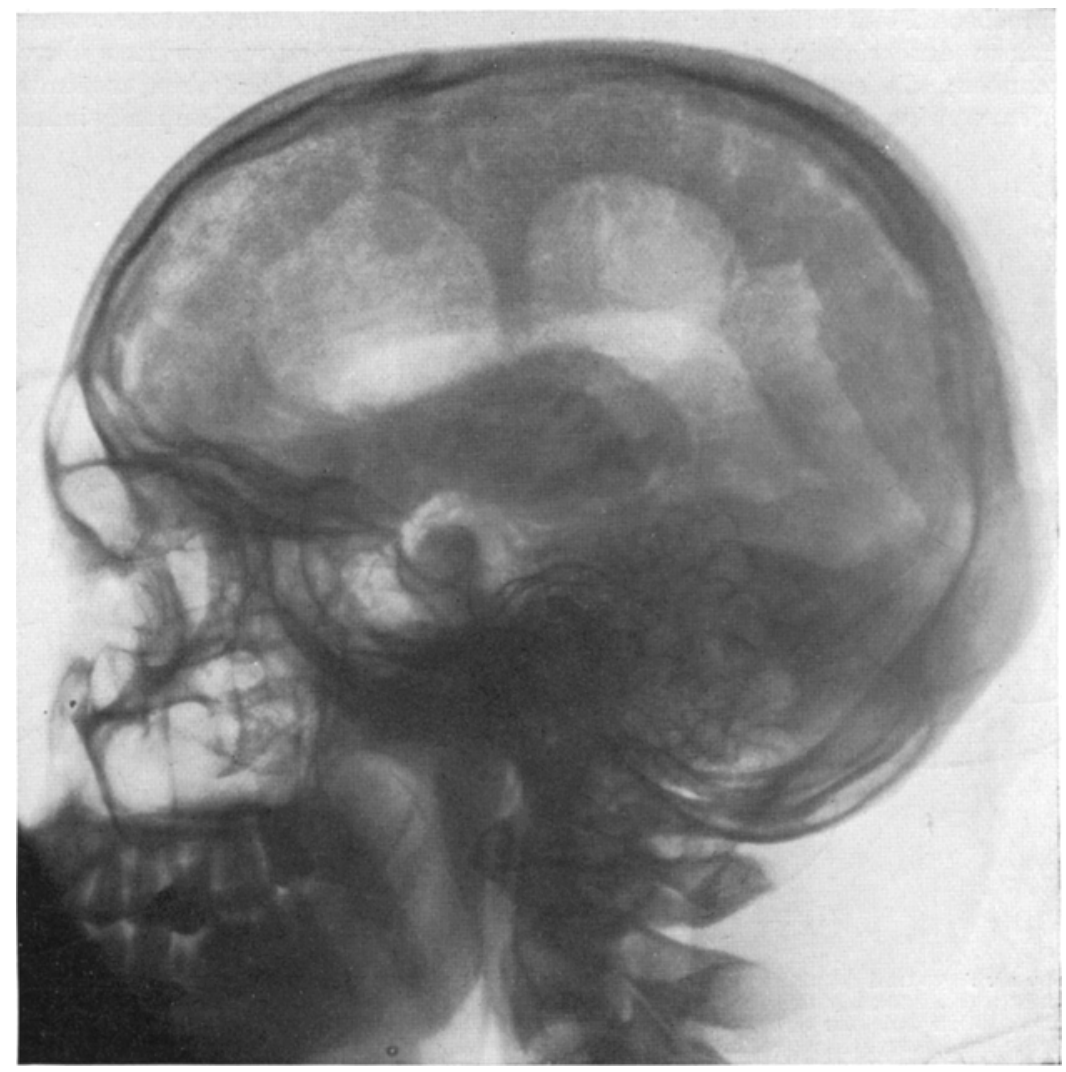

Abb. 32 b. Encephalogramm von Fall 5, Seitenansicht. An den linken Seitenventrikel sind 2 große Cysten angeschlossen, welche durch einen keilförmigen Bezirk derber Gehirnsubstanz voneinander getrennt erscheinen.

1. 4. 1925 Operation. Breite Freilegung der linken Gehimhemisphäre, es blutet stark aus der Dura, da die Meningea media im Knochen verläuft und bei dem Herausheben der umschnittenen Knochenplatte einreißt. Tamponade der blutenden Stelle durch aufgenähtes Muskelläppchen. Galeanaht, Hautnaht. Die herausgeschnittene Knochenplatte zeigt auf der Innenseite zwei flache Gruben, in deren Bereich der Knochen äußerst verdünnt und durchsichtig ist. Diese Gruben entsprechen in ihrer Lage zwei durch die Dura hindurch fühlbaren und sichtbaren cystischen Vorwölbungen des Gehirns, den im Encephalogramm erkennbaren luftgefüllten Hohlräumen an der Gehirnoberfläche.

6. 4. 1925 Operation 2. Akt. Bildung eines großen Duralappens mit temporaler Basis. Dura nirgends mit der Hirnoberfläche vrwachsen. Nach Zurückklappen 
des Lappens sieht man, daß der größte Teil des Stirnlappens von einer apfelgroßen Cyste eingenommen wird (vgl. Abb. 33 I), deren äußere Wand seidenpapierdünn und von feinen Gefäßen durchzogen ist; durch eine sanduhrförmige, eingezogene Brücke sklerosierter Hirnsubstanz (III) getrennt, folgt nach hinten eine zweite gleichartige, mindestens ebenso große Cyste (II), welche Teile der Zentralregion und des Parietallappens einnimmt. Der Temporallappen zeigt ausgesprochene Fluktuation; der Gehirnmantel ist hier papierdünn und stellenweise geradezu durchsichtig, aber die ursprüngliche Rindenstruktur ist fast überall erkennbar; die sklerosierte Gehirnsubstanz, welche die beiden oben erwähnten Cysten voneinander trennt, reicht nach unten $\mathrm{zu}$ in die erste Temporalwindung

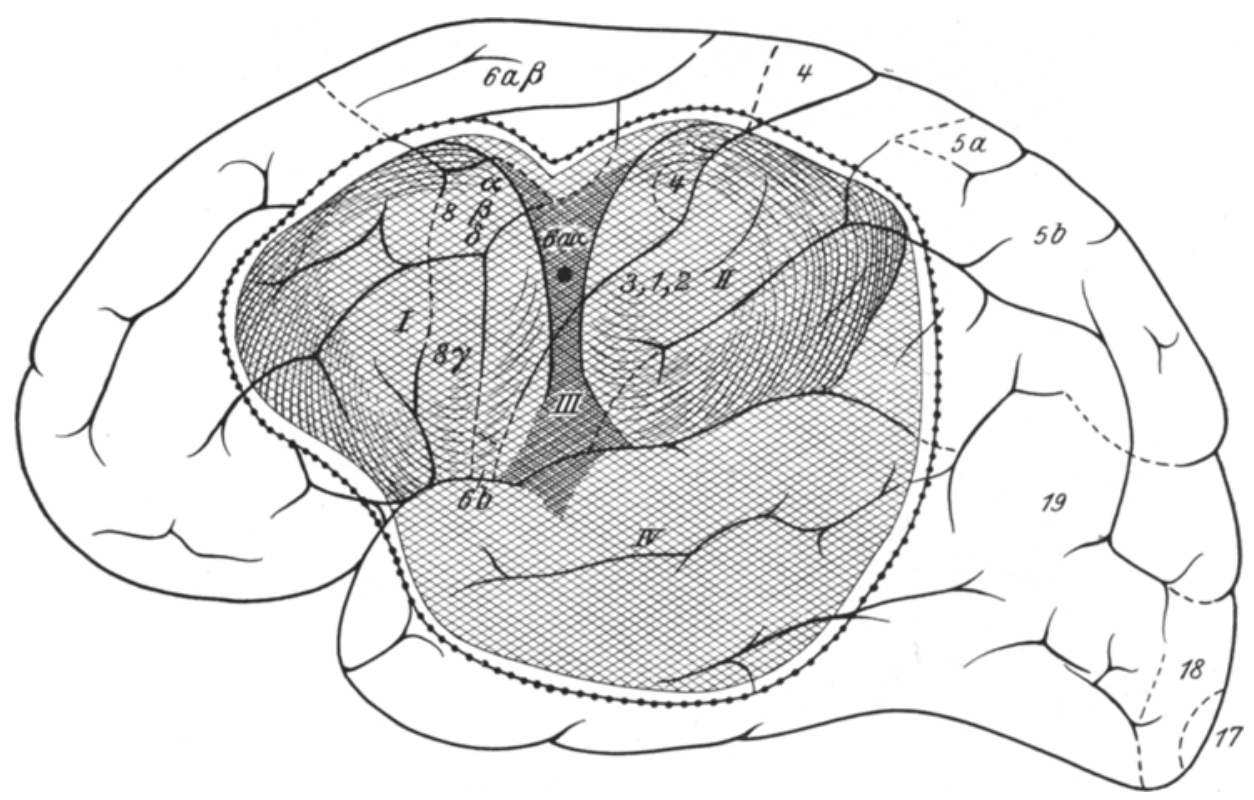

Abb. 33. Lage und Ausdehnung des Herdes in Fall 5. I die den Frontallappen einnehmende cystische Aussackung des linken Seitenventrikels; II die die hintere Zentralwindung und einen großen Teil des Scheitellappens einnehmende cystische Aussackung des Ventrikels; III die zwischen beiden befindliche derbe, sklerosierte eingezogene Hirnpartie; IV papierdünne Wand des stark dilatierten Unterhorns. Auslösungsort des epileptischen Anfalles.

herein. Der Versuch, durch galvanische KSR. die fokale Erregbarkeit der vorderen Zentralwindung zu bestimmen, verläuft völlig erfolglos. Bei Reizung mittels faradischen Stromes an der in der Abb. 33 markierten Stelle, welche innerhalb der zwischen den beiden Cysten gelegenen sklerosierten Brücke gelegen ist, tritt ein epileptischer Anfall auf, der rechte Arm verfällt in tonisch-klonischem Krampf, dann folgt Kopf und- Augendrehung nach rechts und tonisch-klonischer Krampf des rechten Beines. Der Anfall ist also als Adversiofeldanfall des Feldes $6 a \alpha$ aufzufassen, die Area 4 (Area gigantopyramidalis) muß als zerstört betrachtet werden. Umstechung der Cysten und der zwischen ihnen gelegenen sklerosierten Gehirnsubstanz in toto, darauf Excision in dem in der Abb. 33 angegebenen Umkreis, wobei die dem Temporallappen angehörende papierdünne Unterhornwand mit einbezogen wird. Dadurch wird das gesamte Seitenventrikelsystem, Vorderhorn, Cella media und Unterhorn breit eröffnet, die mediale Ventrikelwand mit dem halbkreisförmig 
verlaufenden Schwanzkern und Plexus chorioideus liegt in voller Ausdehnung zutage.

Durch die Excision, welche in der Tiefe die ganze Inselgegend, die äußere Kapsel, den Linsenkern und die innere Kapsel umfaßt hat, sind keinerlei weitere Defekte entstanden als die, welche bereits vorher vorhanden waren; die Sprache ist in keiner Weise alteriert, die Hemiparesis dextra ist genau dieselbe wie vorher, keinerlei Sensibilitätsdefekte sind aufgetreten, was verständlich ist, da durch die Excision kein funktionstüchtiges, sondern vorher bereits total oder fast total destruiertes Hirngewebe geopfert wurde. Der Fall ist ein ausgezeichnetes Paradigma dafür, bis zu welchem Grade selbst bei ausgedehnter Zerstörung der linken Hemisphäre

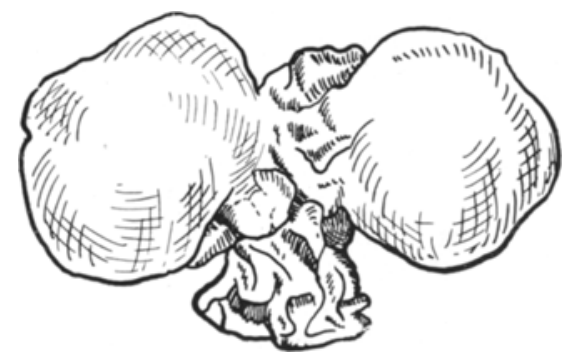

Abb. 34. Gehirnexcisum des Falles 5, bestehend aus den beiden Cystenwänden und der zwischen den Cysten gelegenen sklerosierten Hirnpartie 12,0:6,0 cm breit, 3-4 cm tief.

die rechte einzutreten vermag; soweit die Sprache und die Sensibilität der rechten Körperhälfte in Betracht kommt, ist die Substitutionsleistung der rechten Hemisphäre eine vollkommene, für die Motilität eine recht weitgehende. Nach der Operation Temperaturanstieg, am dritten Tage bis $39^{\circ} \mathrm{C}$ (Ventrikel eröffnet), erst vom 15. Tage ab Temperatur normal. Während der ganzen Zeit der Fiebersteigerung sehr gutes Allgemeinbefinden.

Patient hat bisher keinen Anfall wieder gehabt. Ist im Bürodienst voll tätig (Januar 1930).

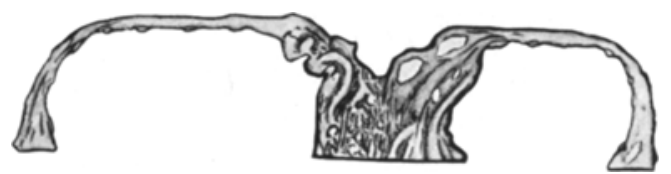

Abb. 35. Gehirnexcisum des Falles $5 \mathrm{im}$ Durchschnitt; zeigt die beiden Cysten und das zwischengelegene derbe Hirngewebe, bestehend aus zahlreichen Strängen.

Anatomischer Befund: Abb. 34 zeigt die Gestalt des Excisums, die beiden Cysten und zwischen ihnen das derbe, sklerosierte Hirngewebe. Die Cystenwandung ist papierdünn, auf der Außenseite derselben zahlreiche feine Blutgefäße, die Innenwand der Cysten ist weiß und weist zahlreiche Markfaserzüge auf. Auf einem Durchschnitt durch die Cysten und das sie verbindende sklerosierte Hirngewebe (Abb. 35) erkennt man, daß letzteres aus zahlreichen Bändern und Strängen besteht. Die mikroskopische Untersuchung wird lehren, daß diese Stränge und Bänder aus Gehirngewebe, welches in bindegewebige Hüllen eingebettet ist, bestehen.

Die histologische Untersuchung lehrt, daß die dünnen Cystenwände äußerst verdünnte Hirnrinde sind. Stellenweise ist überhaupt keine weiße Marksubstanz vorhanden, das Ependym liegt direkt unter der grauen Rinde. Die Astrocyten 
in dieser dünnen Cystenwand haben lange feine Fortsätze, wie sie besonders in Fällen von hochgradigem Hydrocephalus gefunden werden.

Die Bänder und Stränge, welche das zwischen den beiden Cysten gelegene sklerosierte Hirngewebe durchsetzen, zeigen reguläre Bündel von Hirngewebe. Jedes Bündel ist umgeben von einer Scheide von Bindegewebe, ganz ähnlich wie ein Fascikel in einem peripheren Nerven (Abb. 36). Zwisehen den Bündeln liegt reichlich gewelltes kollagenes Bindegewebe. Die Bündel selbst bestehen aus feinen

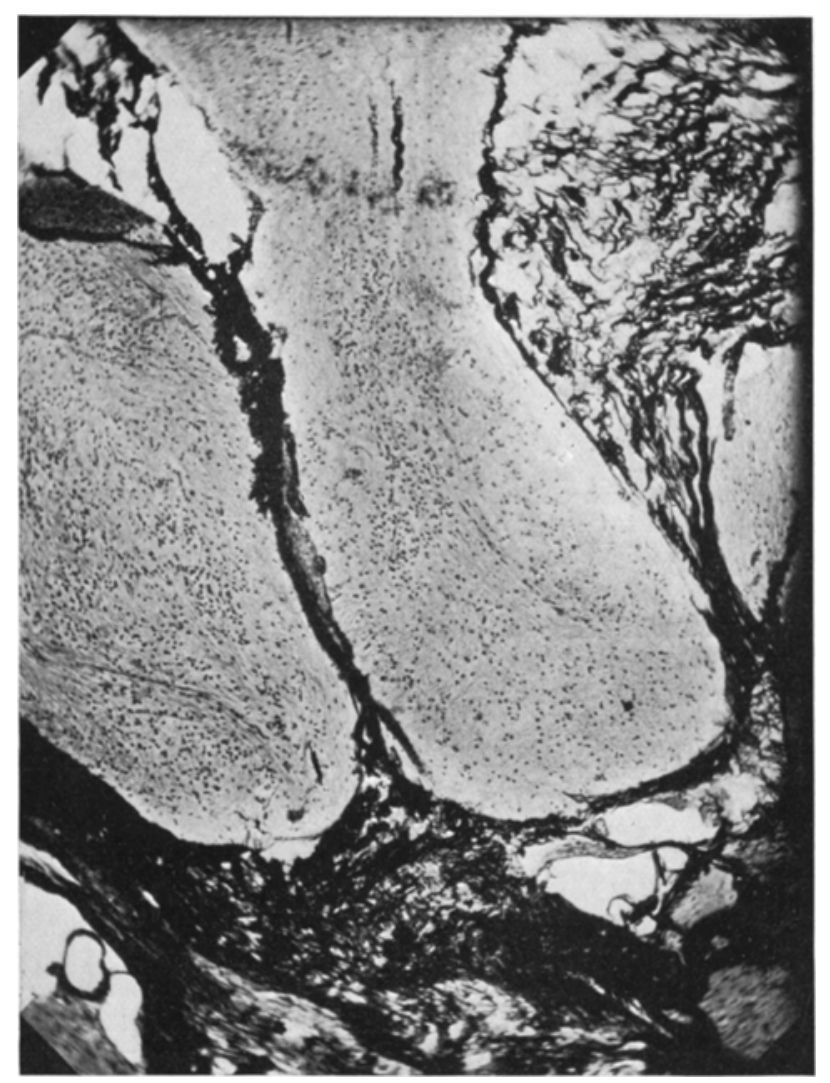

Abb. 36. Mikroskopisches Präparat des Gehirnexcisums von Fall 5. Stränge von Gliagewebe, umgeben von Bindegewebsmänteln. Zahlreiche kollagene Fasern.

Astrocytenfaserzügen (Abb. 37), die Fasern verlaufen zum größten Teil streng parallel in der Längsrichtung des Bündels, aber es bestehen auch stellenweise maschige Durchflechtungen (Abb. 38). An vielen Stellen enden diese Gliafasern mit Füßen an den Gefäßen oder direkt an kollagenen Bindegewebsfasern. Nervenzellen sind überhaupt nicht vorhanden, wohl aber vereinzelte Nervenfasern (Abb. 39).

Zusammenfassung. Es handelt sich um einen Fall ausgedehnter traumatischer Schädigung der linken Hirnhemisphäre durch Zangengeburt. Trotz der Vernichtung des größten Teils der Hemisphäre bestand klinisch nur eine Hemiparesis dextra, keine Sensibilitätsstörungen, 


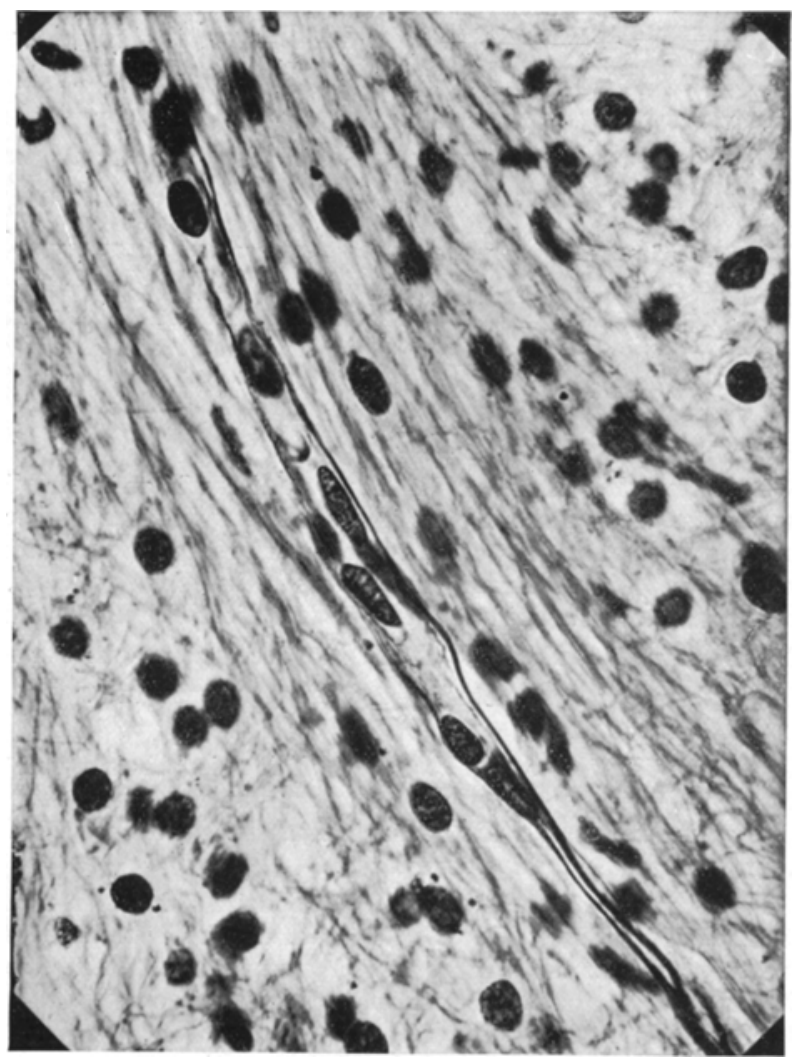

Abb. 37. Mikroskopisches Präparat des Gehirnexcisums von Fall 5 zeigt die Zusammensetzung eines derartigen Gliastranges $(\mathrm{Abb}$. 36) bei 500 facher Vergrö@erung. Zahlreiche Ieine Gliafasern (blaß gefärbt) und Gliakerne; sie kontrastieren mit den dunkel gefärbten kollagenen Fasern entlang der Gefäße. Mikrophotogramm.

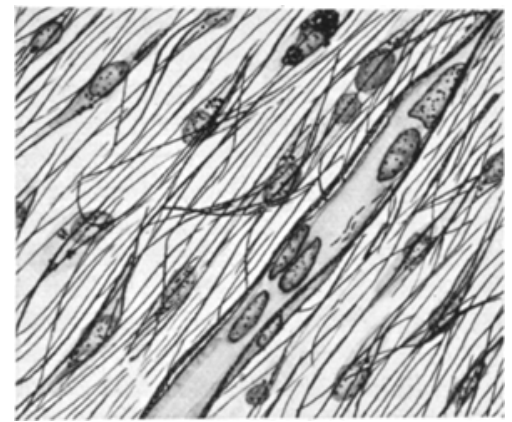

Abb. 38. Mikroskopisches Präparat des Gehirnexcisums von Fall 5 ans derselben Stelle wie Abb. 37. Zeichnung zeigt die zahlreichen Gliafasern sowie ein Gefüß mit 2 kollagene Fasern.

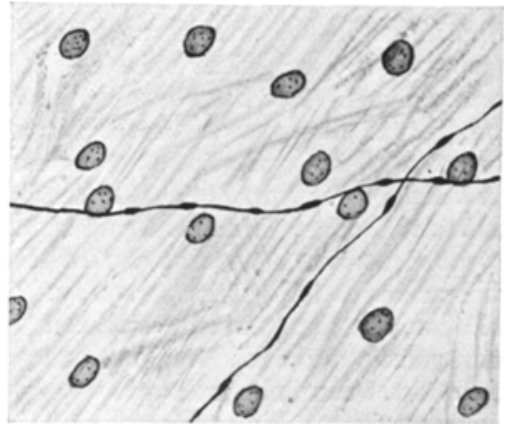

Abb. 39. Mikroskopisehes Präparat des Gehirnexcisums von Fall 5 aus dem derben sklerosierten Hirngewebe (Gliastrang), vereinzelte Nervenfasern mit Nodulationen. Zuhlreiohe Gesichtsfelder der Nachbarsehaft entbehren der Nervenfasern ganz. 
keine Sprachstörungen. Im Alter von 14 Jahren traten die ersten epileptischen Anfälle auf (Typus der Adversiofeldanfälle). Bei der im Alter von 19 Jahren vorgenommenen Operation wurden 2 große Hirncysten samt einer derb sklerosierten zwischen beiden Cysten gelegenen Hirnnarbe exzidiert. Die Cysten waren nichts anderes als stark dilatierte Ventrikelabschnitte. Das sklerosierte Hirngewebe besteht ganz vorwiegend aus Bündeln gliösen Gewebes, welche von Bindegewebsscheiden umgeben sind und welche auffallend den bindegewebigen Hüllen der Fascikel eines peripheren Nerven ähneln.

\section{Fall 6.}

F. W., 29 Jahre alt. April 1916 Tangentialschuß auf der Scheitelhöhe von links nach rechts verlaufend. Debridement, Entfernung zahlreicher extradural gelegener Knochenfragmente. Dura an verschiedenen Stellen durchlöchert. War sofort nach dem Schuß an beiden Beinen und am linken Arm gelähmt, der rechte Arm war nur wenig beteiligt. Urinretention. Allmähliche Besserung der Lähmung.

Okt. 1916 Deckung des Defektes durch Knochenplastik aus der Tibia.

Juli 1917 Eiterung an der Stelle des Knochenimplantats. Excision eines markstückgroßen Knochenteiles.

Dez. 1923 erster epileptischer Anfall. Die Anfälle wiederholen sich in unregelmäßigen Abständen, manchmal bestehen Pausen von 2-3 Wochen, dann aber hat er 2-3 Tage hintereinander sehr gehäufte Anfälle. In der letzten Zeit Anfälle fast täglich, manchmal 5-6 an einem Tage.

15. 10. 1924 aufgenommen. Auf der Höhe des Scheitels, dem hinteren Abschnitte des Os parietale und vorderen oberen Abschnitt des Os occipitale entsprechend eine fünfmarkstückgroße, stark eingezogene Hautnarbe rechterseits, welche etwas über die Mittellinie nach links herüberreicht. Narbe mit der Unterlage fest verwachsen. Der Knochen fehlt an dieser Stelle. Gehirnpulsation schwach fühlbar. Es besteht spastische Paraparese beider Beine, links stärker ausgesprochen als rechts. Beiderseits gesteigerte Dehnungsreflexe, besonders in den Adductoren des Oberschenkels, in den Streckern des Knies und in den Plantarflexoren des Fußes, Patellar- und Fußklonus, Rossolimo +, typische Beuge- und Streckreflexsynergie der Beine, Babinski, Oppenheim usw., Mendel-Bechterew +. Willkürliche Beweglichkeit der Beine, besonders links abgeschwächt. Bei jedem Versuch zu einer isolierten Bewegung eines einzelnen Abschnittes der unteren Extremität tritt die gesamte Beuge- oder Strecksynergie hervor, rechts zum Teil erst bei Widerstandsbewegungen. Gang ausgesprochen spastisch, Bein beim Vorsetzen im Knie wenig gebeugt, Fuß in Supination stark gekantet, streift mit der Spitze über dem Boden, Schrittlänge sehr kurz, ein Bein kreuzt beim Aufsetzen das andere, Zehen krallen sich in den Boden. Die Störungen treten links stärker hervor als rechts. Außerdem besteht deutliche Ataxie an beiden Beinen beim Kniehackenversuch sowie beim Erheben des Beines, links $\geqslant$ rechts. Bauchreflex und Cremasterreflex beiderseits auslösbar, ersterer periostal wesentlich lebhafter als cutan, besonders linkerseits. Seitwärtsneigung und Drehbewegung der Wirbelsäule nach beiden Seiten eingeschränkt, nach links mehr wie nach rechts. Am linken Arm Sehnen- und Periostreflex gesteigert, Finger-Rossolimo + , im übrigen aber Dehnungsreflexe nicht merklich gesteigert. Keine Blasenstörungen. Einzelbewegungen an der oberen Extremität normal. Opposition des Daumens gegen die anderen Finger normal. Keine Ataxie der Arme. Sensibilität an beiden Beinen und den unteren Rumpfabschnitten bis Nabelhöhe für alle Qualitäten stark abgestumpft. Raumsinn der 
Haut erheblich gestört. Bewegungsempfindung an den einzelnen Beinabschnitten gestört, an den Zehen am stärksten, im Hüftgelenk am wenigsten.

Keine Gesichtsfeldeinschränkung. A. H. normal. Gehör, Geruch, Geschmack normal.

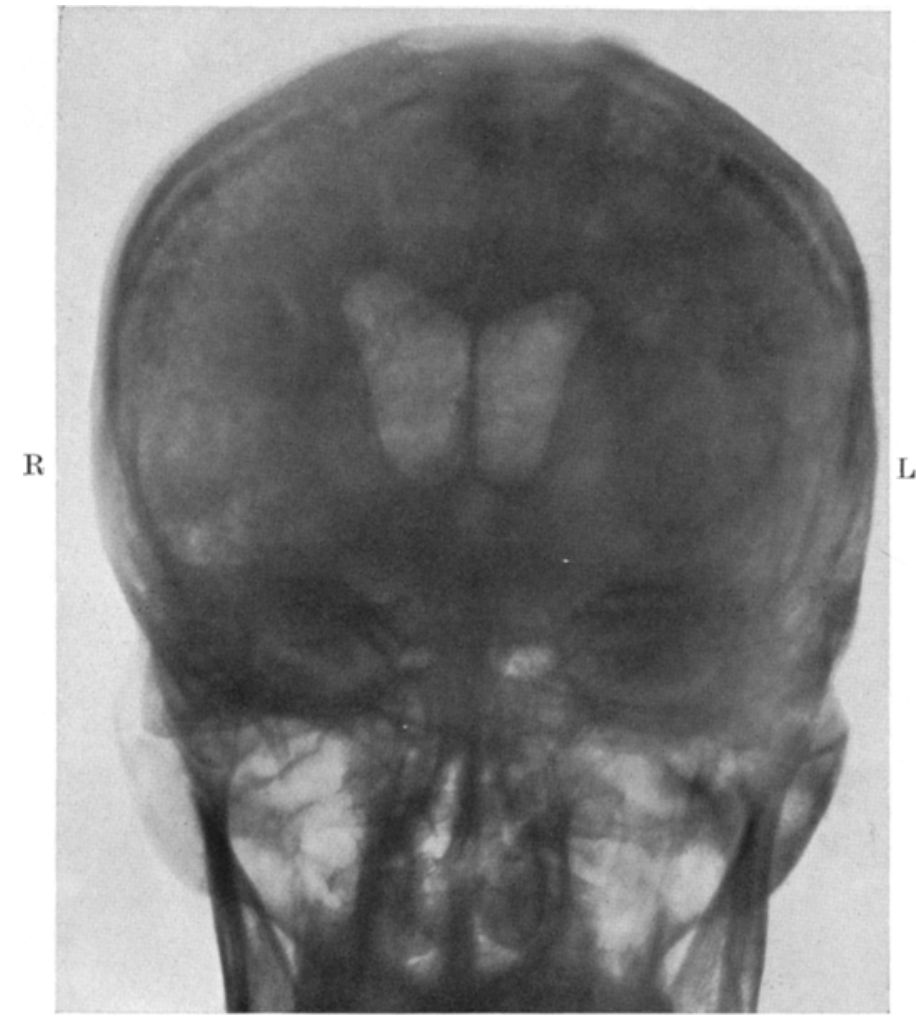

Abb. 40 a. Encephalogramm des Falles 6. Aufnahme in antero-posteriorer Riehtung, Hinterhaupt auf Platte, Dilatation beider. Seitenventrikel, der rechte stärker erweitert als der linke. Hirnherd beiderseitig auf der Höhe des Scheitels, r. $>1$.

Das Encephalogramm (Abb. 40a u. b) zeigt in der fronto-occipitalen Aufnahme eine deutliche Erweiterung beider Seitenventrikel, rechts mehr wie links. Das Dach des rechten Seitenventrikels erseheint im Bereiche der Cella media aufwärts gegen den Knochendefekt zu emporgezogen, wie dies auf dem Sagittalbild zu erkennen ist.

Charakter der Anfialle: Die Anfälle beginnen meist mit Augen-Kopfdrehung nach links, dann folgt Rumpfdrehung nach links und tonisch-klonischer Massenkrampf des linken Armes und Beines, wobei das rechte Bein sich alsbald mitbeteiligt; es handelt sich fast durchweg um starken Beugekrampf des Armes bzw. Beines; erst gegen Ende des Anfalles setzen auch kräftige Extensionsatöße des Armes bzw. Beines ein. Bei diesen Anfällen ist eine sensible Aura nicht sicher festzustellen.

Bei einzelnen Anfällen fehlt die initiale Kopf-Augendrehung, diese beginnen mit einer ausgesprochenen sensiblen Aura in der gesamten linken Körperhälfte, 
worauf simultaner Beugekrampf des linken Armes und Beines einsetzt, worauf das rechte Bein rasch folgt; Kopf-Augen-Rumpfdrehung nach links erfolgt bei diesen Anfällen erst sekundär.

Die erste Kategorie von Anfällen geht also vom rechten Felde 5b, die zweite vom rechten Felde 5a aus.

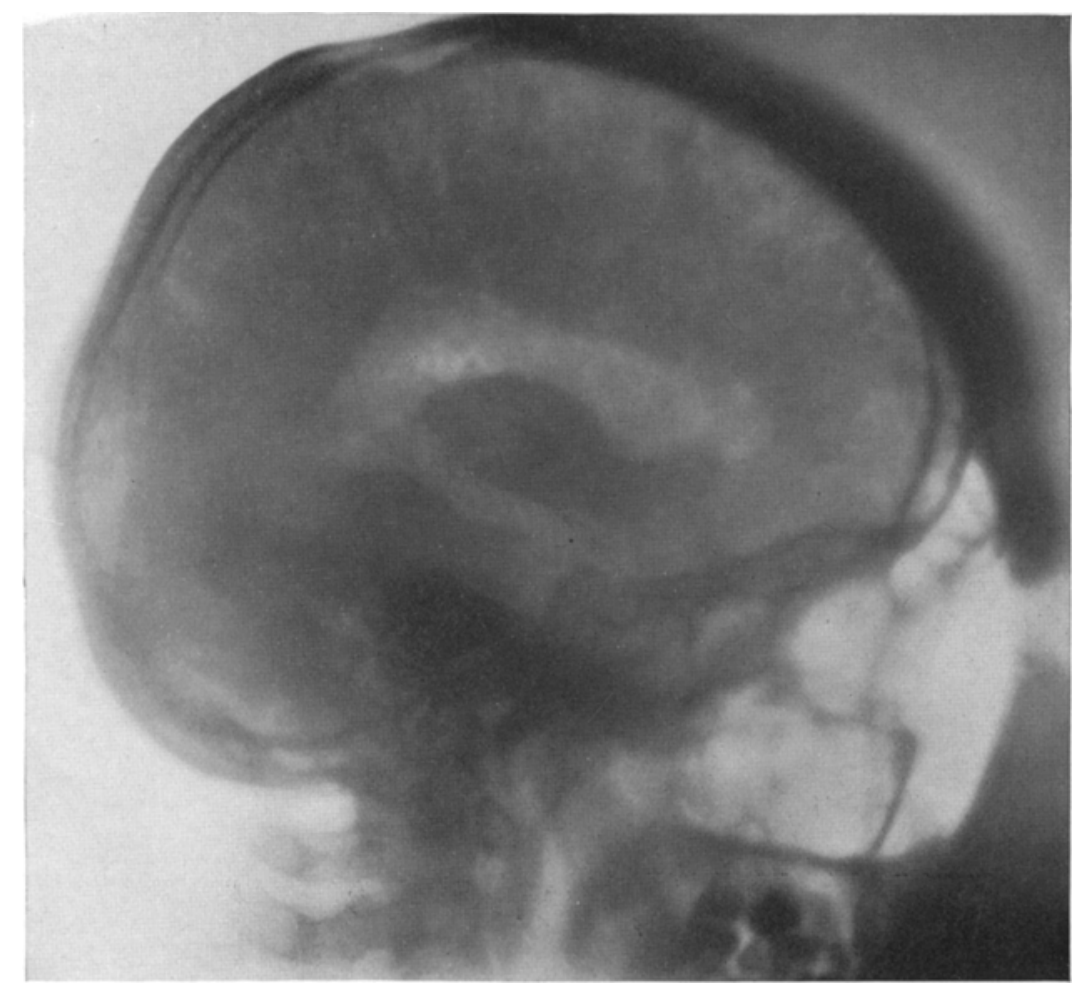

Abb. 40 b. Encephalogramm des Fallew 6. Seitenansicht. Das Dach des rechten Seitenventrikels ist an der Úbergangsstelle der Cella media in das Hinterhorn nach dem Knochendefekt zu ausgezogen.

5. 11. 1924 Operation. Bildung eines Hautlappens um die Narbe herum, Basis nackenwärts. Haut an der Stelle der Narbe und des Knochendefektes sehr fest mit der Unterlage verwachsen. Abpräparieren sehr schwierig; es blutet stark aus der Dura an der Stelle der Verletzung. An dieser ist das Knochenimplantat, welches aber den Knochendefekt nicht ausfüllt, fest mit der Dura verwachsen. Zunächst ausgiebige Erweiterung der Knochenlücke nach links über den Sinus longitudinalis hinaus, nach rechts abwärts etwa bis zur Mitte zwischen Scheitelhöhe und Ohrmuschelansatz; danach Abpräparieren des Knochenimplantats von der Unterlage. Dura an der Stelle der Verletzung teilweise beträchtlich verdickt, teilweise verdünnt und aufgefasert. Darauf Eröffnung der Dura durch Lappenschnitt, Basis dem Sinus longitudinalis entsprechend. Dura ist an der Verletzungsstelle fest mit der Gehimoberfläche verwachsen; daher wird noch ein parallel zum Sinus verlaufender Schnitt angelegt, wodurch die Dura vollkommen zirkulär durchtrennt ist und an der Hirnoberfläche festhaftet. Gehirnsubstanz an der 
Stelle der Verwachsung und in der Umgebung teils bräunlich verfärbt und erweicht, teils narbig verändert (vgl. Abb. 41). Beim Zug mit der Pinzette an der mit der Hirnoberfläche verwachsenen Dura erfolgt ein epileptischer Anfall (Kopf- und Augendrehung nach links, kurzer toniseh-klonischer Krampf des linken Armes und Beines). Fokale Reizung des Beinfeldes der vorderen Zentralwindung mit KSR. und ASR. hat keinerlei Effekt, selbst nicht mit starken Strömen (7-10 mA) dagegen kann etwas nach abwärts vor der Gehirnnarbe der Fokus des Pectoralis major und des Humerus mit $4 \mathrm{~mA}$ KSR. gut bestimmt werden. Galvanische KSR. einer hinter der Gehirnnarbe nahe der Hemisphärenkante gelegenen Stelle ergibt bei $6 \mathrm{~mA}$ simultane Beugezuckung des linken Armes und Beines, bei geringer

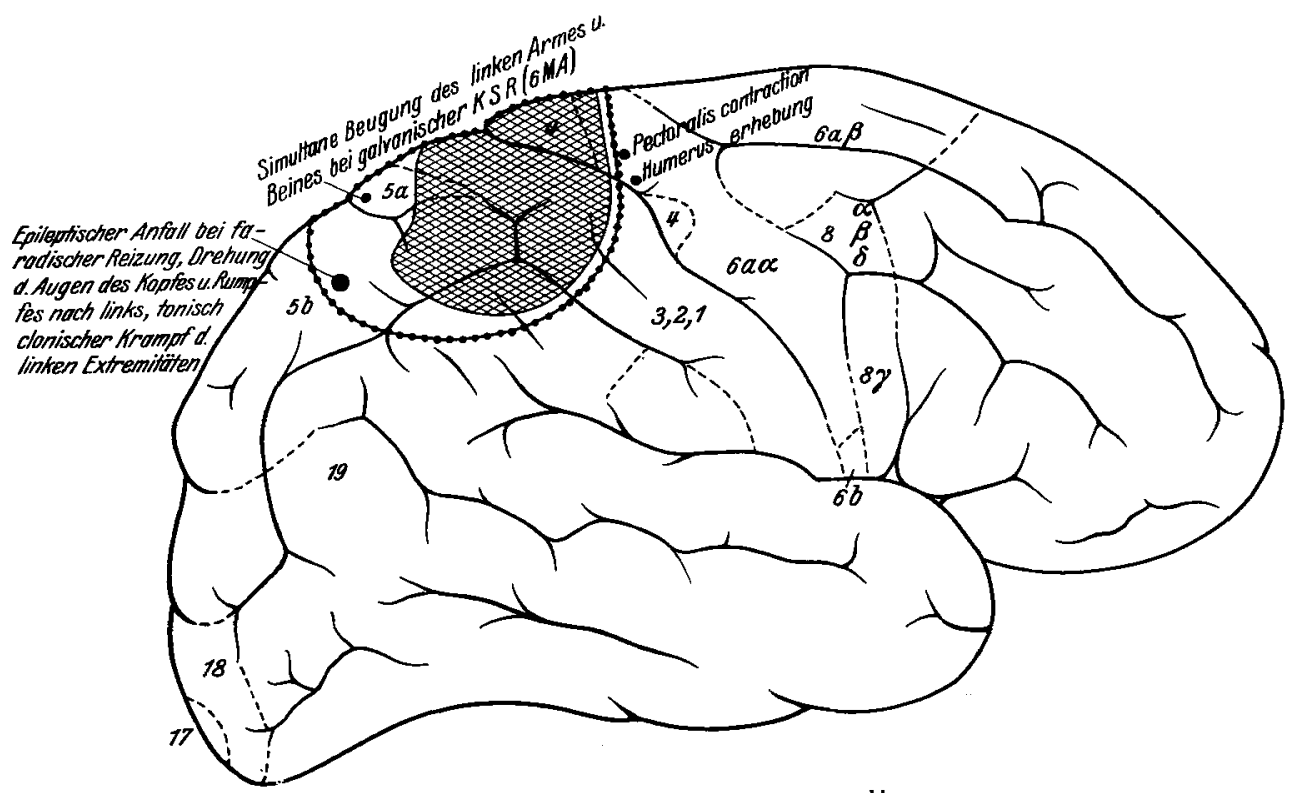

Abb. 41. Lage und Ausdehnung des Rindenherdes in Fall 6. \# Rindenherd, ........- Excisionslinie, $\cdots$ Foki der hinteren Zentrawindung, welche bei KSR. (4 MA) reagierten, - Ort, von dem aus duroh galvanischen Reiz (6 MA.) simultane Beugesynergie des linken Armes und Beines erzielt wurde. Ort, von dem ans durch faradischen Strom ein epileptischer Anfall ausgelöst wurde (sensible Aura, Drehung der Augen und des Kopfes nach links, Drehung des Rumpfes nach links, tonisch-klonischer Massenkrampf der linksseitigen Extremitäten.

Verstärkung des Stromes wird auch das rechte Bein mitgebeugt. Diese Stelle entspricht dem Felde 5a. Bei galvanischer Reizung der noch weiter nach hinten abwärts zu gelegenen Hirnoberfläche tritt selbst bei stärksten galvanischen Schließungsreizen kein Effekt auf, wohl aber erfolgt nach kurzer faradischer Reizung ein epileptischer Anfall, sensible Aura in der linken Körperhälfte, Leibschmerz, kombinierte Kopf-Augendrehung nach links, dann Rumpfdrehung nach links, dann simultaner heftiger tonisch-klonischer Beugekrampf des linken Armes und Beines, das rechte Bein folgt bald nach. Unterbindung der von der Hemisphäre in den Sinus longitudinalis übertretenden Venen, zirkuläre Umstechung der Gehirnnarbe in der in $\mathrm{Abb} .41$ angegebenen Ausdehnung einschließlich des Feldes 5a und der vorderen Abschnitte des Feldes 5b, nach medialwärts greift die Umstechung auf die mediale Fläche der Hemisphäre über. Excision der umstochenen Partie, 
an deren Oberfläche die Dura adhärent ist. Deckung des Duradefektes aus der Fascia lata. Galeanaht. Hautnaht.

Am folgenden Tage (6. 12.) tonische Starre des linken Armes und Beines, welche am 7. 12. noch zunimmt. Daher Wundrevision, welche ein beträchtliches extradurales und intradurales Hämatom feststellt. Dieses rührt zum Teil ans einer juxtasinösen Vene, zum Teil aus einer kleinen Rindenarterie am unteren $\mathrm{Ab}$ schnitt der Excisionsstelle her. Sorgfältige Blutstillung durch Ligatur, Wiederverschluß der Dura und Haut.

3 Stunden nach der Operation ein epileptischer Anfall. Kopf-Augendrehung nach links, tonisch-klonischer Krampf des linken Armes und Beines. Danach schlaffe linksseitige Lähmung, welche aber bald wieder zurückgeht.

25. 2. 1925 entlassen. Objektiver Status quo ante operationem. Keine Anfälle mehr. Hat auch weiterhin während der seit der Operation verflossenen 5 Jahre nie wieder Anfälle gehabt; ist beruflich tätig in der Kriegsverletztenfürsorge des Kyffhäuserbundes. Die Parese der Beine hat sich gebessert. Patient kann mehrstündige Wege selbst im gebirgigen Terrain zurücklegen.

Anatomischer Befund: Es konnte nur ein kleines Stück des exzidierten Hirnstückes mikroskopisch untersucht werden. Dieses zeigte deutliche subpiale vasculäre Plexusbildung (flächenhafte corticale Erweichung). An anderen Stellen ziehen reichlich Gefäße und Bindegewebsfasern in das Gehirn herein, die Fasern der in der Umgebung dieser Bindegewebszüge gelegenen Astrocyten sind alle auf diese zugerichtet.

Zusammenfassung. Es handelt sich um eine Schußverletzung der oberen Scheitelregion, vornehmlich rechterseits, mit spastischer Paraparese der Beine. Knochendefekt. 7 Jahre nach der Verletzung erster epileptischer Anfall. Starke Erweiterung und Ausziehung der Ventrikel nach dem Knochendefekt zu. Haut hier mit der Dura und diese mit der Hirnoberfläche fest verwachsen. Soweit das exzidierte Hirnstück untersucht werden konnte, zeigt es deutlichen Narbenzug innerhalb der Hirnsubstanz.

\section{Fall \%.}

G. Kr., 29 Jahre alt. April 1916. Tangentialschuß an der linken Schädelhälfte, sofort bewußtlos, rechtsseitige Hemiplegie und Aphasie. Debridement. Sprache nach 14 Tagen wieder hergestellt, allmähliche Besserung der rechtsseitigen Lähmung.

Seit November 1923 paroxysmal auftretende Anfälle von Sprachverlust, welche meist nur wenige Sekunden dauern, so daB Patient sehr oft, wenn der Anfall mitten in einem Satze auftritt, nach dem Anfall genau da wieder einsetzt, wo er abgebrochen hatte, manchmal sogar mitten in einem Worte.

18. 2. 1924 erster epileptischer Krampfanfall, beginnend in der rechten Körperhälfte. Allmähliche Häufung der Anfälle, zunehmende Kopfschmerzen, sehr vergeßlich und depressiv gestimmt, weint viel. Muß den Unterricht, den er als Lehrer bis Februar 1924 erteilt hatte, aufgeben.

29. 5. 1925 aufgenommen. Hat in letzter Zeit fast täglich Anfälle, manchmal mehrere an einem Tage.

Auf dem linken Scheitelbein eine $10 \mathrm{~cm}$ lange, $4 \mathrm{~cm}$ breite, von vorn nach hinten verlaufende Narbe, in deren Bereich der Knochen fehlt und die Haut eingezogen und fest mit der Unterlage (Gehirn) verwachsen ist. Gehirnpulsation nicht fühlbar und sichtbar. 
Gehirnnerven o. B, Am rechten Arm gesteigerte Sehnen- und Knochenhautreflexe, Rossolimo an den Fingern +, aber keine Parese der Extremität, Einzelbewegungen der einzelnen Abschnitte der Extremität möglich, auch Opposition des Daumens unter genauer Augenkontrolle möglich, dabei fällt es ihm allerdings schwer, Mitbewegungen der anderen Finger zu unterdrücken.

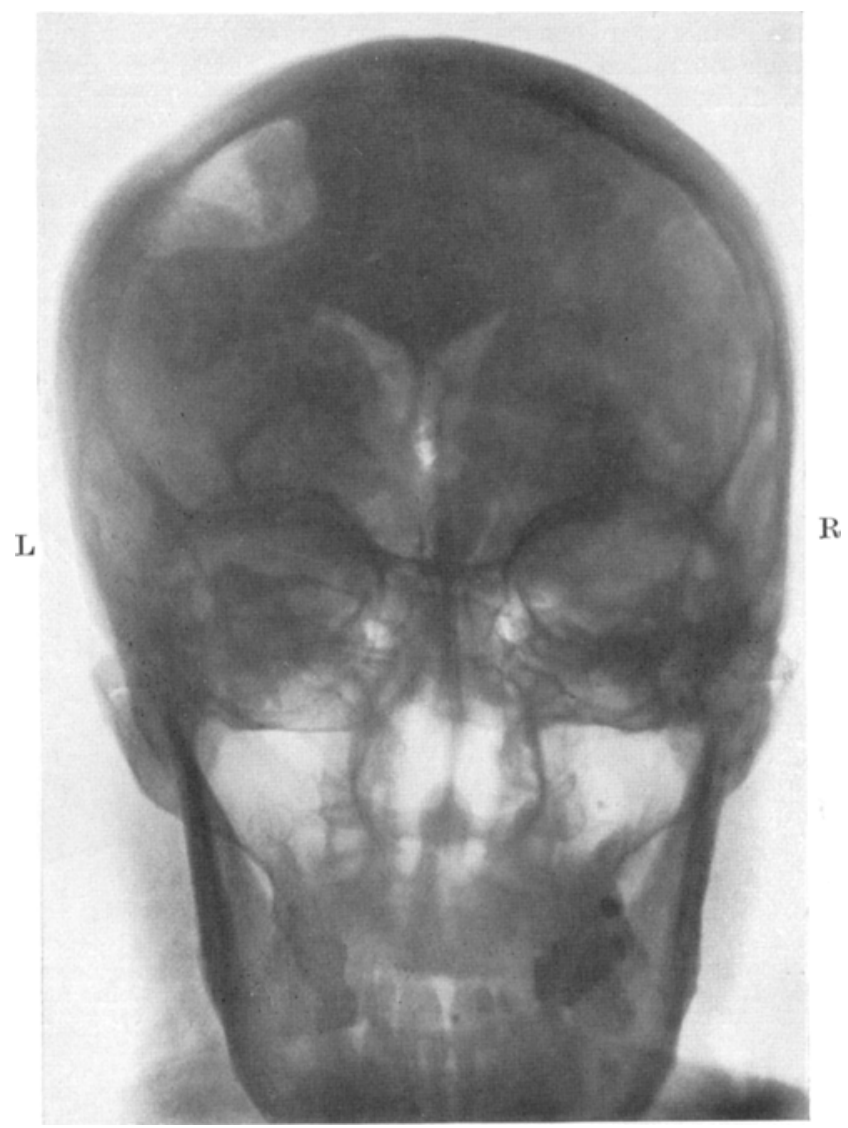

Abb. 42. Encephalogramm von Fall 7. Aufnahme in antero-posteriorer Richtung, Hinterkopf auf Platte. Der linke Seitenventrikel ist etwas nach dem Knochendefokt zu ausgezogen.

Ausgesprochene Ataxie des rechten Armes beim Zeigefingernasenversuch, ausgesprochene Ataxie bei sukzessiver Oppositionsbewegung der Daumenspitze zu den Spitzen der anderen Finger. Feinere Fingerverrichtungen wie Knöpfen, Schreiben usw. sehr erschwert, zum Teil unmöglich.

Lerischer Vorderarmreflex fehlt rechts, ebenso Meyerscher Fingergrundreflex.

$A m$ rechten Bein keinerlei Zeichen einer Pyramidenbahnerkrankung, aber ausgesprochene Ataxie beim Kniehackenversuch. Bauch- und Cremasterreflex fehlt rechts bei cutaner Auslösung, ersterer periostal auslösbar. Sensibilität am rechten Arm und Bein und Rumpf für Schmerz, Berührung und Temperatur leicht herabgesetzt, Hals und Gesicht nicht beteiligt. Raumsinn der Haut rechterseits schwer

Z. f. d. g. Neur. u. Psych. 125. 
geschädigt, Bewegungsempfindungen und Gewichtsschätzungsvermögen rechts schwer gestört, völlige Aufhebung der Fähigkeit der rechten Hand, Gegenstände durch Betasten $z u$ erkennen. Keine Gesichtsfeldstörungen, Augenhintergrund normal, Sprachverständnis intakt, aber deutliche Erschwerung der Wortfindung, Sprache daher verlangsamt. Nachsprechen regelrecht. Lesen intakt, aber Lesesinnverständnis erschwert. Schreiben mit der linken Hand - Patient hat nach seiner Verwundung mit der linken Hand schreiben gelernt - ohne Fehler. Häufig kurzdauernde Zustände totaler Sprachlosigkeit, stockt mitten im Satz, kann dann auch nicht nachsprechen, nach einigen Sekunden oder Minuten Sprechvermögen wieder wie vorher.

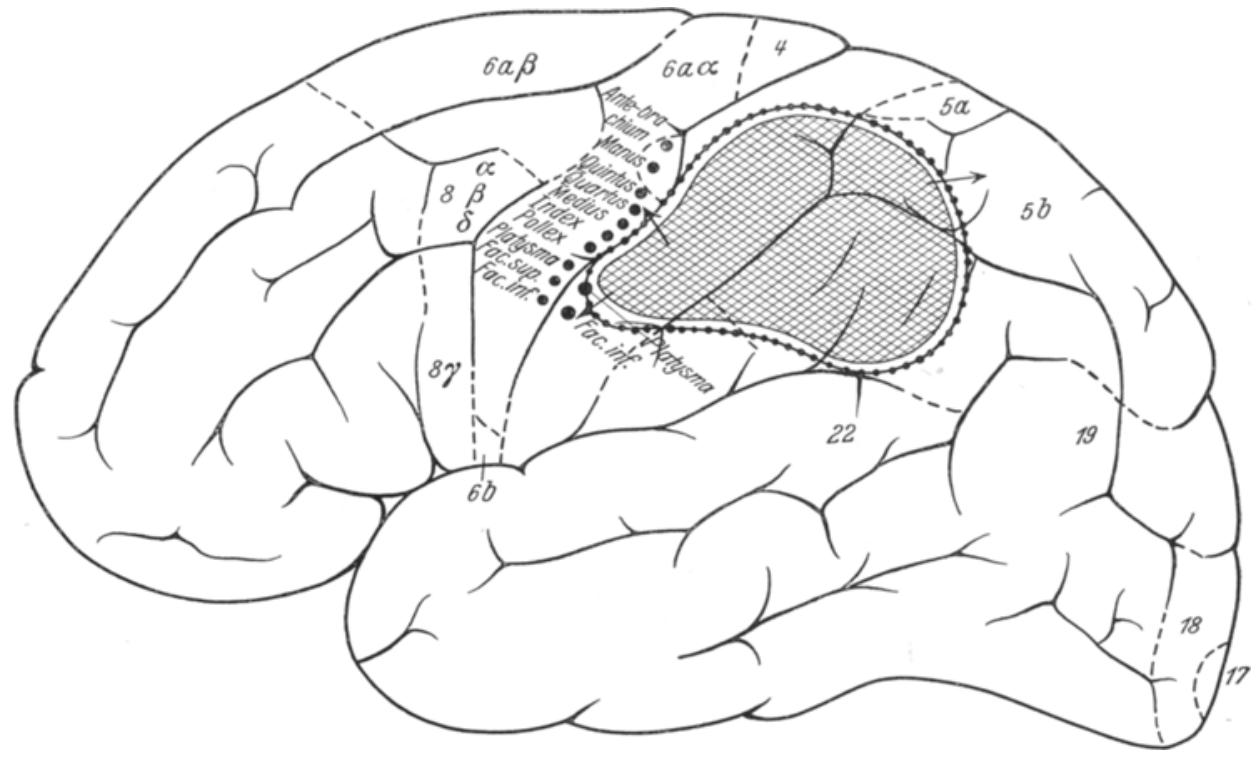

Abb. 43. Lage und Ausdehnung des Rindenherdes in Fall 7. \# Rindenherd, ........ Kxcisionslinie, .... Foki in der hinteren und vorderen Zentralwindung, welche durch $\mathrm{KSR}$. erregt wurden. Die Pfeile $\rightarrow \rightarrow \rightarrow$ deuten die Richtung an, in welcher der Rindenherd als Krampfreiz auf die benachbarten Rindenfelder $4 ; 3,1,2 ; 5 \mathrm{~b}$ gewirkt hat.

Encephalogramm (Abb. 42) zeigt geringe Vergrößerung des linken Seitenventrikels, die Spitze desselben ist deutlich gegen den Knochendefekt zu ausgezogen, außerdem ist das gesamte Ventrikelsystem (dritter Ventrikel und beide Seitenventrikel) etwas nach links verzogen. Im Seitenbild sieht man, daß das Dach der Cella media des linken Seitenventrikels nach dem Knochendefekt zu ausgebuchtet ist.

Charakter der Anfälle. Abgesehen von den sehr oft auftretenden kurzen Anfällen von Sprachverlust und anderen kurzen Absencen treten zweierlei Arten von Anfällen auf, schwere Anfälle, welche mit Kopf-Augen-Rumpfdrehung nach rechts beginnen, der rasch tonisch-klonischer Massenkrampf des rechten Armes und Beines folgt, darauf beteiligt sich auch das linke Bein, dann rasche Generalisierung, tiefer Stertor der Atmung, lange Bewußtlosigkeit ( $1 / 2$ Stunde und mehr). Eine Aura kann bei diesen Anfällen nicht sicher nachgewiesen werden, weil Patient hinterher völlig amnestisch, zum Teil sogar retrograd amnestisch ist und auf Befragen des Kranken zu Beginn des Anfalls keine Antwort mehr erfolgt. Bei 
diesen Anfällen handelt es sich um solche, die vom Felde $5 \mathrm{~b}$ ausgehen und rasch das Feld 5a ergreifen.

Die andere Kategorie von Anfällen beginnt mit klonischen Beugezuckungen des 4. und 5. Fingers der rechten Hand, dann folgt Ulnarflexion der Hand, dann Beugung des Vorderarms, dann Oberarmabduction, Zuckungen in den Schulterhebern, im Pectoralis major, in der Banchmuskulatur, dann folgt das Bein; andererseits schließt sich an die Zuckungen des 4 und 5. Fingers eine solche des 3. und 2. Fingers und des Daumens an, darauf folgt Platysma und Sternocleidomastoideus, darauf Facialis, Zunge, Velum. Bei diesen Anfällen kommt es meist nicht zum Bewußtseinsverlust. Sie verlaufen stets ohne sensible Aura. Es handelt sich um typische Entladungen des Feldes 4. Außerdem aber treten mit diesen eben geschilderten Jacksonschen Anfällen abwechselnd noch folgende Anfälle auf: Ausgesprochene sensible Aura im Gesicht, dann im Munde und am Halse, danach klonische Zuckungen im oberen Facialis, unteren Facialis, Zunge, Gaumensegel, andererseits im Daumen, Zeigefinger und 3. Finger; selten greifen diese Anfälle auf den 4. und 5. Finger über. Diese Anfälle führen ebenso wie die vorgeschilderten fast nie zum Bewußtseinsverlust; sie sind als typische Anfälle des Feldes 3, 1, 2 (Centralis post.) aufzufassen.

22. 6. 1925 Operation. Bildung eines großen Hautlappens, in dessen Zentrum die alte Kopfnarbe gelegen ist. Basis abwärts. Haut im Bereich der Narbe fest mit der Dura verwachsen, Lösung äußerst schwierig. Breite Erweiterung der bestehenden Knochenbresche. Knochen an den Rändern des vorbestehenden Defektes bis zu 2 , ja $3 \mathrm{~cm}$ verdickt. Es blutet stark aus der

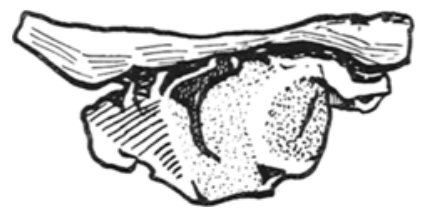

Abb. 44. Dura-Hirnexcisum von Fall7 $5,0 \mathrm{~cm}$ breit, 2,5 cm tief im Durchschnitt. Dura stark verdickt, Gehirn stark narbig verändert, fest an der Unterfläche der Dura adhärierend. Dura nach außen. Galeanaht. Hautnaht.

3. 7. 1925 Operation 2. Akt. Zurückklappen des Hautlappens. Zirkuläre Eröffnung der Dura um die Stelle der Läsion herum. Dura im Bereich der letzteren sehr verdickt und fest an der Gehirnoberfläche adhärent. Es blutet auch nach völliger Umschneidung der Dura noch deutlich aus derselben an der Stelle ihrer Verwachsung mit der Hirnoberfläche nach außen. Gehirn an der Stelle der Verwachsung sehr verhärtet, in der Umgebung bräunlich verfärbt und erweicht. Ausdehnung und Lage des Gehirnherdes gibt Abb. 43 wieder. Bestimmung der Foki des Facialis inferior, Facialis superior, Platysma, Pollex, der Finger, der Hand, des Vorderarms in der vorderen Zentralwindung (2 MA, KSR.). In der hinteren Zentralwindung ist nur der Fokus des Platysma und Facialis inferior bei 4,5 MA KSR. erregbar; bei Reizung dieser Stelle mit schwachem faradischem Strom starkes Kribbelgefühl am Halse, schmerzhaftes Brennen im Gesicht, gleichzeitig Kontraktion der Halsmuskeln und Gesichtsmuskeln. Beim Anfassen der an der Hirnnarbe adhärenten Dura mit der Pinzette setzt ein schwerer epileptischer Anfall ein (Kopf-, Augen,- Rumpfdrehung nach rechts, tonisch-klonischer Massenkrampf des rechten Armes und Beines). Darauf Umstechung des Kontusionsherdes und Excision desselben in der in der Abb. 43 wiedergegebenen Ausdehnung. Die Narbe geht ziemlich tief in das Marklager herein und es müssen auch nach der Excision des Gesamtstückes noch einzelne narbige Reste aus der Tiefe herausgeschnitten werden. Ventrikel wird nicht eröffnet. Am vorderen Rande des Excisionskraters blutet es nach der Excision ziemlich stark. Umstechung einer blutenden Arterie daselbst. Deckung des Duradefektes aus der Fascia lata. Galeanaht. Hautnaht.

Nach der Operation Temperatur unter $38^{\circ} \mathrm{C}$. Heilung per primam.

Am Tage nach der Operation noch 3 Anfälle, beginnend mit klonischen Zuckungen im 4. und 5. Finger, dann Ulnarflexion der Hand, dann Zuckungen der 
anderen Finger, des Daumens, der Halsmuskeln und des Augenfacialis; eine weitere Ausbreitung findet nicht statt. Seither sind keine Anfälle aufgetreten.

13. 2. 1926 entlassen. Objektiver Status wie vor der Operation. Subjektiv ausgezeichnetes Befinden. Kopfschmerzen, depressive Stimmung ganz beseitigt. Bald nach der Entlassung hat Patient seinen früheren Beruf als Lehrer wieder aufgenommen und außerdem eine rege Tätigkeit in der Kriegsverletztenfürsorge entfaltet.

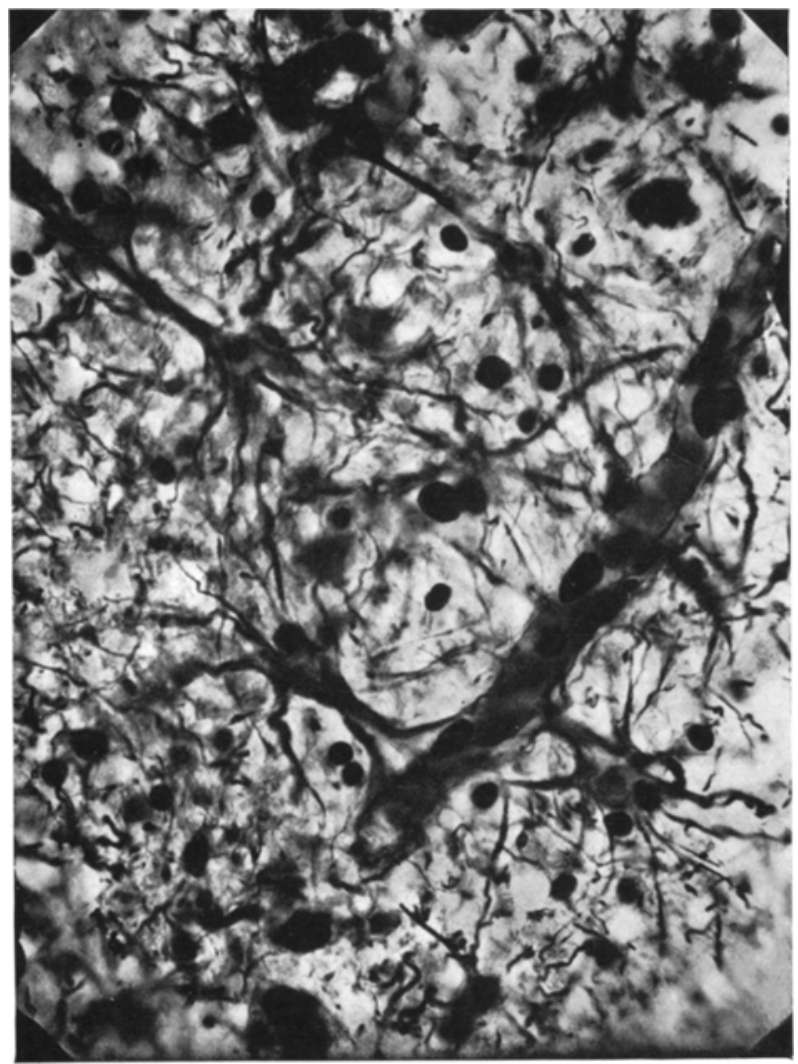

Abb. 45. Mikroskopisches Präparat des Gehirnexcisums von Fall 7 bei 300 facher Vergrößerung. Astrocyten mit dicken fibrösen Fortsätzen, welche an den Gefäßen adhärieren. Hortegas Silbercarbonatfärbung.

Im Oktober 1929 ist zum ersten Male wieder ein epileptischer Anfall aufgetreten, im Beginn einer fieberhaften Pleuritis, unmittelbar im Anschluß an einen heftigen Ärger und Wortstreit, den Patient mit einem Kollegen hatte. Die Bewußtlosigkeit hat etwa 10 Min. gedauert. Der Charakter dieses Anfalles war wieder der des 5b-5a-Anfalles. Seither keine Anfälle bis März 1930.

Anatomischer Befund: An dem exzidierten Dura-Hirnstück (Abb. 44) ist die Dura außerordentlich verdickt (an den exzentrischen Partien $6 \mathrm{~mm}$, im Zentrum etwa $2 \mathrm{~mm}$ Dicke), derbe Bindegewebszüge verlöten das Gehirn mit der Dura. Im mikroskopischen Bilde sieht man, wie diese Bindegewebszüge aus der Dura 
direkt tief in das Hirngewebe eindringen. Unterhalb dieser Bindegewebsinvasionszone findet sich eine Erweichungszone, welche in der Hauptsache auf die weiße Gehirnsubstanz beschränkt ist; in dieser Erweichungszone sind die Gefäße stark vermehrt, die Astrocyten zeigen Sternform und bilden mit ihren Insertionen an den Gefāßen ein ausgeprägtes ,vasoastral framework“ (Abb. 45). Die Neurofibrillen zeigen keine Abweichungen von der Norm.

Zusammenfassung. Es handelt sich um eine Schußverletzung der linken Regio retrozentralis und parietalis mit Sensibilitätsstörungen der rechten Körperhälfte. Die ersten epileptischen Anfälle traten 7 Jahre nach der Verletzung auf (Typus des Feldes 5b u. 5a; 3, 2, 1;4). Es besteht ein Knochendefekt, in dessen Bereich die Haut mit der Dura und diese mit dem Gehirn fest verwachsen ist. Das Ventrikeldach ist nach dem Defekt zu ausgezogen. Mechanischer Zug an der mit dem Gehirn in Verbindung befindlichen Dura rief bei der Operation einen epileptischen Anfall hervor. Die mikroskopische Untersuchung lehrt, daß dichte Bindegewebszüge von der Dura in das Gehirn eindringen und daß unterhalb der Bindegewebsinvasionszone ein dichtes vaso-astrales Netzwerk besteht.

Fall 8.

G. G., 18 Jahre alt. Zangengeburt, am rechten Stirnbein verletzt. Wunde heilte bald, es verblieb aber eine große Beule. Seit der Geburt linksseitige Hemiplegie, die sich aber erheblich ausglich. Lief mit $1^{1 /} / 2$ Jahren allein, ging mit 6 Jahren in die Schule, lernte gut, wurde immer regelmäßig versetzt.

Januar 1918, als er 9 Jahre alt war, erster epileptiseher Anfall, der sich bald wiederholte, Häufung der Anfälle, linksseitige Lähmung tritt wieder stärker hervor. In letzter Zeit fast täglich Anfälle, manchmal mehrere an einem Tage.

April 1919, im Alter von 10. Jahren, erste Aufnahme. Am rechten Stirnbein eine Vorwölbung von der Größe eines Eies, auf derselben eine vertikal verlaufende Narbe. Im Bereich der Beule keine deutliche Pulsation fühlbar, unter der Beule, welche eindruckbar ist, fehlt der Knochen. Im Róntgenbilde (Abb. 46a u. b) fünfmarkstückgroßer Defekt im rechten Stirnbein erkennbar. Es besteht linksseitige spastische Hemiparese, Gesicht und Zunge wenig beteiligt. Linker Oberarm steht leicht abduziert, stark innenrotiert, Vorderarm stark gebeugt, Hand proniert, Daumen adduziert, Finger leicht gebeugt; lebhaft gesteigerte Dehnungsreflexe an den Muskeln des linken Armes, Finger-Rossolimo +, lebhaft gesteigerte Sehnenund Periostreflexe. Willkürliche Beweglichkeit des linken Armes behindert, bei allen energischen Bewegungen tritt die Beuge- bzw. die Strecksynergie stark hervor. Isolierte Fingerbewegungen unmöglich, Daumenopposition und Abduction ganz aufgehoben, beim Faustschluß erfolgt energische Flexion der Hand. Keine Ataxie der oberen Extremität. Seitwärtsneigung und Drehung der Wirbelsäule nach links merklich eingeschränkt. Bauch- und Cremasterreflex links cutan auslösbar, ersterer periostal gesteigert. Linkes Bein steht in der Hüfte innenrotiert und adduziert, im Knie leicht gebeugt, Fuß in ausgesprochener Equinovarusstellung, Zehen, besonders Großzehe in Dorsalflexion. Starke Dehnungsreflexe besonders in den Innenrotatorea und Adductoren der Hüfte, den Streckern des Knies, den Plantarflexoren des Fußes, Patellar- und Fußklonus, Rossolimo stark +, lebhaft gesteigerte Patellar- und Achillessehnenreflexe, lebhafte voll ausgeprägte Beuge- und Streckreflexsynergie am linken Bein, Babinski + , Oppenheim +- . Bei willkürlichen Bewegungen des linken Beines tritt die Beuge- bzw. Strecksynergie deutlich hervor. Beim Gange linkes Bein mangelhaft vorgesetzt, dabei innenrotiert und adduziert, 


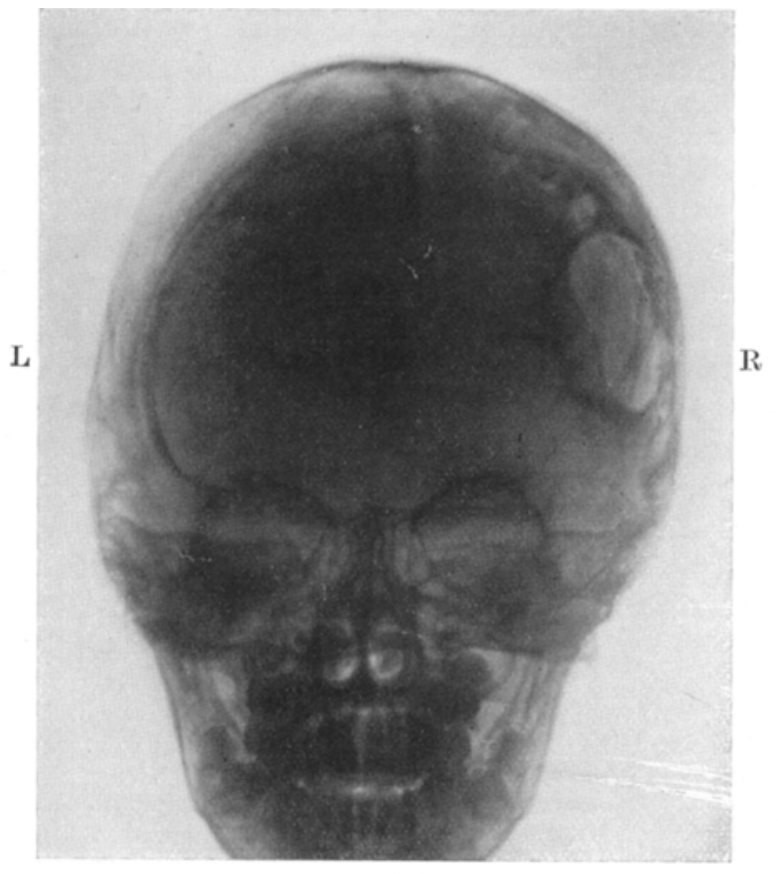

a

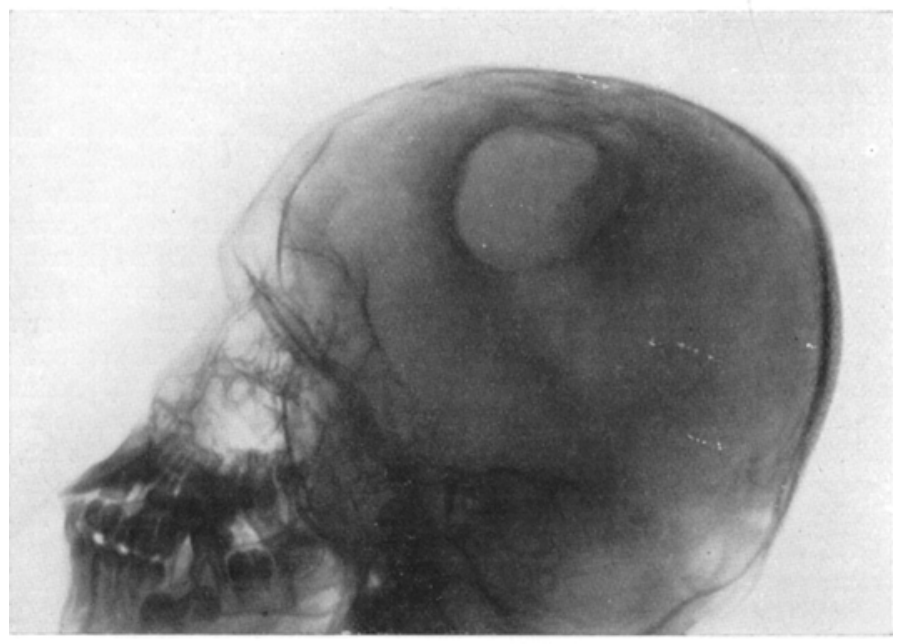

Abb. 46a u. b. Röntgenbilder von Fall 8 zeigen den durch den Forceps gesetzten Knochendefekt. 
im Knie weniger gebeugt als das rechte, Fuß wird stark supiniert, aber mangelhaft dorsalflektiert.

Keine Ataxie des linken Beines. Keinerlei Sensibilitätsstörungen an der linken Körperhälfte. Auch Raumsinn der Haut sehr gut. Keine Astereognosie.

15. 4. 1919 Operation. Bogenförmiger Hautschnitt um die Beule an der rechten Stirn herum, Basis abwärts, Abpräparieren der Haut, welche im Bereich der Beule stark mit der Unterlage verwachsen ist. Diese letztere besteht aus derbem schwieligem Gewebe, in dessen Bereich in der Tiefe eine knochenharte Resistenz fühlbar ist. Incision auf diese Stelle. Es wird ein dreimarkstückgroßes Knochenfragment herauspräpariert, das tief ins Gehirn hereinreicht (vgl. Abb. 47), außerdem noch zwei kleinere Knochenfragmente. Bei der Auslösung des Knochens erfolgt ein epileptischer Anfall: Kopf-Augen-Rumpfdrehung nach links, tonisch-klonischer Massenkrampf des linken Armes und Beines. Eine Excision der narbig veränderten Hirnpartie wurde damals nicht vorgenommen. Galeanaht, Hautnaht.

Nach der Operation keine Anfälle mehr. 7 Monate später eigenartiger Zustand: Nach vorausgehenden furchtbaren Kopfschmerzen plötzliche Verschlechterung der linksseitigen Parese, bis zur fast völligen Lähmung führend. Durch mehrere Ventrikelpunktionen wieder völlig beseitigt; es handelte sich offenbar um eine plötzliche erhebliche Drucksteigerung im rechten Seitenventrikel. Danach ausgezeichnetes Befinden, im Kaufmannsberuf tätig.

Im Jahre 1926, nach 7jähriger Pause, wieder Anfälle, anfangs selten. Seit Ende 1927 etwa

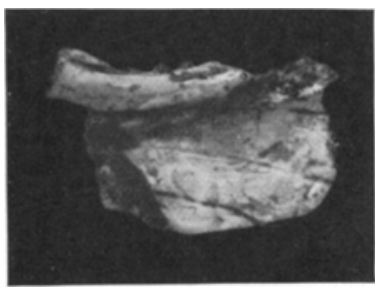

Abb. 47. Knochenfragment, welches durch den Forceps in das Gehirn hineingetrieben war; $4,0: 3,0$ om breit, $0,5-1,0 \mathrm{~cm}$ dick (Fall 8). alle 3 Wochen.

21. 2. 1928 wieder aufgenommen. An der Stelle der früheren Operation starker Prolaps. Gehirnpulsation schwach sichtbar und fühlbar. Hemiparesis spastica sinistra wie früher.

Encephalographie (Abb. 48a u. b) zeigt auf der Aufnahme in antero-posteriorer Richtung eine riesige Dilatation des rechten Seitenventrikels, welcher bis an die Hirnoberfläche heranreicht. Auch der linke Ventrikel ist dilatiert, ebenso der dritte, welcher deutlich schräg nach rechts oben gestellt erscheint. In der Seitenaufnahme (Abb. $48 \mathrm{~b}$ ) ist die handtellergroße Trepanationsöffnung der früheren Operation deutlich sichtbar, der rechte Ventrikel erscheint enorm dilatiert, sein Dach ist zur Stelle des Knochendefektes emporgezogen.

Charakter der Anfälle. Die Anfälle haben von Anfang an das Gepräge des frontalen Adversivfeldanfalls (Feld $6 a \beta$ ) gehabt. Auch die 7 Jahre nach der ersten Operation wiederkehrenden und jetzt immer wieder auftretenden Anfälle haben durchaus dasselbe Gepräge: Keine Aura, Kopf-Augendrehung nach links, extreme Rumpfdrehung nach links, so daß der Kranke manchmal aus dem Bett nach links herausfällt, oder wenn der Anfall im Stehen einsetzt, nach links hinten herumgerissen wird, tonisch-klonischer Massenkrampf des linken Armes und Beines, meist Beug krampf mit starkem Streckstößen alternierend, tiefer Stertor, Zungenbiß, lange Bewußtlosigkeit.

Das psychische Verhalten des Kranken weist hochgradige Reizbarkeit und Unruhe auf, sehr weinerlich.

6. 3. 1928 Operation. Semizirkulärer Hautschnitt um den bestehenden Knochendefekt herum, Haut in dessen Bereich stark mit der Unterlage verwachsen, das Abpräparieren bereitet große Schwierigkeiten. Knochenbresche nach allen Seiten erweitert, zirkuläre Eröffnung der Dura. Dura mit der Hirnoberfläche in großer Ausdehnung fest verwachsen. Gehirnsubstanz auch in der Umgebung der 
Verwachsung stark verändert. Ausłehnung des Herdes in Abb. 49 wiedergegeben. Beim Anfassen der an der Hirnoberfläche adhärierenden Dura und ganz leichten Zug ausgeprägter Anfall (Typus 6a $\beta$ ). Keine fokale Erregbarkeit der vorderen Zentralwindung, auch keine der nach hinten oben vom Herde gelegenen normal

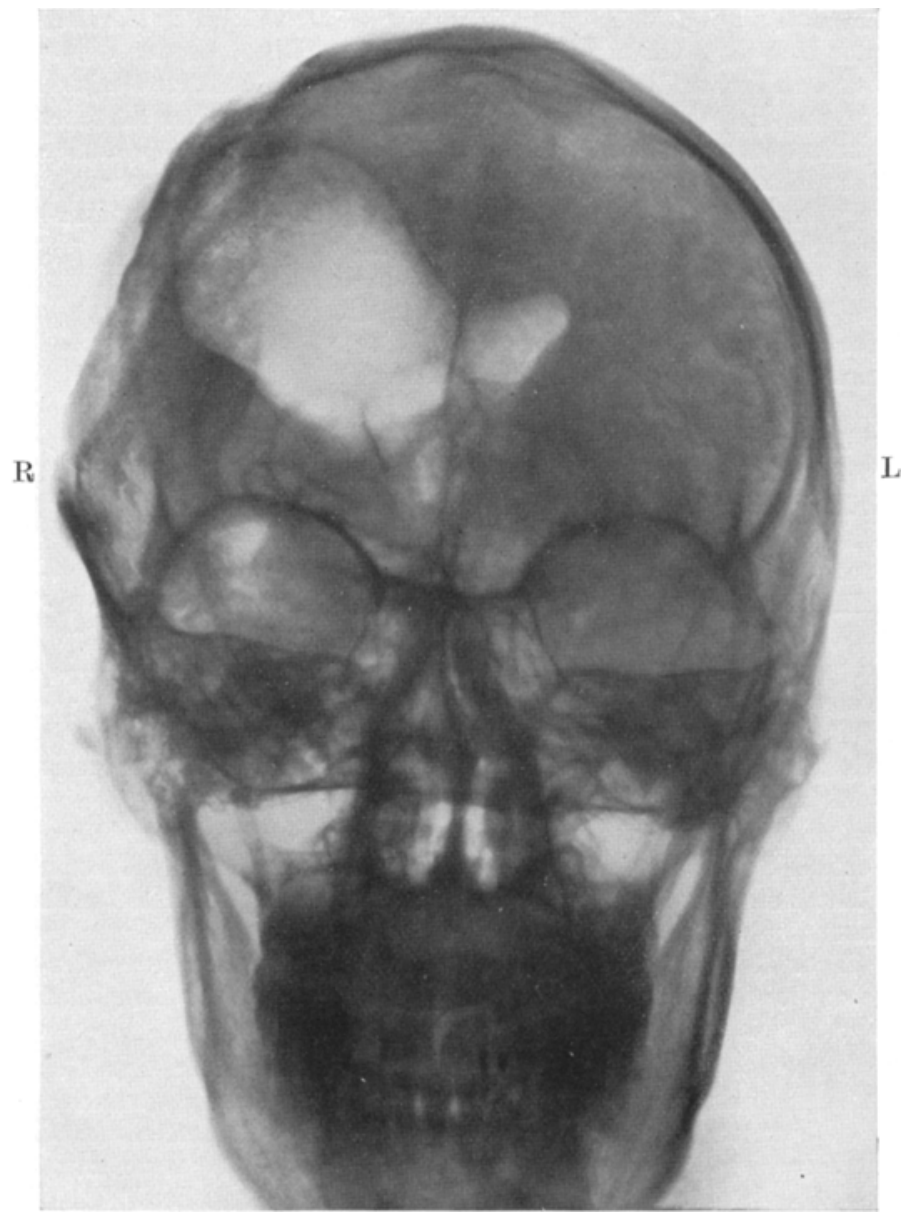

Abb. 48 a. Ineephalogramm von Fall 8. Anfnahme in antero-posteriorer Richtung, Hinterkopf auf l'latte. Dilatation beider Seitenventrikel und des 3. Ventrikels; der rechte enorm dilatierte Seitenventrikel reicht bis zum Knochendefekt hin. Das ganze Ventrikelsystem nach rechts verzogen.

erscheinenden Abschnitte derselben, Umstechung des Herdes und Excision desselben in der angegebenen Ausdehnung; dabei wird der Ventrikel breit eröffnet, da die an der Dura anhaftende Schicht von Hirnmantelsubstanz sehr dünn ist. Deckung des Duradefektes aus der Fascia lata; Galeanaht. Hautnaht. Heilung per primam.

In den folgenden Tagen Temperaturen von $39-40^{\circ} \mathrm{C}$ (Ventrikel eröffnet), erst vom 17. 4. ab normale Temperaturen. Während dieser Zeit starke Vorwölbung an der Stelle der Operation, bedingt durch starke Liquorproduktion, wiederholte 
Punktionen und Extraktion von 40-50 ccm Liquor, derselbe ist anfangs xanthochrom, später klar, stets keimfrei. Hemiparese nicht verändert.

3. 5. 1929 auf Wunsch der Mutter entlassen. Keine Anfälle mehr, Status im übrigen unverändert. Weiterer Verlauf unbekannt.

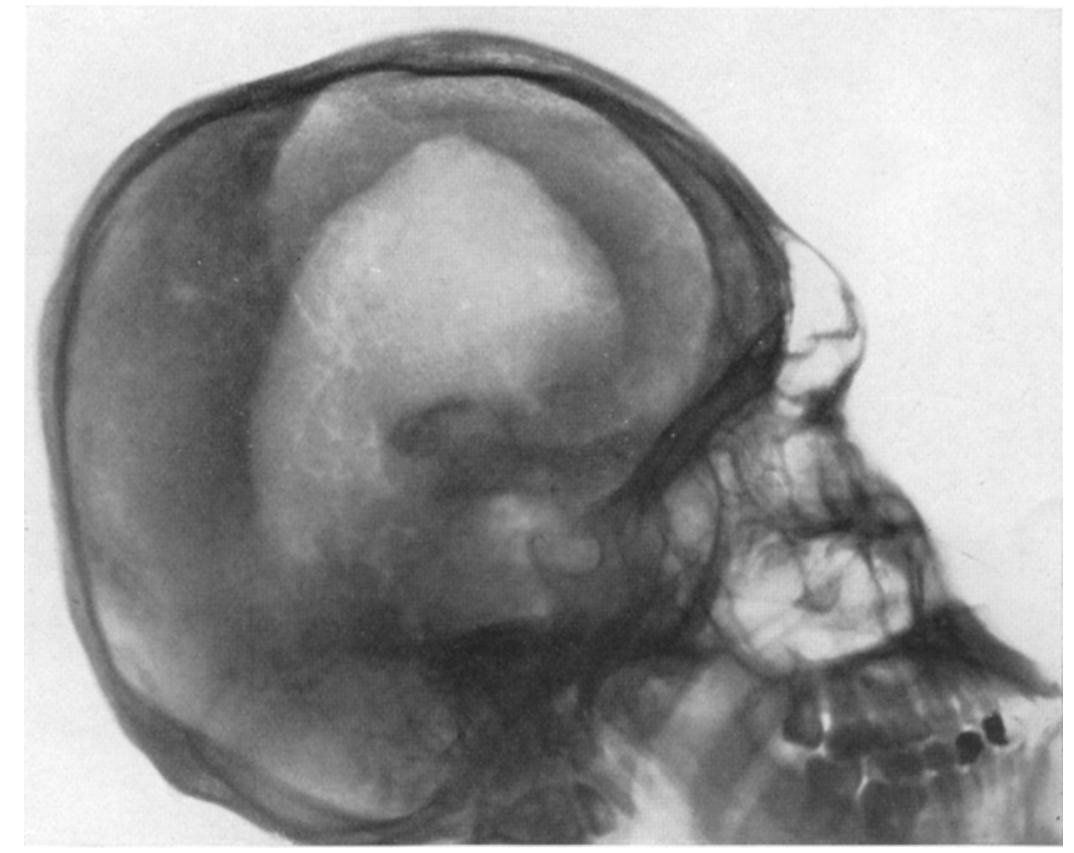

Abb. 48b. Encephalogramm von Fall 8. Seitenbild. Enorme Dilatation des rechten Seitenventrikels, dessen Dach spitz nach oben zu gegen den Knochendefekt zu ausgezogen ist.

Anatomischer Befund: Abb. 50 zeigt das exzidierte Dura-Hirnstück; der Durchmesser des Hirnstückes beträgt 4,5:6,0 cm, die Dicke variiert von $1,0-2,5 \mathrm{~cm}$. Dura verdickt; fest verwachsen mit der Hirnoberfläche.

Die mikroskopische Untersuchung zeigt, daß an zahlreichen Stellen dichte Bindegewebszüge von der Dura ins Gehirn eindringen. Zwischen Dura und Gehirn finden sich eigenartige Gebilde: Inseln und lange Röhren von Gehirngewebe, umgeben von kollagenen Bindegewebsscheiden (Abb. 51), welche wieder sehr den Faszikeln eines peripheren Nerven ähneln und welche bereits im Fall 7, der ebenfalls eine Geburtsschädigung des Gehirns betraf, beschrieben worden sind. Diese Röhren bestehen aus Gliagewebe, Astrocyten mit langen geschlängelten Fasern; die Astrocytenfortsätze enden vielfach an den kollagenen Fasern der Bindegewebsinvasionszone (Abb. 52), ähnlich wie die Astrocyten unterhalb der Pia im normalen Gehirn. Auch enden einzelne dieser Astrocytenfasern auf den Bindegewebsfasern der oben erwähnten bindegewebigen Scheiden der Bündel, aber weitaus die größte Mehrzahl der Astrocytenfasern verläuft parallel zur Längsrichtung der Gehirnröhren und nicht quer zu diesen.

In den tieferen Gehirnmassen schließt sich an die Bindegewebsinvasionszone eine markante Gliose an; auch bestehen einzelne Erweichungsherde, in denen Astrocyten mit sehr großen Zelleibern vorhanden sind. An manchen Stellen sind 
die Gefäße außerordentlich vermehrt, welche in die Gefäße der darüberliegenden Schichten übergehen.

Oligodendroglia ist in dem gesamten exzidierten Hirnstück schwer verändert; die Zellen zeigen zum Teil akute Schwellung und ihre Fortsätze sind fragmentiert

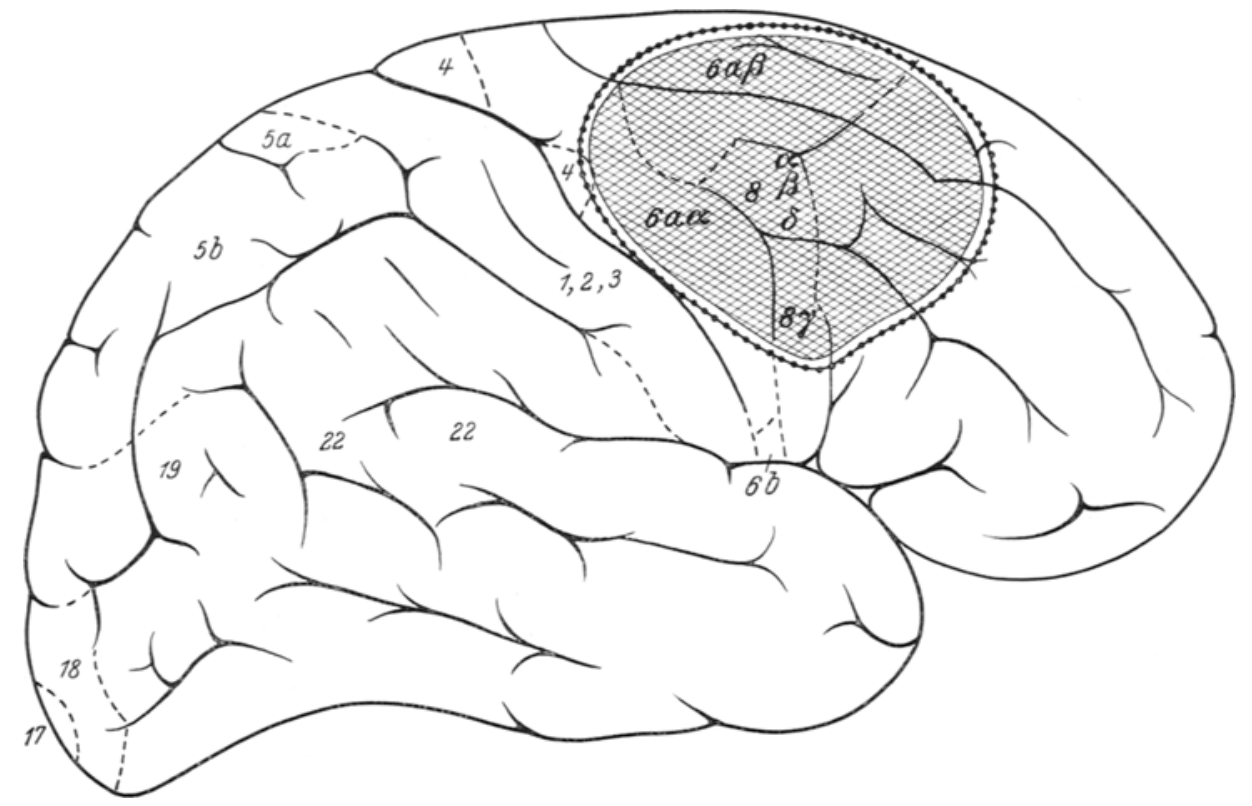

Abb. 49. Lage und Ausdehnung des Rindenherdes in Fall 8.

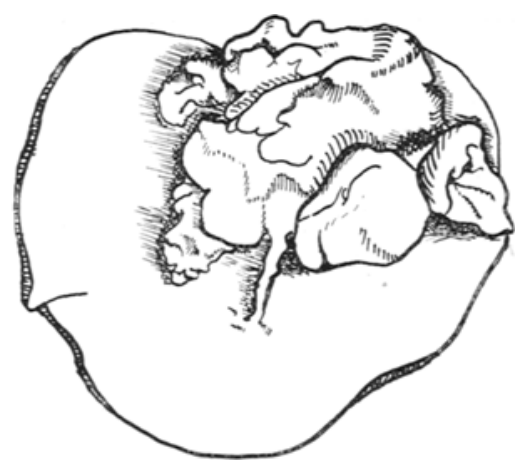

Abb. 50. Dura-Hirnexcisum von Fall 8; 4,5:6,0 $\mathrm{em}$ breit, 1,0-2,5 $\mathrm{cm}$ dick, von der Unterseite gesehen. Gehirnmasse an der verdickten Dura fest adhärent.

(Abb. 53). Derartige Veränderungen der Oligodendroglia werden bei Intoxikationszuständen und komatösen Zuständen beobachtet und sie sind von dem einen von uns (Penfield) auch in einem Gehirnexcisum eines Falles mit Status epilepticus gefunden worden. 
Zusammenfassung. Es handelt sich um einen Fall von schwerer traumatischer Geburtsschädigung der rechten Gehirnhemisphäre mit großem Knochendefekt; ein dreimarkstückgroßes Knochenfragment ist tief in das Gehirn hineingetrieben worden. Hemiparesis sinistra. Im

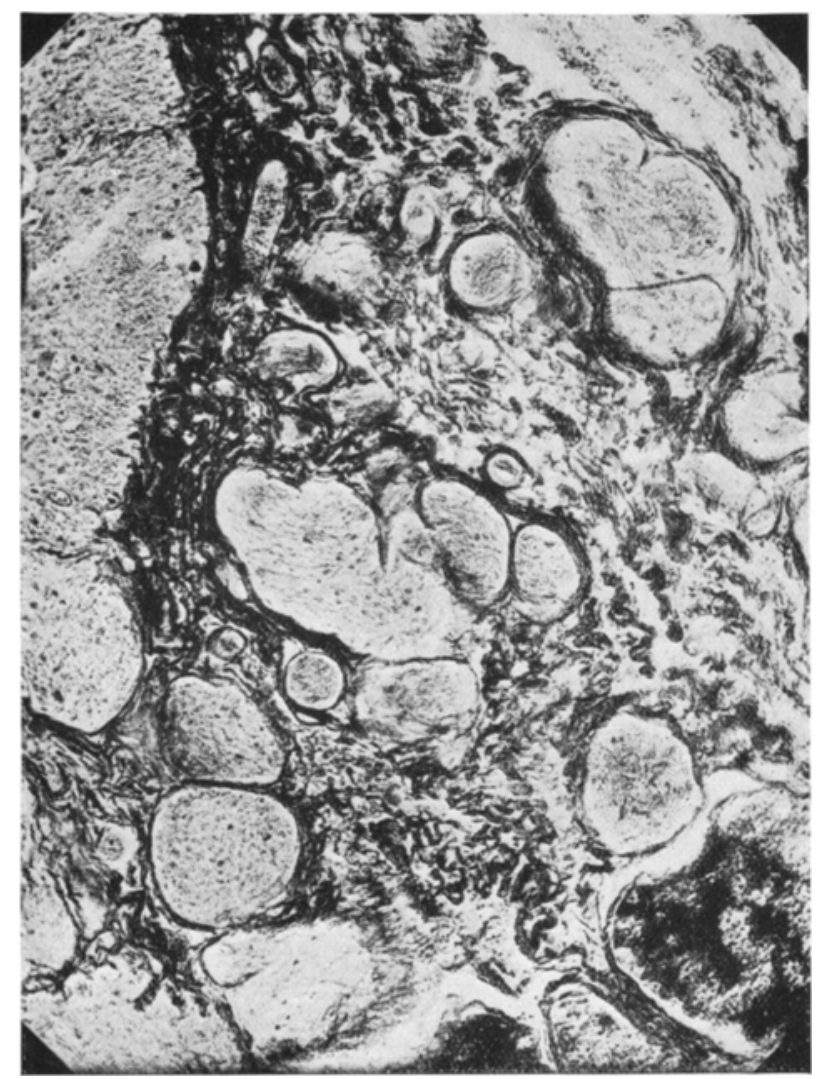

Abb. 51. Mikroskopisches Präparat des Gehirnexcisums von Fall 8 bei 125 facher Vergrößerung. Gliazylinder umgeben von Bindegewebsscheiden. Kollagene Fasern.

Alter von 9 Jahren erste epileptische Anfälle (Typus $6 \alpha \beta$ ). Im Alter von 10 Jahren operative Entfernung der eingesprengten Knochenfragmente; darauf epileptische Anfälle 7 Jahre lang beseitigt. Dann erneutes Auftreten derselben. Im Encephalogramm rechter Ventrikel bis dicht an den Defekt ausgezogen, das gesamte Ventrikelsystem nach rechts verzogen. Haut im Bereich des Knochendefektes mit der Dura fest verwachsen, diese ihrerseits mit der Hirnoberfläche fest verlötet. Beim Zug an der der Hirnoberfläche adhärenten Dura epileptischer Anfall. Excision des Durahirnstückes. Ventrikel breit eröffnet. In dem 


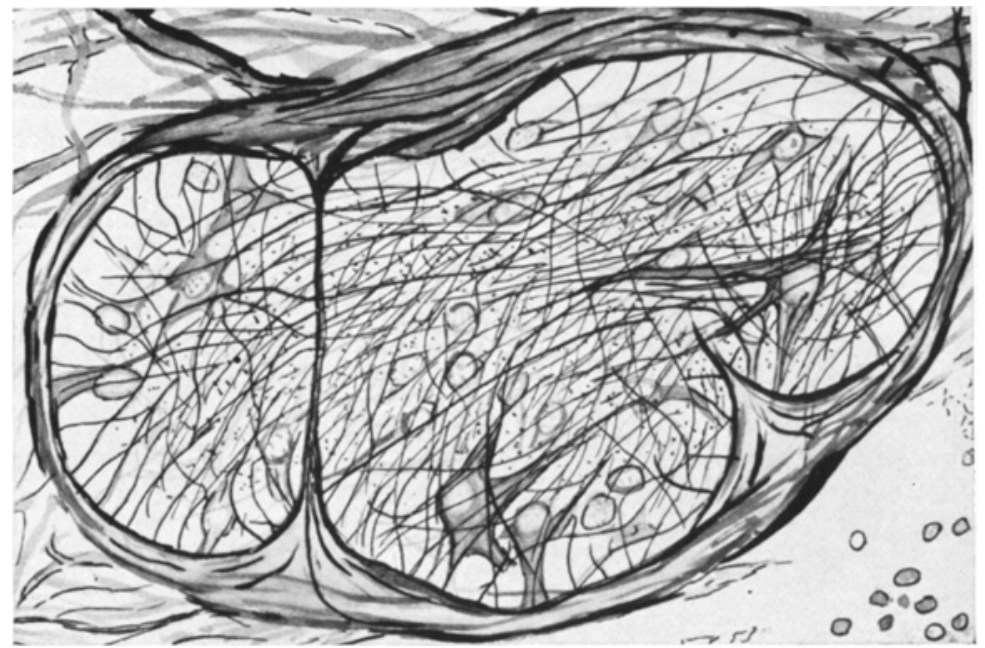

Abb. 52. Mikroskopisches l'räparat des Hirnexcisums von Fall 8 stellt einen der Gliazylinder (Abb 51) bei starker Vergrößerung dar; der Zylinder besteht aus einem dichten Netz von Gliafasern; einzelne Gliazellen inserieren mit einem Fuß an der umgebenden Bindegewebsscheide.

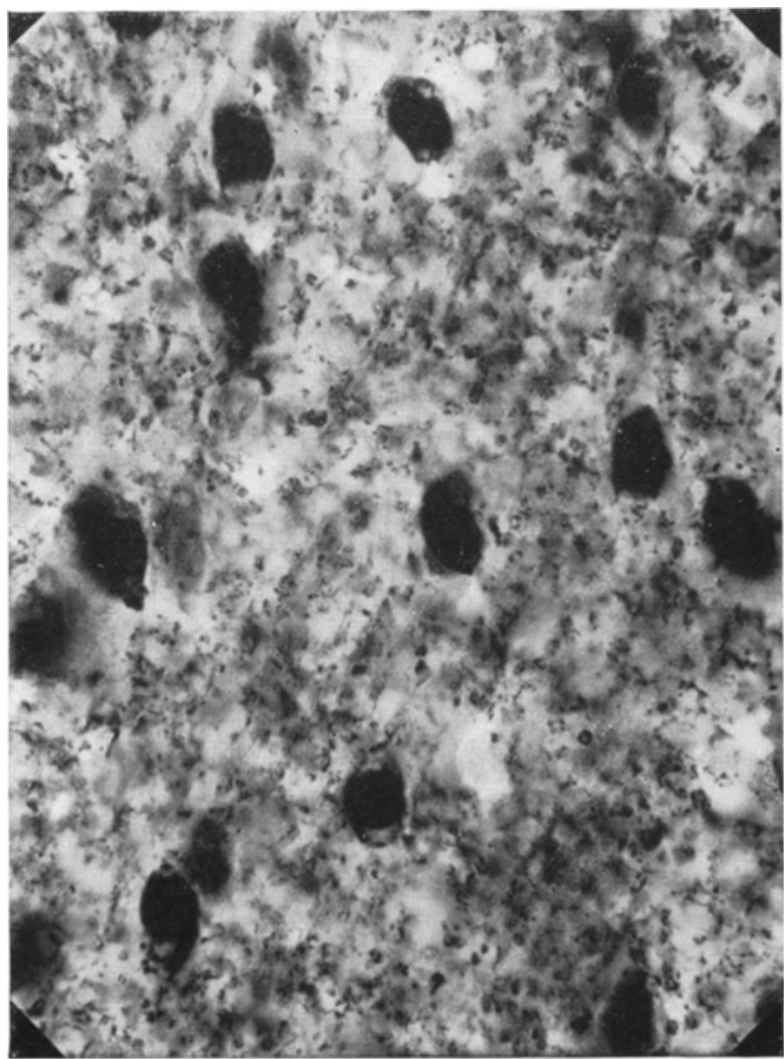

Abb. 53. Mikroskopisches Präparat des Hirnexcisums von Fall 8. Vergrößerung 600fach. Zeigt die akute Schwellung der Oligodendroglia mit Fragmentierung der Fortsä.tze. 
Excisum starke Bindegewebsinvasion von der Dura aus ins Gehirn, darunter starke Gliose. Außerdem Inseln und Röhren von gliösem Hirngewebe, von bindegewebigen Scheiden umgeben. Überall akute Schwellung der Oligodendroglia.

\section{Fall 9.}

W. L., 31 Jahre alt. Nov. 1914 Tangentialschuß am rechten Os occipitale, sofort bewußtlos, nachher mehrere Tage blind; dann allmähliche Besserung, seither besteht aber Hemianopsia sinistra. Sofort nach der Verwundung Debridement. Klagt seit der Verwundung über Kopfschmerz und Schwindel, zeitweilig Doppelsehen. Große Alkoholintoleranz, Abnahme des Gedächtnisses, starke Depression.

Januar 1926 erster epileptischer Anfall, allmähliche Häufung der Anfälle.

1917 luetische Infektion.

Mai 1926 Suicidversuch in einer Depression.

16. 11. 1926 aufgenommen. Am rechten Hinterkopf eine $8 \mathrm{~cm}$ lange, vertikal gestellte Narbe, Knochen fehlt darunter, Haut eingezogen im Bereich des Knochendefektes, an der Unterlage angewachsen. Keine Gehirnpulsation. Linksseitige Hemianopsie mit Aussparung der Maculahälfte. Liquordruck $150 \mathrm{~mm}$ im Liegen, Wa.R. +, starke Lymphocytose, organische Mastixzacke.

Encephalogramm (Abb. 54a u. b) zeigt auf der Aufnahme in antero-posteriorer Richtung, daß der rechte Seitenventrikel und mit ihm der dritte Ventrikel leicht nach rechts verzogen sind; nach außen vom rechten Seitenventrikel findet sich eine breite Luftmasse, welche einerseits mit dem rechten Seitenventrikel kommuniciert, andererseits nach außen bis an den Knochendefekt heranreicht. Auf der Seitenaufnahme sieht man, daß das Hinterhorn des rechten Seitenventrikels stark kolbig aufgetrieben ist, und daß sich an diese Auftreibung, von ihr durch eine Einschnürung abgesetzt, ein großer lufterfüllter Raum anschließt, welcher bis an den Defekt nach hinten heranreicht.

Charakter der Anfalle: Die Anfälle beginnen stets mit optischer Aura, Patient sieht Leuchtkugeln, alle möglichen Personen und Tiere von links her auf sich zukommen, dann folgt tonischer Blickkrampf nach links, danach Kopf- und Rumpfdrehung nach links, tonisch-klonischer Krampf der linken Extremitäten, generalisierte Krämpfe, tiefer Stertor, schwere Cyanose, Bewußtlosigkeit manchmal 1/2 Stunde und länger. Es handelt sich also um Anfälle, welche vom Felde 19 ihren Ausgang nehmen.

Wegen der vorhandenen Lues cerebrospinalis wird zunächst eine kombinierte Hg-Inunktionskur und endolumbale Salvarsanautoserumbehandlung eingeleitet. Keine Besserung. Da die Anfälle immer häufiger auftreten (mehrere an einem Tage und immer schwerer werden, wird die Operation beschlossen.

10. 1. 1927 Operation. Bildung eines Hautlappens um den vorhandenen Knochendefekt herum mit breiter Basis nach abwärts. Haut mit der Unterlage im Bereich des Knochendefektes fest verwachsen, Lösung sehr schwierig; Verbreiterung der Knochenbresche, bis etwas über den Sinus longitudinalis nach links und bis an den Sinus transversus nach abwärts. Zirkuläre Durchtrennung der Dura neben dem Sinus longitudinalis und transversus entlang, ferner breit nach oben und außen. Dura fest an der Außenfläche des Occipitallappens adhärent. Beim Anfassen derselben mit der Pinzette und Zurückschlagen entleert sich aus der Stelle der Verwachsung heraus reichlich Liquor. Gehirnsubstanz in der Umgebung der Verwachsung bräunlich verfärbt und schwammig, fast die gesamte Außenfläche des Occipitallappens erscheint verändert. Dagegen bietet die Innenfläche desselben, die Calcarinaumgebung, normalen Aspekt. Über die Ausdehnung des Herdes 
belehrt Abb. 55. Bei faradischer Reizung des Hinterhauptspoles sieht Patient eine belle Leuchtkugel, die gerade vor ihm still steht, bei Reizung an der Außenseite des Occipitallappens (Abb. 55, Feld 18) schlagen dem Patienten Flammen von links unten entgegen und bei Reizung einer Stelle dicht unterhalb der Incisura parieto-occipitalis (Abb. 55, Feld 19) sieht Patient Personen und

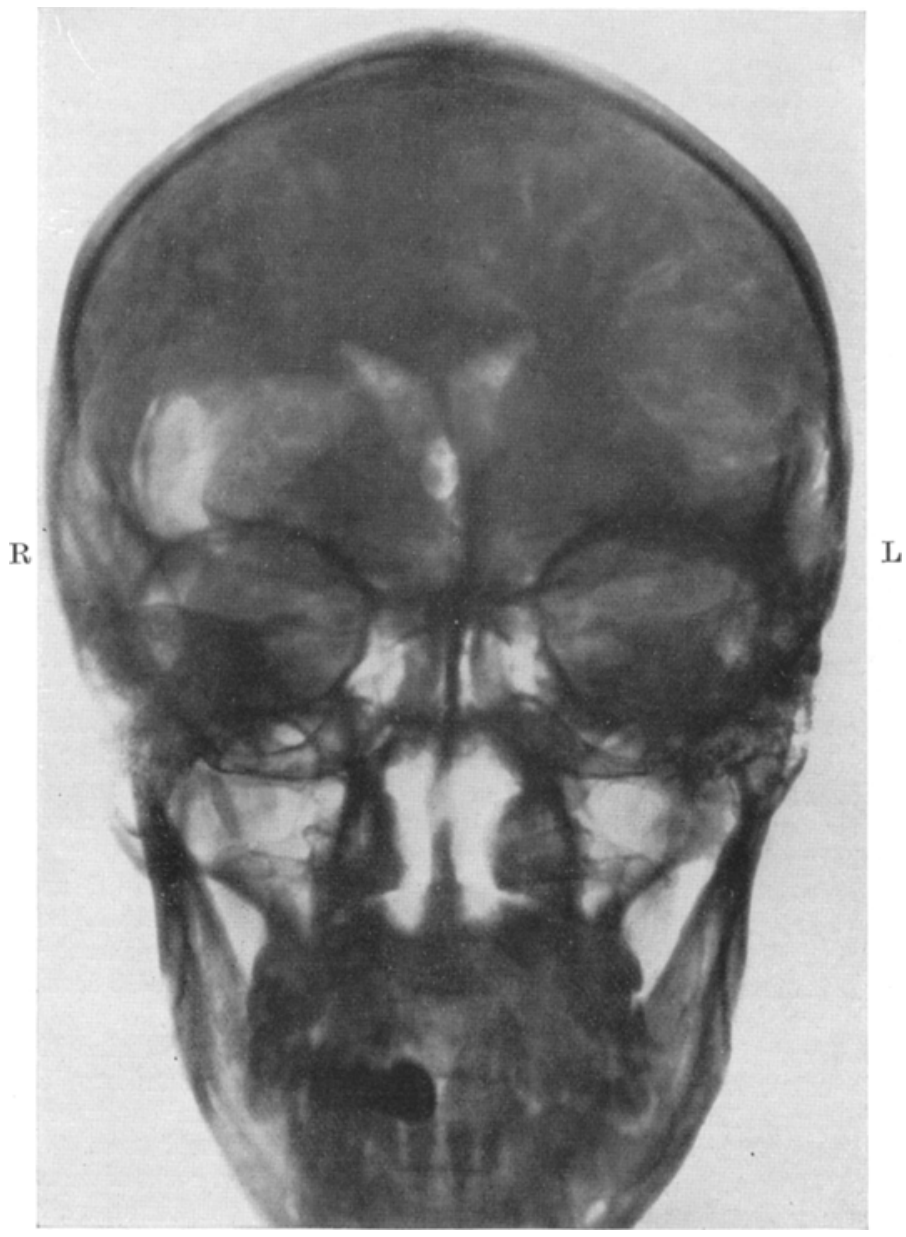

Abb. 54 a. Encophalogramm des Falles 9. Aufnahme in antero-posteriorer Richtung, Hinterhaupt auf Platte. Rechter Seitenventrikel und 3. Ventrikel dentlich nach reehts verzogen. Rechtes Hinterhorn bildet einen großen Luftraum, der bis zum Knochendefekt hinreicht.

Tiere von links auf sich zuspringen. Eine motorische Reaktion wurde nicht erzielt. Umstechung des Herdes, Excision desselben. Der Ventrikel (Hinterhorn) wird dabei breit eröffnet; es zeigt sich, daß das Hinterhorn bis dicht an den Herd heranreicht und daß die Ventrikelwand nur sehr dünn ist. An der Medialseite des eröffneten Ventrikels liegt der Calcar avis in vollkommener Ausdehnung zutage; 
derselbe erscheint bräunlich verfärbt. Der Plexus chorioideus ist im vorderen Bereiche des eröffneten Ventrikels sichtbar, seine Berührung mit der Pinzette löst heftigen rechtsseitigen Kopfschmerz aus. naht.

Deckung des bestehenden Duradefektes aus der Fascia lata. Galeanaht. Haut.

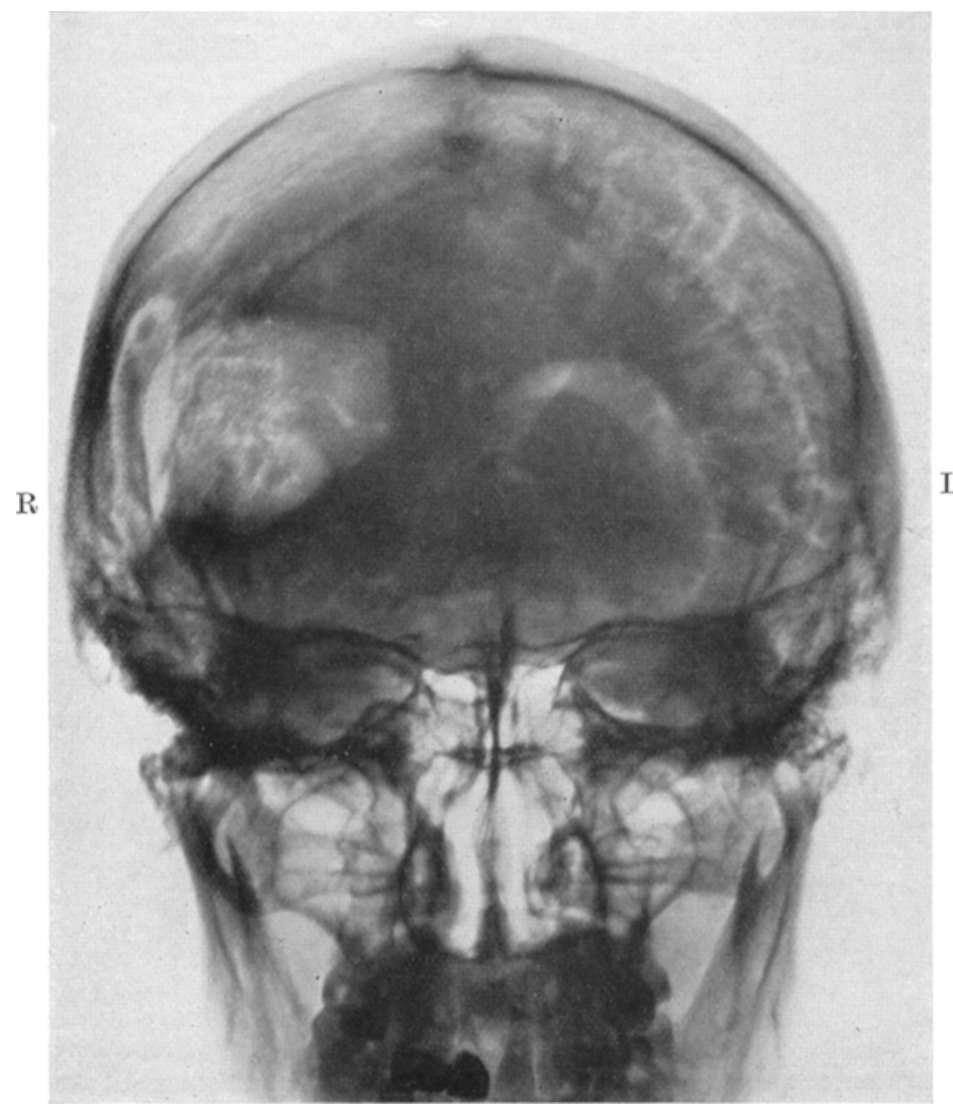

Abb. 54b. Encephalogramm des Falles 9. Aufnahme in postero-anteriorer Richtung. Rechtes Hinterhorn bildet einen großen Luftraum der bis zum Knochendefekt hinreicht.

Wundheilung erfolgt nicht ganz per primam, aus dem inneren unteren Wundwinkel entleert sich ständig etwas koaguliertes Blut. Am 28. 1. 1927 Temperaturanstieg über $39^{\circ} \mathrm{C}$, welcher andauert; daher am 5. 2. 1927 Wundrevision, Zurückklappen des Hautlappens. Ausgiebige Reinigung der gesamten Wundfläche mit Wasserstoffsuperoxyd. Implantierte Dura gut eingeheilt. Rückklappen des Hautlappens, Situationsnähte. Allmählicher Temperaturabfall, rasche Heilung der Wunde; es bleibt aber am unteren inneren Wundwinkel eine kleine Fistel, aus der sich ständig etwas rahmiges Sekret entleert; auf dem Grunde dieser Fistel rauher Knochen fühlbar. Eine erneute Wundrevision zum Zwecke der Entfernung des offenbar mortifizierten Knochens lehnt Patient ab. Anfang Februar Wiederaufnahme der $\mathrm{Hg}$ - und endolumbalen Salvarsanautoserumbehandlung. 
5. 9. 1927 entlassen.

Patient hat seit der Operation am 11. 8. einen Anfall gehabt. Seitens des übrigen Status ist zu bemerken, daß eine leichte Hemihypästhesie der ganzen linken Körperhälfte sowie eine geringe Ataxie des linken Armes besteht. Der linke Arm zeigt beim exterozeptiven Zeigeversuch deutlich nach rechts vorbei. Ferner besteht Nystagmus beim Blick nach links, noch stärker nach rechts. Rechte Pupille fast lichtstarr. Es ist schwer zu entscheiden, ob diese über den Status quo ante hinausgehenden Symptome die Folge des operativen Eingriffs (keine primäre

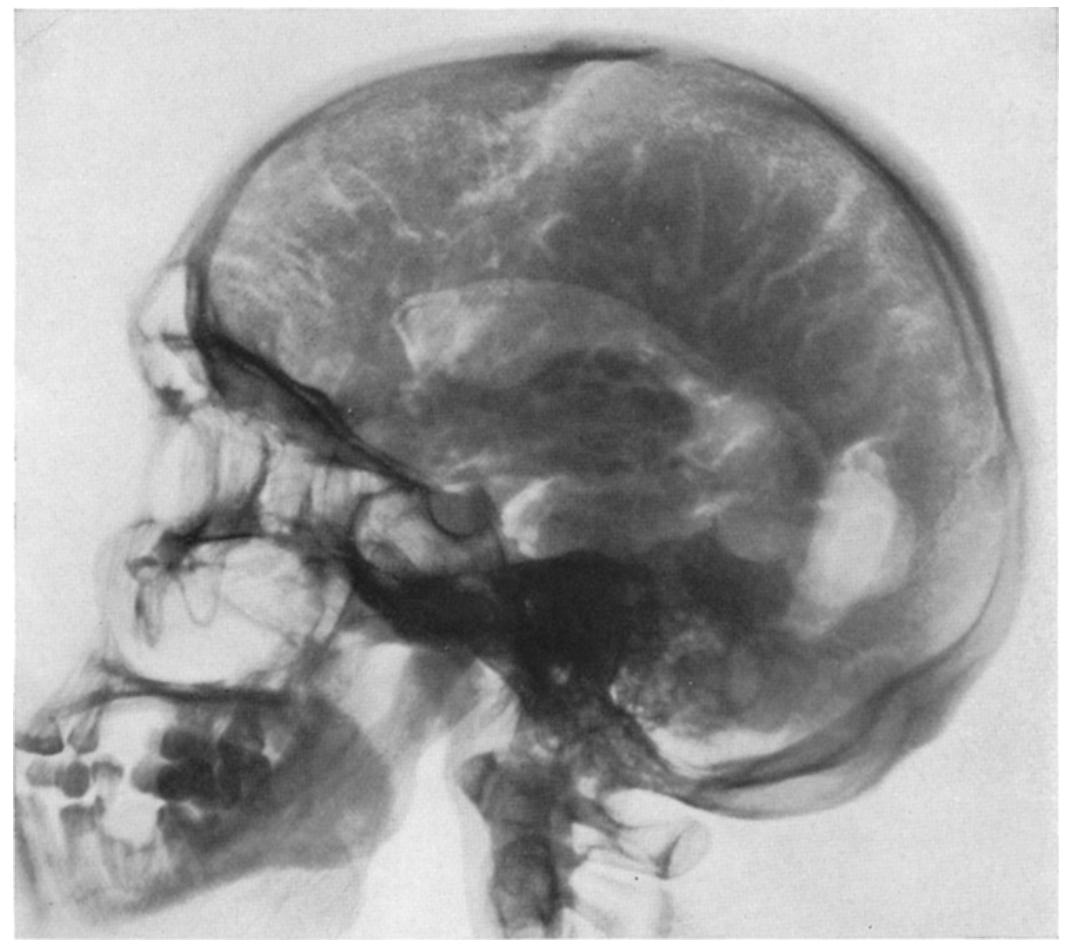

Abb. 54 c. Encephalogramm des Falles 9. Seitenansicht An das rechte Hinterhorn ist nach hinten zu eine große gekammerte Ventrikelaussackung angeschlossen, die bis zum Knochendefekt hinreicht.

Wundheilung) oder der gleichzeitig bestehenden Lues cerebri sind. Die Symptome haben sich erst allmählich entwickelt. Als direkte Folgen der Excision der Rinde an der Konvexität des Occipitallappens sind folgende Symptome hervorzuheben. Sofort nach der Operation fiel auf, daß der optomotorische Nystagmus beim Vorbeibewegen des Objektes von links nach rechts wesentlich schwächer ist als bei Bewegung der Objekte in umgekehrter Richtung. Diese Differenz hat mehrere Wochen bestanden, sich aber dann wieder ganz verloren. Ferner bestand einige Tage lang nach der Operation eine konjugierte Blickparese nach links (Excision des rechten Feldes 19), aber auch diese hat sich sehr rasch wieder ganz verloren. Der weitere Verlauf konnte nicht verfolgt werden.

Anatomischer Befund: Das exzidierte Dura-Hirnstück hat über Fünfmarkstückgröße. Das der Dura fest anhaftende Hirngewebe erscheint grau gelatinös. 
Die mikroskopische Untersuchung zeigt eine ausgesprochene Invasion von dichten Bindegewebsfaserzügen von der Dura ins Gehirn; diese dringen von außen strichweise in das Hirngewebe ein, welehes dadurch in zahlreiche aufwärts gerichtete zungenförmige Gebilde aufgeteilt erscheint. Das Hirngewebe besteht in den der Dura anliegenden Abschnitten aus Astrocyten mit zahlreichen langen geschlängelten Gliafasern, die alle parallel angeordnet sind, nach aufwärts den Bindegewebsfasern zustrebend. Beide Faserkategorien haben strikte dieselbe Richtung. In den darunter gelegenen Hirnabschnitten besteht reichliche Gliavermehrung und starke Gefäßneubildung.

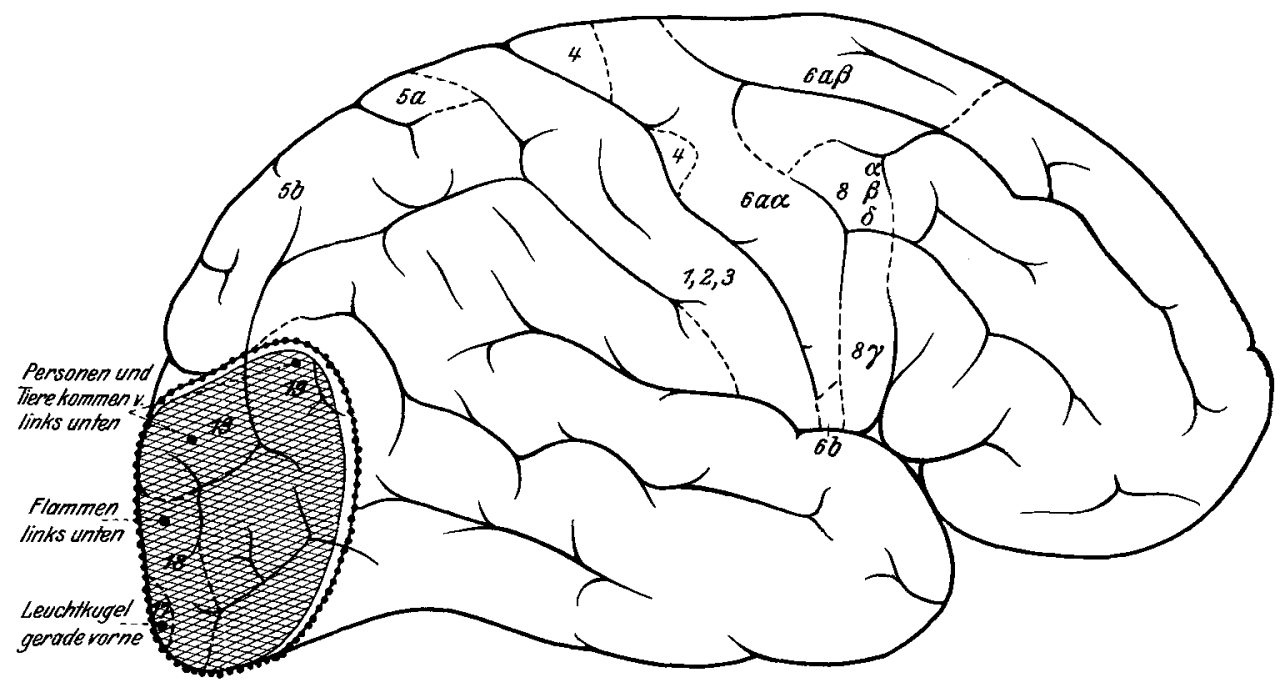

Abb. 55. Lage und Ausdehnung des Rindenherdes in Fall 9. \# Rindenherd, ........ Fxcisionslinie,... Stellen, bei deren faradischer Reizung Photome und optische Halluzinationen auftraten.

Zusammenfassung. Es handelt sich um eine Schußverletzung der rechten Occipitalregion mit linksseitiger Hemianopsie. 2 Jahre nach dem Trauma epileptische Anfälle (Typus Feld 19). Außerdem Lues cerebrospinalis. Knochendefekt, in dessen Bereich Haut, Dura und Hirnoberfläche fest verwachsen. Ventrikelsystem nach rechts verzogen, vor allem aber rechtes Hinterhorn mit einer großen cystenartigen Bucht bis an den Defekt heranreichend. Das exzidierte Durahirnstück zeigt breite parallel angeordnete Bindegewebsgliafaserzüge von der Dura bis an das Ventrikelependym heran.

\section{Fall 10.}

H. Sch., 14 Jahre alt. Vater luetisch infiziert, Mutter hatte mehrere Fehlgeburten, leidet an epileptischen Anfällen.

1920 stürzte Patient im Alter von 7 Jahren über das Treppengeländer des ersten Stockwerkes in den Keller, bewußtlos, Blutung aus Nase und Ohr, Brechen. Rechtsseitige Körperlähmung, Sprachlähmung. Allmählicher Rückgang aller dieser Erscheinungen.

Z. f. d. g. Neur. u. Psych. 125. 
1924 traten die ersten epileptischen Anfälle auf. Allmähliche Häufung derselben, in letzter Zeit jeden zweiten Tag ein oder mehrere Anfälle. Abnahme der geistigen Leistungsfähigkeit, kommt nicht mehr in der Schule fort.

21. 4. 1927 aufgenommen. Infantil-hypogenitaler Habitus. Kindliche Stimme, keine Pubes, Testes auffallend klein. Adipositas, Mammae.

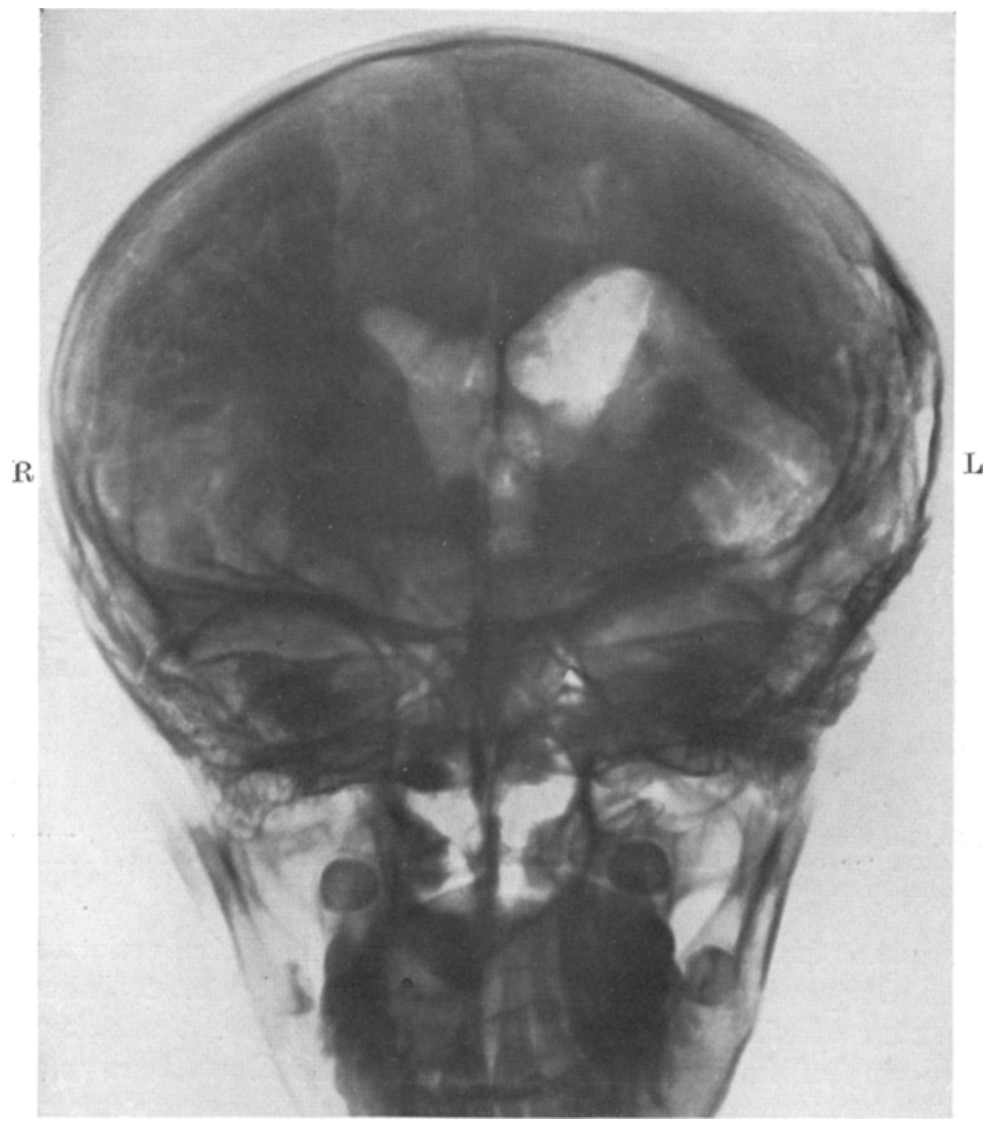

Abb. 56a. Encephalogramm des Falles 10. Aufnahme in antero-nosteriorer Richtung, Hinterhaupt auf Platte. Wrhebliche Dilatation beider Seitenventrikel und des 3.Ventrikels: vom linken Seitenventrikel, der viel stärker dilatiert ist als der rechte, ist auch das Hinterhorn und Unterhorn sichtbar; das ganze Ventrikelsystem ist nach links verzogen. Am linken Parietale ist die Fraktur erkennbar.

An der linken Schädelhälfte im Bereich des unteren Teiles des Scheitelbeines und des oberen Abschnittes der Schläfenbeinschuppe eine Narbe, welche mit dem darunter gelegenen, wulstig verdickten unebenen Knochen verwachsen ist.

Zunge weicht beim Vorstrecken eine Spur nach rechts ab, Gaumensegel, Gesichtsmuskulatur o. B. Am rechten Arm kein Zeichen einer Pyramidenbahnschädigung, keine Ataxie, kein Vorbeizeigen, nur bei feinen Fingerverrichtungen (Knöpfen, Schreiben), geringe Ungeschicklichkeit der rechten Hand, Handschrift ist nicht so gut wie sie es vor dem Unfall war, aber keinerlei Zeichen von Agraphie. Am rechten Arm leichte Dysdiadochokinesis im Vergleich zu links. 
Keine Einschränkung der Neigung und Drehung der Wirbelsäule nach rechts. Cutaner Bauchreflex und Cremasterreflex rechts gleich links.

Am rechten Bein ganz geringe Zeichen einer Pyramidenbahnschädigung (Babinski, Oppenheim, Mendel-Bechterew, Rossolimo +) aber keine Erhöhung der Dehnungsreflexe, keine Kloni, sehr geringfügige Steigerung des rechten Patellarund Achillesreflexes. Willkürliche Einzelbewegungen der einzelnen Abschnitte des

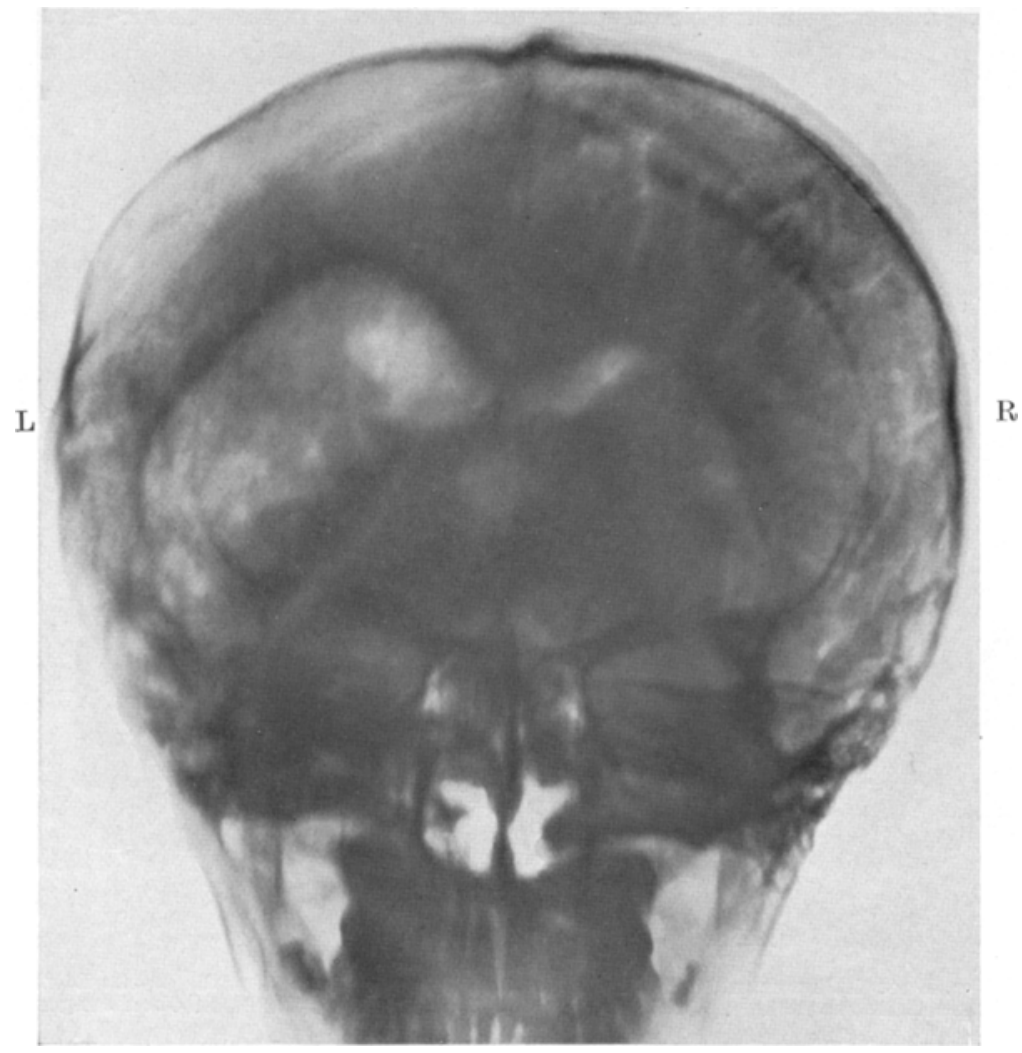

Abb. 56 b. Encephalogramm des Falles 10. Anfnahme in postero-anteriorer Richtung. Stirn auf PIatte. Zeigt die besonders starke Dilatation des linken Hinter- und Unterhorns. Das ganze Ventrikelsystem nach links verzogen.

rechten Beines vollkommen intakt; auch bei Widerstand keine Zeichen der Beuge- oder Strecksynergie. Keine Ataxie des rechten Beines. Bein wird beim Gange eine Spur geschleppt.

Keinerlei Störungen der Sensibilität an der rechten Körperhälfte, auch keine solchen des Raumsinns der Haut und der Fähigkeit, Gegenstände durch Tasten zu erkennen. Keine Apraxie, Sprache und Lesen intakt, ebenso Schreiben. Gesichtsfeld normal, Augenhintergrund normal.

Encephalographie (Abb. 56 a-c) zeigt eine riesige Erweiterung des linken Seitenventrikels sowohl auf der fronto-occipitalen wie auf der occipito-frontalen Aufnahme; auch der rechte Seitenventrikel und der dritte Ventrikel sind erweitert; 
das ganze Ventrikelsystem ist nach links verzogen. Auch auf der Seitenaufnahme erkennt man die starke Dilatation des linken Seitenventrikels; die Cella media erscheint auf dieser Seitenaufnahme deutlich nach oben ausgezogen.

Charakter der Anfälle: Sämtliche Anfälle, die bei dem Patienten beobachtet werden konnten, hatten denselben stereotypen Charakter: Kopf-Augen-Rumpfdrehung nach rechts, tonisch-klonischer Massenkrampf des rechten Armes und Beines, dann generalisierte Krämpfe, tiefe Bewußtlosigkeit. Wiederholt Urinabgang und Zungenbiß. Keine sensible oder optische Aura feststellbar. Aber fast

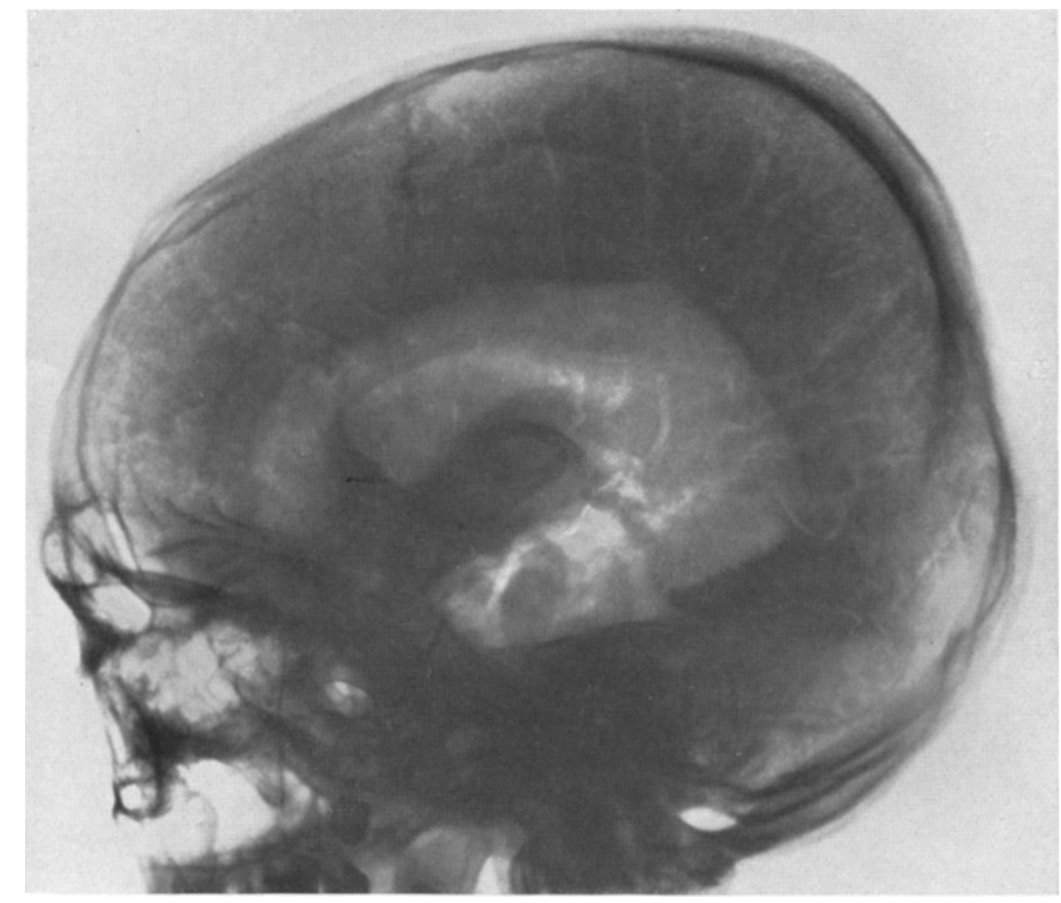

Abb. $56 \mathrm{c}$. Fncephalogramm des Falles 10. Seitenbild, zeigt besonders die starke Dilatation des linken Seitenventrikels. Das Dach der Cella media ist spitz nach oben ausgezogen.

vor jedem Anfall schreckt der Kranke stark auf. Es ist also nicht unwahrscheinlich, daß eine akustische Aura den Reigen eröffnet; sobald aber die motorische Entladung einsetzt, kann Patient nicht mehr sprechen und nach Ablauf des Anfalles ist er vollkommen amnestisch.

9. 5. 1927 Operation. Bildung eines großen Hautlappens um die Narbe herum, Basis abwärts gelegen. Lösung des Hautlappens von der Unterlage im Bereich der Narbe sehr schwierig, da hier eine feste Verwachsung besteht; im Knochen findet sich hier ein etwa $4 \mathrm{~cm}$ langer, $2 \mathrm{~cm}$ breiter rinnenförmiger Defekt. In breitem Umkreis um diesen Defekt herum wird der Knochen zirkulär durchtrennt und dann die ganze Platte abgehoben; dabei zeigt sich, daß der Knochen an den Rändern des Defektes mit der Dura fest verwachsen ist; diese Verwachsungen müssen mit dem Messer gelöst werden, dabei tritt ein epileptischer Anfall auf. Nach vollkommener Entfernung des Knochens sieht man, daß an der Stelle des knöchernen Defektes an der Hirnoberfläche die Dura fehlt, gelblich-bräunlich 
verfärbte schwammige Hirnmasse wölbt sich vor. Aus dieser blutet es ziemlich stark. Stillung der Blutung durch einige Ligaturen. Zurückklappen des Hautlappens, Galeanaht, Hautnaht.

10.5. 1927 Operation, 2. Akt. Nach Wiedereröffnung des Hautlappens zirkuläre Durchtrennung der Dura entsprechend der bestehenden breiten Trepanationsöffnung. Die Dura ist an der Hirnoberfläche rings um den bereits vorerwähnten Kontusionsherd herum fest angewachsen. In der Umgebung der Verwachsungsstelle erscheint die Gehirnsubstanz schwer verändert; Lage und Ausdehnung des Herdes in Abb. 57 wiedergegeben. Bestimmung der Foki des Vorderarms, der Hand, der Finger, des Daumens, der Halsmuskeln, des oberen und unteren Facialis und

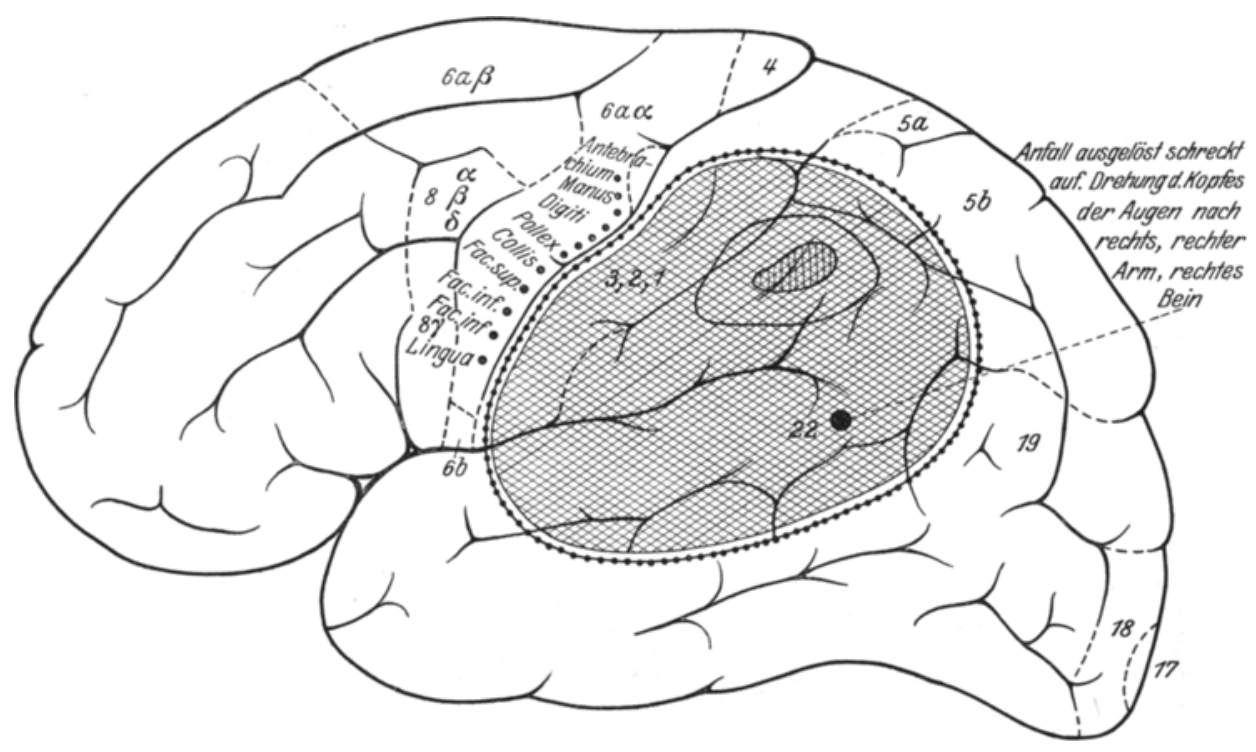

Abb. 57. Lage und Ausdehnung des Rindenherdes von Fall 10. \# Rindenherd, ........ Excisionslinie, die bei den im Bereiche des unteren Scheitellappens befindlichen konzentrischen Kreise markieren die Stelle der Adhäsion zwischen Dura und Hirnoberfläche, ... Foki der vorderen Zentralwindung, von welchen aus durch KSR. Effekte erzielt wurden, Stelle, von der aus ein epileptischer Krampfanfall ausgelöst wurde.

der Zunge in der vorderen Zentralwindung (3 MA KSR.). Diese Foki liegen dicht vor dem vorderen Rande des Hirnherdes. Die hintere Zentralwindung ist elektrisch unerregbar, sie bildet den vorderen Abschnitt des Destruktionsherdes; dieser umfaßt außerdem den Hauptabschnitt des unteren Scheitellappens und den größten Teil der ersten Schläfewindung sowie Teile der zweiten Temporalis. Die Fossa Sylvii ist stark eingezogen. Vom hinteren Teil des Herdes im Bereich der ersten Schläfewindung wird durch faradische Reizung ein epileptischer Anfall ausgelöst, der genau dasselbe Gepräge hat wie die sonst bei dem Kranken beobachteten Anfälle, beginnend mit einem starken schreckerfüllten Aufschrei. Danach Umstechung des Herdes in der in Abb. 57 angegebenen Ausdehnung und Excision. Dabei wird der Ventrikel (Cella media und Unterhorn) eröffnet; in der Gegend der Fossa Sylvii ist die exzidierte Hirnsubstanz dick und sehr derb, an den peripheren Teilen des Excisums zum Teil sehr dünn. Der Ventrikel reicht hier fast bis an die Hirnoberfläche heran. 
Deckung des Duradefektes aus der Fascia lata. Galeanaht. Hautnaht. Heilung per primam. Am folgenden Tage Temperatur 39,5 (Ventrikel breit eröffnet). Die hohen Temperaturen halten bis zum 29. 5. an; dann allmählicher Abfall, aber erst Anfang Juli normale Temperaturen.

In den ersten Tagen nach der Operation ausgesprochene Ataxie des rechten Armes, welche sich aber rasch zurückbildet. Rechtsseitige Hemianopsie ohne Aussparung der Macula (vorderer Teil der Sehstrahlung durch die Excision mitgetroffen);

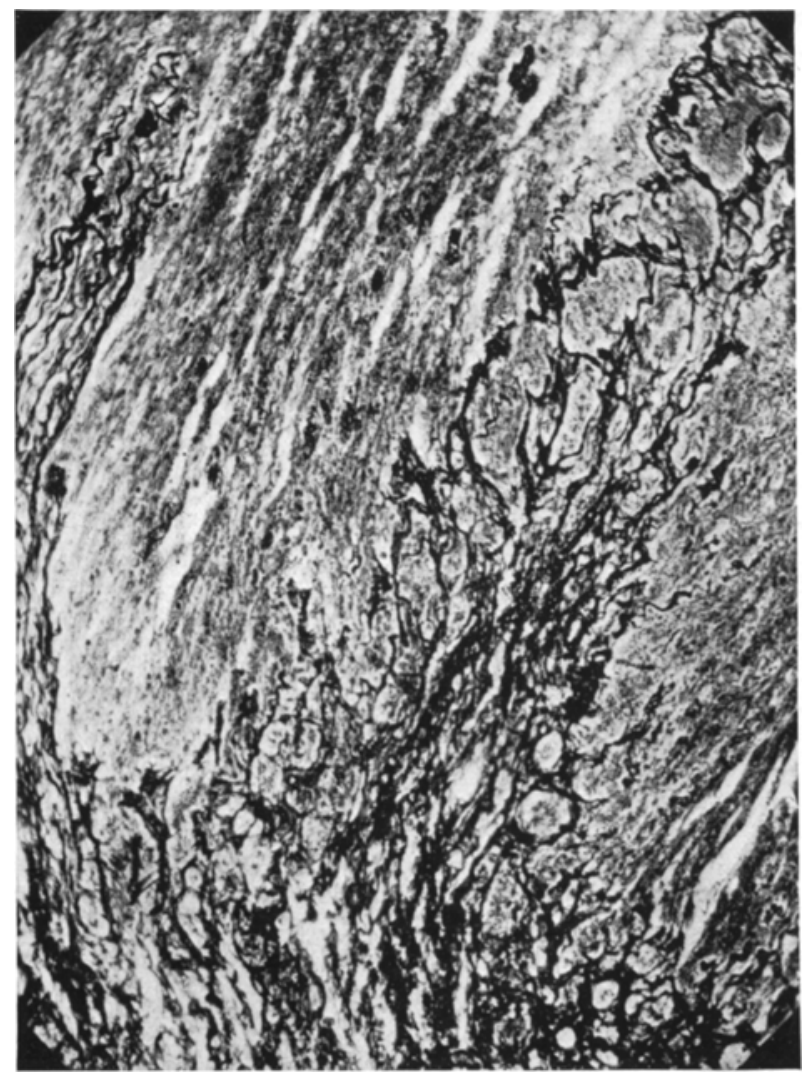

Abb. 58. Mikroskopisches Präparat des Gehirnexcisums von Fall 10 bei 125 facher Vergrößerung. Invasion des Gehirngewebes mit kollagenen Bindegewebsfasern, ausgehend von der auf der Hirnoberflache befindlichen Bindegewebsnarbe.

später engt sich die Hemianopsie ein und betrifft nur die unteren Quadranten; es ist also nur der obere Teil der Sehmarklamelle definitiv zerstört. Macula ausgespart. Anfangs etwas verlangsamtes Erkennen beim Betasten von Gegenständen mit der rechten Hand; doch verliert sich auch diese Störung bald wieder ganz. Sprache, Lesen, Schreiben Status quo ante. Keine Apraxie.

2. 7. 1927 entlassen. Anfälle sind nicht mehr aufgetreten. Laufend beobachtet bis Dezember 1929. Patient ist im Beruf täuig (Schuhmacher).

Anatomischer Befund: Es liegen zwei Blöcke von Hirnsubstanz vor, der größere hat einen Durchmesser von 5,0:4,5 cm und eine Dicke von 1,5 cm. Das Hirnstück 
ist sehr derb und grau-braun verfärbt. Die Blöcke sind von der Dura, an welcher die exzidierte Hirnmasse adhärierte, abgelöst.

Die mikroskopische Untersuchung lehrt, daß zahlreiche Gefäße und breite Bindegewebsżüge von der Oberfläche in das Gehirn eindringen, an diese mesodermale Invasionszone schließt sich eine Zone fibröser Glia an, in welcher lange dünne, durchweg parallel gerichtete Fasern vorhanden sind, welche dieselbe Richtung wie die Bindegewebsfasern in der außerhalb gelegenen mesodermalen Invasionszone aufweisen. An der Übergangsstelle wechseln Bindegewebsfaserzüge und Gliafaserzüge miteinander ab, sie schieben sich innig ineinander (Abb. 58).

Zusammenfassung. Es handelt sich um einen Fall einer bei einem Knaben im Alter von 7 Jahren entstandenen traumatischen Hirnschädigung mit sehr geringen definitiven klinischen Ausfallserscheinungen. Trotz ausgedehnter Zerstörung der linken Retrozentral-Parietal, und Temporalregion bestehen keine Sensibilitätsstörungen, keine Aphasie, keine Apraxie, keine Lese- und Schreibstörungen. Epileptische Anfälle 4 Jahre nach dem Trauma. Rinnenförmiger Knochendefekt, Haut, Dura und Hirn in dessem Bereich fest verwachsen. Ventrikelsystem nach links verzogen, enorme Dilatation und Verziehung des linken Ventrikels nach dem Defekt zu. Bei der Operation Excision einer sehr großen Durahirnnarbe. Ventrikel breit eröffnet. Das Excisum zeigt die typischen parallel gerichteten von der Stelle der Verwachsung in die Tiefe des Gehirns eindringenden Bindegewebsgliafaserzüge.

\section{Fall 11.}

F. L., 31 Jahre alt. Jan. 1914 Tangentialschuß an der rechten Kopfhälfte, nicht bewußtlos, keine Lähmungserscheinungen. Großer Knochendefekt am Stirnbein. Wunde eitert lange. 1915 Deckung des Knochendefektes durch Tibiaspan.

1928 erster epileptischer Anfall; in demselben Jahre 2 weitere Anfälle. Seit 1925 starke Häufung der Anfälle, in letzter Zeit fast täglich schwere Anfälle. Seit 1918 häufig heftige Kopfschmerzen und leichte Schwindelerscheinungen; zunehmend reizbar und vergeßlich.

11. 11. 1925 aufgenommen. Am Übergang des rechten Stimbeins zum Scheitelbein Haut stark narbig verändert, mit dem darunter befindlichen Knochen fest verwachsen. Knochen in dieser Gegend stark uneben. Keine Lähmungserscheinungen, keine Sensibilitätsstörungen, keine Reflexstörungen. Stützreaktionen nicht untersucht. Beim exzeroceptiven Zeigeversuch Tendenz nach links vorbei- zuzeigen, mit dem rechten Arm mehr als mit dem linken. Beim Stehen mit gerade vorgestreckten Armen bei Augenschluß Drehung des Rumpfes und der Arme nach rechts; dabei auch wiederholt Fallneigung nach rechts hinten. Sinnesorgane o. B. Augenhintergrund normal.

Charakter der Anfälle: Typische frontale Adversivfeldanfälle (Feld 6a $\beta$ ): Keine Aura, Drehung der Augen und des Kopfes nach links, Rumpfdrehung nach links, tonisch-klonischer Krampf des linken Armes und Beines; der linke Arm wird unter Außenrotation stark erhoben, der Vorderarm gebeugt, die Hand proniert, die Finger und der Daumen werden stark extendiert und gespreizt; das Bein wird stark extendiert und adduziert, der FuB unter starker Supination plantarflektiert; auf der Höhe des Anfalls Beteiligung der rechten Extremitäten. Gegen Ende des Anfalls kommt es zu alternierenden Beuge- und Streckstößen des linken Armes und Beines; die Beugebewegung des Armes verläuft wie oben geschildert, der 
Streckstoß besteht in energischer Adduction des Oberarmes, Streckung des Vorderarmes, wobei die pronierte Hand meist zur Faust geballt wird. Am Bein verläuft die Beugung synchron im Hüft-, Knie- und Fußgelenk, der Oberschenkel wird

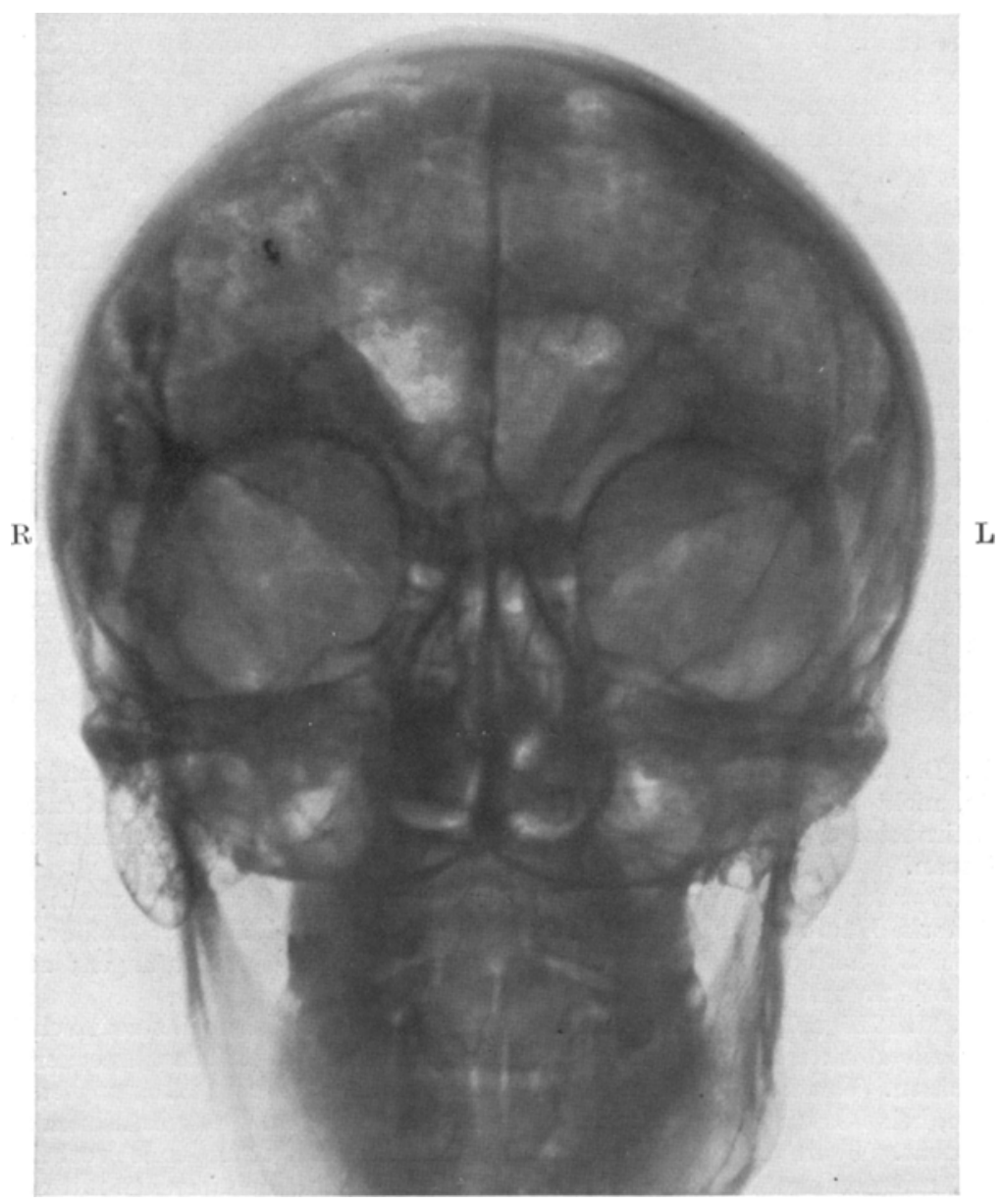

Abb. 59a. Fncephalogramm des Falles 11. Aufnahme in antero-posteriorer Richtung. Hinterhaupt auf Platte. Starke Dilatation beider Seitenventrikel und des 3. Ventrikels. Rechter Seitenventrikel stärker dilatiert als linker, deutlich zum Knochendefekt hin ausgezogen; an ihm angeschlossen eine bis zum Defekt hinreichende cystische Kammer. Das ganze Ventrikelsystem nach rechts verzogen, dicht unter dem Defekt ein Corpus alienum.

dabei stark abduziert und außenrotiert, der Fuß stark supiniert, die Zehen dorsalflektiert; der Streckstoß des Beines verläuft wie oben zu Beginn des Anfalls geschildert. Nach dem Anfall lange Bewußtlosigkeit, danach sehr heftige Kopfschmerzen.

Encephalographie (Abb. 59 a u. b). Die Aufnahme in antero-posteriorer Richtung zeigt eine starke Dilatation beider Seitenventrikel, der rechte ist erheblich 
mehr dilatiert und nach oben außen gegen den Knochendefekt zu ausgezogen. Dritter Ventrikel nach rechts verzogen. Unterhalb des Knochendefektes Metallsplitter. Auf der Seitenaufnahme erscheint der knöcherne Defekt sehr deutlich, in dessen Bereich mehrere Splitter. Der rechte Ventrikel mehr dilatiert als der linke. Das Dach beider gegen den Knochendefekt zu ausgezogen.

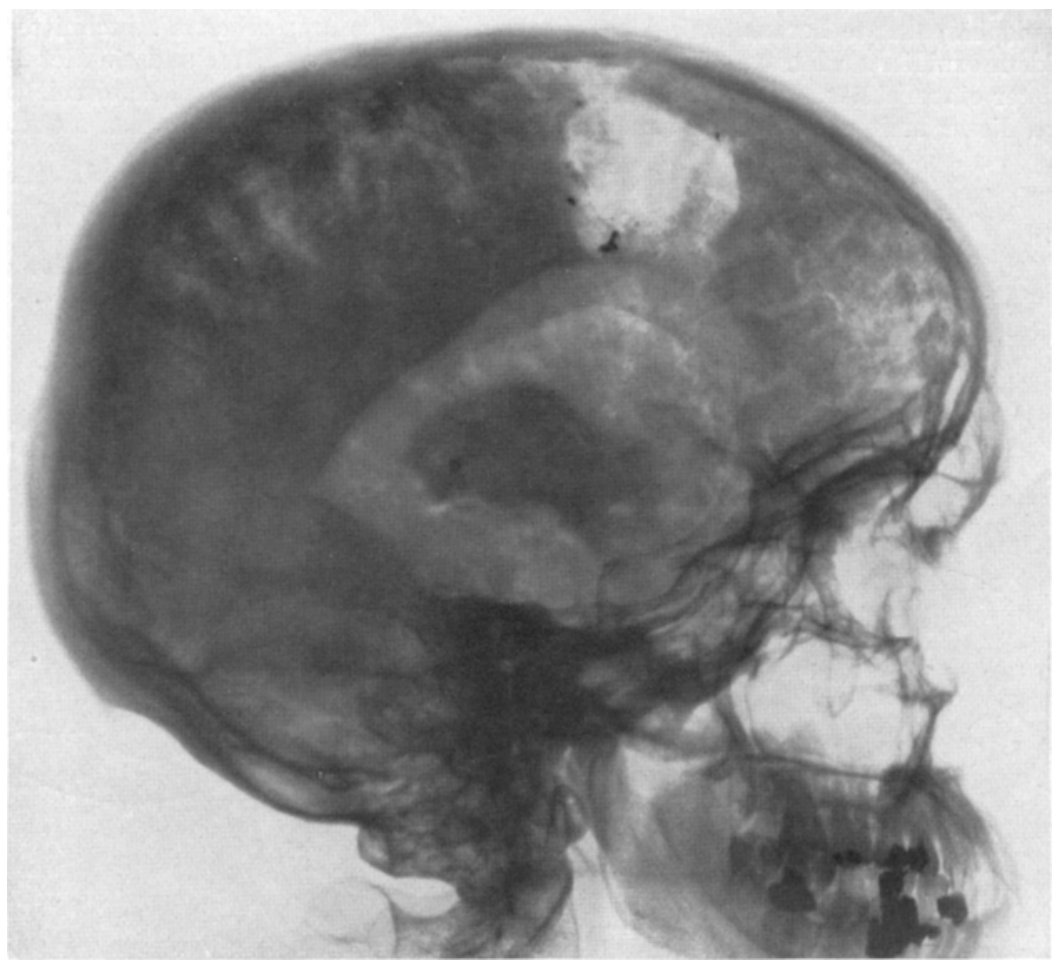

Abb. 59 b. Encephalogramm des Falles 11. Seitenbild. Beide Ventrikel dilatiert, der rechte mehr wie der linke. Das Dach des Vorderhorns deutlich nach dem Knochendefekt zu ausgezogen. Im Bereich des Defektes mehrere Corpora aliena.

26. 11. 1925 Operation. Bildung eines Hautlappens mit temporaler Basis, die Sagittalnaht nach links überschreitend, Hautlappen schwer von der Unterlage abpräparierbar. Im Stirnbein ein fünfmarkstückgroßer Knochendefekt, in dessen Mitte das eingesetzte, den Defekt aber nicht ausfüllende Knochenstück mit der Dura fest verwachsen ist. Sorgfältiges Herauspräparieren des Knochenimplantats und Erweiterung der Knochenbresche. Im Zentrum derselben ist die Dura fest mit dem darunter liegenden Gehirn verwachsen. Zirkuläre Durchtrennung der Dura um die Stelle der Adhäsion herum; auch nach dieser Prozedur blutet es noch erheblich aus der Verwachsungsstelle zwischen Dura und Hirnoberfläche nach außen heraus. An der Stelle der Verwachsung und in ihrer Umgebung Gehirnsubstanz teils sehr verhärtet, teils bräunlich verfärbt und erweicht. Beim Ablösen der Dura bis an die Stelle der unlösbaren Verwachsung heran, entleert sich eine pflaumengroße oberflächliche Cyste. Lage und Ausdehnung des. Hirnherdes ist in Abb. 60 dargestellt. Bestimmung der Foki der Hand, der Finger, des Daumens, des Platysmas und Sternocleidomastoideus, des oberen und unteren Facialis und der Zunge in 
der vorderen Zentralwindung (KSR. 2,0 MA). Bei Kathodenschlußdauerreizung mit $6 \mathrm{MA}$ tritt von dem in der Abb. 60 markierten Punkte innerhalb des Feldes $6 \alpha \beta$ ein typischer epileptischer Anfall auf, genau wie früher geschildert. Schon vorher war beim Ziehen mit der Pinzette an der circumcidierten Dura ein gleicher epileptischer Anfall aufgetreten. Umstechung der narbig veränderten Hirnpartie sowie des angrenzenden, intakt erscheinenden Teiles des Feldes $6 \alpha \beta$ bis über die obere Hemisphärenkante heraus (vgl. Abb. 60). Excision des umstochenen Abschnittes. In dem exzidierten Hirnstück finden sich mehrere Knochensplitter und ein Metallsplitter eingebetttet. Durch die Excision, welche bis in den Ventrikel hereinreicht, wird dieser breit eröffnet, Schwanzkernkopf, Plexus chorioideus, Foramen Monroi

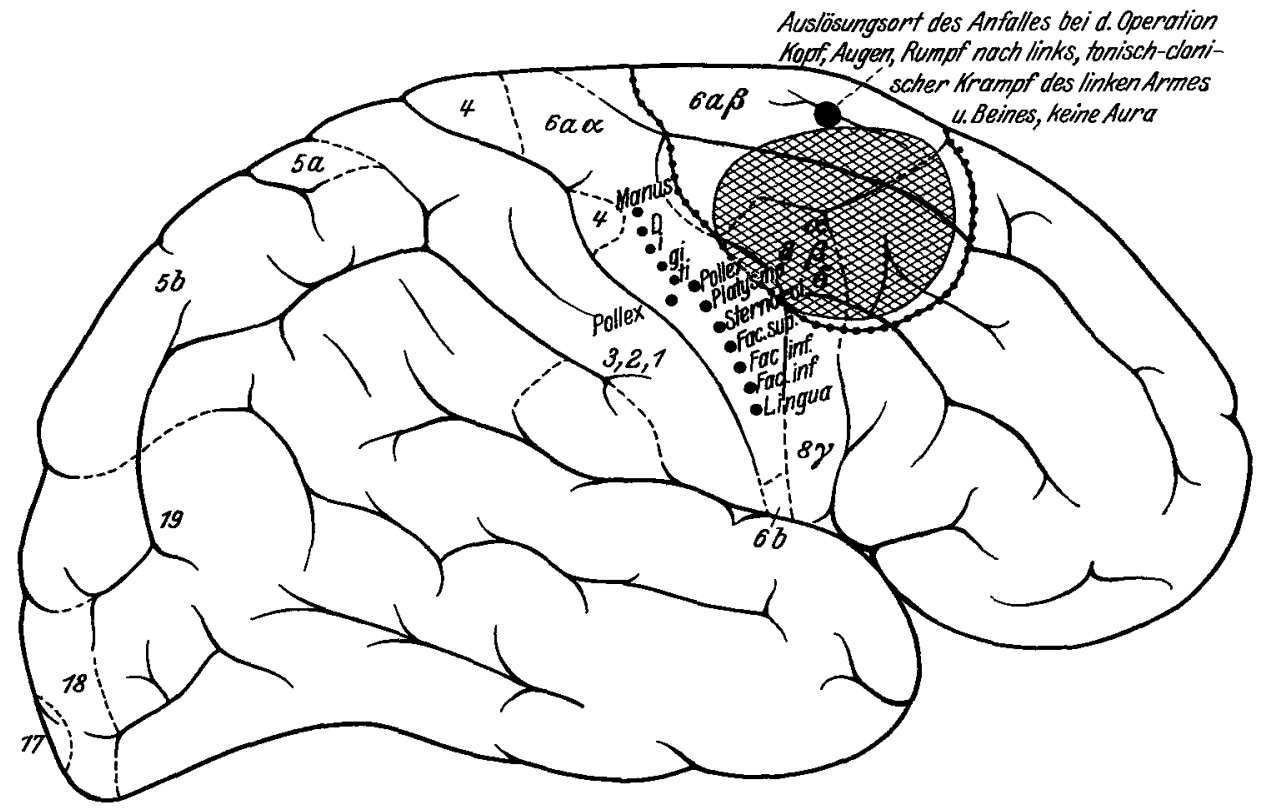

Abb. 60. Lage und Ausdehnung des Rindenherdes in Fall 11. \# Rindenherd, ........ Excisionslinie, . . Foki im Bereiche der vorderen Zentralwindung, welehe durch KSR. erregt wurden, Stelle, von der aus bei der Operation ein epileptischer Krampfanfall ausgelöst werden konnte.

ausgezeichnet sichtbar. Bei Berührung des Plexus mit der Pinzette heftiger rechtsseitiger Kopfschmerz. Nach sorgfältiger Blutstillung Deckung des Duradefektes mittels Lappens aus der Fascia lata. Galeanaht. Hautnaht. Heilung per primam.

Vom 29. 11 bis 3. 12. Temperaturen bis $39^{\circ} \mathrm{C}$ und darüber (Ventrikel breit eröffnet), dabei subjektiv vollkommenes Wohlbefinden. Vorübergehend beginnende Neuritis optica. Vom 4.-5. 12. Temperatur $38^{\circ} \mathrm{C}$, vom 6. 12. ab normal. Neuritis optica wieder ganz geschwunden. In der Folge ausgezeichnetes Wohlbefinden.

20. 3. 1926 entlassen. Keine Anfälle seit der Operation. Auch das vorher festgestellte Abweichen der Arme nach links beim exterozeptiven Zeigeversuch und beim Stehen mit gerade vorgestreckten Armen ist verschwunden. 3 Jahre lang war Patient völlig anfallsfrei. Sommer 1929 sind vereinzelte, aber sehr leichte Anfälle von Bewußtlosigkeit ohne Krampfentladung aufgetreten. Patient übt seinen Beruf als Gärtner aus. 
Anatomischer Befund: Das ausgeschnittene Dura-Hirnstück hat reichlich Fünfmarkstückgröße. Gehirn haftet der Dura an. Zwischen beiden stellenweise graue gelatinöse Massen, in diese Knochen- und Metallsplitter eingebettet.

Die mikroskopische Untersuchung zeigt zahlreiche, parallel angeordnete Bindegewebsfasern von der Oberfläche in das Hirngewebe eindringend und an diese

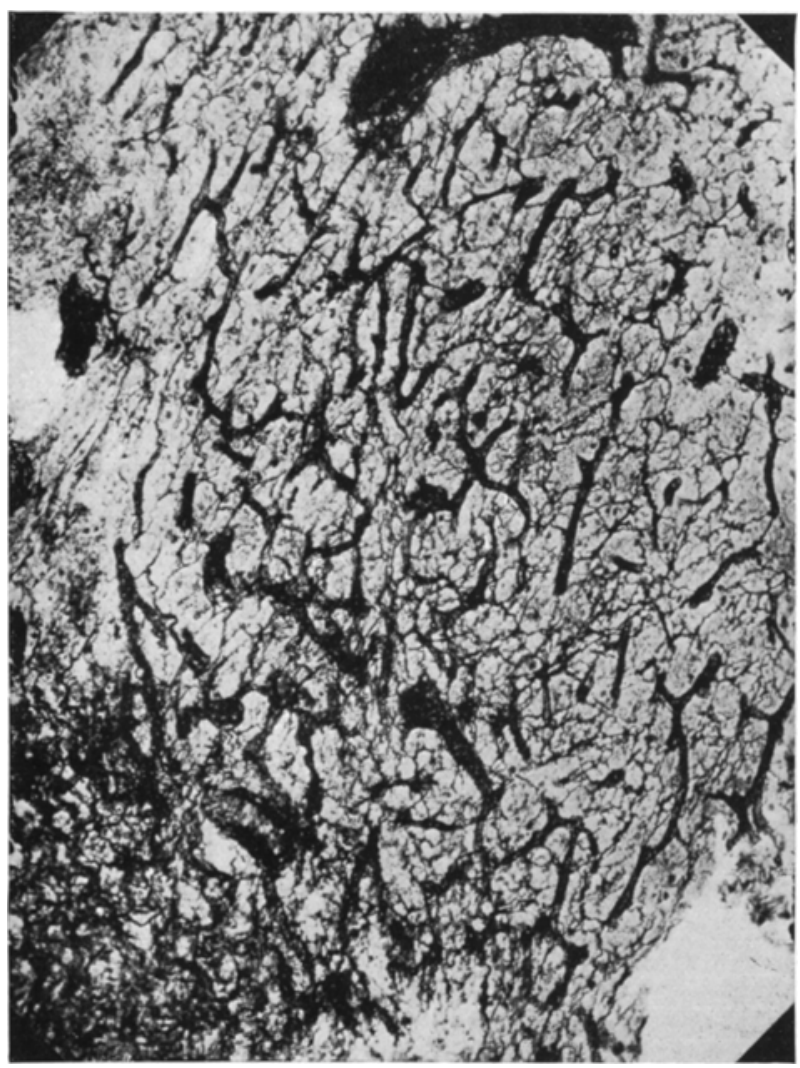

Abb. 61. Mikroskopisches Prăparat des Gehirnexcisums ron Fall 11 bei 125 facher Vergrößerung. Gefäßplexus in das Hirngewebe eindringend untermischt mit zahlreichen kollagenen Bindegewebsfaserbündeln.

anschließend und teilweise mit ihnen alternierend parallele, in der gleichen Richtung angeordnete Gliafaserzüge. Zwischendurch reichlich Gefäße. Stellenweise bilden letztere einen regelrechten Plexus, besonders da, wo sie von der Oberfläche her eindringen (Abb. 61).

Zusammenfassung. Es handelt sich um einen Fall von traumatischer Schädigung der rechten Frontalregion. Keine erheblichen klinischen Ausfallsymptome. 4 Jahre nach dem Trauma Beginn der epileptischen Anfälle (Typus Feld $6 \alpha \beta$ ) Haut, Dura und Hirnoberfläche an der Stelle der Verletzung fest verwachsen. Rechter Seitenventrikel nach dieser hin stark ausgezogen. Gesamtes Ventrikelsystem etwas nach rechts verzogen. 
Eingesprengte Knochen- und Projektilteile. Bei der Operation epileptischer Anfall infolge leichten Zuges an der circumcidierten, dem Gehirn adhärierenden Dura. Excision der Durahirnnarbe bis in den Ventrikel. Im Excisum typische mesodermale Invasion von der Dura ins Gehirn (Gefäße und Bindegewebsfaserzüge, parallel angeordnet), an diese anschließend parallele, gleichgerichtete Gliafaserzüge.

\section{Fall 12.}

A. B., 31 Jahre alt. 5. 3. 1916 Granatsplitterverletzung am rechten Scheitelbein. Sofort bewußtlos. Lähmung der linken Körperhälfte. Langdauernde Eiterung, deshalb Incision am rechten Margo supraorbitalis, wo sich viel Eiter entleerte.

August 1916 Knochenplastik. Kurz darauf epileptischer Anfall, beginnend im linken Gesicht. Nov. 1917 erkrankt er an starken Kopfschmerzen, Genicksteifigkeit, Fieber, Erbrechen; dieser Zustand dauerte bis 15. Dezember 1917.

März 1918 wurde bei einem starken Niesanfall ein Granatsplitter in den Rachen geschleudert und dann ausgespuckt. Die epileptischen Anfälle wiederholten sich mehrfach. Meist mit Bewußtlosigkeit und Urinabgang; in einem Anfall wurde Pat. aus dem Bett geschleudert.

Mai 1925 wieder hohes Fieber, Kopfschmerzen, Erbrechen, Nackensteifigkeit, starke Rückenschmerzen von 8 Tagen Dauer.

Juli 1925 derselbe Zustand. Anfang August 1925 wieder derselbe Zustand, dabei zahlreiche Anfälle.

5. 8. 1925 aufgenommen. Klagt über heftige Kopfschmerzen. Temperatur normal; es besteht deutliche Nackensteifigkeit und Kernigsches Phänomen. Liquor enthält zahIreiche Lymphocyten, Eiweißgehalt nicht vermehrt.

Eine bogenförmige Narbe zieht vom linken Ohr aufwärts zum Scheitel und dann auf dessen Höhe nach vorne. Eine zweite Narbe zieht vom Ohransatz nach dem äußeren Augenlidwinkel zu. Der äußere Teil des Margo supraorbitalis fehlt. Zwischen beiden Narben findet sich auf dem rechten Scheitelbein ein etwa dreimarkstückgroße Beule, die sehr druckempfindlich ist.

Linksseitige Parese des Lippenfacialis, am linken Arm Finger-Rossolimo +, Kraft des linken Armes etwas herabgesetzt, aber alle Einzelbewegungen in vollem Umfange möglich. Keine Ataxie beim Zeigefinger-Nasenversuch, wohl aber eine solche des Daumens bei der Opposition desselben gegen die anderen Finger, Ungeschicklichkeit der linken Hand beim Knöpfen.

Bauchreflex cutan links = rechts, ebenso Cremasterreflex. Am linken Bein Oppenheim + , sonst keine Abwegigkeiten.

Sensibilität am linken Daumen und Zeigefinger gestört, leichte Abstumpfung der Temperaturempfindung und erhebliche Störung des Weberschen Raumsinnes daselbst, ferner Unfähigkeit, Gegenstände durch alleiniges Betasten mit dem Daumen und Zeigefinger zu erkennen, während beim Betasten mit den anderen Fingern alle Gegenstände prompt erkannt werden. Keine Störungen des Gesichtsfeldes, Augenhintergrund normal. Keine Gehörs-, Geruchs-, Geschmacksstörung.

Sprechen, Schreiben, Lesen intakt. Keine Apraxie. Merkfähigkeit herabgesetzt. Stimmung hypochondrisch-depressiv.

Encephalographie (Abb. $62 \mathrm{a}-\mathrm{c}$ ). Auf der Aufnahme in antero-posteriorer Richtung starke Erweiterung beider Seitenventrikel, der rechte viel stärker dilatiert als der linke, das ganze Ventrikelsystem einschließlich des dritten Ventrikels nach rechts verzogen. Starke Luftansammlung an der Oberfläche rechts. Auf der Seitenaufnahme ist die stärkere Dilatation des rechten Ventrikels gleichfalls deutlich erkennbar, das Dach der Cella media ist stark nach oben ausgezogen. Auf der Scheitelhöhe Knochen frakturiert. 
Charakter der Anfülle. Die Anfälle beginnen meist mit Parästhesien (schmerzhaftem Brennen) im linken Daumen und Zeigefinger, dasselbe greift von hier aus auf den Hals und das linke Gesicht über und verdichtet sich besonders in der Umgebung des Mundes, speziell am linken Mundwinkel; bald darauf setzen klonische Zuckungen ein, beginnend im Zeigefinger und Daumen, dann auf die Halsmuskeln

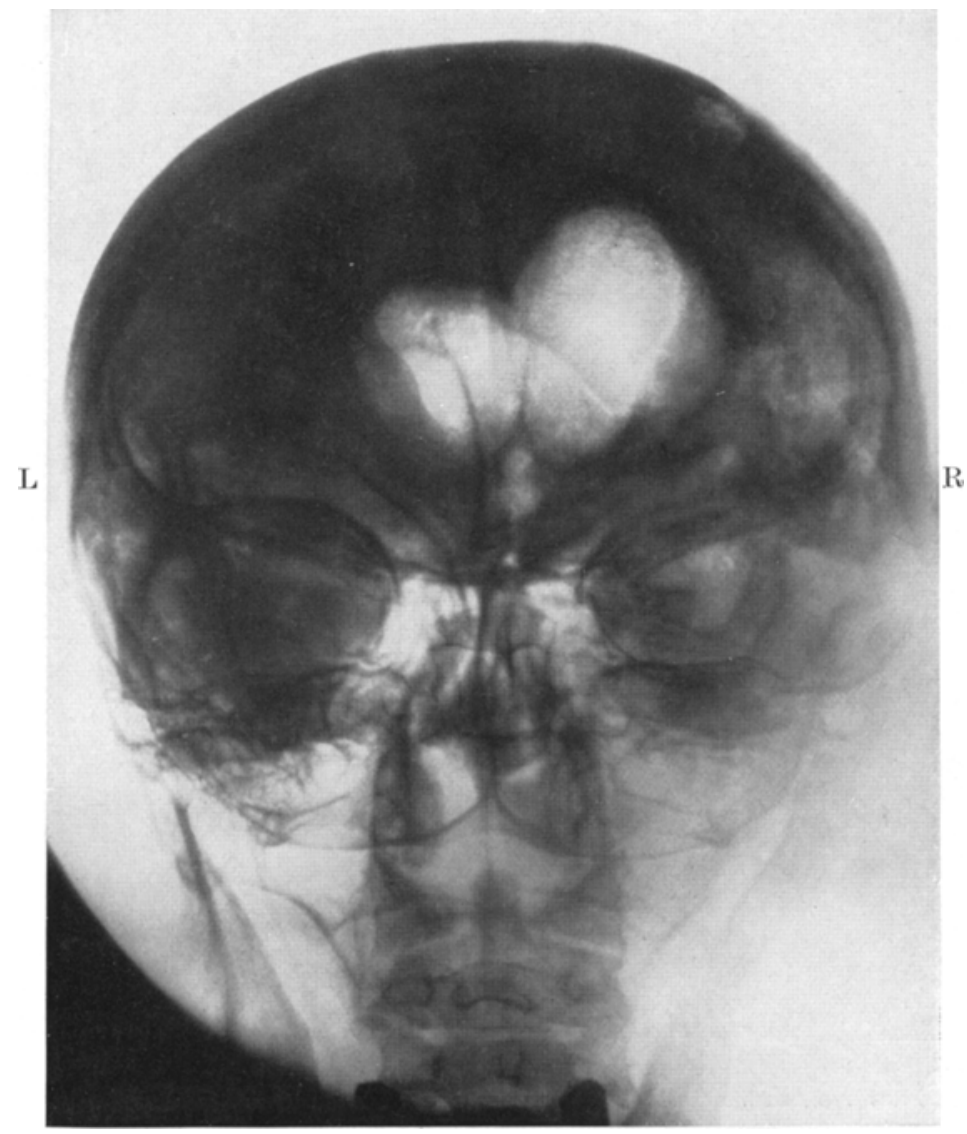

Abb. 62a. Encephalogramm des Falles 12. Aufnahme in antero-posteriorer Richtung. Hinterhaupt auf Platte. Starke Dilatation beider Seltenventrikel und des 3. Ventrikels, der rechte starker dilatiert als der linke, deutlich zum Defekt hin ausgezogen; das ganze Ventrikelsystem nach rechts verzogen.

(Platysma, Sternocleidomastoideus), dann auf oberen und unteren Facialis und Zunge übergreifend, andererseits breitet sich die Krampfwelle vom Zeigefinger auf den Mittelfinger, die anderen Finger, die Hand, den Vorderarm, Oberarm, Schulter, Pectoralis, Bauchmuskeln, Bein aus. Manchmal beginnt der Anfall auch mit Parästhesien am Mundwinkel und dann beginnen auch die motorischen Entladungen im Facialisgebiete oder es setzen zuerst Parästhesien am Halse ein und der Anfall beginnt mit einer isolierten Drehung des Kopfes nach links (rechter Sternocleidomastoideus). Manche Anfälle bleiben beschränkt und das Bewußtsein bleibt erhalten, andere Anfälle breiten sich rasch über die ganze linke Körperhälfte 
aus, dann wird auch die rechte ergriffen, das Bewußtsein erlischt, tiefer Stertor, Urin- und Stuhlabgang, lange Bewußtlosigkeit; hinterher längere Zeit große Schwäche und Ungeschicklichkeit des linken Armes, hochgradige Gefühlsstörung desselben. Es handelt sich also bei B. um typische Anfälle des Feldes 3, 1, 2 (hintere Zentralwindung).

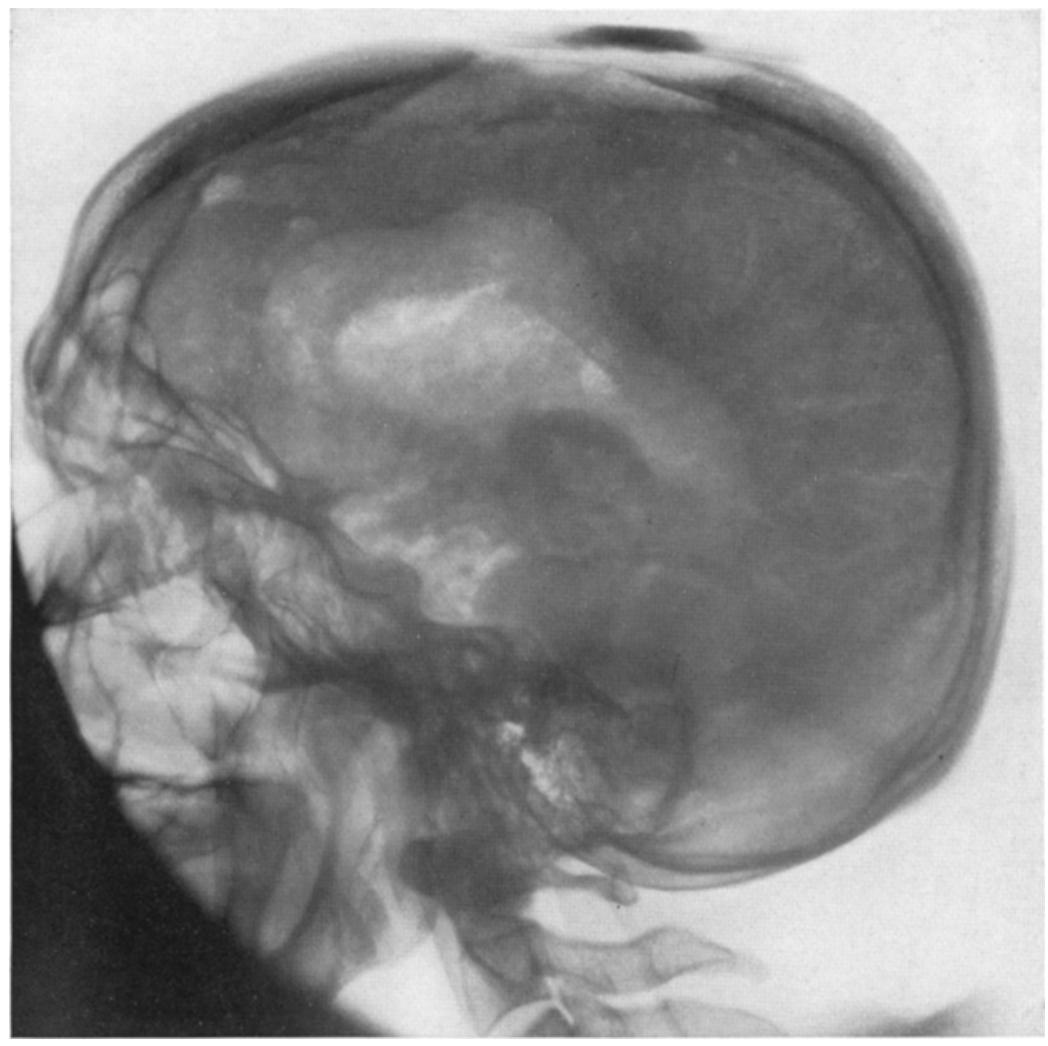

Abb. 62 b. Encephalogramm des Falles 12. Seitenaufnahme. Zeigt die starke Dilatation besonders des rechten Ventrikels, dessen Dach stark nach dem Knochendefekt zu ausgezogen ist.

16. 9. 1926 Operation. Großer bogenförmiger Hautschnitt, etwas hinter und oberhalb des Processus mastoideus beginnend, bis zur Scheitelhöhe empor, auf dieser entlang nach vorne, dann nach dem Jochbogen zu absteigend. Haut stellenweise sehr fest am Knochen adhärent. In der Mitte des Scheitelbeins besteht eine 1,5 cm breite Spalte im Knochen, aus dieser stürzt beim Abpräparieren der Haut Liquor in großer Menge hervor; dieser Spalt bildet die untere Grenze des implantierten Knochenstückes. Dieses ist schwer von der darunter liegenden Dura abzulösen. Nach seiner Entfernung ausgiebige Verbreiterung der Knochenbresche, Knochen an einzelnen Stellen enorm verdickt. Die gebildete Knochenbresche reicht nach oben fast bis zum Sinus nach unten bis über die Fossa Sylvii hinaus nach vorne bis in den Bereich des Stirnhirns, nach hinten umfaßt sie die ganze vordere Hälfte des Parietallappens. Dura um die Stelle, an welcher der 
Liquorabfluß erfolgt, herum stark verdickt. Zirkuläre Durchtrennung der Dura um die verdickte und verhärtete Stelle herum; an dieser selbst ist sie fest angewachsen. Gehirnmasse hier bräunlich-wabig verändert, fühlt sich derb an; nach vorne oben von diesem Kontusionsherd Hirnrinde etwas verfärbt, erscheint oberflächlich arrodiert. Lage und Ausdehnung des Herdes in Abb. 63 wiedergegeben. Bestimmung der Foki des Vorderarmes, der Hand, der Finger, des Daumens, des Halses, des oberen und unteren Facialis in der vorderen Zentralwindung (2 MA KSR.), darauf Bestimmung der Foki des Index, Pollex, Halses, oberen und unteren Facialis in der hinteren Zentralwindung (4,5 MA KSR.),

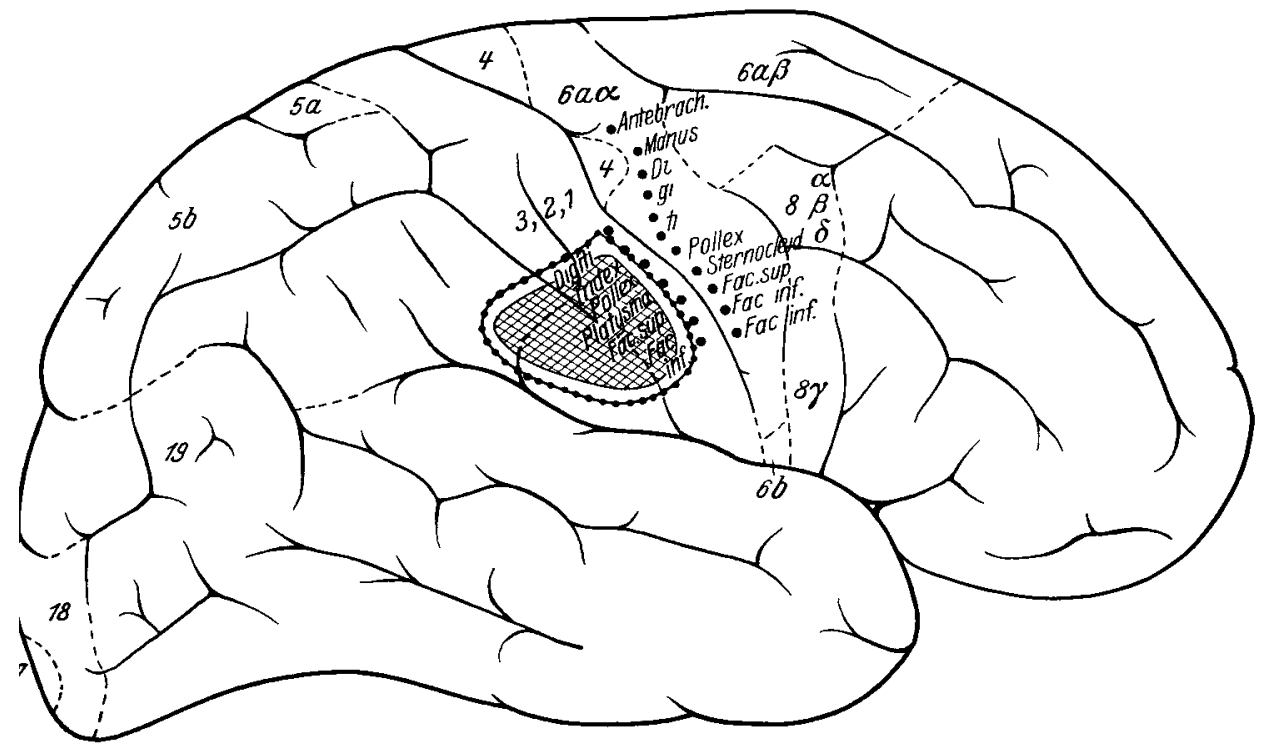

Abb. 63. Lage und Ausdehnung des Rindenherdes in Fall 12. \# Rindenherd, -........ Excisionslinie, ... Foki im Bereiche der hinteren und vorderen Zentralwindung, welche durch KSR, gereizt wurden.

Darauf Umstechung des Herdes und Excision desselben in der in der Abb. 63 wiedergegebenen Ausdehnung. Das exzidierte Stück enthält in seinem Innern einen Knochensplitter. Deckung des Duradefektes aus der Fascia lata, Galeanaht, Hautnaht. Heilung per primam. Keine Temperatursteigerung (Ventrikel nicht eröffnet).

In den ersten Tagen nach der Operation Beweglichkeit der Finger der linken Hand eingeschrankt, Ataxie des linken Armes. Lagegefühlsstörungen an allen Fingern, sowie Abstumpfung der Hautsensibilität an der ganzen Hand, am Hals und im Gesicht. Dieser Ausfall engt sich aber rasch wieder ein. Bestehen bleibt nur eine leichte Abstumpfung der Sensibilität am Index, Pollex, Hals und Gesicht, sowie vor allem Störungen des Raumsinnes der Haut in diesen Bezirken, aufgehobene Stereognose des Daumens und Zeigefingers. Keine Anfälle mehr.

22. 3. 1926 entlassen. Patient hat seither (bis April 1930 beobachtet) nie wieder Anfälle gehabt und lange Zeit seinen Beruf als Lehrer ausgefüllt.

Anatomischer Befund: An dem exzidierten Dura-Hirnstück fällt die stark verdickte Dura auf. Das Hirngewebe ist fest adhärent an der Dura. Schon mit bloßem Auge sieht man Bindegewebszüge von der Dura in das Gehirn eindringen. In 
letzterem ein Knochensplitter eingebettet. Bei der mikroskopischen Untersuchung dasselbe Bild wie in den vorbeschriebenen Fällen. Besonders an der Stelle, an der der Knochensplitter logiert ist, ganz exuberante Bindegewebsfaserbildung um das Knochenfragment herum und von diesem aus nach der Dura zu. In der Hirnsubstanz durchweg parallelfaserige Gliabildung teilweise mit Bindegewebsfaserzügen alternierend; einzelne Gliafaserzüge von regulären Bindegewebsschichten umgeben. Stellenweise reichliche Gefäßneubildung. Mikroglia normal.

Zusammenfassung. Es handelt sich um eine traumatische Schädigung der rechten Retrozentralregion mit fokal begrenzten Sensibilitätsdefekten (Pollex, Index, Collis, Facies). Epileptische Anfälle treten zum ersten Male in unmittelbarem Anschluß an eine osteoplastische Deckung des Knochendefekts auf, 5 Monate nach dem Trauma. Wiederholt Zustände starker meningealer Reizung mit Fieber eingergehend. Starke Dilatation und Verziehung des linken Seitenventrikels nach dem Knochendefekt zu, Verziehung des gesamten Ventrikelsystems nach links. Haut, Dura und Gehirn fest verwachsen. Im exzidierten Hirnstück Knochenfragment enthalten. Ausgesprochene Bindegewebsgliafasernarbenbildung vom Defekt nach dem Ventrikeldach zu.

\section{Zusammenfassung der Ergebnisse.}

Wir wollen in dieser Arbeit auf die interessanten klinischen Eigentümlichkeiten der 12 Fälle nicht näher eingehen. Es sei nur kurz das Wichtigste hervorgehoben. In 9 Fällen handelte es sich um Schuß. verletzungen des Gehirns, 2mal um Geburtstraumen (Zangengeburt, Fall 5 u. 8) und in einem Fall um eine Schädelverletzung durch stumpfe Gewalt (Fall 10). Nur in 2 Fällen war der Schädel nicht verletzt (Fall 3 Schußverletzung, Fall 5 Zangengeburt). Alle übrigen Fälle waren mit mehr oder weniger großem Knochendefekt gepaart. Von besonderem Interesse ist die Tatsache, daß in vielen unserer Fälle das Intervall zwischen dem Zeitpunkte des Traumas und dem ersten Auftreten der epileptischen Anfälle sehr lang war, wir geben kurz die Intervalle an:

\begin{tabular}{|c|c|c|c|}
\hline Fall & 1 & \multicolumn{2}{|c|}{6 Jahre } \\
\hline , & 2 & 10 & ,, \\
\hline ," & 3 & 13 & ," \\
\hline ," & 4 & 1 & , \\
\hline , & 5 & 14 & ", \\
\hline , & 6 & 7 & ", \\
\hline ", & 7 & 8 & ", \\
\hline ", & 8 & 9 & " \\
\hline$"$ & 9 & 2 & $"$ \\
\hline & 10 & 4 & $"$ \\
\hline & 11 & ${ }_{5}^{4}$ & "' \\
\hline
\end{tabular}

Das bedeutet ein durchschnittliches Intervall von 5,8 Jahren.

Unter den über 100 Fällen von traumatischer Epilepsie, welche wir in der Zeit nach dem Kriege operiert haben, ist die Zahl der Fälle, 
in welchen das Intervall zwischen Trauma und erstem Auftreten der epileptischen Anfälle mehrere Jahre beträgt, ganz erstaunlich groß. Wir werden auf diesen für die Unfallsbegutachtung wichtigen Punkt in einer besonderen Arbeit demnächst zurückkommen. Für die Unfalls begutachtung ist ferner der Fall 3 von grösster Bedeutung, insofern als hier, ohne erkennbare Knochenverletzung, durch den leichten Kopfstreifschuß ein Contusionsherd im Gehirn gesetzt wurde, der keinerlei objektive klinische Ausfallsymptome erzeugte und erst 11 Jahre nach dem Trauma die ersten epileptischen Anfälle hervorrief. Wir verweisen in dieser Beziehung auf die Ausführungen, welche der eine von uns in seinem Referat über die Pathogenese des epileptischen Krampfanfalles, in Sonderheit über die traumatische Epilepsie gemacht hat (Literaturverz. 1:7).

Was den Charakter der Anfälle anlangt, so hatten diese in allen unseren Fällen ein areales Gepräge. Folgende Kolonne gibt eine kurze Übersicht darüber.

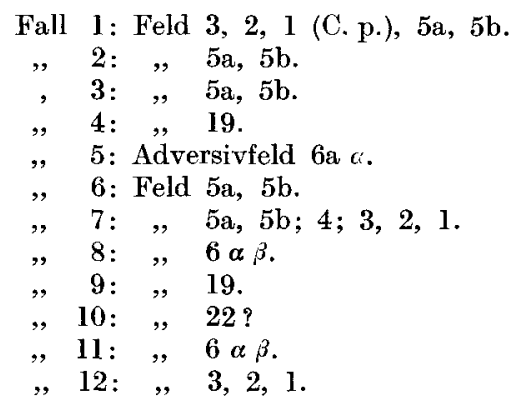

In Abb. 64, welcher die von $O$. Vogt geschaffene cytoarchitektonische Gliederung der menschlichen Großhirnrinde zugrunde liegt, sind die von uns am Menschen ganz unabhängig von den Vogt schen anatomischen Feststellungen erzielten Ergebnisse der elektrischen Reizung der einzelnen Rindenfelder eingetragen. Wir geben hier eine kurze Übersicht uber diese Ergebnisse, verweisen im übrigen auf unsere früheren Arbeiten über diesen Gegenstand (Literaturverz. 1).

1. Feld 4, die Area giganto pyramidalis astriata, das Ursprungsfeld der Pyramidenbahn, das Primärfeld für isolierte Bewegungen der einzelnen Extremitätenabschnitte und Körperabschnitte, ist ausgezeichnet durch seine weitgehende somatotopische fokale Gliederung. Diese kann beim Menschen. der nicht unter der Wirkung einer Allgemeinnarkose steht, am besten durch galvanische Reizung mittels Schwellenreizen (durchschnittlich 1,0-2,0 MA, K. S. R.) aufgedeckt werden; in Narkose wirkt meist der galvanische Reiz nicht, wohl aber der faradische Strom; in sehr tiefer Narkose versagt oft auch dieser. Bei galvanischer Reizung tritt eine schnelle kurze klonische Zuckung in der dem gereizten Fokus zugeordneten Muskelgruppe oder einem einzelnen Muskel auf, bei faradischer Reizung ist die Kontraktion tetanisch. Das Feld erreicht beim Menschen die Hirnoberfläche nur im Bereiche des Parazentrallappens, eines an diesen anstoß nden kleinen Bezirkes auf der Konvexität und eines von diesem letzteren getrennten, weiter abwàrts gelegenen kleinen Bezirkes der $\mathrm{C}$ a. Von diesen, das Culmen der vorderen Zentralwindung bzw. des Parazentrallappens erreichenden Bezirken abgesehen, liegt beim Menschen (im Gegensatz zum Affen) das Feld 4 innerhalb der 


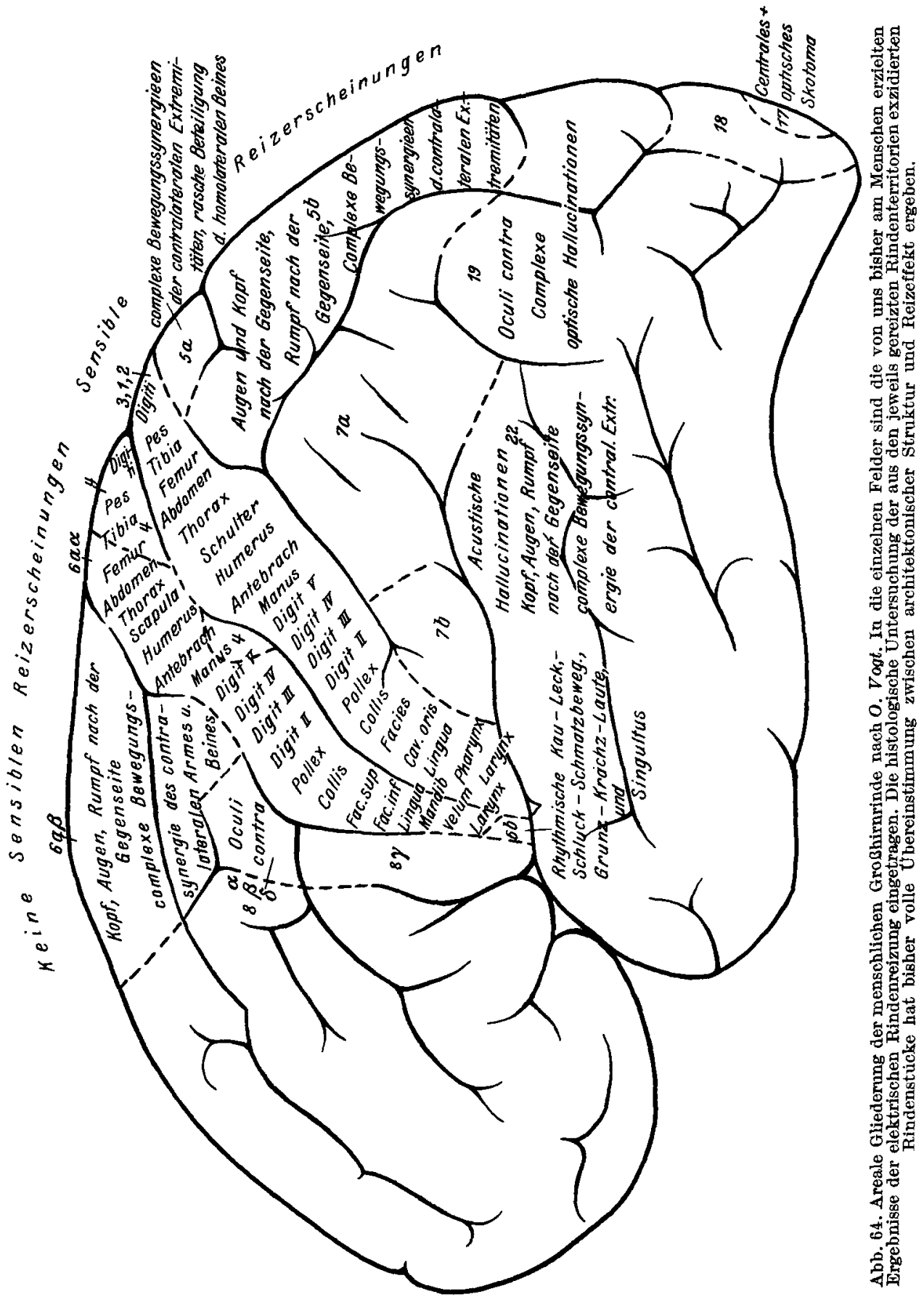


Zentralfurche, es nimmt den die vordere Wand der Zentralfurche bildenden Tei der Zentralwindung ein. Im Grunde der Zentralfurche hört das Feld auf, scharf abgesetzt gegen das Feld 3. Das Feld erreicht nach unten zu die Fissura Sylvii nicht ganz.

Die vom Felde 4 ausgehenden epileptischen Anfälle sind charakterisiert durch die der somatotopischen Gliederung des Feldes entsprechende Sukzession der klonischen Krampfentladungen in den einzelnen Muskelgruppen der Extremitäten und des Körpers, wobei der primär erregte Fokus des Feldes den Reigen eröffnet und sich von ihm aus die Krampfwelle sukzessive ausbreitet (motorischer Jacksonscher epileptischer Rindenanfall). Die vom Felde 4 ausgelösten motorischen Effekte, sowohl die bei elektrischer Reizung erzielbaren, wie die im Krampfanfall auftretenden, sind gebunden an die Integrität der Pyramidenbahn.

Sensible Erlebnisse treten bei Reizung des Feldes 4 nicht auf, der epileptische Anfall verläuft ohne sensible Aura.

2. Das Feld $6 a \alpha$. Sekundärfeld für isolierte Bewegungen der einzelnen Extremitätenabschnitte und Körperabschnitte, ausgezeichnet durch die gleiche somatotopische fokale Gliederung wie das Feld 4, nimmt das Culmen, der vorderen Zentralwindung ein, soweit dieses nicht von der Area 4 besetzt ist; das Feld ist etwas schwerer erregbar als Feld 4, die Reizschwelle liegt durchschnittlich bei 1,5-2,5 MA (KSR.) beim nicht narkotisierten Menschen. Die bei Reizung des Feldes ausgelösten Einzelbewegungen bleiben aus, wenn Feld 4 zerstört ist, oder wenn die Pyramidenbahn unterbrochen ist; die Einzelbewegungen kommen also nur zustande durch Überleitung der in 6a $\alpha$ erzeugten Erregung auf das Feld 4 und erst von diesem aus gelangt die Erregung via Pyramidenbahn zu den einzelnen Muskelgruppen. Diese Utberleitung der Erregung von Feld 6a $a$ auf Feld 4 findet durch Vermittlung der oberen Rindenschichten statt; wenn diese abgetragen sind, oder ein Einschnitt in die Rindenoberfläche gemacht wird, der die äußersten Rindenschichten durchtrennt, so bleibt ein vor diesem Einschnitt auf das Culmen der vorderen Zentralwindung applizierter elektrischer Reiz wirkungslos, soweit Einzelbewegungen in Betracht kommen. Wenn Feld 4 zerstört ist oder die Pyramidenbahn unterbrochen ist, so tritt bei Reizung des Feldes $6 a a$, aber erst bei stärkeren Strömen und zumeist nur bei Applikation des faradischen Stromes, ein Effekt ein, welcher bei Reizung des Feldes 6a $\beta$ primär auftritt, nämlich kombinierte Drehung der Augen, des Rumpfes und des Kopfes nach der Gegenseite und komplexe Bewegungssynergien (Beuge- oder Strecksynergie) des kontralateralen Armes u. Beines, also im Gegensatz zum Effekt des Feldes 4 oder dem primären Effekt des mit Feld 4 in intakter Verbindung befindlichen Feldes 6a a, welcher in isolierten Bewegungen der einzelnen Extremitäten- und Körperabschnitte besteht, eine komplexe Massenbewegung der gesamten kontralateralen Körperhälfte, eine Adversivbewegung. Das Feld 6a $\alpha$ ist also nicht nur ein Feld für das Zustandekommen isolierter Bewegungen einzelner Körperabschnitte, sondern zugleich ein Adversivfeld (zentrales Adversivfeld). Diese vom Felde 6a $\alpha$ auslösbare Massenbewegung kommt durch direkten $A b f l u B$ der Erregung vom Felde $6 a \alpha$ auf dem Wege des Eigenstabkranzes dieses Feldes zu subcorticalen Zentren und von diesen über das Rückenmark zu den Muskeln zustande (extrapyramidale cortico-subcortico-spino-muskuläre Leitungsbahn des Feldes 6a $a$ ). Dieser Effekt geht nur verloren, wenn der Eigenstabkranz des Feldes 6a $\alpha$ vernichtet ist. Bei elektrischer Reizung des Feldes 6a $a$ treten keine sensiblen Reizerscheinungen auf.

Der vom Felde 6a $\alpha$ ausgehende epileptische Anfall gleicht durchaus dem vom Felde 4 ausgehenden, es besteht keine sensible Aura, die Krampfentladung ist charakterisiert durch die der somatotopischen fokalen Gliederung des Feldes entsprechende Sukzession der klonischen Muskelzuckungen in den einzelnen Muskelgruppen der Extremitäten und des Körpers. Voraussetzung für diese sukzessive fokale Entladung ist die Integrität des Feldes 4 bzw. der Pyramidenbahn. Bei 
Zerstörung des Feldes 4 oder Unterbrechung der Pyramidenbahn hat der vom Felde 6a $\alpha$ ausgehende Krampfanfall durchaus das Gepräge des vom Felde 6a $\beta$ ausgehenden Anfalles (tonischer Krampf der Kopf-Augen-Rumpfwender nach der Gegenseite, tonisch-klonischer Massenkrampf der kontralateralen Extremitaten; zentraler Adversivanfall).

Cyto- und myeloarchitektonisch gehört das Feld 6a a zur Regio frontalis agranularis unistriata, besitzt aber seine eigene Struktur gegenüber dem Felde 6a $\beta$.

3. Feld $6 a \beta$. Frontales Adversivfeld, reagiert nur auf starke faradische Ströme, auch beim nichtnarkotisierten Menschen; nur in Fällen von Epilepsie haben wir gelegentlich auch bei Anwendung des galvanischen Stromes einen Effekt beobachtet, aber niemals bei einfacher Schließung des Stromes, sondern nur bei kontinuierlicher Durchströmung. Der Reizeffekt besteht in kombinierter Drehung der Augen, des Kopfes und Rumpfes nach der Gegenseite sowie komplexer Bewegungssynergie (Beuge- oder Strecksynergie) des kontralateralen Armes und Beines. Dieser Masseneffekt kann simultan auftreten, es kann aber auch vorkommen, daß die Kopf-Augenwendung den Reigen eröffnet und die anderen Komponenten sich erst anschließen; doch kommt es auch vor, daß gelegentlich der Arm den Anfang macht und dann erst die anderen Bewegungen nachfolgen.

Dieser motorische Effekt ist unabhängig von der Integrität der Felder 4 und 6a $a$; er kommt zustande auf dem Wege des direkt vom Felde $6 a \beta$ zu subcorticalen Zentren ziehenden Stabkranzes; von den subcorticalen Zentren wird die Erregung zum Rückenmark und den Muskeln weitergeleitet (extrapyramidale cortico-subcortico-spinomuskuläre Leitungsbahn des Feldes 6a $\beta$ ).

Bei elektrischer Reizung des Feldes $6 a \beta$ treten keine sensiblen Reizerscheinungen auf. Dementsprechend besitzt der von diesem Felde ausgehende epileptische Anfall keine sensible Aura; er besteht in tonischer Krampfdrehung der Augen, des Kopfes und Rumpfes nach der Gegenseite und tonisch-klonischem Massenkrampf der kontralateralen Extremitäten. Cyto- und myeloarchitektonisch gehört das Feld 6a $\beta$ zur Regio agranularis frontalis unistriata, es besitzt aber seine Sonderstruktur gegenüber dem Felde 6 a $\alpha$.

4. Feld $8 \alpha \beta \delta$. Frontales Augenfeld. Dasselbe ist vielfach bereits durch galvanische Schließungsreize erregbar (4-8 MA KSR.), in anderen Fallen spricht es nur auf faradischen Strom an, auch beim Nichtnarkotisierten. Der Effekt besteht in isolierter Wendung der Augen nach der Gegenseite, die bei galvanischer Reizung blitzschnell abläuft, bei faradischer Reizung in tetanischer Kontraktion der Augenwender besteht. Mehrfach fanden wir auch die Seitenwendung der Augen mit Aufwärtswendung kombiniert. Kopfdrehung tritt bei isolierter Erregung dieses Feldes nicht auf. Das Feld besitzt einen eigenen Stabkranz, von der Rinde direkt ohne Unterbrechung zu den Augenmuskelkernen verlaufend. Bei seiner Erregung treten keine optischen Reizerscheinungen auf; der von ihm ausgehende epileptische Anfall hat keine optische Aura; er beginnt mit klonischen Zuckungen der Bulbi nach der Gegenseite und wenn der Krampfreiz auf das Feld $8 a \beta \delta$ beschrankt bleibt, so bleibt auch die Krampfentladung auf die Augenmuskeln beschrankt. Meist aber greift die Erregung auf die benachbarten Rindenfelder 6a $\beta$ oder 6a $\alpha$ und 4 über; es schließt sich dann an die anfangs isolierten klonischen Zuckungen der Augen nach der Gegenseite die komplexe 6a $\beta$-Entladung an oder die Krampfwelle ergreift die vordere Zentralwindung und es kommt zu Zuckungen im Facialisgebiet, im Halsgebiet, in den Fingern usw. Wir sahen wiederholt, daß die Erregung, welche primar auf das Feld $8 \alpha \beta \delta$ beschrankt war und zu isolierten Augenzuckungen führte, raseh auf das Halsgebiet der vorderen Zentralwindung übergreifend, zu klonischen Zuckungen des Sternocleidomastoideus führte, so daß der Kopf nach der Gegenseite gedreht wurde, woran sich dann weiter rasch die einzelnen Finger-, Hand-, Arm-, Rumpf- und Beinmuskeln anschlossen; ein derartiger Anfall kann, 
wenn er in seiner Entwicklung nicht aufmerksam verfolgt wird, auf der Höhe sehr leicht einen Anfall vom Typus des Feldes 6a $\beta$ vortäuschen.

Das Feld $8 \alpha \beta \delta$ gehört cyto- und myeloarchitektonisch zur Regio frontalis intermedia; die Rinde besitzt eine schwache innere Körnerschicht.

5. Das Feld $8 \gamma$ ist beim Menschen reizphysiologisch noch nicht genügend charakterisiert.

6. Das Feld $6 b$ schließt sich nach unten zu an das Feld $6 a \alpha$ an und nimmt den der vorderen Zentralwindung angehörigen Teil des Operculum centrale ein. Bei faradischer Reizung, seltener auch schon bei galvanischer Durchströmung, treten rhythmische Kau- oder Leck- oder Schluckbewegungen auf, manchmal haben wir auch Schnalz- oder Schmatzlaute, gelegentlich auch Krächz- oder Grunzlaute beobachtet; ferner sahen wir wiederholt ausgesprochenen Singultus, der sich rhythmisch wiederholte, auftreten. Das Charakteristische des Reizeffektes des Feldes $6 \mathrm{~b}$, das der Kürze halber als Mastikationsfeld bezeichnet wird, ist einmal die Tatsache, daß auf den permanenten Reiz hin rhythmische Bewegungseffekte erfolgen und ferner die Tatsache, daß der Effekt den Reiz oft erheblich überdauert; diese beiden Eigenheiten kommen den anderen Rindenfeldern nicht zu. Sie treten nur dann auch bei ihnen in Erscheinung, wenn der Reiz zu einem epileptischen Anfall führt.

Der epileptische Anfall, welcher vom Felde $6 \mathrm{~b}$ ausgeht, ist äußerst charakteristisch, er beginnt mit rhythmischen Kau-Leck-Schluckbewegungen oder mit Schmatz-, Schnalz-, Grunz- oder Krächzlauten; wiederholt wurde er auch durch starken Singultus eingeleitet. Der Anfall kann sich auf diese Phänomene beschränken; meist aber greift die Rindenerregung auf die benachbarten Felder 4, 6a $a$ und 3, 1, 2 über und es schließen sich die für diese Fehler charakteristischen Krampfentladungen an die Entladung des Feldes $6 \mathrm{~b}$ an.

7. Das Feld 3, 1, 2, Retrozentralfeld, corticale Endstätte der sensiblen Leitungsbahnen, beginnt scharf abgesetzt in der Tiefe der Zentralfurche, bildet die hintere Wand dieser Furche und greift nach der Konvexität über, das gesamte Culmen der hinteren Zentralwindung einnehmend; im Parazentrallappen, der zum größten Teil vom Felde 4 besetzt ist, nimmt es den hintersten Teil ein. Bei faradischer Reizung des Feldes 3, 1, 2 treten sensible Reizerscheinungen in Gestalt von Parästhesien auf, und zwar weist das Feld 3, 1, 2 als Endstätte der sensiblen Leitungsbahnen eine weitgehende somatotopische Gliederung auf, jeder einzelne Extremitäten- und Körperabschnitt ist in einem besonderen eng umschriebenen Fokus vertreten, wie es in der Abb. 64 dargestellt ist. Bei galvanischer Schließungsreizung treten die sensiblen Phänomene nicht hervor. Außerdem reagiert aber das Feld 3, 1, 2 auf die elektrische Reizung, und zwar beim Nichtnarkotisierten auch auf den galvanischen Sehließungsreiz, mit genau den gleichen isolierten Bewegungen der einzelnen Extremitäten- und Körperabschnitte wie das Feld 4 bzw. $6 a \alpha$; es weist in dieser Hinsicht genau die gleiche weitgehende somatotopische fokale motorische Gliederung wie das Feld 4 und 6a $a$ auf. Aber es besteht ein Untersehied in bezug auf die Reizschwelle, welche an der hinteren Zentralwindung höher ist als an der vorderen, die Differenz beträgt in der Regel 2,0-2,5 MA die Schwelle schwankt also von 3-5 MA KSR. Die isolierten Bewegungen der einzelnen Extremitäten- und Körperabschnitte, welche bei Reizung der hinteren Zentralwindung auftreten, sind an die Integrität des Feldes 4 bzw. der Pyramidenbahn gebunden; sie entstehen durch Überleitung der Erregung vom Felde 3, 1, 2 auf das Feld 4, von wo die Erregung auf dem Wege der Pyramidenbahn zu den einzelnen Muskelgruppen der Muskeln gelangt. Das Feld 3, 1, 2 besitzt keinen eigenen Stabkranz für isolierte Impulse zu den einzelnen Muskeln, ebensowenig wie das Feld 6a $\alpha$ einen solchen besitzt. Die Überleitung der Erregung von Cp. auf das Feld 4 erfolgt auf dem Wege der tiefen U-Fasern, welche in Cp. ent. springen, um den Grund der Zentralfurche herumbiegen und in das Feld 4 einmünden. 
Durch Abtragung der oberen Rindenschichten des Feldes 3, 1, 2 wird das Zustandekommen der isolierten Bewegungen nicht aufgehoben, wohl aber durch Unterschneidung der hinteren Zentralwindung, sofern diese dicht unterhalb der Rinde erfolgt; ebenso erlischt die fokale Erregbarkeit der hinteren ZentraIwindung, wenn deren Rinde bis in die tieferen Schichten abgetragen wird. Daraus dürfte hervorgehen, daß bei der Reizung der hinteren Zentralwindung und der Auslósung der isolierten Bewegungen der einzelnen Extremitäten- und Körperabschnitte die tiefen Rindenschichten des Feldes 3, 1, 2 in Erregung geraten und die Erregung auf dem Wege der tiefen U-Fasern auf das Feld 4 übertragen, von wo dieselbe auf dem Wege der Pyramidenbahn zu den einzelnen Muskeln geleitet wird.

Wenn das Feld 4 zerstört ist oder die Pyramidenbahn unterbrochen ist, so reagiert das Feld 3, 1,2 auf den elektrischen Strom in ganz anderer Weise als unter normalen Verhältnissen; aber es sind zur Erziehung motorischer Effekte nunmehr starke faradische Ströme erforderlich. Der Effekt ist dann der gleiche wie der vom Felde 6a $\alpha$ ausgelöste Anfall, wenn das Feld 4 zerstört ist; er besteht in kombinierter Drehung der Augen, des Kopfes und Rumpfes nach der Gegenseite und komplexen Bewegungssynergien (Beuge- oder Strecksynergie) des kontralateralen Armes und Beines. Dieser Effekt (retrozentrale Adversivbewegung) kommt zustande durch direkten Abfluß der Erregung von der Rinde des Feldes 3, 1, 2 auf dem Wege des Eigenstabkranzes dieses Feldes zu den subcorticalen Zentren und von diesen zum Rückenmark und den Muskeln (extrapyramidale cortico-subcorticospinomuskuläre Leitungsbahn 3, 1, 2). Das Feld 3, 1, 2 ist also gleichzeitig ein Adversivfeld (retrozentrales Adversivfeld) wie auch das Feld 6a $\alpha$ gleichzeitig das Sekundärfeld für isolierte Bewegungen einzelner Extremitäten- und Körperabschnitte und ein Adversivfeld ist.

Der vom Felde 3, 1, 2 ausgehende epileptische Anfall ist durch die sensible Aura charakterisiert, welche den motorischen Entladungen vorausgeht. Die sensiblen Reizerscheinungen (Paràsthesien) beginnen in demjenigen Extremitätenoder Körperabschnitt, welcher dem primàr gereizten Fokus der hinteren Zentralwindung zugeordnet ist und sie ergreifen nun der Reihe nach die anderen Korperabschnitte in der der somatotopischen Gliederung des Feldes 3, 1, 2 entsprechenden Sukzession. Die Parästhesiewelle läuft in mehr oder weniger rascher Folge über die einzelnen Körper- und Extremitatenabschnitte dahin (sensibler Jacksonscher Anfall). Sehr oft und rasch schließen sich aber motorische Entladungen an, welche in derselben Weise wie bei der Entladung des Feldes 4, durch dessen Vermittlung sie ja uberhaupt nur zustandekommen, ablaufen. Dabei kann die motorische Entladungswelle in ihren einzelnen Phasen mit der sensiblen Welle zeitlich fast ganz zusammenfallen, sie kann aber auch erheblich nachhinken. Im ersteren Falle treten die Parästhesien in einem bestimmten Körperabschnitt auf und unmittelbar danach beginnen auch schon die klonischen Muskelzuckungen in diesem Körperabschnitt; dann greift die Parasthesie auf den benachbarten Körperabschnitt über und sogleich wird auch dieser von klonischen Zuckungen ergriffen, und so geht es sukzessive weiter. Im anderen Falle der zeitlichen Inkongruenz dagegen hat die Parảsthesiewelle bereits zahlreiche Abschnitte der kontralateralen Körperhálfte durchlaufen, ja sie kann bereits ganz abgelaufen sein, ehe die motorischen Entladungen beginnen. Die motorischen Entladungen der Feldes 3, 1, 2 sind übrigens nicht selten dadurch charakterisiert, daß den klonischen Muskelzuckungen ein feinschlägiger Tremor des betreffenden Körper- oder Extremitatenabschnittes vorausgeht. Ferner fallt auf, daß der 3. 1. 2. Anfall, soweit die motorischen Entladungen in Betracht kommen, vielfach eine geringere Extensität der Ausbreitung der corticalen Erregungswelle besitzt als der Anfall der Felder 4 und 6a $\alpha$; es werden im allgemeinen weniger Foki in die Krampfentladung einbezogen. Die epileptische Erregung des Feldes 3, 1, 2 kann sich auch lediglich auf das Auftreten 
der sensiblen Reizerscheinungen beschränken, indem motorische Entladungen ganz fehlen (reiner sensibler epileptischer Rindenanfall).

8. Das Feld 5a, Area praeparietalis, nimmt den unmittelbar an die hintere Zentralwindung anstoßenden, obersten vorderen Abschnitt des oberen Scheitellappens ein und greift von hier aus auf die mediale Fläche der Hemisphäre über, den vorderen oberen Abschnitt des Praecuneus bildend. Das kleine Feld hat eine sehr charakteristische reiz-physiologische Dignität. Es reagiert auf den faradischen Strom, manchmal aber auch schon auf starke galvanische Schließungsreizungen $(6-10 \mathrm{~mA})$ mit simultanen komplexen Bewegungssynergien des kontralateralen Armes und Beines; meist handelt es sich um die Beugesynergie sowohl am Arm wie am Bein; an diese simultane komplexe Bewegungssynergie des kontralateralen Armes und Beines schließt sich bei fortgesetzter Reizung sehr rasch auch eine Beugesynergie des homolateralen Beines an, seltener kommt auch noch eine Beugesynergie des homolateralen Armes dazu. Außer diesem motorischen Effekt kommt es aber bei Reizung des Feldes 5a auch zu sensiblen Reizerscheinungen; es treten Parästhesien auf, welche simultan mehr oder weniger die gesamte kontralaterale Körperhälfte befallen, aber sehr rasch auch auf die homolaterale Körperhälfte übergreifen, besonders das homolaterale Bein und die homolaterale Rumpfhälfte, aber auch den homolateralen Arm umfassend. Manchmal haben diese Parästhesien deutlich schmerzhaften Charakter, wiederholt trat sehr heftiger Leibschmerz von ausgesprochen kolikartigem Charakter auf.

Der vom Felde 5a ausgehende epileptische Anfall hat fast stets eine sensible Aura, eine Parästhesiewelle ergreift mehr oder weniger simultan die gesamte kontralaterale Körperhälfte und oft und rasch auch Abschnitte der homolateralen Körperhälfte und darauf kommt es zu simultanen tonisch-klonischem Massenkrampf des kontralateralen Armes und Beines, wobei auch, wie bei der elektrischen Reizung des Feldes, die Beugebewegung vorherrscht; und ebenso schließt sich an diese sehr rasch ein tonisch-klonischer Beugekrampf des homolateralen Beines an, es kann schließlich auch der homolaterale Arm partizipieren.

Sowohl der unmittelbare motorische Reizeffekt des Feldes 5a, wie der von ihm ausgehende epileptische Anfall sind nicht an die Integrität des Feldes 4 oder 3, 1, 2 gebunden, sie kommen auch bei Zerstörung dieser Felder zustande; das Feld 5a besitzt einen eigenen Stabkranz zu subcorticalen Zentren.

Cyto- und myeloarchitektonisch ist das Feld ausgezeichnet durch die starke Ausprägung der Körnerschichten, durch das Vorhandensein zweier Baillargerscher Streifen und durch die Anwesenheit einer Lage relativ großer Pyramidenzellen in der fünften Schicht.

9. Das Feld $5 b$. Area parietalis superior, nimmt den nicht von dem Felde 5a besetzten Hauptteil des oberen Scheitellappens und Praecuneus ein; das Feld zeigt eine große Ausdehnung. Bei seiner Reizung - wir fanden bisher nur starke faradische Ströme wirksam - tritt primär eine Wendung der Augen und des Kopfes, bei stärkerer Reizung auch des Rumpfes nach der Gegenseite ein, an welche sich sekundär auch eine simultane komplexe Bewegungssynergie (wieder vornehmlich Beugesynergie) des kontralateralen Armes und Beines anschließt; auch eine Mitbeteiligung des homolateralen Beines wird beobachtet, sie tritt aber nur bei Reizung der vorderen Abschnitte des Feldes hervor. Der primäre Reizeffekt, kombinierte Kopf-Augendrehung ohne oder mit Rumpfdrehung bedient sich eines eigenen vom Felde $5 \mathrm{~b}$ zu subcorticalen Zentren gehenden Stabkranzes, er kommt auch zustande bei Zerstörung des Feldes 4 und 3, 1, 2; ob aber der Sekundäreffekt, die simultane komplexe Bewegungssynergie des kontralateralen Armes und Beines ebenfalls vermittels dieses Eigenstabkranzes zustandekommt oder vielmehr durch Übergreifen der Erregung auf das Feld 5a, von dem aus die Erregung erst zur Peripherie abfließt, konnten wir bisher noch nicht sicher ermitteln; das letztere erscheint uns aber viel wahrscheinlicher, da wir mehrere 
Fälle beobachtet haben, in denen bei Erregung des Feldes 5b stets nur Drehung des Kopfes und der Augen auftrat, ohne jede Beteiligung der Extremitäten. Das gilt besonders für die hinteren Abschnitte des Feldes.

Bei faradischer Reizung des Feldes 5b können auch sensible Reizerscheinungen auftreten, sie gleichen nach unseren bisherigen Erfahrungen den bei Reizung des Feldes 5a auftretenden. $\mathrm{Ob}$ sie der direkten Erregung des Feldes 5b unmittelbar zugeordnet sind, oder ob ihnen ein Übergreifen der Erregung vom Felde 5b auf das Feld 5a zugrunde liegt, können wir noch nicht mit Sicherheit entscheiden.

Der vom Felde 5b ausgehende epileptische Anfall hat häufig eine sensible Aura, wir fanden aber auch mehrfach, daß sie fehlte. Wenn sie vorhanden ist, gleicht sie der des vom Felde 5a ausgehenden Anfalles. Die motorische Entladung beginnt mit kombinierter Kopf-Augendrehung nach der Gegenseite, daran schließt sich Rumpfdrehung nach der Gegenseite an und an diese schließen sich fruher oder später simultane klonisch-tonische Massenkrämpfe (meist Beugekrampf) des kontralateralen Armes und Beines an, bald folgt dann auch das homolaterale Bein. Die Krampfentladung des Feldes 5b kann aber auch auf eine Krampfwendung der Augen und des Kopfes allein beschränkt bleiben.

Bei elektrischer Reizung der Felder $7 a$ und $7 b$ haben wir bisher noch niemals einen Reizeffekt beobachten können. Nur bei Epileptikern sahen wir bei starker anhaltender faradischer Reizung des unteren Scheitellappens gelegentlich epileptische Krämpfe auftreten, welche bei Reizung der vorderen Abschnitte durchaus das Gepräge des 3. 1. 2. Anfalles hatten, während bei Reizung der hinteren Abschnitte ein typischer 5b-Anfall erfolgte.

10. Das Feld 17, die Area striata, die corticale Endstätte der Sehleitung, nimmt die obere und die untere Lippe der Calcarina ein, ist also im wesentlichen an der medialen Hemisphärenfläche gelegen; auf die Konvexität greift es nur am Hinterhauptspol in einem individuell wechselnden Ausmaße etwas über. Bei faradischer Reizung des Feldes 17 treten Lichterscheinungen auf, welche bei Reizung des Hinterhauptspoles und der hinteren Abschnitte der Calcarinagegend an der Medialseite der Hemisphäre als gerade vor der Versuchsperson gelegen und als feststehend bezeichnet werden. Bei faradischer Reizung der weiter nach vorn gelegenen $\mathrm{Ab}$ schnitte der Calcarinarinde treten Photome auf, welche nach außen in die Peripherie des Gesichtsfeldes verlegt werden und zwar bewegen sich diese von außen her auf die Mitte zu; dabei „,kommt" bei Reizung der Ober lippe der Calcarina in den vorderen Abschnitten ,,das Photom von unten außen her", bei Reizung der Unterlippe ,von oben außen her".

Motorische Reizeffekte haben wir bei faradischer Reizung des Feldes 17 beim Menschen niemals beobachtet.

11. Feld 19, occipitales Augenfeld. Dasselbe ist an der Konvexität des Occipitallappens gelegen, es ist von $O$. Vogt noch nicht nach allen Seiten genau abgegrenzt. Bei faradischer Reizung dieses Feldes treten auch optische Reizphänomene auf, Photome, aber auch viel komplexere Gebilde, Figuren, Personen, Gegenstände; man kann, da diese Gebilde Realitätscharakter besitzen, geradezu von optischen Halluzinationen sprechen. Diese Gebilde erscheinen nach unseren Erfahrungen stets in Bewegung, sie kommen von au ßen her auf die Versuchsperson zu.

Außerdem treten aber bei faradischer Reizung des Feldes 19 Augenbewegungen auf, beide Bulbi wandern nach der Gegenseite und werden dort so lange festgehalten, als der Reiz andauert; manchmal ist die Seitenwendung mit Aufwärtswendung der Bulbi kombiniert. Das Feld 19 stellt also das occipitale optomotorische Feld dar. Durch galvanisehen Reiz ist es uns niemals gelungen, einen motorischen Effekt zu erzielen.

Das Feld 18 haben wir reizphysiologisch noch nicht genügend charakterisieren können. 
Die epileptischen Anfälle, welche von den Feldern 17, 18 oder 19 ausgehen, sind alle durch ihre optische Aura charakterisiert; vielfach stellen die optischen Erlebnisse sogar das Einzige dar, was bei der epileptischen Occipitalrindenreizung auftritt. Die Aura des Anfalles, welcher vom Felde 19 ausgeht, hat zumeist komplexeren Charakter als die des Anfalles des Feldes 17. Halluzinationen, die zum Teil sehr komplex gestaltet sind, bilden die Aura des ersteren, einfache Photome, Lichterscheinungen, Scotoma scintillans und ähnliche Gebilde die des letzteren. Doch haben wir auch bei Anfällen, die vom Felde 17 ihren Ausgang nahmen, gelegentlich ausgesprochene optische Halluzinationen als Aura auftreten sehen. Die motorische Krampfentladung des von der Occipitalrinde ausgehenden epileptischen Anfalls beginnt mit isolierter Wendung der Augen nach der Gegenseite, diese tritt bei Anfällen des Feldes 19 relativ sehr früh auf, während sie bei Anfällen, die von der Area striata ausgehen, relativ spät folgt; sie tritt hierbei erst auf, wenn die corticale Erregungswelle vom Felde 17 auf das Feld 19 ubergegriffen hat. An die Augenwendung schließt sich Kopf- und Rumpfdrehung nach der Gegenseite an, und auf diese folgt tonisch-klonischer Krampf der kontralateralen Extremitäten; alle diese Krampferscheinungen treten erst auf, wenn die Erregung vom Felde 19 auch auf das Feld $5 b$ und weiterhin auch auf das Feld 5a übergegriffen hat.

12. Feld 22. Temporales Adversivfeld innerhalb der ersten Temporalwindung gelegen. Cyto- und myeloarchitektonisch seinen Grenzen nach von 0 . Vogt noch nicht nach allen Seiten genau abgegrenzt. Bei starker faradischer Reizung des Feldes, besonders bei Reizung der mittleren Partien der ersten Temporalis treten akustische Reizerscheinungen auf; die Versuchsperson hört Geräusche, Donner, Brausen, Zischen, Pfeifen, Singen, verworrene Stimmen usw. Ferner kommt es zu einer typischen Adversivbewegung, Augen, Kopf und Rumpf werden nach der Gegenseite gedreht und die kontralateralen Extremitäten führen eine komplexe Bewegungssynergie (Beuge- oder Strecksynergie) aus. Dieser motorische Effekt wird leichter von den rückwärtigen Abschnitten der ersten Temporalwindung erzielt. Die von dieser Temporalregion ausgehenden epileptischen Anfälle können eine akustische Aura aufweisen. Wir haben aber auch beobachtet, daß starke Gehörsreize, welche von außen her plötzlich das Individuum treffen, den Anfall auslösen; der Kranke schreckt dabei auf, fährt zusammen und alsbald beginnt die eigentliche motorische Krampfentladung in Gestalt der typischen Adversivfeldentladung, forcierte krampfhafte Kopf-Augen-Rumpfdrehung nach der Gegenseite, tonisch-klonischer Massenkrampf der kontralateralen Extremitäten.

In fast allen unseren Fällen traten die Anfälle gehäuft auf, viele wurden im Status epilepticus eingeliefert. In 5 Fällen (Fall 6, 7, 8, 10 u. 11) wurde bei der Operation ein epileptischer Anfall durch mechanischen Reiz, (durch Zug an der Dura an der Stelle ihrer Verwachsung mit der Hirnoberfläche) und in fast allen Fällen durch faradische Reizung des Gehirns an der Stelle der Verletzung bzw. deren unmittelbarer Umgebung ausgelöst. Der jeweils provozierte Anfall glich seinem Gepräge nach im einzelnen Falle vollkommen den spontanen Anfällen des Einzelfalles.

Die Tatsache, daß es gelingt, epileptische Anfälle durch einen mechanischen, das Gehirn treffenden Reiz epileptische Anfälle auszulösen, ist an sich sehr lange bekannt. Es wird ibr aber, nach unserer Meinung, nicht gebührende Beachtung geschenkt. Die Empfindlichkeit des Gehirns solchen mechanischen Reizen gegenüber ist in vielen Fällen außerordentlich groß. Wir haben wiederholt erlebt, daß schon das einfache vorsichtige Wischen mit einem Tupfer über die freigelegte Gehirnrinde bei Epileptikern schwere Anfälle auslöste, vollends haben wir derartiges recht oft beim Auslösen von Knochensplittern oder Projektilteilen aus dem Gehirn in Fällen 
von traumatischer Epilepsie, ferner bei der sog. Rindentoilette, d. h. der vorsichtigen Lösung von Verwachsungen zwischen Hirnoberfläche und Dura bei traumatischer Epilepsie beobachtet. Einige Male sahen wir sogar epileptische Anfälle bei der einfachen Perkussion des intakten Schädels, mit dem Finger in Fällen von tuberkulöser Meningitis, von Meningitis serosa cystica, von Meningeoma durae matris, von Cysticercosis cerebri auftreten. DaB in Fällen, die an epileptischen Krampfanfällen leiden, ganz einerlei welcher Genese, Anfälle im Anschluß an Kopftraumen auftreten, haben wir recht oft beobachtet; mehrfach bildeten in Fällen von Gehirntumor oder von Cysticercus cerebri, von Lues cerebri, von Alkoholismus, Kopftraumen den unmittelbaren Anlaß zum erstmaligen Auftreten epileptischer Anfälle. Daß bei sog. genuiner Epilepsie - wir nennen sie kryptogenetische Epilepsie ein Kopftrauma unmittelbar Anfälle hervorrufen kann, daß ferner im Anschluß an ein solches Zahl und Schwere der Anfälle zunehmen kann, halten wir auf Grund eigener Beobachtungen trotz der gegenteiligen Behauptung anderer Autoren für sicher; wir halten den Einfluß eines Kopftraumas in jedem Falle, der an Krampfanfällen leidet, nicht nur im Sinne eines unmittelbaren anfallsauslösenden Faktors, sondern auch im Sinne einer Verschlimmerung des Grundleidens fürso bedeutsam, daß wir jedem Krampfkranken die Ausübung jeglichen Sportes, bei dem die Gefahr eines Stoßes oder Schlages gegen den Kopf in nennenswertem Umfang vorhanden ist, strikte verbieten.

Utber die Resultate der operativen Intervention in unseren Pällen gibt folgende Tabelle Auskunft.

Zeit post operationem

Fall 1: 4 Jahre

" 2: 1 Jahr 9 Monate

, 3; 1 Jahr 9 Monate

, 4: 5 Jahre

, 5: 5 Jahre

"6: 5 Jahre 3 Monate

, 7: 4 Jahre 6 Monate

, 8: 1 Jahr 8 Monate

, 9: 2 Jahre 9 Monate

"10: 2 Jahre 7 Monate

, 11: 4 Jahre 4 Monate

, 12: 3 Jahre 4 Monate

\section{Resultat}

Kein Anfall.

Kein Anfall.

Kein Anfall.

Kein Anfall.

Kein Anfall.

Kein Anfall.

1 Anfall nach 4 Jahren 3 Monaten.

Verlauf unbekannt.

Verlauf unbekannt.

Kein Anfall.

3 Jahre anfallsfrei, seither vereinzelte leichte Absencen Kein Anfall.

In allen Fällen waren die eingangs hervorgehobenen Verziehungen am Ventrikelsystem im encephalographischen Bilde deutlich zu erkennen. Zum mindesten war der der Seite der Verletzung entsprechende Seitenventrikel dilatiert und nach der Stelle des Knochendefektes, d. i. nach der Stelle der Adhäsion zwischen Haut, Dura und Hirnoberfläche verzogen. Am geringsten ausgesprochen war diese Veränderung im Fall 3 und 7, geradezu grotteske Dimensionen erreicht sie aber in den Fällen 2, $5,8,9,10,11$ u. 12 , in allen diesen mit Ausnahme des letzteren erreicht der Ventrikel der verletzten Seite die Hirnoberfläche, und wurde er bei der Operation in breitem Ausmaße eröffnet; letzteres fand auch im Falle 1 statt, in dem ebenfalls der Ventrikel bis hart an die Hirnoberfläche heranreicht; nur tritt die Dilatation in diesem Falle im encephalographischen Bilde nicht so markant hervor. Bemerkenswert ist, daß 
die Ventrikeldilatation in mehreren Fällen durchaus den Charakter einer cystischen Aussackung aufweist, das ist besonders in Fall 2, 5 und 9 sehr deutlich. Fall 1 zeigt besonders markant, wie das ganze Ventrikelsystem, also auch der Ventrikel der unverletzten Seite und der dritte Ventrikel nach der Seite des Defektes herübergezogen sind. Fall 6, in welchem die Verletzung auf der Scheitelhöhe liegt, zeigt, daß das Dach beider Ventrikel nach oben gezogen ist, der rechte Ventrikel ist stärker dilatiert als der linke, entsprechend der Tatsache, daß die Läsion die rechte Seite erheblich stärker betraf als die linke.

Es fragt sich nun, wodurch diese Ventrikelverziehung bedingt ist.

Das Prinzip des Narbenzuges bei experimentell erzeugten Gehirnwunden ist bereits weiter oben auseinandergesetzt worden. Die histologische Untersuchung der Excisa unserer 12 Fälle zeigt klar, daß derselbe Vorgang in jedem einzelnen Falle im Spiele ist. Selbst in den Fällen, in welchen intracerebrale Cysten gefunden wurden, fand sich induriertes Gewebe in deren unmittelbarer Nachbarschaft, welches mit der Dura und durch diese mit der Haut in adhäsiver Verbindung stand. In jedem Falle ist reichlich Bindegewebe, das viel Kollagen enthält, in das Gehirn eingewandert, und in den anliegenden Hirnpartien sind die fibrösen Astrocyten stark vermehrt. Ferner weisen die Blutgefäße sowohl im Wundbereich wie darum herum eine beträchtliche Vermehrung auf. Die Astrocytenfasern lassen eine ausgesprochene Längsanordnung auf das Zentrum der Narbe zu und von diesem weg erkennen. Vom histologischen Standpunkte aus muß also gesagt werden, da $B$ alle Bedingungen für das Zustandekommen einer Narbenschrumpfung, eines Narbenzuges, vorhanden sind, und daß dieser Narbenzug auf das vasoastrale Gerüst des Gehirns eine Wirkung ausübt.

Ein Unterschied zwischen den Befunden am Tier und denen am Menschen fällt in die Augen. In unserem vom Menschen gewonnenen Material finden sich viel mehr parallel gerichtete Gliafasern (Gliagewebe mit zahlreichen feinen parallelen Fasern). Dieser Gliatypus wird besonders bei Strangdegenerationen im Rückenmark gefunden, ferner in alten Plaques bei der multiplen Sklerose. Jakob hat von isomorpher Glia gesprochen. Die Einwanderung der Bindegewebsfasern ins Gehirn und die Durchmischung derselben mit längsgerichteten Gliafasern, welche dieselbe Längsanordnung wie die ersteren zeigen, ist in den beiden Fällen von Geburtstrauma (Zangengeburt, Fall 5 und 8) so weit fortgeschritten, daß 18 Jahre nach dem Trauma Röhren und Stıänge solchen Gliagewebes, von regelrechten Bindegewebsscheiden umgeben, in dem exzidierten Hirngewebe vorgefunden wurden. Im Tierexperiment ist wahrscheinlich die Zeit für eine derartige Gliaentwicklung viel zu kurz, da kein Tier länger als 7 Monate am Leben gelassen wurde. Andererseits schwankt in dem von uns untersuchten menschlichen Material das Intervall zwischen dem Trauma und der Excision der Hirnnarbe von 7 bis zu 
18 Jahren. Während dieser langen Periode findet offenbar eine progressive Zerstörung von Hirngewebe statt. In vielen unserer Fälle sind in den Narbenzonen überhaupt keine Ganglienzellen mehr vorhanden, die Neurofibrillen sind sehr spärlich und anormal in ihrem Aspekt. Daß dieser
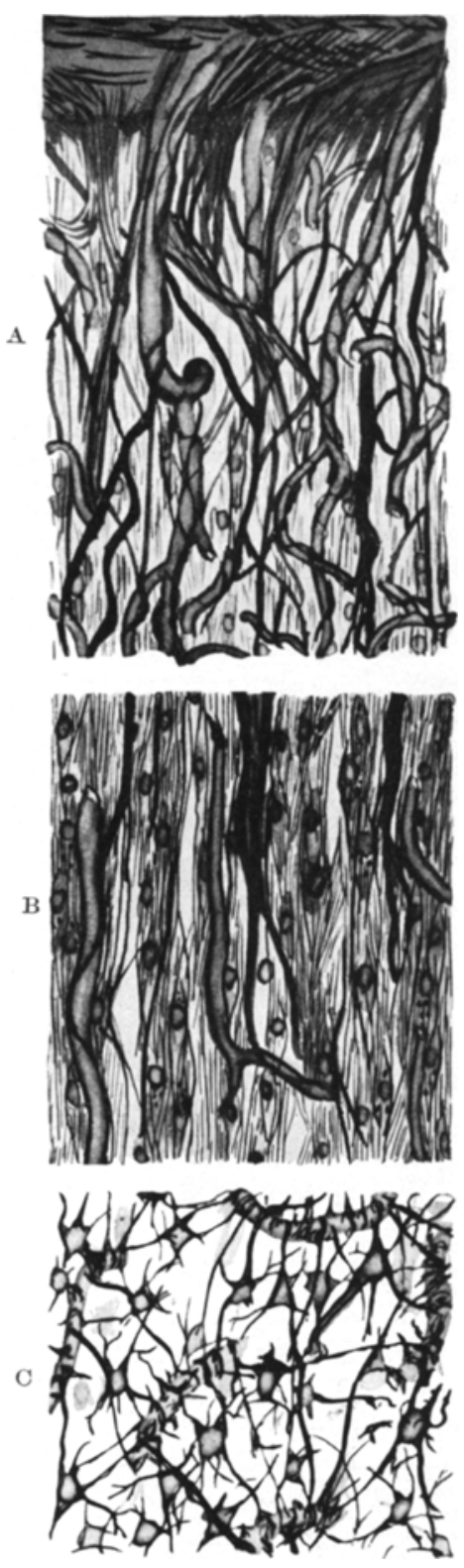
destruktive Prozeß progressiv ist, wird durch die Anwesenheit zahlreicher pigment. beladener Zellen um einzelne Gefäße herum und durch die herdweise vorhandene Alteration der Hortegaschen Gliazellen, selbst 10 bzw. 13 Jahre nach dem Trauma (vgl. Fall 2 u. 3), bewiesen. Das herdweise Auftreten solcher Gehirngewebsdestruktionen legt den Gedanken nahe, daß hierbei einzelne kleine Gefäße verlegt worden sind und man könnte annehmen, daß der progressive Narbenzug einzelne Gefäße verschließt und dadurch eine lokale Nekrose hervorruft.

In einem unserer Fälle (Fall 8) wurde eine akute Schwellung der Oligodendroglia diffus über das ganze exzidierte Hirnstück verbreitet gefunden. Dieser Fall befand sich vor und während der Operation im Status epilepticus und die Veränderung der Oligodendroglia, welchehier gefunden wurde, ist wahrscheinlich auf die gehäuften epileptischen Anfälle zurückzuführen; sie entsteht vielleicht auch durch die unmittelbar vor jedem einzelnen Anfalle auftretende plötzliche Verengerung der Gehirngefäße.

Der Unterschied zwischen den Befunden bei experimentell erzeugten Hirnwunden und den Befunden beim Menschen liegt also zum großen Teil in dem starken Hirngewebsschwund bei unseren Kranken. Der Mechanismus der Narbenschrumpfung ist beiden gemein. Narbenschrumpfung findet auch in anderen Organen statt und da unsere

Abb. 65. Schematische Darstellung der 3 Zonen innerhalb einer meningeocerebralen Narbe von langer Dauer. A obere Schicht, kollagene Fasern und Gefäße von der Dura ins Gehirn eindringend, wenig Gliaelemente. $\mathrm{B}$ tiefere Schicht, zahlreiche parallel angeordnete feine Gliafasern, weniger kollagene Fasern. C Vasoastrales Gerüst des Gehirns unterhalb der eigentlichen Narbe. 
Gehirnnarben dasselbe Bindegewebe enthalten wie jede andere Narbe, so ist eine progressive Narbenschrumpfung von vornherein zu erwarten. Das Gehirn als Organ vermag einem auf dasselbe einwirkenden Zuge so gut wie gar keinen Widerstand entgegenzusetzen, weil es der Bindegewebssepten entbehrt. Die Abb. 65 veranschaulicht in schematischer Form die wichtigsten Gewebselemente, welche an dem Narbenzug im Gehirn beteiligt sind. Der Gefäßbaum mit dem an ihm überallinserierenden Füßen der Astrocytenfasern stellt das Substrat dar, auf das der Zug einwirkt. Der progressive Schwund von Nervengewebe kann den Prozeß der konzentrischen Schrumpfung nur begünstigen.

Da sich das vaso-astrale Stützgerüst durch das ganze Gehirn fortsetzt, so ist klar, daß durch die Übertragung des Narbenzuges auf dieses Stützgerüst das ganze Gehirn nach der Narbenstelle zu hingezogen wird, das ganze Ventrikelsystem rückt gleichsam an letztere heran; wobei der der Seite der Verletzung korrespondierende Seitenventrikel dem Zuge am stärksten ausgesetzt ist und den Reigen eröffnet.

Eine sehr eindrucksvolle Beobachtung, welche beweist, daß die Duragehirnnarbe einen konstanten Narbenzug auf das ganze Gehirn ausübt, konnte in Fall 3 gemacht werden; unmittelbar nachdem die Dura rings um die Stelle, an welcher sie mit der Gehirnoberfläche verwachsen war, umschnitten war, invaginierte sich die in der Mitte des Duralappens befindliche Narbe beträchtlich. unterhalb der Adhäsionsstelle fand sich ein schwammig fibröser Bindegewebskeil, welcher von der Dura her tief ins Gehirn eingedrungen war. Das sofortige auffällige Einsinken der Stelle der Adhäsion ist nur verständlick unter der Annahme, daß auf diese ein starker Zug von Gehirn br ausgeübt wurde, bzw. daß sie vorher durch die Adhärenz gegen die ja allseitig straff gespannte Dura nach außen gezogen worden war.

Wenn man das Vorhandensein eines konstanten Narbenzuges auf das Gehirn und damit auch auf das Ventrikelsystem nicht annehmen will, so müssen wir uns fragen, welche anderen Erklärungsmöglichkeiten für die Ventrikelverziehung etwa sonst vorhanden sind. Man könnte daran denken, daß ein erhöhter intrakranieller Druck eine Rolle spielt, und da $\beta$ speziell innerhalb des der Seite der Verletzung entsprechenden Seitenventrikels eine stärkere Liquorsekretion stattfindet als in den übrigen Abschnitten des Ventrikelsystems; man könnte daran denken, daß der Plexus chorioideus der verletzten Hemisphäre durch das Trauma besonders stark irritiert worden ist. Durch diese Annahme wird aber höchstens die starke Dilatation des Ventrikels der verletzten Seite, aber nicht die Tatsache erklärt, daß doch gar nicht selten auch der Ventrikel der anderen gesunden Seite und selbst der dritte Ventrikel deutlich nach der Stelle der Verletzung hin verrückt erscheinen. Ferner kann durch die Annahme einer einseitigen gesteigerten Liquorsekretion nicht erklärt werden, daß so oft die Wandung des Ventrikels ganz lokal nach der Stelle 
des Hirnkontusionsherdes zu ausgebuchtet erscheint, und daß an dieser Stelle manchmal regelrechte cystische Aussackungen des Ventrikels, förmliche ventrikuläre Nebenkammern, vorhanden sind, wie es besonders in Fall 2, 5, 9 und 10 der Fall ist.

Zweifellos ist ja bei solch hochgradigen Ventrikeldilatationen, wie sie z. B. in Fall 2, 5, 8, 10 und 11 vorhanden sind, eine erhebliche Atrophie des Hirnmantels vorhanden. Es fragt sich, ob eine solche hochgradige Atrophie rein durch eine einseitige Liquorüberproduktion hervorgerufen werden kann, oder ob an ihrem Zustandekommen nicht vielmehr die durch den Narbenzug verursachte Behinderung der Blutzirkulation der betroffenen Gehirnhälfte wesentlich beteiligt ist. $\mathrm{Zu}$ berücksichtigen ist auch, daß bei einseitigen cerebralen Atrophien, wie sie z. B. im Anschluß an Verlegung einer größeren Gehirnarterie mit konsekutiver Erweichung entstehen, zwar auch der Ventrikel dieser Seite stets mehr oder weniger vergrößert ist, aber in diesen Fällen fehlt wiederum die Verlagerung des anderen Seitenventrikels und des dritten Ventrikels. Ferner konnten wir in unseren Fällen mehrfach feststellen, daß die Dilatation des Seitenventrikels der verletzten Seite ganz unbedeutend ist, daß aber gleichwohl die Verlagerung des gegenüberliegenden Seitenventrikels und des dritten Ventrikels in die Augen springt. Die cerebrale Atrophie ist in diesen Fällen gering, die Verziehung beträchtlich.

Es bleibt also unseres Erachtens für die in den hier mitgeteilten Fällen von Gehirntrauma erhobenen abnormen Befunde am Ventrikelsystem gar keine andere Erklärung übrig als die, daß die Narbenschrumpfung das ganze Gehirn allmählich nach der Stelle der Verletzung, wo Haut, Dura und Hirnoberfläche verwachsen sind und von welcher aus die bindegewebige gliöse Narbe mehr oder weniger tief ins Gehirn eindringt, hingezogen wird, und daß bei diesem $Z$ ug das vaso-astrale Gerüst, welches mit der Narbe in innigen Kontakt steht, die Vermittlung leistet.

Was nun die Beziehungen zwischen Narbenzug und epileptischen Anfällen anlangt, so haben wir bereits eingangs darauf hingewiesen, daß in Fällen von traumatischer Epilepsie gar nicht selten durch mechanischen Zug an der Dura ein epileptischer Anfall ausgelöst werden kann. In unseren 12 Fällen gelang dies in 5 Fällen. Wir haben ferner erwähnt, daß gelegentlich schon ein Zug an der Haut, welcher sich durch deren adhäsive Verbindung mit der Dura auf letztere und damit auf die Hirnnarbe und durch diese auf die benachbarten Hirnpartien überträgt, einen solchen Anfall auslösen kann. Wenn dieser mechanische Reiz auch keineswegs so sicher krampfauslösend wirkt wie der elektrische Reiz, welcher auf die Gehirnrinde im Bereich der Narbe appliziert wird, so ist die Tatsache als solche doch höchst beachtenswert und da wir glauben nachgewiesen zu haben, daß durch den Vorgang der Narbenschrumpfung von der Stelle der Adhäsion aus ein permanenter Zug auf die umgebenden Gehirnpartien ausgeübt wird, so liegt es nahe anzunehmen, daß dieser permanente 
mechanische Reiz in der Genese der epileptischen Anfälle in diesen Fällen eine gewisse Rolle spielt. Wenn wir dies annehmen, so wird uns auch die Tatsache einigermaßen verständlich, $d a B$ in so vielen Fällen das Intervall zwischen Trauma und erstem Auftreten der epileptischen Anfälle so auffallend lang ist. In unseren hier mitgeteilten Fällen betrug es durchschnittlich 5 Jahre 6 Monate, in manchen Fällen 14 Jahre (vgl. die Übersicht auf S. 554). Wir können uns vorstellen, daß der Narbenzug erst bei einem bestimmten Grade der Narbenschrumpfung zu einem überschwelligen Krampfreiz wird, und daß der Prozeß der Narbenschrumpfung in den einzelnen Fällen ganz verschieden schnell abläuft. Selbstredend spielen bei der Frage der Länge des Intervalls auch noch andere Faktoren eine Rolle, vor allem die ungeheuer große individuelle Verschiedenheit der präexistierenden Krampfreizschwelle; bei hoher Schwelle braucht ein krankhafter Prozeß naturgemäß viel längere Zeit, bis er überschwellig wird als bei niederer Schwelle.

Eine weitere Frage, die sich angesichts unserer Befunde erhebt, ist die, auf welche Elemente der mechanische krampfauslösende Reiz des Narbenzuges einwirkt, ob direkt auf die nervösen Elemente oder zunächst auf die Gefäße. Daß die Blutgefäße eine wichtige Rolle im Kausalnexus des epileptischen Krampfanfalls spielen, ist allerdings unsere feste Überzeugung (vgl. Lit. 1:7). Innerhalb der Narbe und in ihrer Umgebung sind zahlreiche neu gebildete Gefäße vorhanden; eine große Zahl selbst größerer Gefäße dringt von außen in die Gehirnnarbe ein; sie anastomosieren in so weitgehendem Maße mit den intracerebralen Gefäßen, daß die Außenfläche der Dura noch beträchtlich blutet, nachdem die Dura rings um die Narbe herum circumcidiert worden ist. Die Kommunikation der extracerebralen Duragefäße und der intracerebralen Gefäße ist auch durch Gefäßinjektionen direkt nachweisbar, indem die Gefäße der Gehirnnarbe sowohl von der Carotis interna wie von der Carotis externa her injiziert werden können (10). In einer Anzahl unserer Fälle war die sog. flächenhafte Rindenerweichung sehr deutlich ausgesprochen, $d . h$. es sind in der Rinde etwas unterhalb der Pia zahlreiche Gefäße und kollagene Fasern vorhanden und bilden hier eine regelrechte Schicht. Größere Gefäße sind an ihrer Eintrittsstelle in das Gehirn manchmal von einem Ring konzentrisch angeordneter Gliaelemente umgeben. Andererseits ist das Nervengewebe selbst im Bereich der Narbe und zum Teil auch in deren Umgebung einer progressiven Destruktion unterworfen. Man kann sich vorstellen, daß die zahlreichen neugebildeten Blutgefäße im Bereiche der Narbe einer dauernden Reizung ausgesetzt sind, und daß sie möglicherweise der Ausgangspunkt sympathischer Gefäßreflexe sind, welche sich auf die Gehirngefäße in der Umgebung und eventuell auf den gesamten Gefäßbaum des Gehirns ausbreiten. Es ist zwar bisher nicht erwiesen, daß alle die neugebildeten Gefäße im Bereich der Gehirnnarbe von einem nervösen Netzwerk umgeben sind, aber gerade ihre Kommunikation 
mit den Gefäßen der Dura, welche von einem üppigen Nervennetz umsponnen sind, legt den Gedanken nahe, daß auch die neugebildeten Gefäße im Gehirn daran partizieren.

Zum Schluß einige Bemerkungen über die rationelleTherapie der traumatischen Epilepsie. Wir haben weiter oben dargelegt, daß wir auf dem Standpunkt stehen, daß es in Fällen von traumatischer Epilepsie unbedingt erforderlich ist, die gesamte Durahirnnarbe zu exzidieren; die Excision muß so weit in die Tiefe reichen, als das narbig veränderte Gewebe reicht. In allen Fällen, in welchen der Ventrikel an die Oberfläche reicht, haben wir seine Wandung mit der Duranarbe exzidiert, so da $\beta$ der Ventrikel breit eröffnet wurde. Den entstehenden Duradefekt haben wir stets sorgfältig durch Plastik aus der Fascia lata gedeckt. Die Knochenlücke wurde niemals geschlossen. Durch die experimentellen Untersuchungen am Tier ist aufgezeigt worden, daß eine glatte Excision von Hirngewebe keine Narbe hinterläßt, sondern daß eine flüssigkeiterfüllte Höhle resultiert, ohne Bindegewebs- und Gefäßproliferation und mit äußerst geringer gliöser Reaktion. Wir verfügen bisher über keinen anatomischen Beleg aus der menschlichen Pathologie, daß die Verhältnisse beim Menschen analog liegen, aber wir können unseres Erachtens aus den Erfolgen der Therapie, welche sich die ausgedehnte Resektion alles narbigen Gewebes zur Richtschnur macht und welche wir seit 1920 konsequent üben, doch einen Rückschluß ziehen, besonders wenn wir die Resultate dieser Art des operativen Vorgehens mit denen anderer Methoden vergleichen. Während der Kriegsjahre 1914-1918 und noch in den beiden folgenden Jahren haben wir den Fällen von traumatischer Epilepsie gegenüber einen viel weniger radikalen Standpunkt eingenommen. Wir haben zwar auch stets den vorhandenen Knochendefekt beträchtlich erweitert, bzw. da wo kein Defekt bestand, den Knochen über der inkulpierten Rindenregion entfernt, wir haben die Dura an der Stelle, wo sie an der Hirnoberfläche adhärierte, stets abpräpariert, haben Knochensplitter und Projektilteile, wenn solche vorhanden waren, ausgelöst, wir haben aber höchst selten das veränderte Hirngewebe selbst exzidiert und sicher niemals in genügender Ausdehnung. Der Duradefekt wurde stets durch Plastik aus der Fascia lata gedeckt, so wie wir es auch bei unserem jetzigen Vorgehen tun. Die Resultate dieser sog. Rindentoilette waren aber sehr schlecht, wohl wurden die epileptischen Anfälle für kurze Zeit beseitigt, aber früher oder später kehrten sie in unverminderter Heftigkeit wieder. Wir haben einen 1916 derartig operierten Fall, der immer wieder an Anfällen litt, die sich immer mehr häuften, vor $21 / 2$ Jahren wieder operiert und konnten feststellen, daß die Haut wieder mit der eingesetzten Fascie, diese wieder mit der Hirnoberfläche adhäirerte, und daß von der Stelle der Adhäsion eine derbe Narbe bis an den Ventrikel reichte. Wir haben die gesamte Durahirnnarbe bis in den Ventrikel exzidiert und es 
ist nie wieder ein epileptischer Anfall aufgetreten. Der Fall ist in dieser Arbeit nicht mit verwertet.

In den Fällen, in welchen bei der Operation der Ventrikel eröffnet wird, kollabiert der Gehirnmantel und die Ränder des Loches sinken tief in den Ventrikel herein. In diesen Fällen bleibt dann stets ein breiter Zwischenraum zwischen Hirnoberfläche und Dura und es ist wohl ausgechlossen, daß es hier zu einer erneuten Verwachsung zwischen Gehirnoberfläche und Dura, bzw. dem in sie eingesetztem Fascienlappen kommt, während die Haut wahrscheinlich wieder mit der Dura verwächst. Da wo der Ventrikel nicht eröffnet, sondern nur die Narbe exzidiert wird, wäre es denkbar, daß eine erneute Adhäsion auftritt, aber wie gesagt, einen bioptischen oder autoptischen Beleg dafür besitzen wir bisher nicht. Eines aber müssen wir in diesem Zusammenhang hervorheben, die Fälle, in welchen wir den Ventrikel breit eröffnet haben, sind bisher größtenteils vollkommen anfallsfrei geblieben, selbst über Jahre hinaus, während ein Teil der Fälle mit bloßer Excision der Narbe ohne Ventrikeleröffnung trotz weitgehender Excision doch gelegentlich wieder einen oder mehrere Anfälle bekommen hat. Diese Tatsache spricht durchaus zugunsten der ganz radikalen Therapie. Dieser sind nun aber doch Grenzen gezogen. Wenn wir in einem Falle mit wenig tiefdringender Narbe und geringer Ventrikelerweiterung eo ipso bis in den Ventrikel hinein exzidieren wollten, würden wir unter Umständen schwerwiegende Opfer an funktionstüchtiger Hirnsubstanz bringen, Lähmungen und andere Ausfallssymptome, die vorher nicht vorhanden waren, erzeugen. In diesem Dilemma muß das Pro und contra sorgfältig abgewogen werden, und nur wenn die Zahl und Heftigkeit der Anfälle es gebieterisch fordern, wird man sich hier zu dem radikalen, mit Opfern verbundenen Vorgehen entschließen.

Die Knochenlücke haben wir niemals geschlossen. Wir legen großen Wert darauf, daß dieses Ventil dauernd offen bleibt. Nachteil haben wir niemals davon gesehen. Wohl aber sind uns viele Falle unter die Augen gekommen, in denen unmittelbar oder bald nach der von anderer Seite vorgenommenen Implantation einer Knochenplatte in den bestehenden Defekt erstmalig epileptische Anfälle auftraten, oder wenn solche schon vorher bestanden, erheblich verschlimmert wurden. Man kann allerdings einwenden, daß in allen diesen Fällen, deren Zahl nicht gering ist, niemals die Durahirnnarbe exzidiert worden ist, also die eigentliche Causa peccans nicht beseitigt wurde. Aber warum kommt es so oft nach der Knochenimplantation zu einer so evidenten Verschlechterung der Epilepsie, bzw. warum treten nach ihr die Anfälle überhaupt erst zum ersten Male auf? Das spricht doch dafür, daß die Einsetzung des köchernen Implantats eine Schädlichkeit schafft. Wir haben deshalb stets das Implantat entfernt, die Duragehirnnarbe, welche mehrfach Knochen und sogar Projektilteile eingebettet enthielt, exzidiert, die Duraplastik angeschlossen, aber die Knochenbresche belassen. Es ist sehr wohl 
möglich, daß nach sorgfältiger Excision der Durahirnnarbe und sorgfältiger Deckung des Duradefektes durch ein Implantat aus der Fascia lata die Knochenlücke ohne Schaden auch verschlossen werden könnte. Nicht zu übersehen ist aber, daß die Knochenbresche oft ein beträchtliches Ausmaß besitzt und ihre Deckung in keinem Falle leicht sein würde.

\section{Literatur.}

${ }^{1}$ Foerster, O.: Encephalographische Erfahrungen. Z. Neur. 94, H. 4 (1924). Foerster, O.: Leitungsbahnen des Schmerzgefühls. S. 314. Berlin 1927. - Foerster, O.: Tagg südostdtsch. Chir. Liegnitz 1927. Zbl. Chir. 1927. - Foerster, O.: Tagg südostdtsch. Neur. u. Psychiater 1929. Arch. f. Psychiatr. 88, H. 3. - Foerster, O.: Operative Behandlung der Epilepsie. Breslau. Chir. Ges. Dez. 1924. Zbl. Chir. 1925. - Foerster, O.: Operative Behandlung der Epilepsie. Verh. Ges. dtsch. Nervenärzte 1925. - Foerster, O.: Pathogenese der epileptischen Krampfanfälle. Verh. Ges. dtsch. Nervenärzte 1926. $-{ }^{2}$ Schwab, O.: Z. Neur. 102 (1926). $-{ }^{3}$ Rosenstein, A.: Z. Neur. 102 (1926). $-{ }^{4}$ Bielschowsky, P.: Z. Neur. 117 (1928). $-{ }^{5}$ Wartenberg: Z. Neur. 94, H. 4 (1924). - ${ }^{\circ}$ Heidrich: Erg. Chir. 1927. -7 Penfield, W.: The mechanism of cicatricial contraction in the brain. Brain 50, 499 (1927). 8 Penfield, W.: Meningo-cerebral adhesions. Surg. etc. 39, 803 (1924). $-{ }^{9}$ Hortega, del Rio $P$. and $W$. Penfield: Cerebral cicatrix. The reaction of neuroglia and microglia to brain wounds. Bull. Hopkin Hosp. 41, 278 (1927). - ${ }^{10}$ Penfield, $W$. and R. Buckley: A study of brain punctures. Arch. of Neur. and Psych. (1928). 11 Penfield, $W$. and $W$. Cone: Acute swelling of oligodendroglia. Arch. of Neur. and Psych. 16, 131 (1926). - 12 Penfield, $W$. and $W$. Cone: Staining of neuroglia and microglia. Mc Clungs Handbook of Microscopic Technique. Philadelphia 1928. 